\title{
التحليل الجغرافي للأنماط المكانية لاستخدام الأرض التجاري بمنطقة المسجد الأحمدي بطنطا
}

$$
\begin{aligned}
& \text { دكتور / مجدي محمد علي حسن } \\
& \text { مدرس الجغرافيا البشرية } \\
& \text { معهد الدراسات الأدبية - الإسكندرية }
\end{aligned}
$$


ترتكز المدينة بمفهومها المتعدد زمنياً ومكانياً علي ثوابت أساسية، يمكن أن نطلق علي

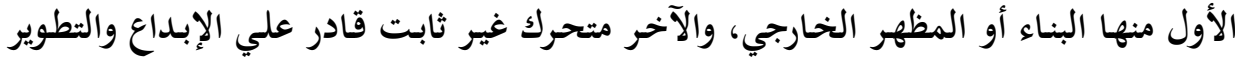

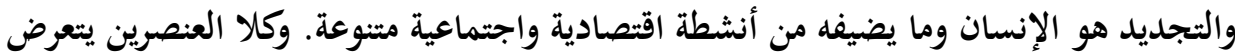

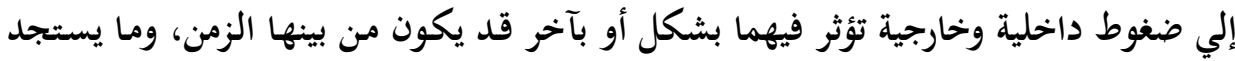

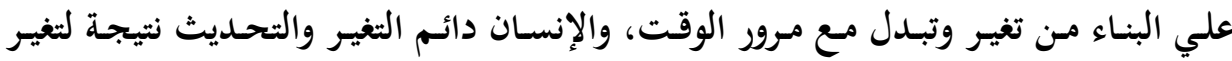

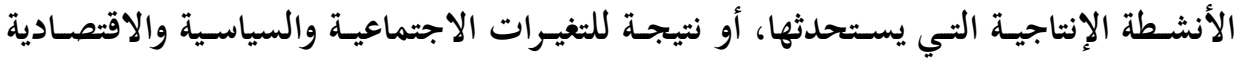
والدينية التي يحيها.

إن مفهوم استعمالات الأرض الحضرية من المفاهيم الواسعة والمعقدة، ومهما تعددت

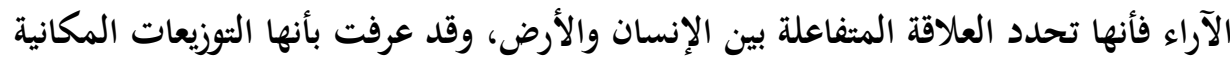

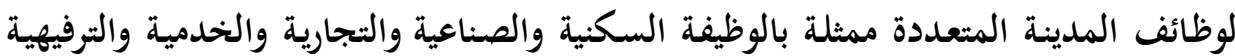

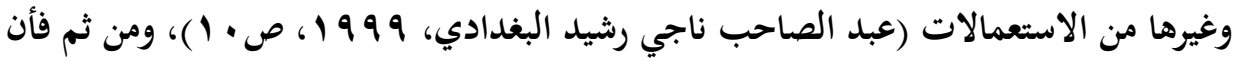

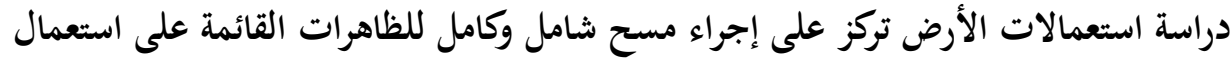

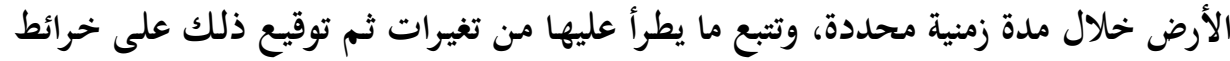

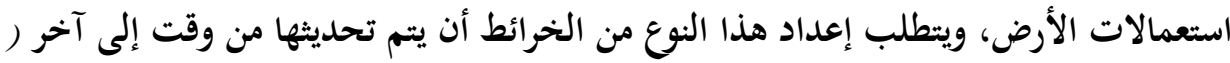
. Rhind, D, \& Hudson, R., 1980 ,P32. ولعل ما يعنينا في هذه الدراسة تتبع أثر الوظيفة الدينية علي استخدام الأرض التجاري

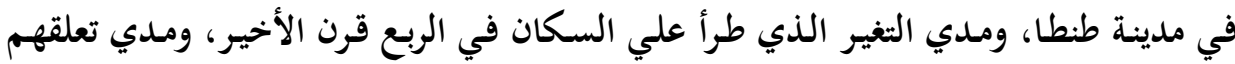

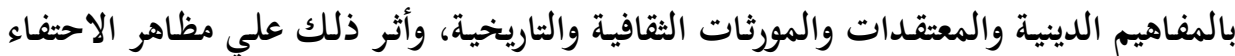

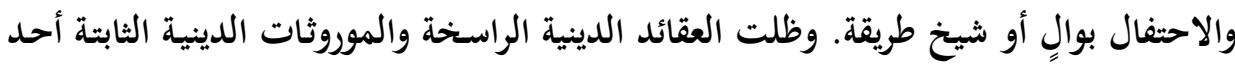

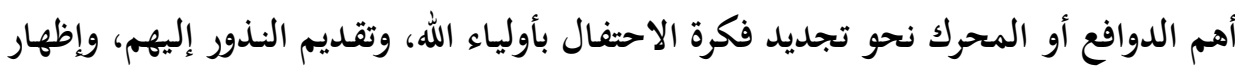

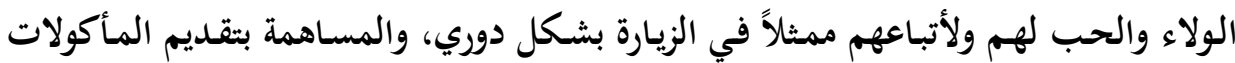

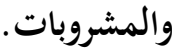

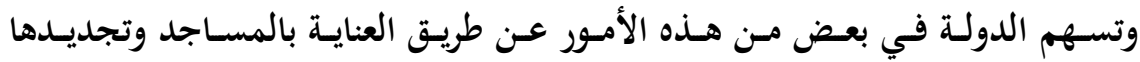

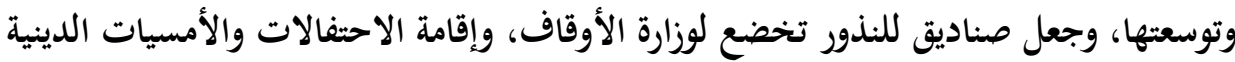

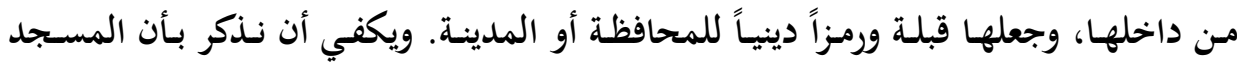

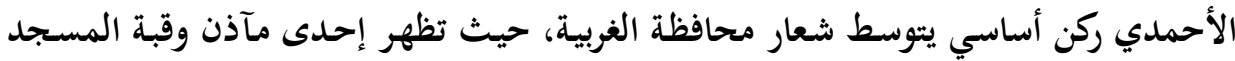

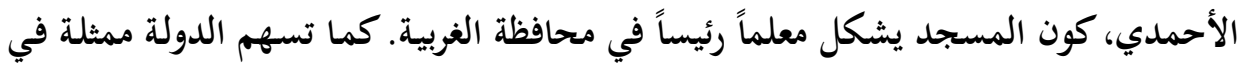

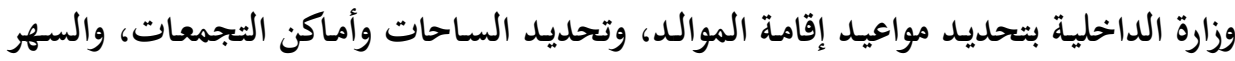


علي حماية الوافدين إلي هذه الأماكن من المجرمين منعاً لانتشار السرقة والنصب وغيرها من الأمور المحرمة والمخلة بالآداب العامة.

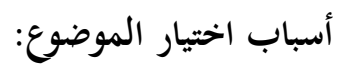
1 ـ أهمية المدينة ومسجدها وما يحيط بهما من قدسية في نفوس الكثير من الأتباع

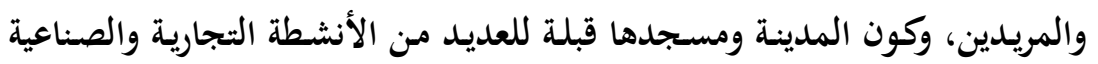

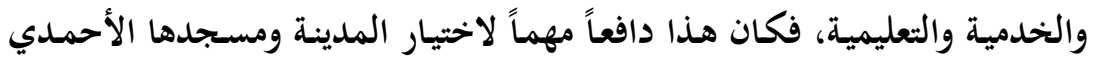
موضوعاً للدراسة. r ـ إظهار أثر المسـجد الأحمـدي في تكـوين شخصـية المدينسة، وقيـام العديـد مـن

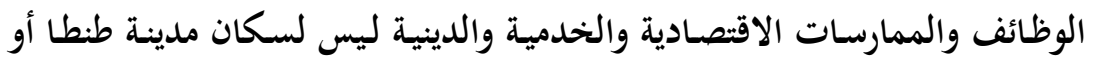
محيطها، بل يتعدي الأمر إلي المحافظات والمدن والقرى المجاورة.

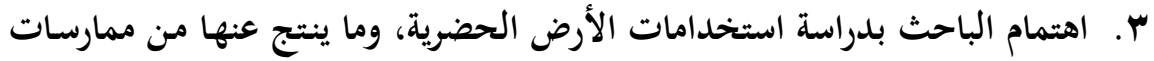

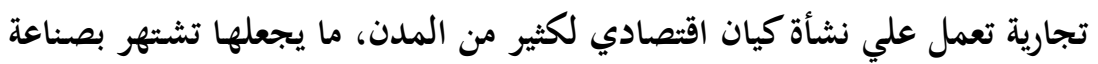

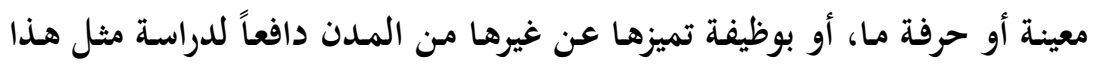
النوع من وظائف المدن.

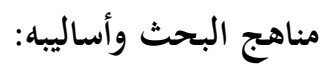

تعد دراسة الاستخدامات التجارية جزء من دراسة التركيب الحضري المكاني، التي نالت التها

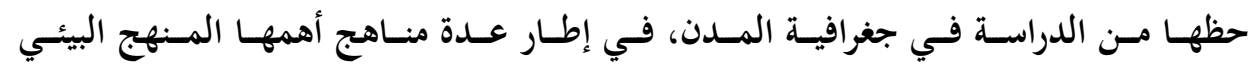

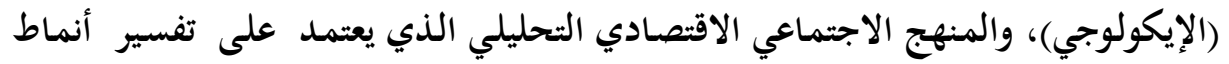

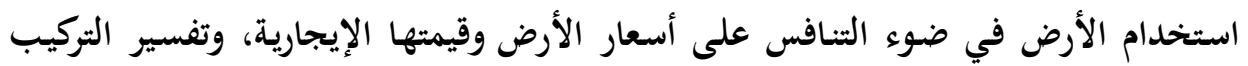

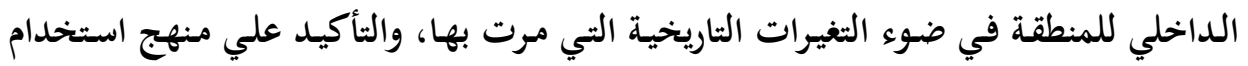

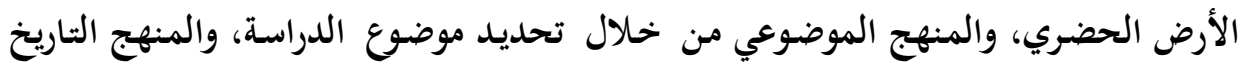

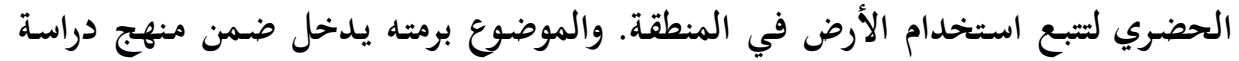

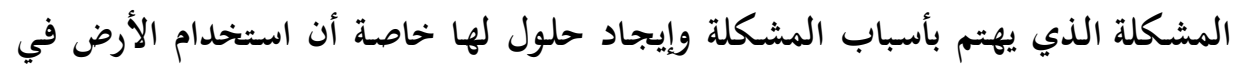

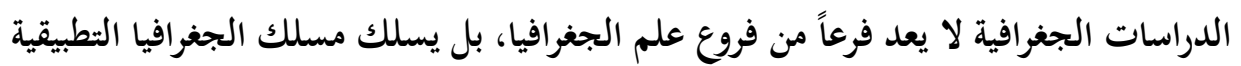

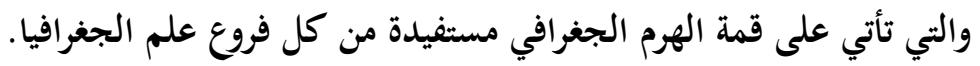
الدراسة الميدانية:

ومر البحثث بعدد مـن الخطوات منها: التجهيز والتحضير للعمل الميـداني والزيارات

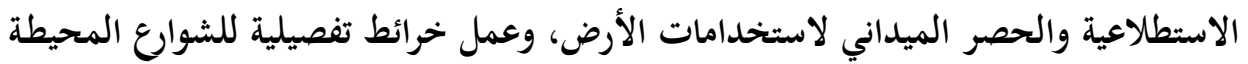




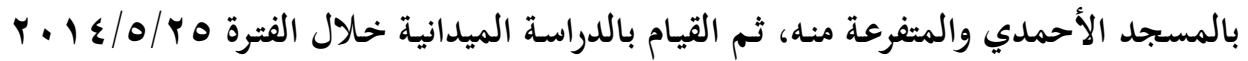

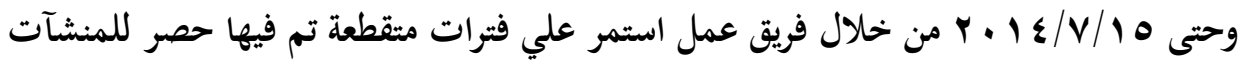

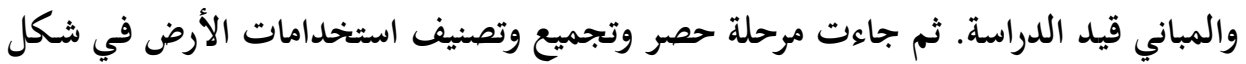
مجموعات حتى يتسنى توظيفها بشكل سليم.

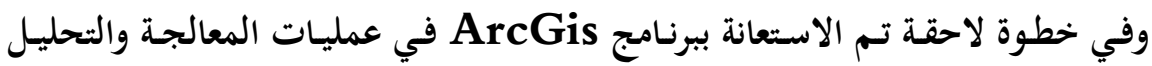

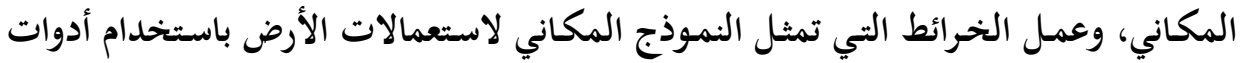
التحليل الإحصائي Spatial Statistics Tools، والتحليل المكاني Spatial Analyst Tools في واجهة Arc ToolBoxs التي تعد أهم وظائف نظم المعلومات الجغرافية، مستفيدة من وجودها بهيئة رقمية في ذاكرة الحاسب الآلي كأدوات تحليلية تمكنها من القيام

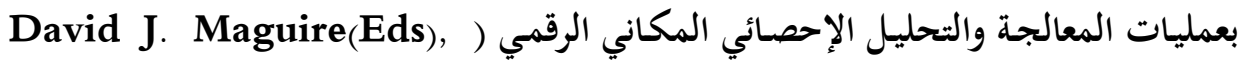
.2005

إن ما يهم الجغرافي عند دراسته لتوزيع الظواهر هو معرفة ما إذا كان توزيعها يُشكل

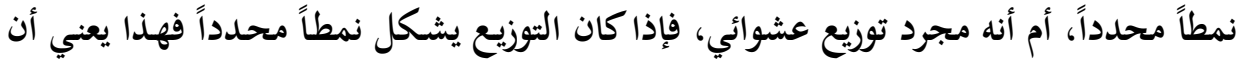

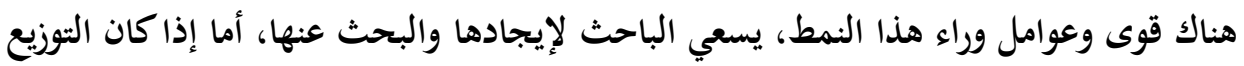

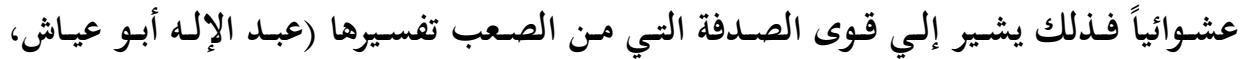
ع تساؤلات الدراسة:

وبعد العرض السابق يمكن الآن طرح عدد من التساؤلات الآتية:

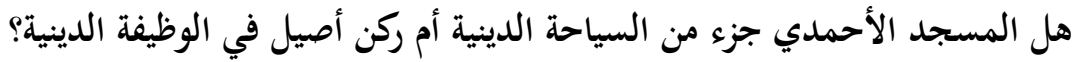

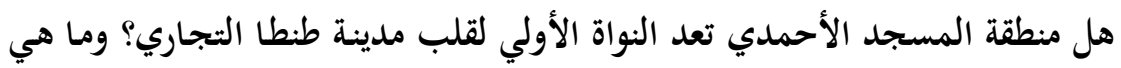

سماته؟

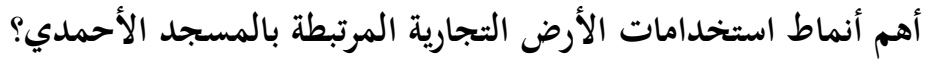

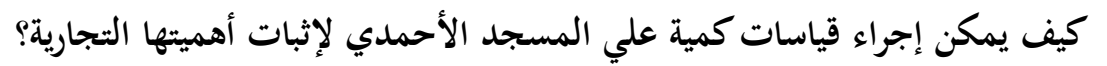
موقع مدينة طنطا: تقع مدينة طنطا حاضـرة محافظة الغربية في منتصف أرض الدلثنا، في مركز يتوسط

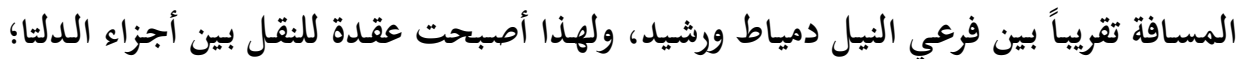

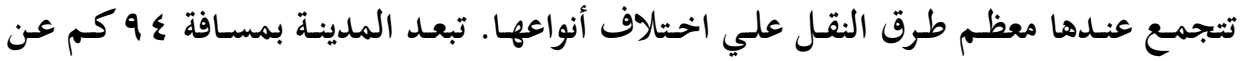

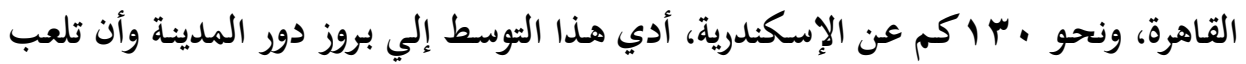




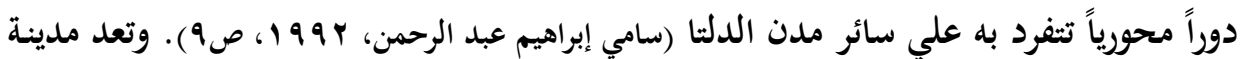

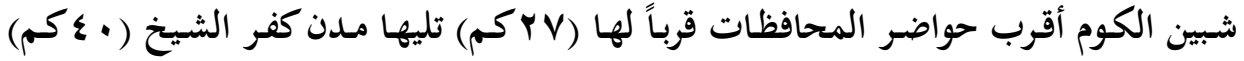

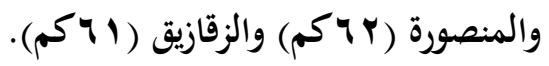

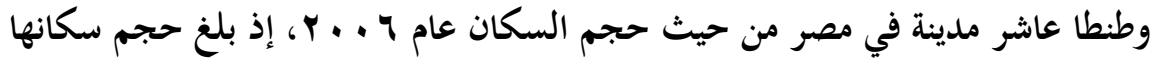

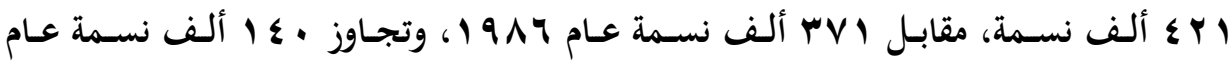

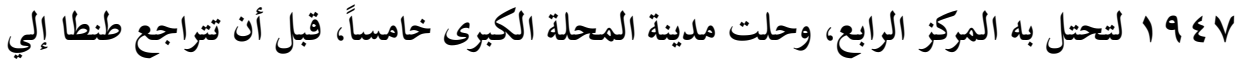

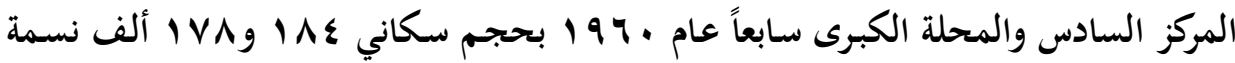

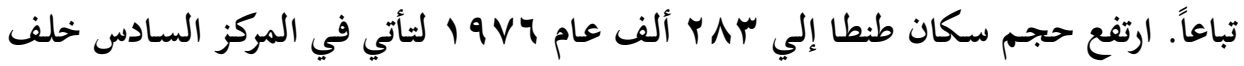

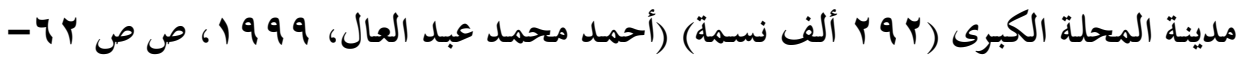

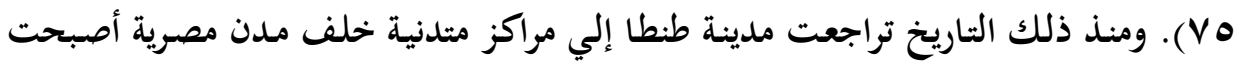

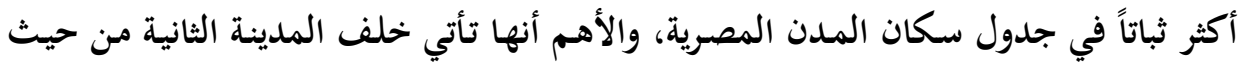
الترتيب الوظيفي داخل محافظة الغربية.

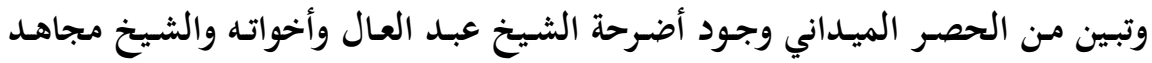

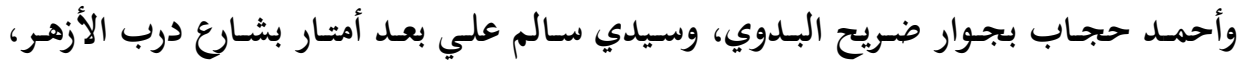

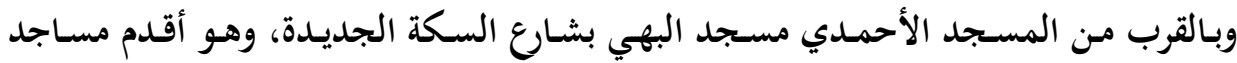

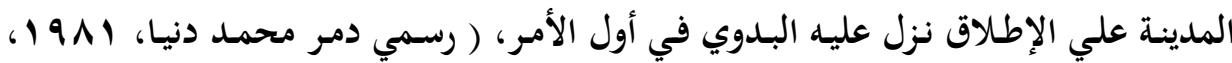

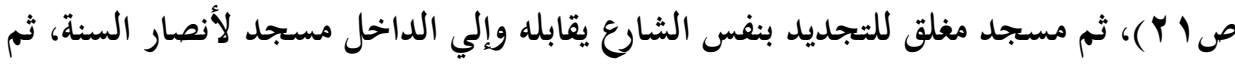

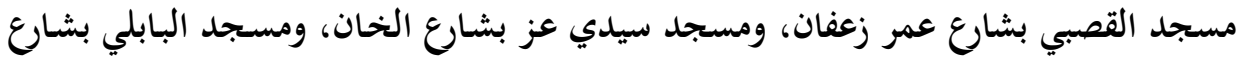

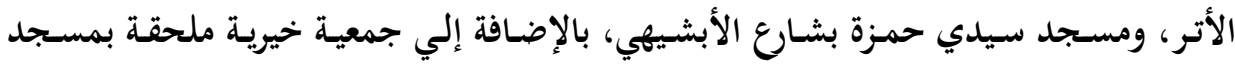

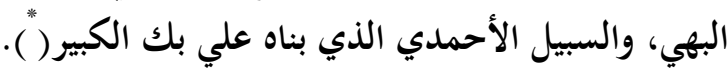

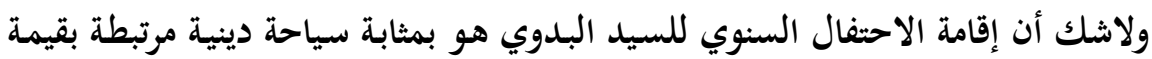

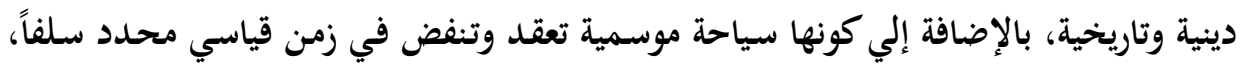

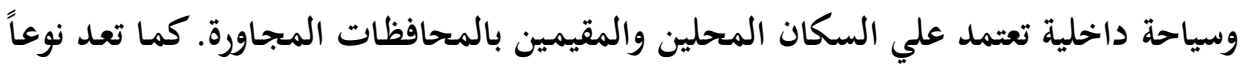

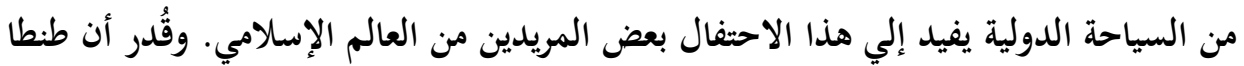

(") ومن بين هذه الأضرحة والمساجد عبد المتعال الأنصاري وعبد الرحيم نور الدين وعلي الحامولي ومحمد العمري نوار

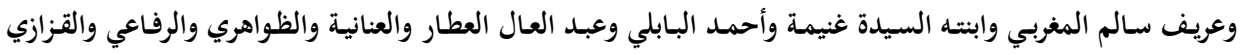

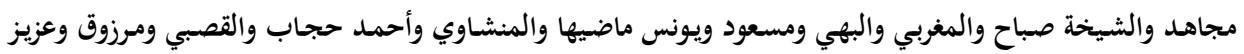

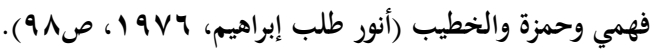


تستقبل سنوياً من ربع إلي نصف مليون في أسبوع المولد (جمال حمدان، 9VV) (

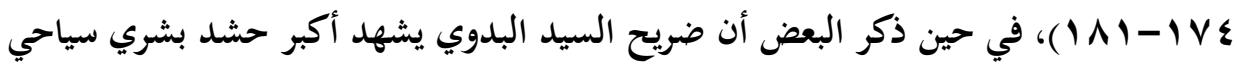

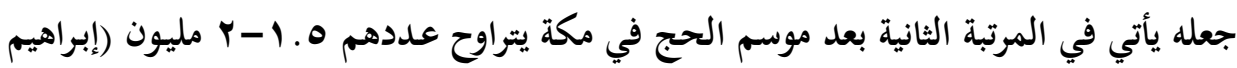

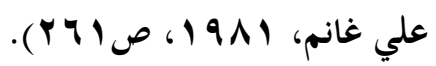

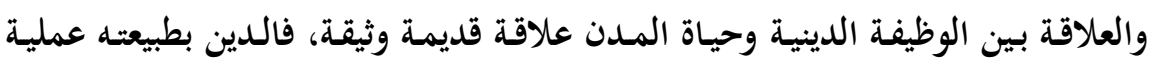

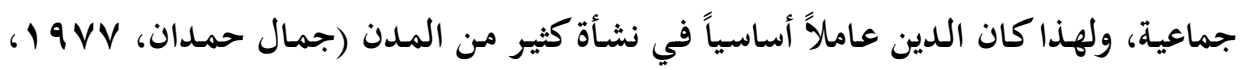

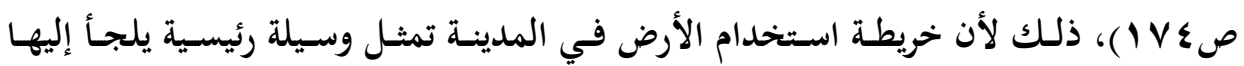

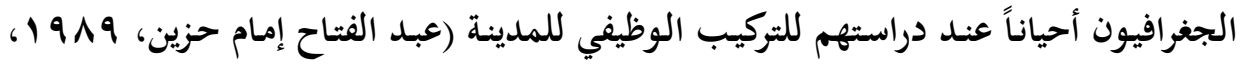

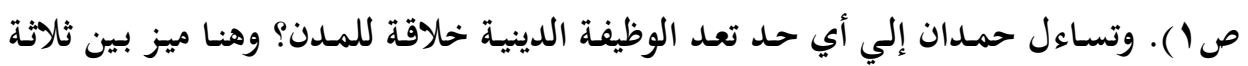

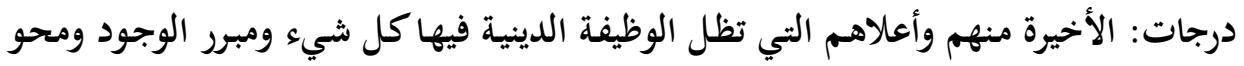

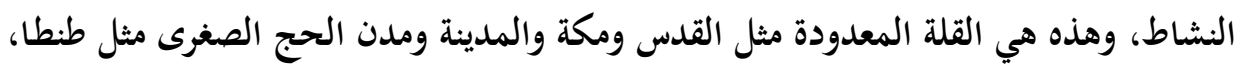

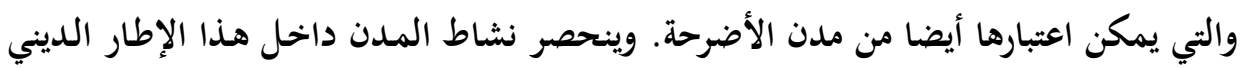

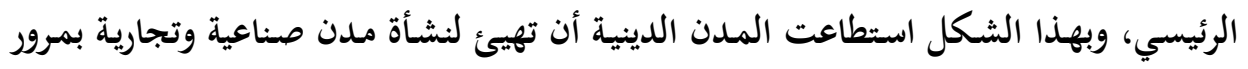

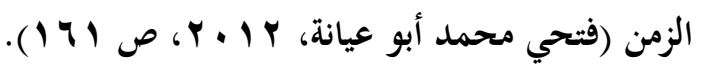

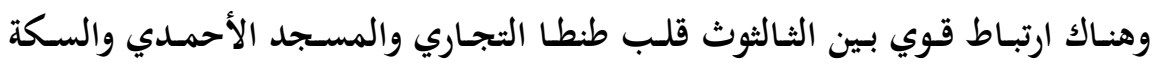

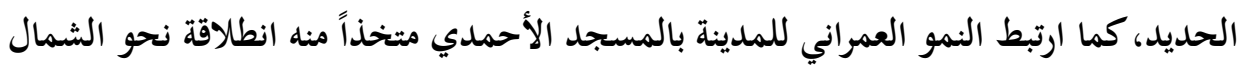

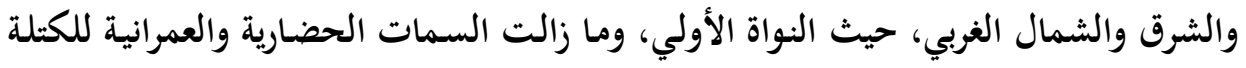

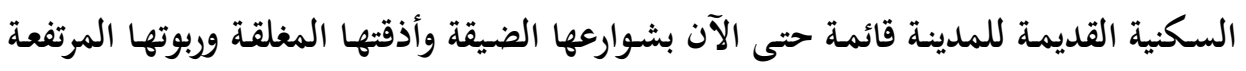

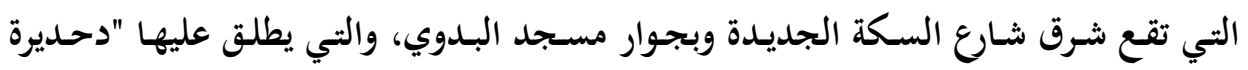
صبرى".

كان لهذا الوضع أثره قديماً في وقوف العمران جنوبـاً وغربـا، حيـث تحيط بالمدينة

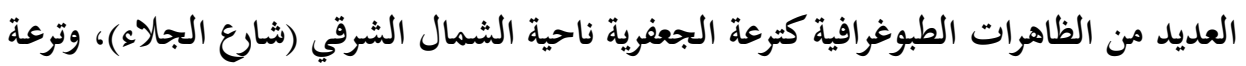

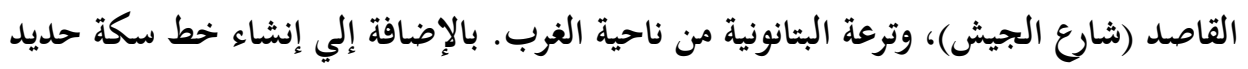

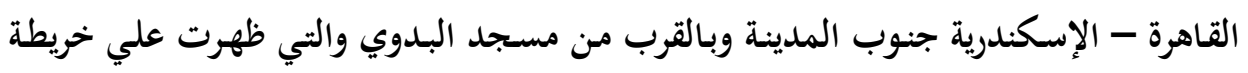

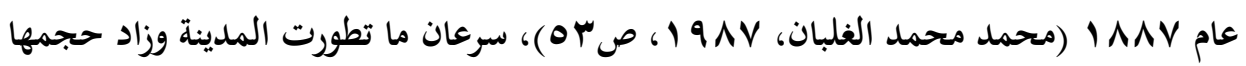
العمراني والسكاني بعد أن أصبحت حاضدة محافظة العان، لغران الغربية، وارتباط المدينة بالوظيفة التجارية. أولاً: الملامح العامة لمنطقة الدراسة 


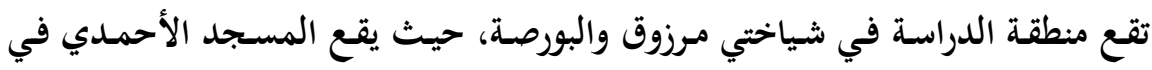

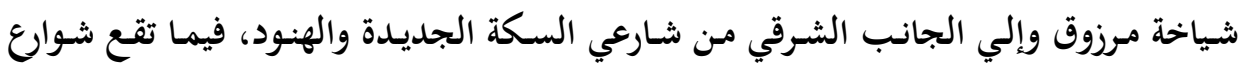

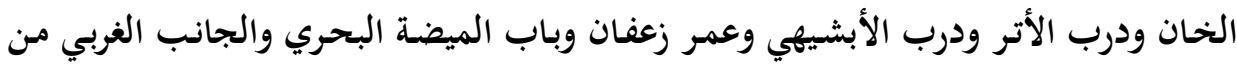

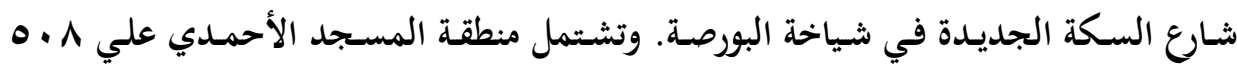

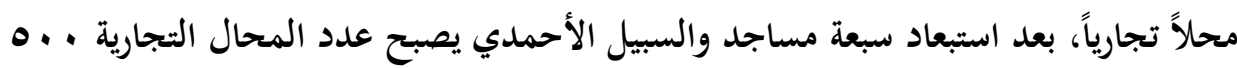
محلاً، وسوف تستبعد الدراسة الاستخدام الديني.

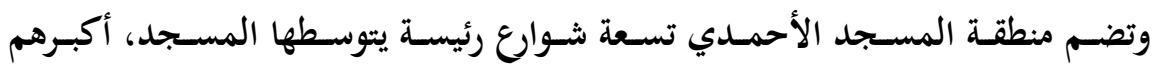

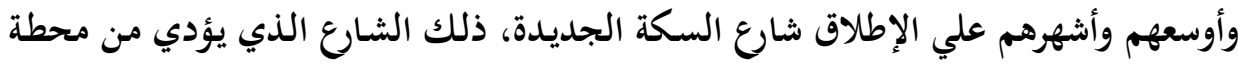

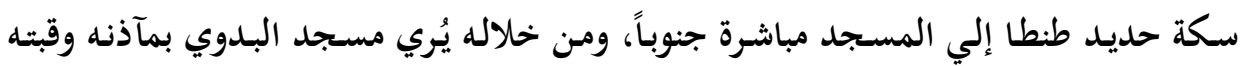

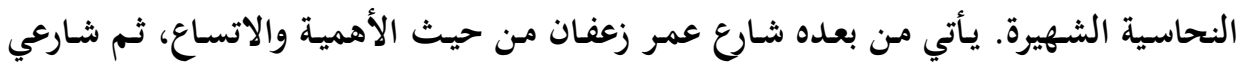

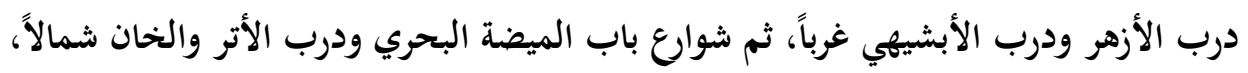

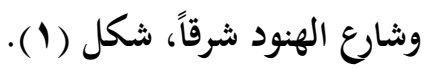

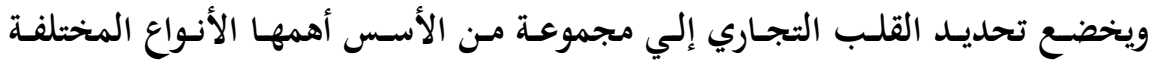

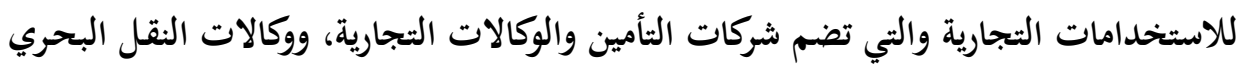

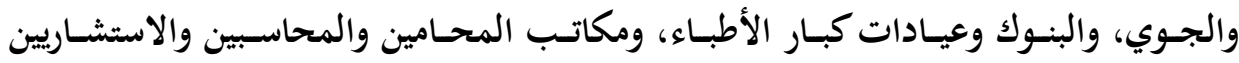

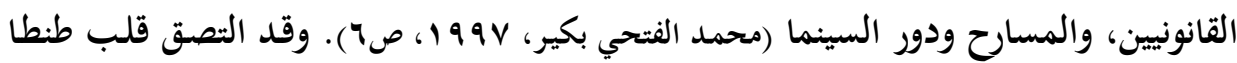

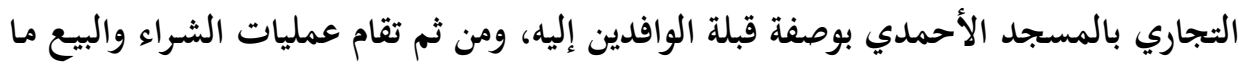

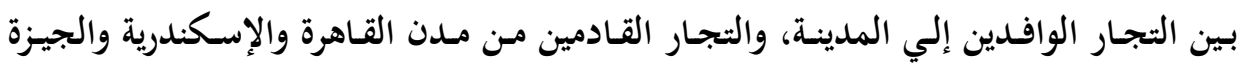

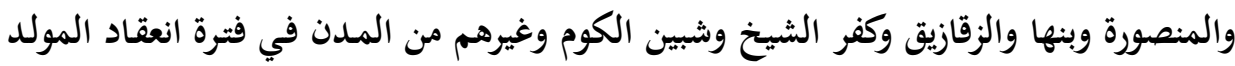
الرجبي في شهر مايو، والمولد الكبير في شهر أكتوبر.

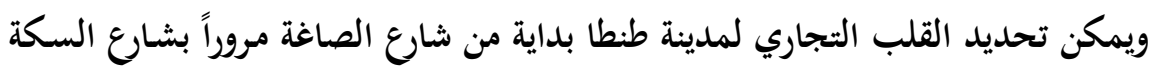

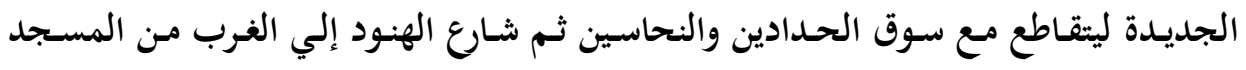

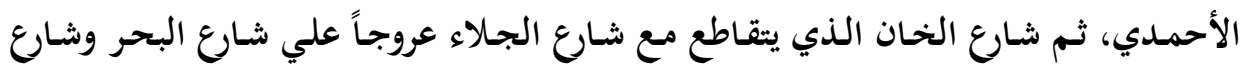

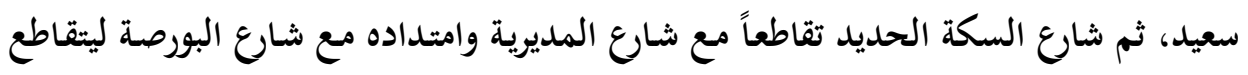
معه شارعي عمر زعفان ودرب الأبشيهي ودرب الأتر مع شارع الجلاء وشارع حلقة القطن. 


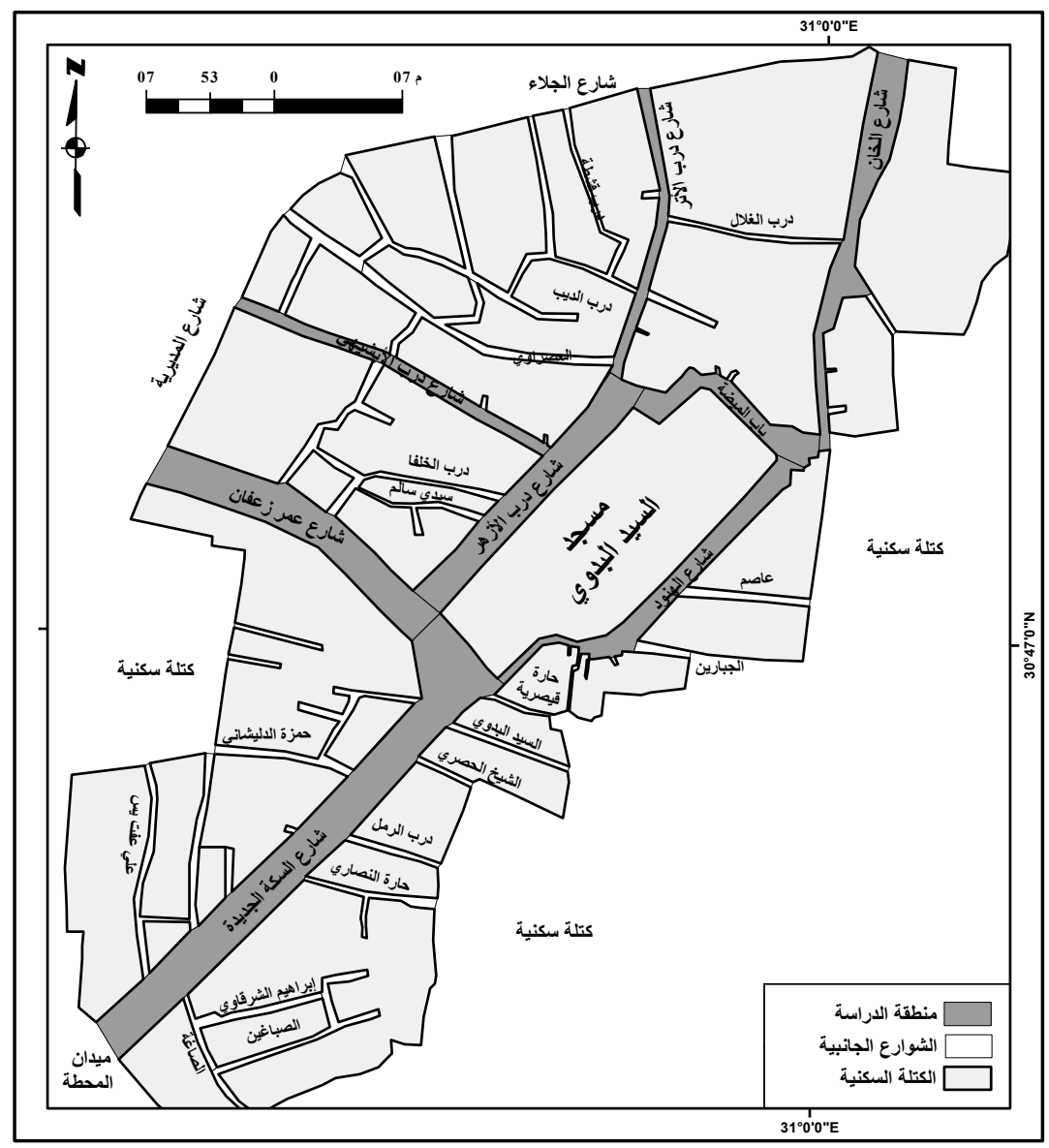

ArcMap10.2 \& Google Earth Pro Ver.7.1 المصدر/ تم الرسم وتوقيع الأماكن من قبل الباحث اعتماداً علي برنامجي

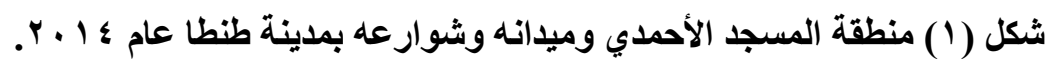

ومع اتساع رقعة المدينة واتساع أنشطتها التجارية نظراً للزيادة السكانية، ظهرت نويات جديدة للقلب التجاري سواء في شكل تجمعات تجارية أو في شكل أسواق خطية، واشتهرت

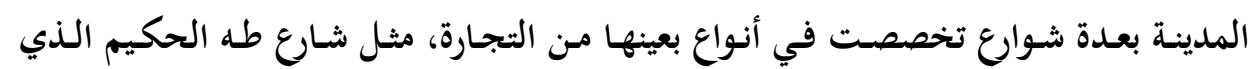
اشتهرت ببيع أجهزة الهواتف، وسعد الدين الذي تخصص في بيع الأدوات الكهربائية ولوازم

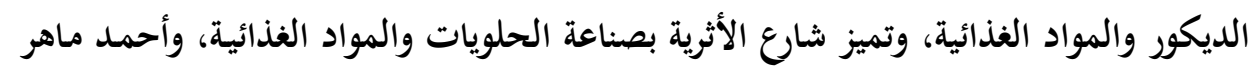

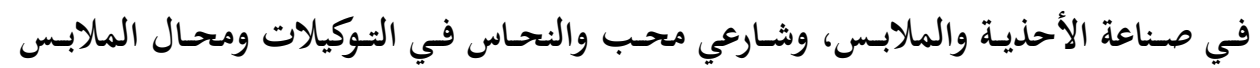

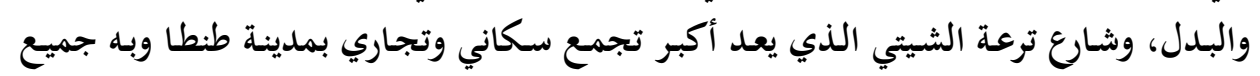
الخدمات التجارية والصناعية والخدمية. 
1 ـ مسطحات الشوارع وكثافة المحال التجارية:

يمكن التأكيد علي أن وجود تباينات في مسطحات الشوارع وأطوالها تعود إلي طبيعة

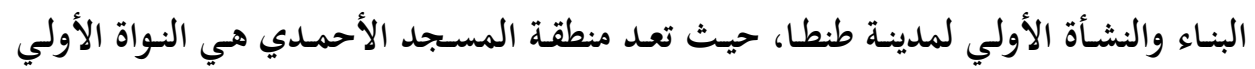

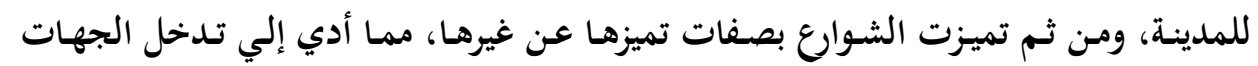

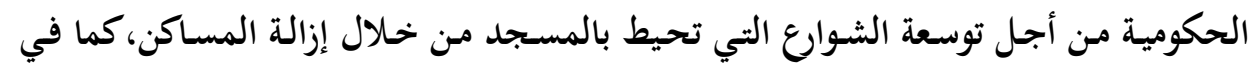

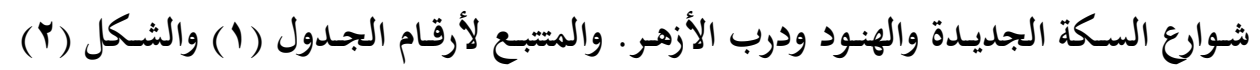

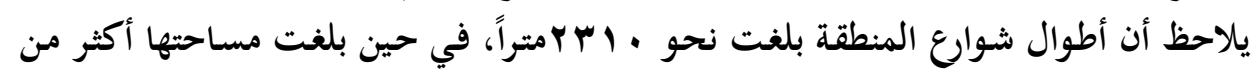

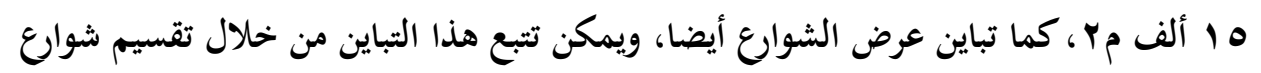

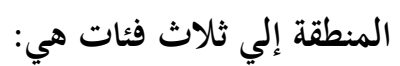

جدول ( ) التوزيع العددي والنسبي لأطوال ومساحة وعرض الثئ الثوارع الرئيسية

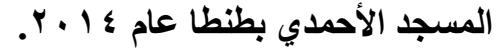

\begin{tabular}{|c|c|c|c|c|c|c|c|c|}
\hline \multirow{2}{*}{ الكثافة } & \multirow{2}{*}{ المحال } & \multicolumn{2}{|c|}{ العرض } & \multicolumn{2}{|c|}{ الطول } & \multicolumn{2}{|c|}{ المساحة } & \multirow{2}{*}{ الثوارع } \\
\hline & & $\%$ & (ค) & $\%$ & (P) & $\%$ & $\left(T^{5}\right)$ & \\
\hline 1.1 & VI & 0.9 & 7 & 10.9 & rik & YQ. & 1919 & الخان \\
\hline r. & $11 \mathrm{~V}$ & Y1.7 & YY & ro.s & $\Delta \wedge V$ & $r \leqslant . \wedge$ & rAYT & السكة الجديدة \\
\hline$\varepsilon . \wedge$ & $\varepsilon r$ & 11.1 & IY & $\vee . \wedge$ & $1 \wedge$. & $0 . \wedge$ & $9 . r$ & الهنود \\
\hline 0.1 & YY & 9.1 & 1. & r.7 & $\Delta r$ & Y.Q & $r \wedge q$ & باب الميضة البحري \\
\hline r.६ & $V^{2}$ & 7.9 & $\mathrm{~V}$ & $10 . r$ & ror & $1 \pi . \wedge$ & rITA & درب الأبشيهي \\
\hline \&. & 79 & 0.9 & 7 & $1 \% .9$ & rqq & $1 \cdot . v$ & $170 \%$ & درب الأتر \\
\hline $0 . r$ & rq & $1 V .7$ & 11 & $\varepsilon .9$ & 114 & $r .0$ & $0 \leqslant V$ & درب الأزهر \\
\hline Yr.q & FY & . & . & Y. .7 & 09 &. .9 & $1 T V$ & سور المسجد \\
\hline Y.\& & $\leqslant V$ & 19.7 & r. & 11.7 & YTV & $1 Y .0$ & 1941 & عمر زعفان \\
\hline$r . r$ & $0 \ldots$ & $1 \ldots$ & $1 . r$ & $1 \ldots$ & rTI. & $1 \ldots$ & $10 \leqslant \leqslant 0$ & جملة \\
\hline
\end{tabular}

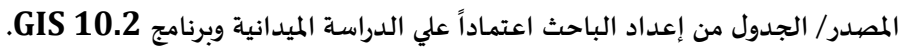

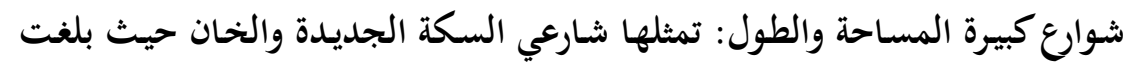

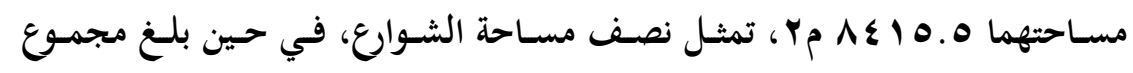

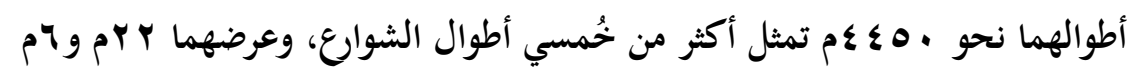

$$
\text { يمثلان } 7 .
$$

شوارع متوسطة المساحة والطول: تمثلها شوارع عمر زعفان ودرب الأبشيهي ودرب

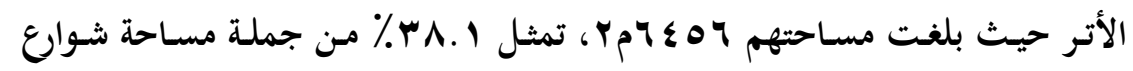

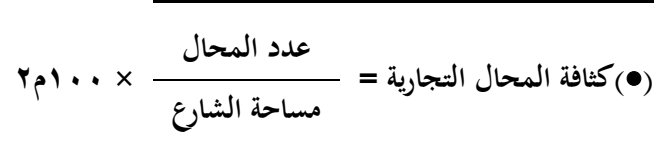




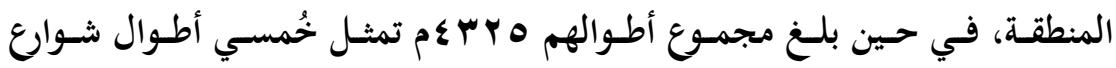

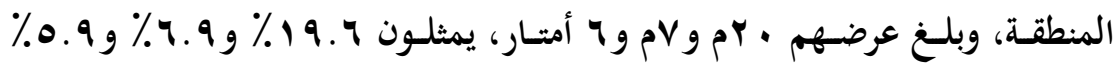
تباعاً.

شوارع صغيرة المساحة والطول: تمثلها شوارع الهنود ودرب الأزهر وباب الميضسة

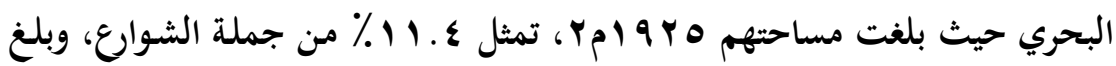

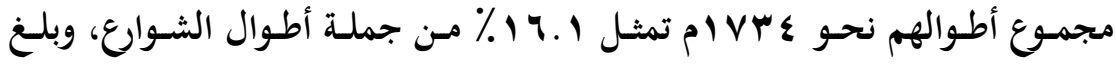

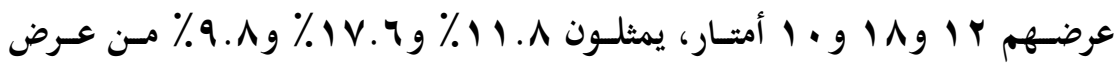
الشوارع.

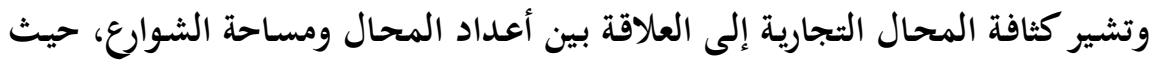

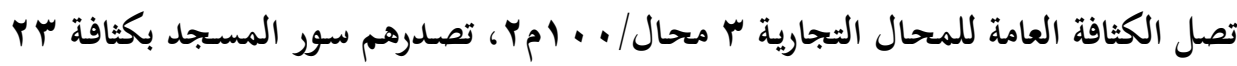

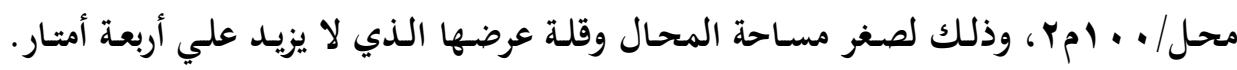

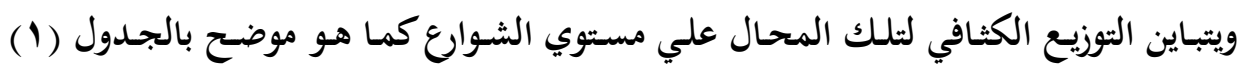

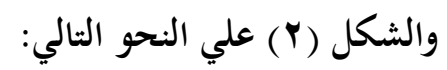

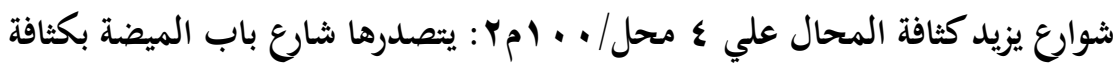

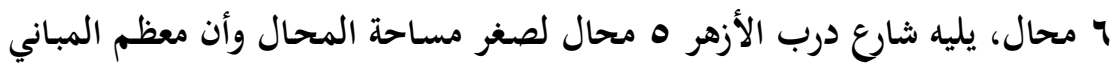

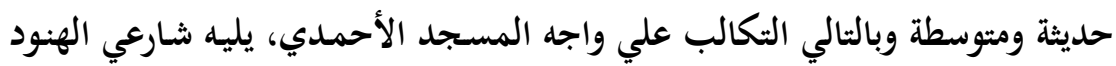

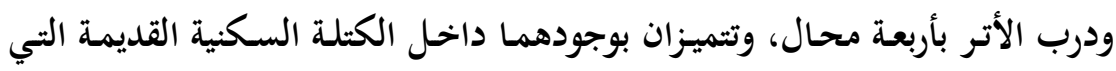
تنميز بكبر مساحة مبانيها.

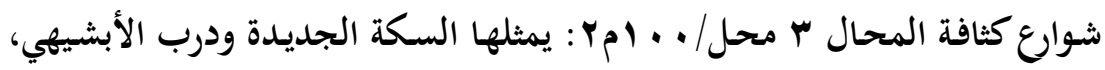

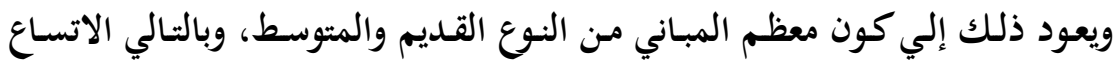
النسبي لمساحة المحال التجارية، وعدم وجود فراغات بيني دينيه بين المحال. 


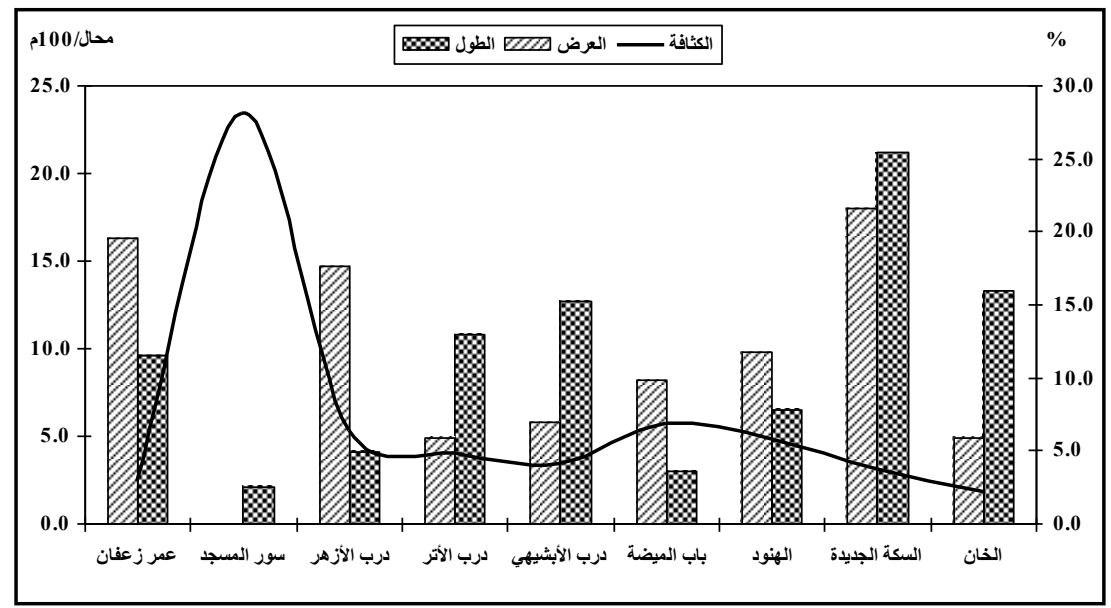

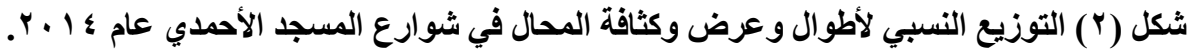
شوارع كثافة المحال تقل عن ب محل/ • • امج : تضم عمر زعفان والخحان، ويتميز بكبر مساحتها وعظم طولها، وغالبية مبانيها قديمـة كبيرة المساحة، أزيلـت أدوارهـا العليـا، رخيصـة الإيجـار، وهـو مـا أدي إلي وجـود أنواع معينـة مـن الاسـتخدامات لا لا تتوافر في بقية الشوارع الأخرى مثل الأجهزة الكهربائية والمنزلية والأقمشة ...الخ. ץ. ت توزيع المحال التجارية:

تبين من الدراسة الميدانية وجود تباين في أعداد المحال التجارية من شارع لآخر ومنطقة لأخرى سواء علي طول الثارع أو علي جانبيه، حيث بلغ أعداد المحال التجارية ـ . ـ مححلاً،

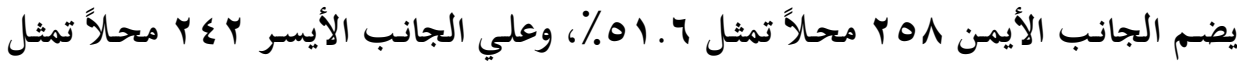

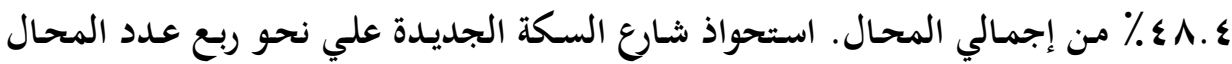
بعدد I V محل، أكثر من نصفها علي الجانب الأيمن. في حين نجد الشوارع التي تقع إلي الشمال من المسجد والتي تضم باب الميضة والخان ودرب الأتر وسور المسجد اله 9 و محال تمثل نحو خُمسس عدد المحال، وعدد المحال التي تقع إلي الشرق من المسجد ممثلة في

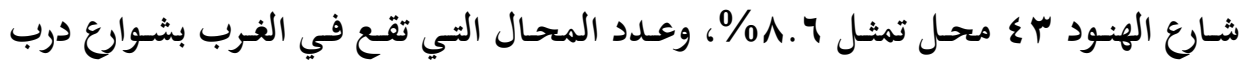

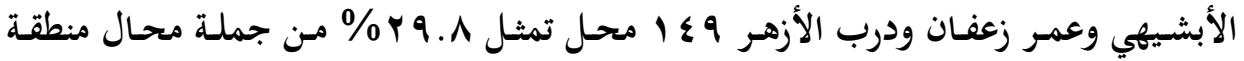

وفيمـا يخص الجانب الأيمسن فقد تركزت المحال التجاريـة علي هـذا الجانب بالعلامـة الكاملة في شارع الهنود وسور المسجد بإجمالي ه Vحل، ونسب تجاوزت النصف بشارعي عمر زعفان والسكة الجديدة، وعلي الجانب الأيسر سجل شـارعي درب الأزهر وباب الميضة 
العلامة الكاملة بعدد الج محل، في حين اقتربت من الثلثين بشارع الخان، بسبب وجود منطقة

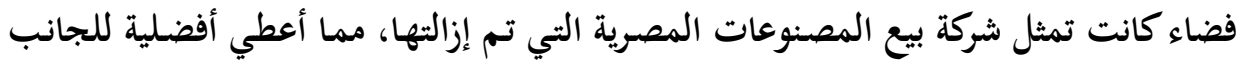

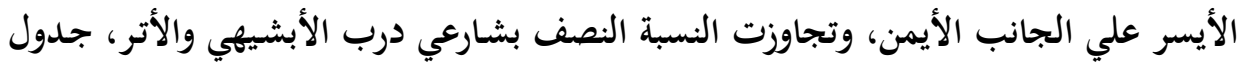

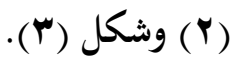

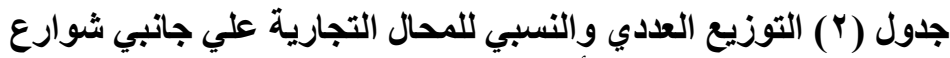

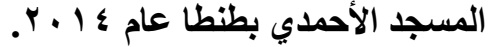

\begin{tabular}{|c|c|c|c|c|c|c|}
\hline \multicolumn{2}{|c|}{ جملة جملة } & \multicolumn{2}{|c|}{ أيسر } & \multicolumn{2}{|c|}{ أيمن(") } & \multirow{2}{*}{ الثوارع } \\
\hline$\%$ & 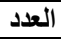 & $\%$ & العدد & $\%$ & العدد & \\
\hline rT.s & $11 \mathrm{~V}$ & $\leqslant r .7$ & 01 & 07.4 & 74 & السكة الجديلة \\
\hline $1 \leqslant .7$ & Vr & $0 \leqslant .1$ & $\varepsilon$ & $\leqslant 0 . r$ & rr & درب الأبشيهي \\
\hline $1 \varepsilon . Y$ & vi & $7 \varepsilon .1$ & $\leqslant 1$ & ro.r & Yo & الخان \\
\hline IT.Y & 79 & or. & ro & $\varepsilon V_{.} \cdot$ & $\mu$ & درب الأتر \\
\hline 9.8 & $\varepsilon V$ & $\varepsilon \cdot . \varepsilon$ & 19 & 09.7 & $r \wedge$ & عمر زعفان \\
\hline 1.7 & $\varepsilon r$ & - & - & $1 \ldots$ & $\varepsilon r$ & الهنود \\
\hline 7.5 & rY & - & - & $1 \ldots$ & $r r$ & سور المسجد \\
\hline $0 . \wedge$ & rq & $1 \ldots$ & rq & - & - & درب الأزهر \\
\hline$\varepsilon . \varepsilon$ & YY & $1 \cdots$ & rY & - & - & باب الميضةٌ البحري \\
\hline $1 \ldots$ & $0 \ldots$ & $\varepsilon \wedge . \varepsilon$ & $r \leqslant Y$ & 01.7 & 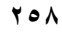 & جملة \\
\hline
\end{tabular}

المصدد/ الجدول من إعداد الباحث اعتماداً علي الدراسة الميدانية.

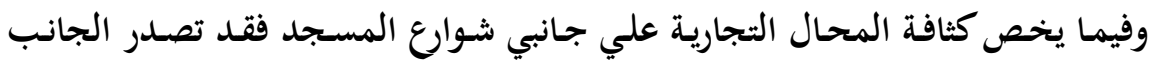

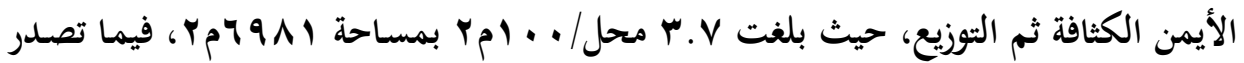

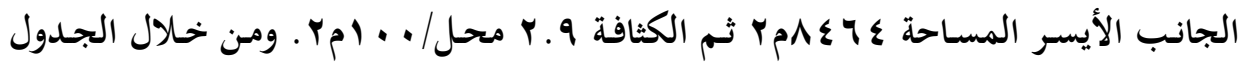

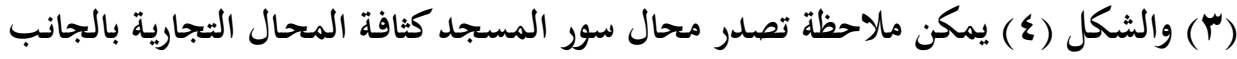

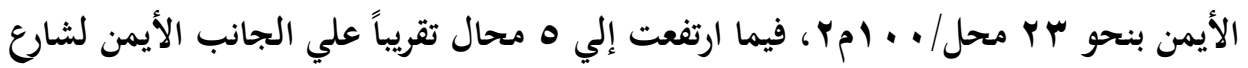

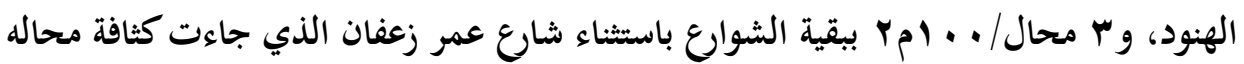

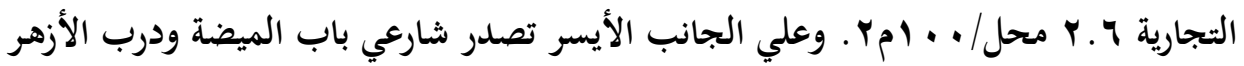

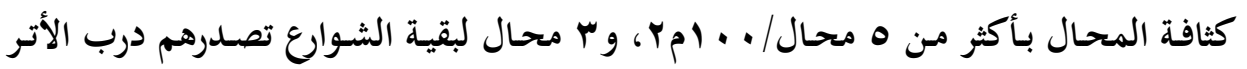

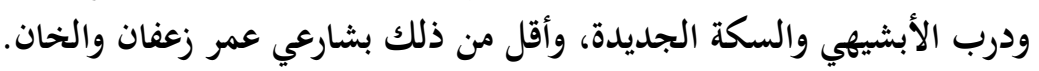

( ) "تم تحديد الجانب الأيمن من بداية الشارع وفي اتجاه المسجد الأحمدي. 


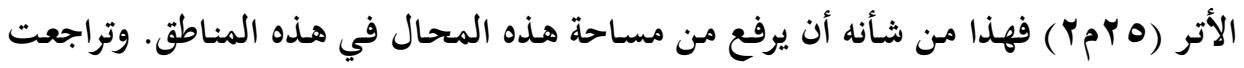

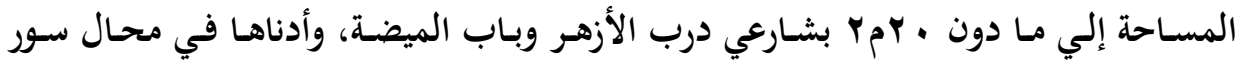

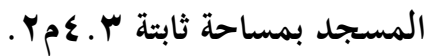

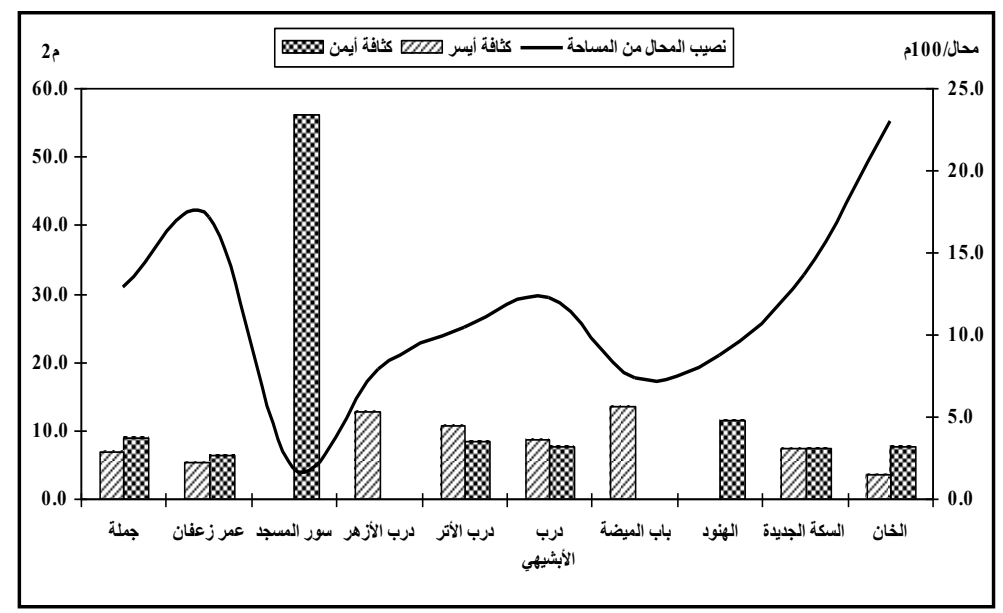

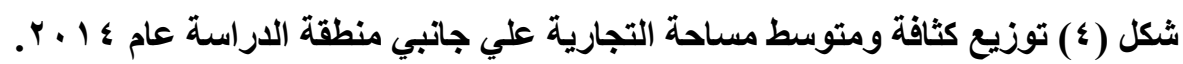
ثانياً: خصائص المباني بمنطقة الدراسة تسهم خصائص المباني إلي حد كبير في تفسير خريطة استخدامات الأرض في المدن

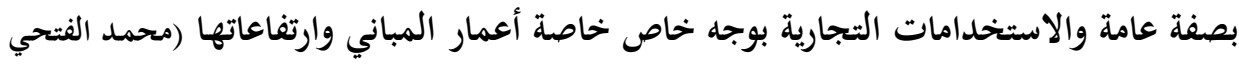

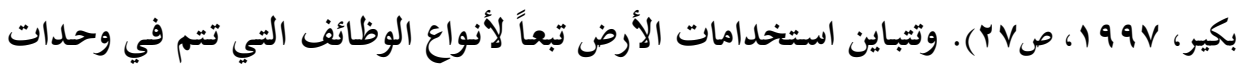

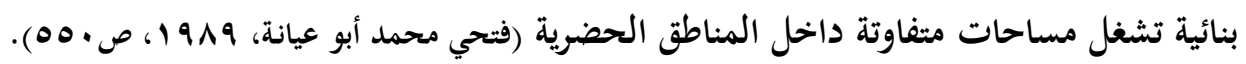

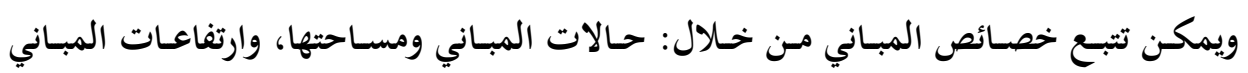

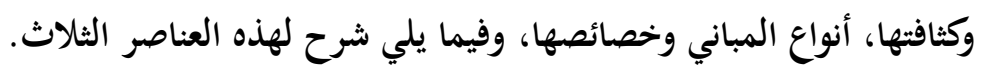

\section{ا ـ الات المباني ومساحتها:}

نظراً للقصسور في حصر المنشآت السكنية حسب أعمارهـا فقـد اعتمد الباحث علي

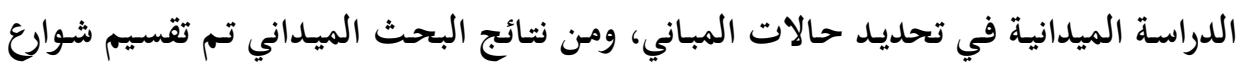

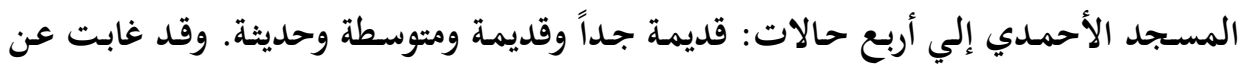

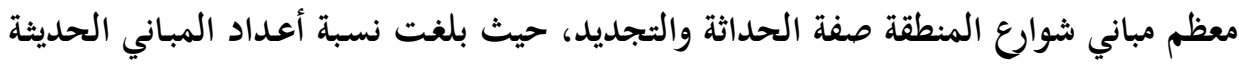

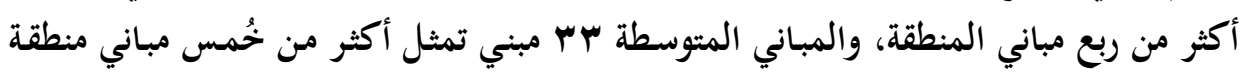




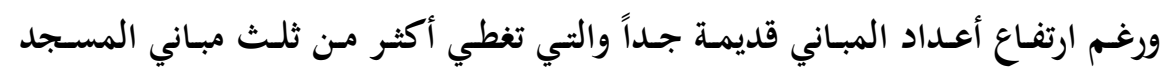

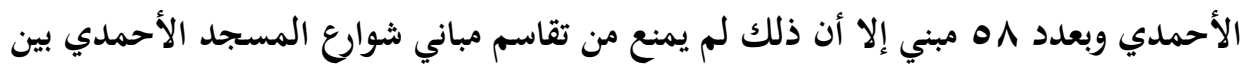

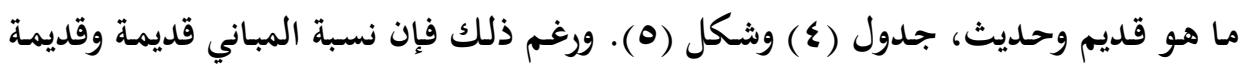

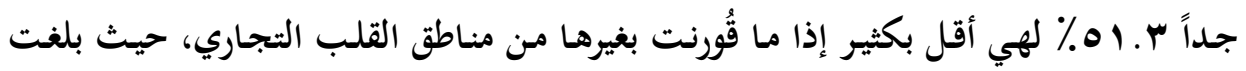

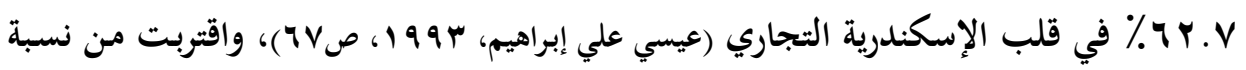

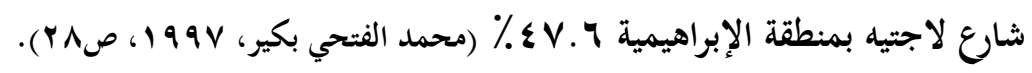

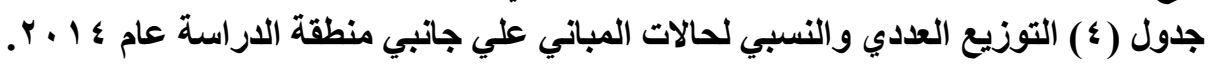

\begin{tabular}{|c|c|c|c|c|c|c|c|c|c|c|c|c|}
\hline \multicolumn{4}{|c|}{ الجملة } & \multicolumn{4}{|c|}{ الجاتب الأيسر } & \multicolumn{4}{|c|}{ الجاتب الأيمن } & \multirow{3}{*}{ المبني } \\
\hline \multicolumn{2}{|c|}{ المساحة } & \multicolumn{2}{|c|}{ المبني } & \multicolumn{2}{|c|}{ المسناحة } & \multicolumn{2}{|c|}{ المبني } & \multicolumn{2}{|c|}{ المسـاحة } & \multicolumn{2}{|c|}{ المبني } & \\
\hline$\%$ & $\left(r_{p}\right)$ & $\%$ & العدد & $\%$ & $\left(Y^{p}\right)$ & $\%$ & العدد & $\%$ & $\left(r_{P}\right)$ & $\%$ & العدد & \\
\hline$r \bar{r}$ & $\leqslant 199$ & $r v . r$ & $\Delta \wedge$ & $r \cdot . \cdot$ & $1 \leq V$. & $\leqslant \leqslant . \wedge$ & YY & $v \cdot . \cdot$ & $r \leq Y q$ & $00 . Y$ & rr & قديم جدا \\
\hline 18.1 & 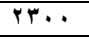 & $1 \leq .1$ & Yr & $\leqslant 0.0$ & $1 . \leq V$ & $0 \leqslant .0$ & $1 Y$ & $0 \leqslant .0$ & IrOT & $\leqslant 0.0$ & 1. & قديم \\
\hline 19.8 & $r 900$ & YI.Y & $r r$ & 71.9 & IAYA & 79.8 & $r r$ & $r .1$ & $\Lambda Y V$ & $r \cdot . r$ & 1. & متوسط \\
\hline r..9 & एятq & YV.T & $\varepsilon r$ & $\leqslant \Lambda .7$ & $187 \varepsilon$ & $\$ 1.9$ & 11 & 01.5 & 1190 & $0 \wedge .1$ & ro & حديث \\
\hline $1 \ldots$ & $T r \leqslant \Lambda T$ & $1 \ldots$ & 107 & $\{0 . r$ & 71.9 & $0 . .7$ & 199 & $0 \leqslant . V$ & VTVE & $\leqslant 9.5$ & $V V$ & جملة \\
\hline
\end{tabular}

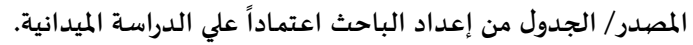

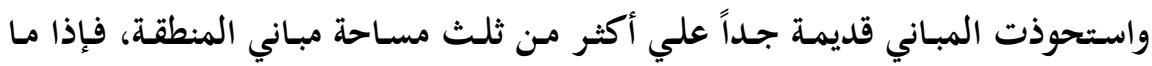

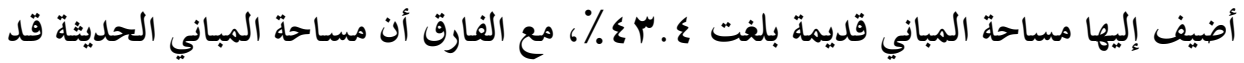

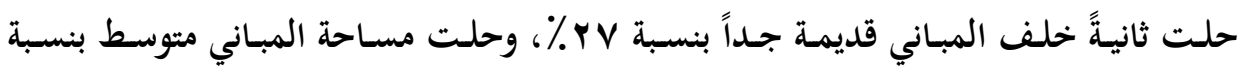

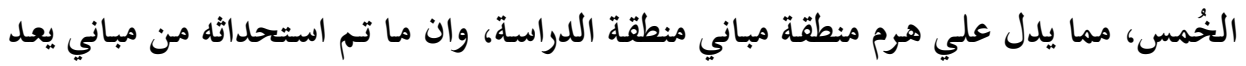

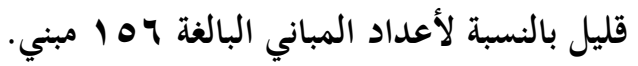

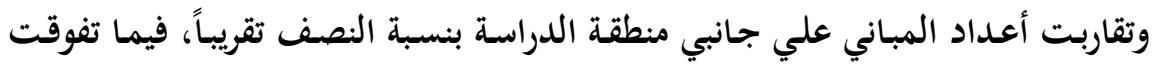

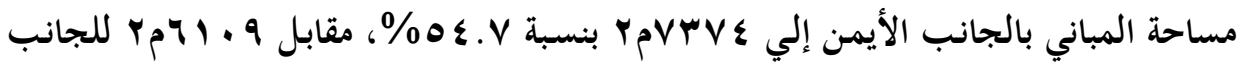

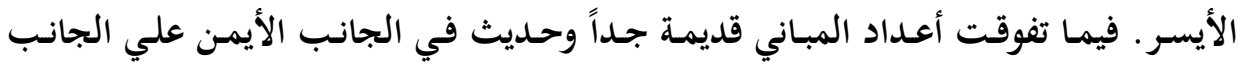

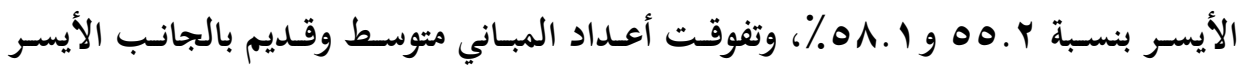
وبنسبة • V و ه. \& ه \% لكل منهما.

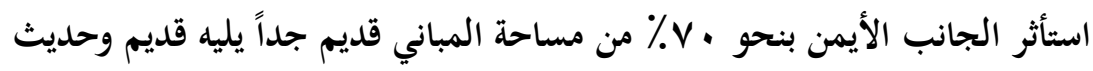

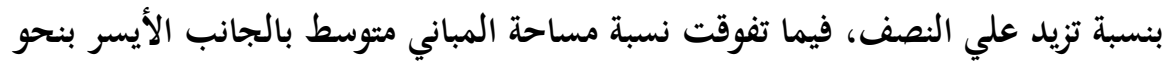

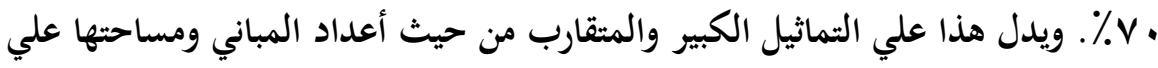

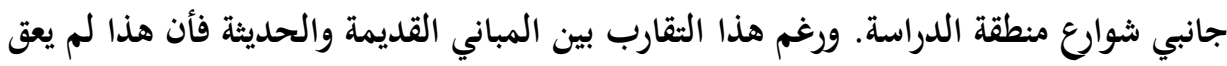

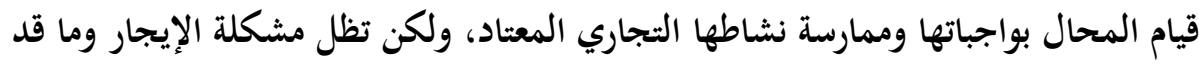

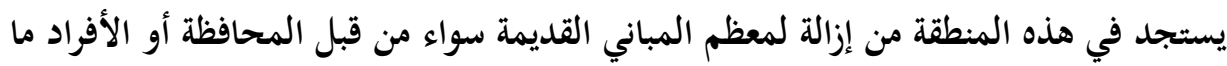

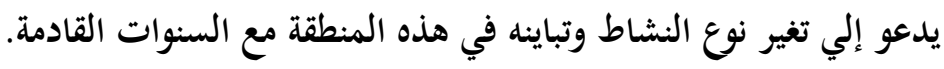




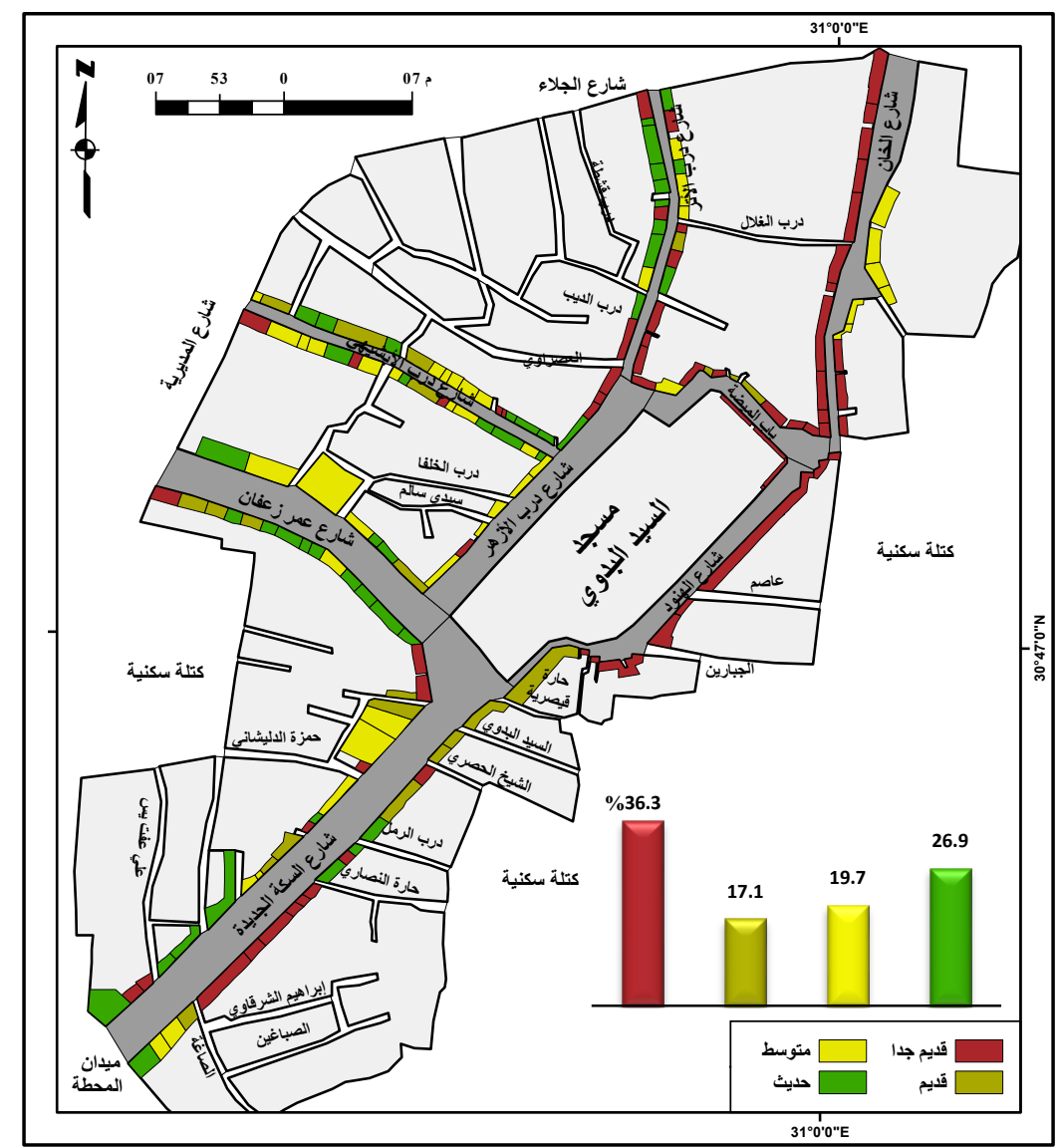

شكل (0) توزيع حالات المباني بمنطقة المسجد الأحمدي بمدينة طنطا عام ع ا ـ ب.

$$
\text { r. أعداد طوابق المباني وكثافتها: }
$$

تتصـف منطقـة القلـب التجـاري بقلـة أعـداد طوابـق بنايتها، حيـث تميـل إلي الارتفـاع المحدود الذي يتراوح بين ب-ع طوابق خاصة المباني السكنية القديمة التي بنيت مع نهاية القرن التاسع عشر وأوائل القرن العشرين، وهذا ما ينطبق ويسود غالبية شوارع المنطقة التي

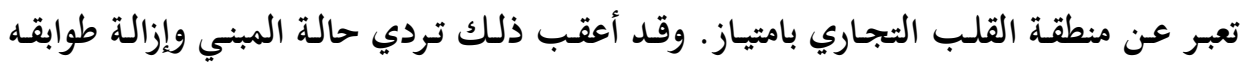
العلوية ولم يتبق سوي الطابق الأرضي فقط، ورصدت نتائج الدراسة الميدانية عدة مؤشرات عن

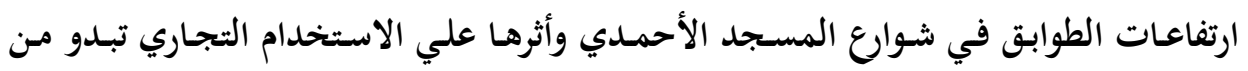
الجدول (•) والشكل (7). 
ويغلب علي منطقة الدراسة صفة الطابق الواحد (الطابق الأرضي) وذلك بعد إزالة معظم

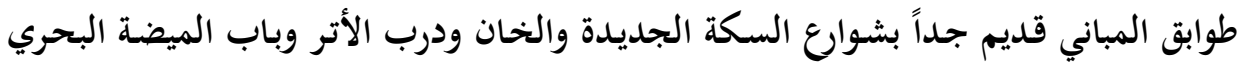

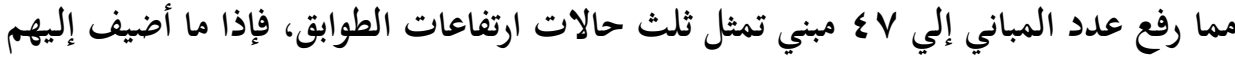

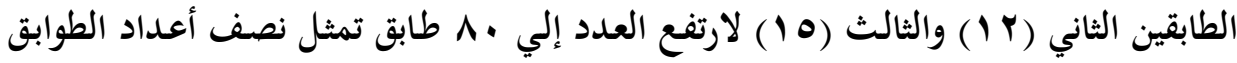

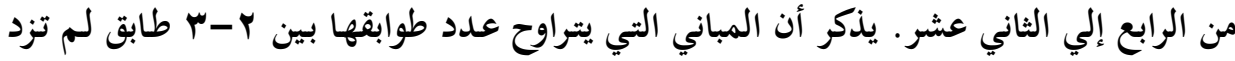

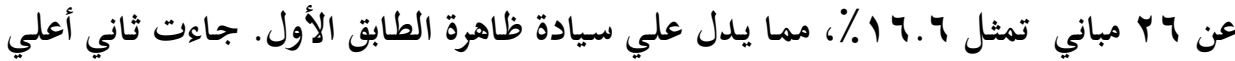

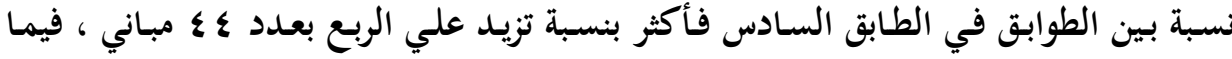

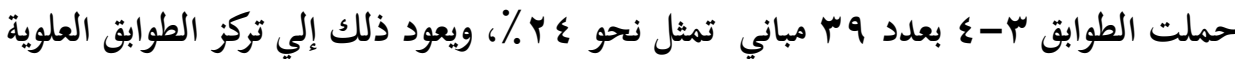

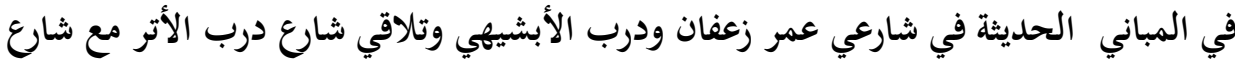

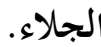

جدول (0) أعداد طو ابق المباني وكثافتها علي جانبي شوارع المسجد الأحمدي عام ؛ الـ ب.

\begin{tabular}{|c|c|c|c|c|c|}
\hline \multirow{2}{*}{ الكثافة } & \multicolumn{2}{|c|}{ المساحة } & \multicolumn{2}{|c|}{ المبني } & \multirow{2}{*}{ المبني } \\
\hline & $\%$ & $\left(Y_{\rho}\right)$ & $\%$ & العدد & \\
\hline 1.1 & TY.Y & \& rrq & r.o & $\varepsilon V$ & طابق \\
\hline 1.1 & $1 V . \varepsilon$ & rror & 17.7 & YY & $r-r$ \\
\hline 1.1 & YY.* & rol. & rr.q & $r q$ & $0 . \varepsilon$ \\
\hline $1 . r$ & $r \leqslant . \varepsilon$ & rYAO & $r V_{.} \cdot$ & $\leqslant \varepsilon$ & ستة فأكثر \\
\hline $1 . r$ & $1 \ldots$ & $I r \leqslant \Lambda T$ & $1 \ldots$ & 107 & جملة \\
\hline
\end{tabular}

المصددر/ الجدول من إعداد الباحث اعتماداً علي الدراسة الميدانية.

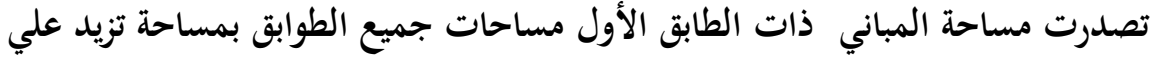

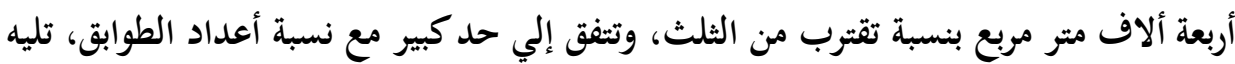

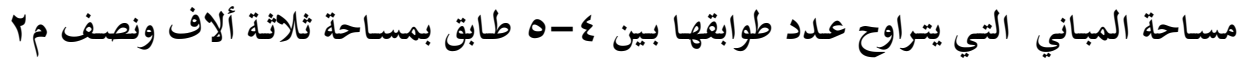

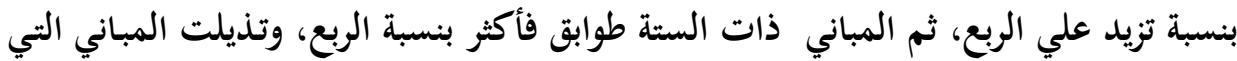

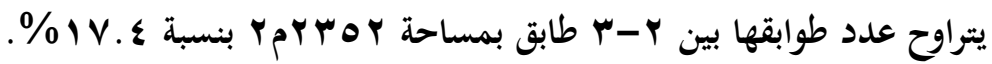

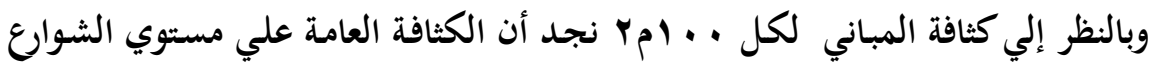

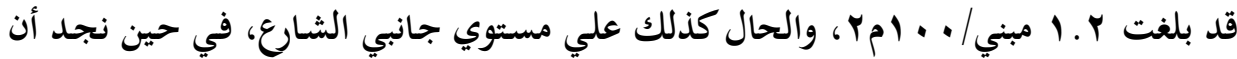

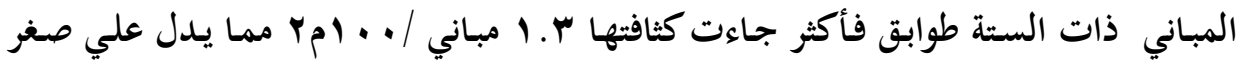

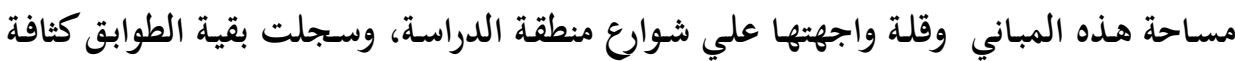

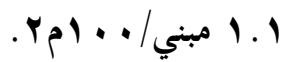

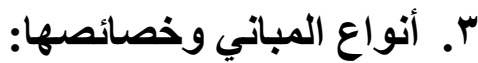


لا يمكن تحليل توطن أي نوع من استخدامات الأرض وتوزيعه مثل الاستخدام الصـناعي

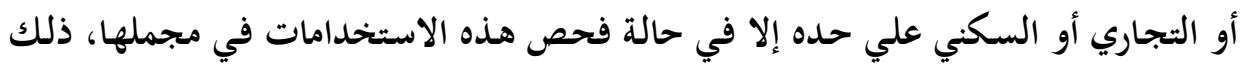

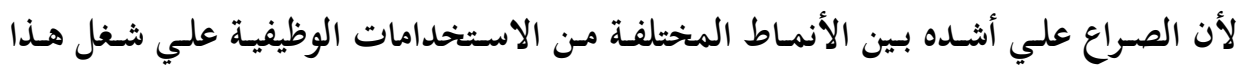

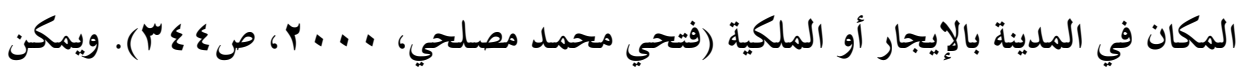

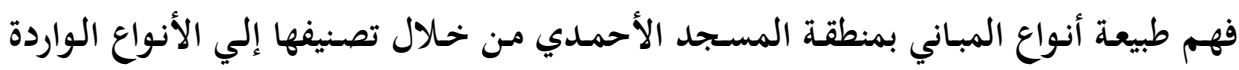

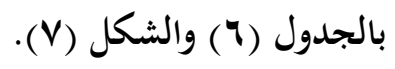

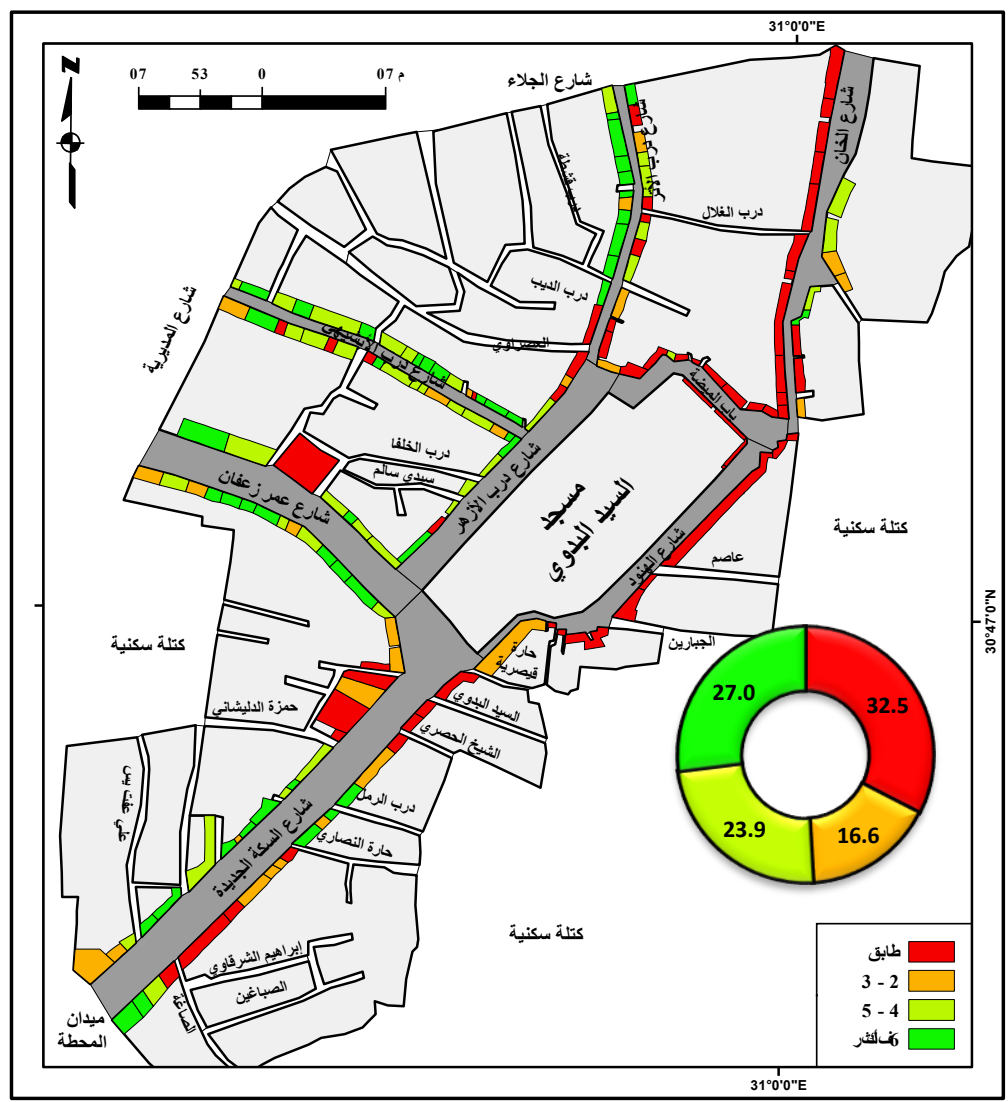

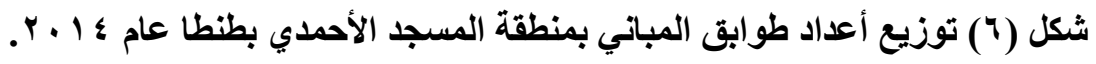
استحوذت المباني التي تصنف علي أنها استخدام سكنية كصفة غالبة في معظم الطوابق

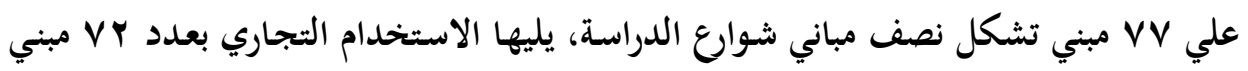

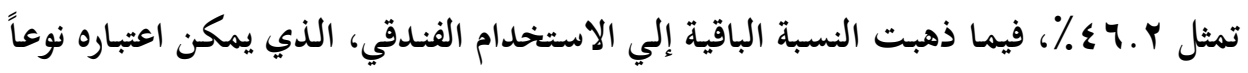




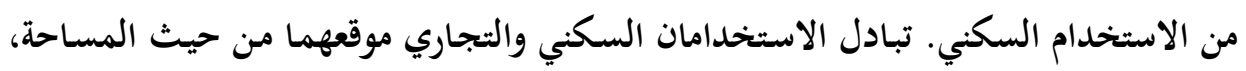

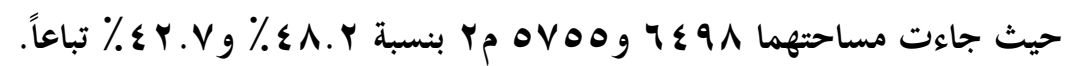

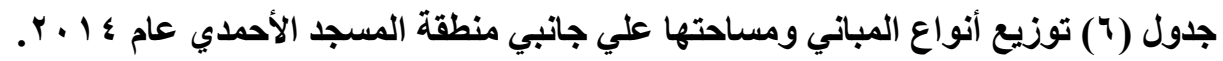

\begin{tabular}{|c|c|c|c|c|c|c|c|c|c|c|c|c|}
\hline \multicolumn{4}{|c|}{ الجملة } & \multicolumn{4}{|c|}{ الجاتب الأيسر } & \multicolumn{4}{|c|}{ الجاتب الأيمن } & \multirow{3}{*}{ ألمبني } \\
\hline \multicolumn{2}{|c|}{ المساحة } & \multicolumn{2}{|c|}{ المبني } & \multicolumn{2}{|c|}{ المساحة } & \multicolumn{2}{|c|}{ المبني } & \multicolumn{2}{|c|}{ المساحة } & \multicolumn{2}{|c|}{ المبني } & \\
\hline$\%$ & $\left(\gamma_{p} \rho\right)$ & $\%$ & العدد & $\%$ & $\left(Y_{\rho}\right)$ & $\%$ & العدد & $\%$ & $\left(Y_{\rho}\right)$ & $\%$ & العدد & \\
\hline$\varepsilon \wedge . r$ & $7 \leqslant 91$ & 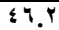 & VY & $\leqslant 9.1$ & YqqV & $\leqslant 9.8$ & rq & $\leqslant V .0$ & $r 0.1$ & $\varepsilon Y . q$ & $r r$ & تجاري \\
\hline$\varepsilon Y . V$ & OVOD & $\leqslant 9 . \xi$ & VV & $\leqslant \curlyvee . \wedge$ & YIIV & $\leqslant 7 . \wedge$ & $r v$ & $\leqslant Y .7$ & גוrk & 01.9 & $\leqslant$ & سكنى \\
\hline 9.1 & Irr. & \&.0 & V & $\Lambda .1$ & $\leq 9 \leq$ & $r . \Lambda$ & $r$ & $1 \cdot$. & VTY & $0 . Y$ & $\varepsilon$ & فندق \\
\hline $1 \ldots$ & $T r \leqslant \Lambda T$ & $1 \ldots$ & 107 & $1 \ldots$ & 71.9 & $1 \ldots$ & 199 & $1 \ldots$ & VRV & $1 \ldots$ & VV & جملة \\
\hline
\end{tabular}

المصددر/ الجدول من إعداد الباحث اعتماداً علي الدراسة الميدانية.

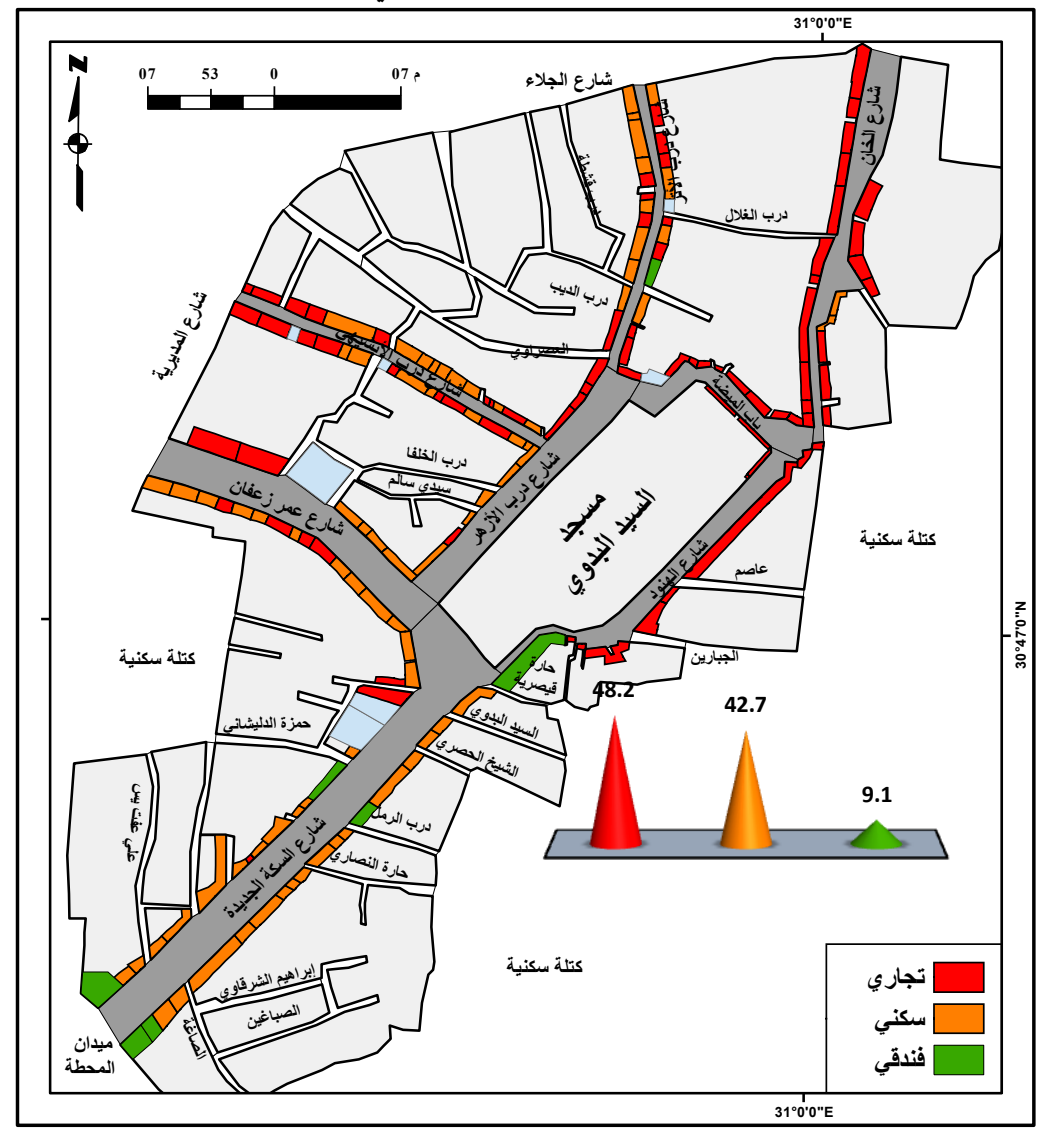

شكل (V) توزيع أنواع المباني بمنطقة المسجد الأحمدي بطنطا عام ع ا بـ.

استحوذت مباني الاستخدام السكني علي أكثر من نصف الاستخدامات الجانب الأيمن

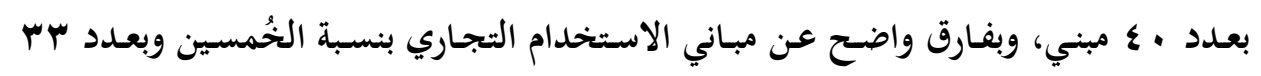

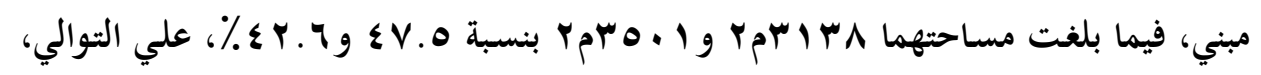




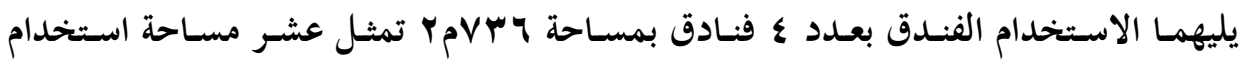

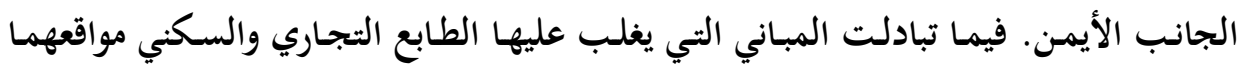

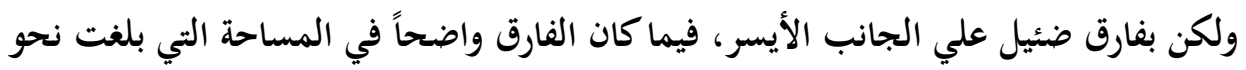

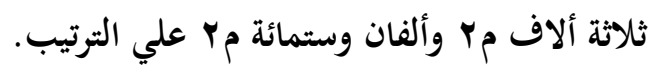

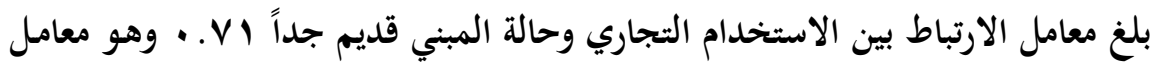

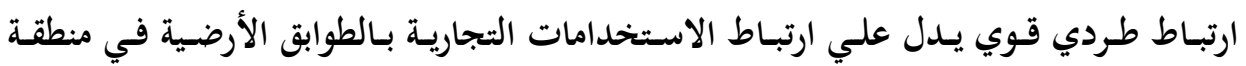

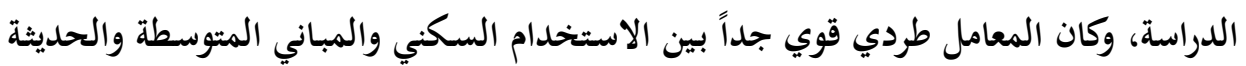

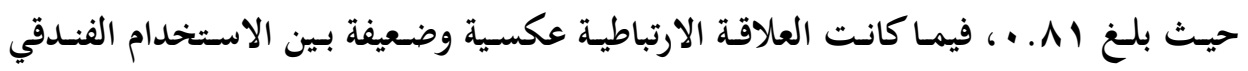

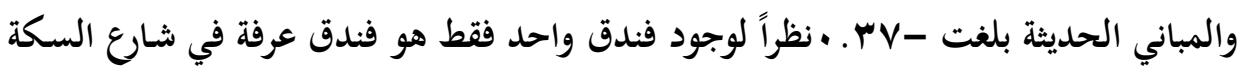

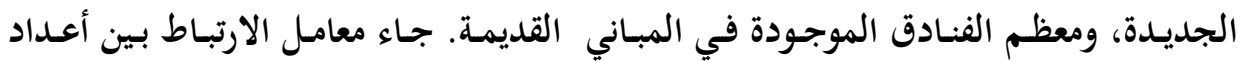

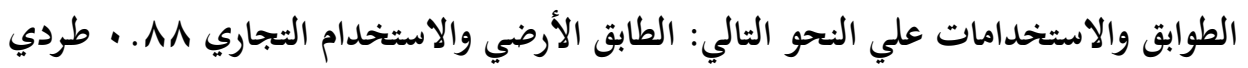

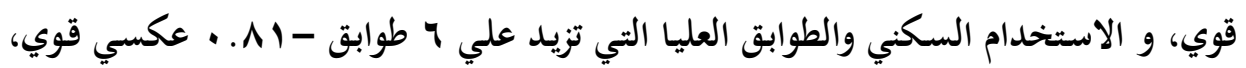

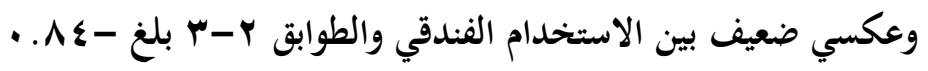

ثالثاً: خصائص شوارع منطقة الدراسة

أظهرت الدراسة الميدانية وجود 1 • ه استخدام أرضي، منهم ثمان مساجد، توزعت

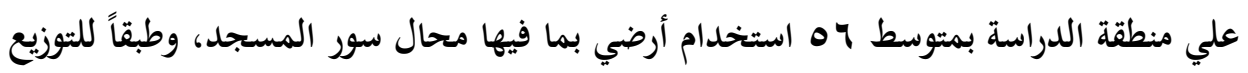

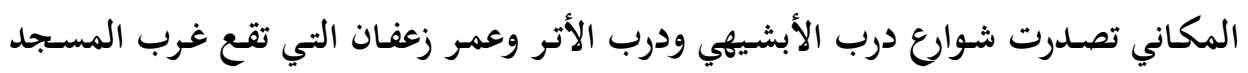

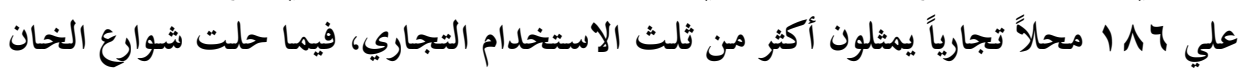

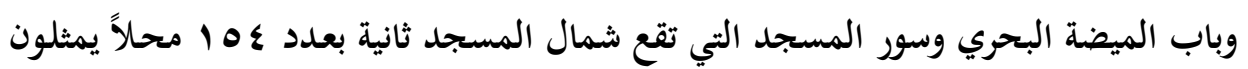

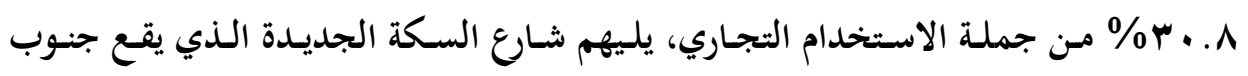

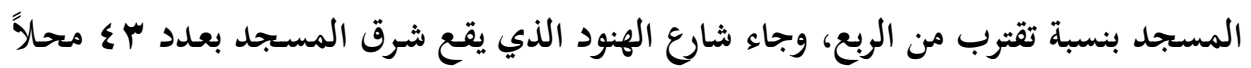
يمثلون أقل من عشر الاستخدام التجاري. ا ـ . حالات مباني المحال التجاريـة:

تؤودي التباينـات المكانيـة للمحال التجاريـة إلي إظهار الأهميـة النسبية لها، وإمكانيـة

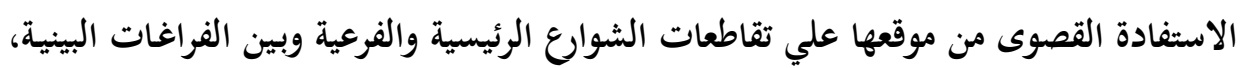

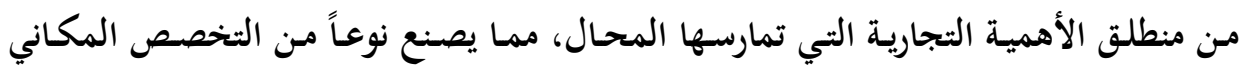

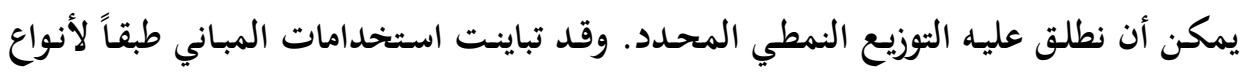


المحال التجارية علي مستوي شوارع المسجد الأحمدي من شارع لآخر، حيث أمكن تحديد

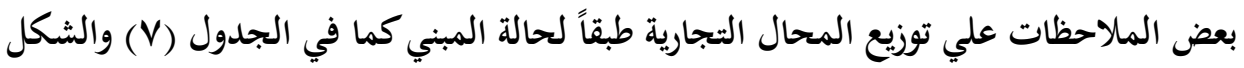

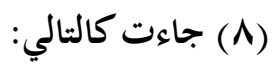
* بلغت أعداد المحال التجارية الموجود بالمبني قديم جداً 191 19 محلاً تمثل خُمسمي المحال بمنطقة الدراسة، فإذا ما أضيفت إليهم محال المباني قديمة والباد البالغة

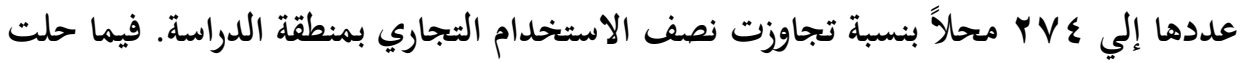

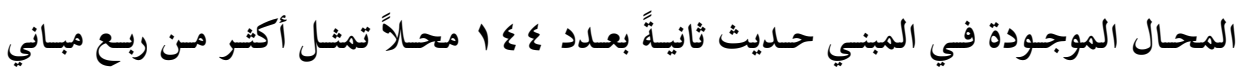

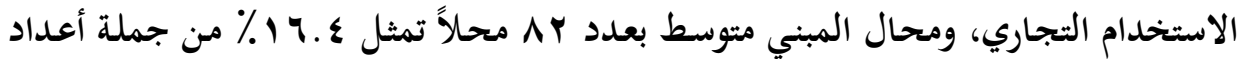
المحال.

* ضـمت حالة المبني قـديم جـداً الاستخدام التجاري بشـارعي الهنود وبـاب الميضسة

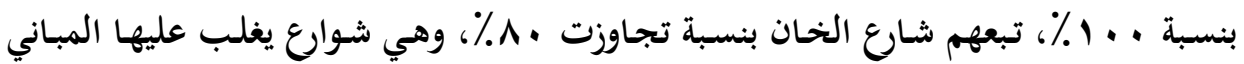

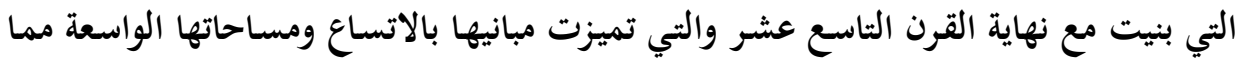

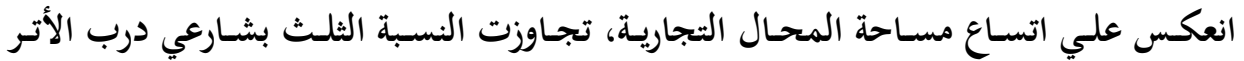
والأزهر، والربع بشارع السكة الجديدة.

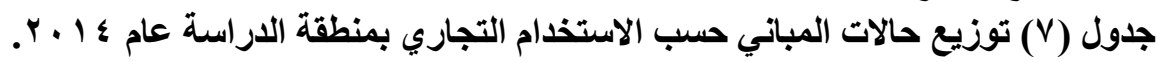

\begin{tabular}{|c|c|c|c|c|c|c|c|c|c|}
\hline \multirow{2}{*}{ جملة } & \multicolumn{2}{|c|}{ حديث } & \multicolumn{2}{|c|}{ متوسط } & \multicolumn{2}{|c|}{ قايم } & \multicolumn{2}{|c|}{ قديم جدا } & \multirow{2}{*}{ المبني } \\
\hline & $\%$ & العدد & $\%$ & العدد & $\%$ & العدد & $\%$ & العدد & \\
\hline VI & & & $1 \wedge . r$ & ir & & & $\Lambda I . V$ & $\Delta \wedge$ & الخان \\
\hline 118 & rr. & $r V$ & 9.5 & 11 & $\varepsilon \cdot . r$ & $\varepsilon V$ & YV.E & Mr & السكة الجديدة \\
\hline$\varepsilon r$ & & & & & & & $1 \ldots$ & $\varepsilon r$ & الهنود \\
\hline rr & & & & & & & $1 \ldots$ & rY & باب الميضة البحري \\
\hline Vr & $r \varepsilon . r$ & ro & rY.q & $r \varepsilon$ & rr.r & IV & 9.7 & $\mathrm{~V}$ & درب الأبشيهي \\
\hline 79 & $\leqslant 0.0$ & $r$. & $1 \% .7$ & 9 & r.. & $r$ & rv. $q$ & ro & درب الأتر \\
\hline rq & $1 \% . \Lambda$ & $\varepsilon$ & $01 . V$ & 10 & & & $r \leqslant .0$ & 1. & درب الأزهر \\
\hline Tr & $1 \cdots$ & rr & & & & & & & سور المسجد \\
\hline$\leqslant V$ & $00 . r$ & Y & rI.r & 1. & YI.r & 1. & Y.I & 1 & عمر زعفان \\
\hline $0 \ldots$ & $r \wedge . \wedge$ & $1 \leq \varepsilon$ & 17.8 & $\Lambda r$ & $10 . r$ & VI & $r 9.7$ & 191 & جملة \\
\hline
\end{tabular}

المصدر/ الجدول من إعداد الباحث اعتماداً علي الدراسة الميدانية.

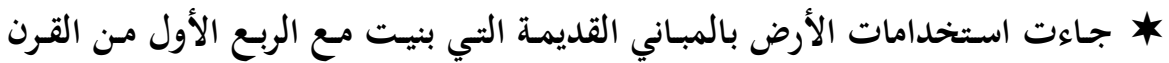

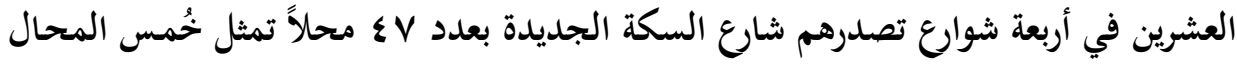

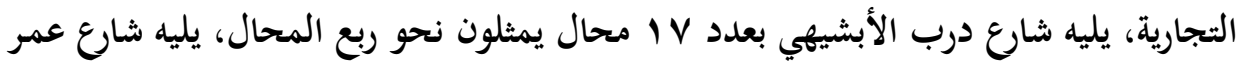

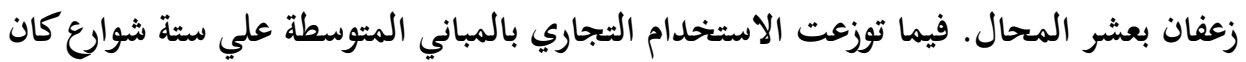

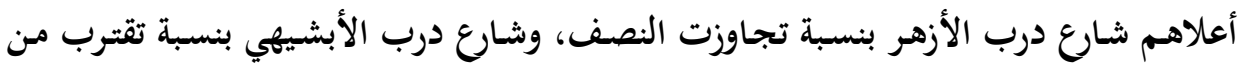

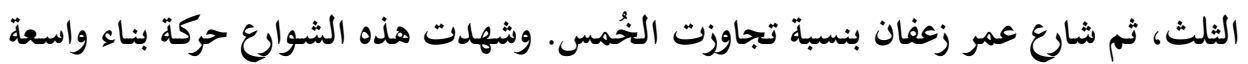


منذ منتصف القرن الماضي جاءت استجابة لحركة الهدم والتوسعة التي أتبعتها محافظة الغربية لتوسعة الشوارع المحيطة بالمسجد.

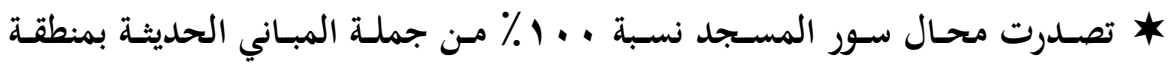

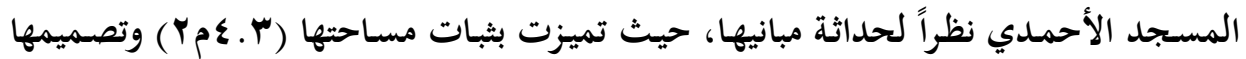

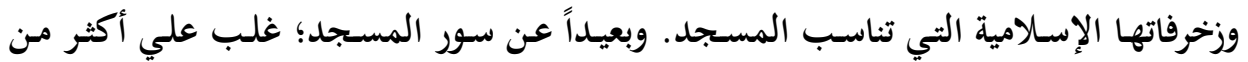

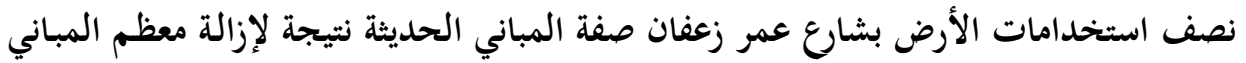

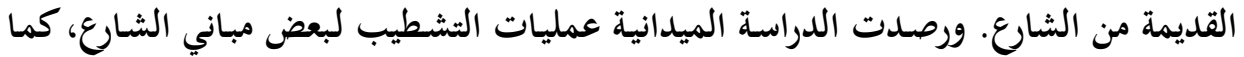

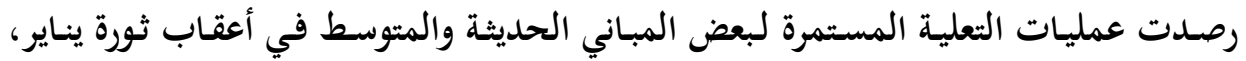

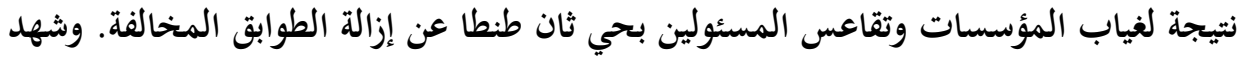

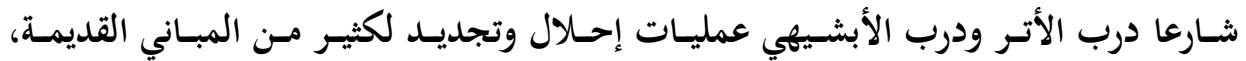

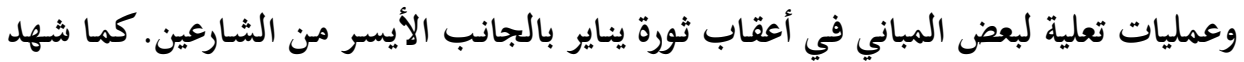

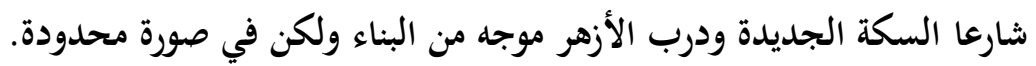

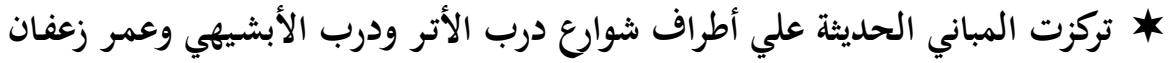

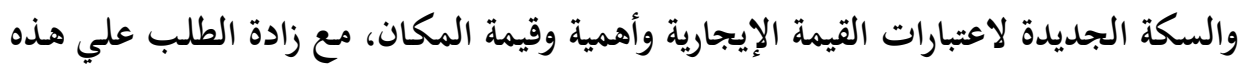

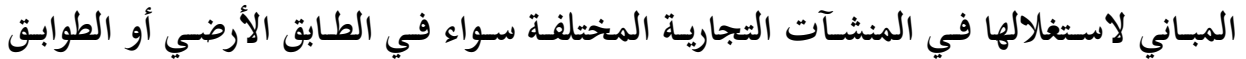

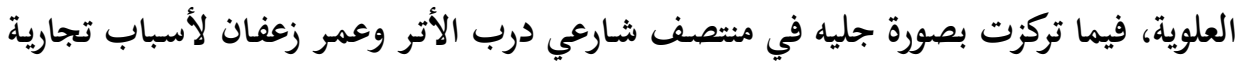
بحتة سيرد ذكرها لاحقاً.

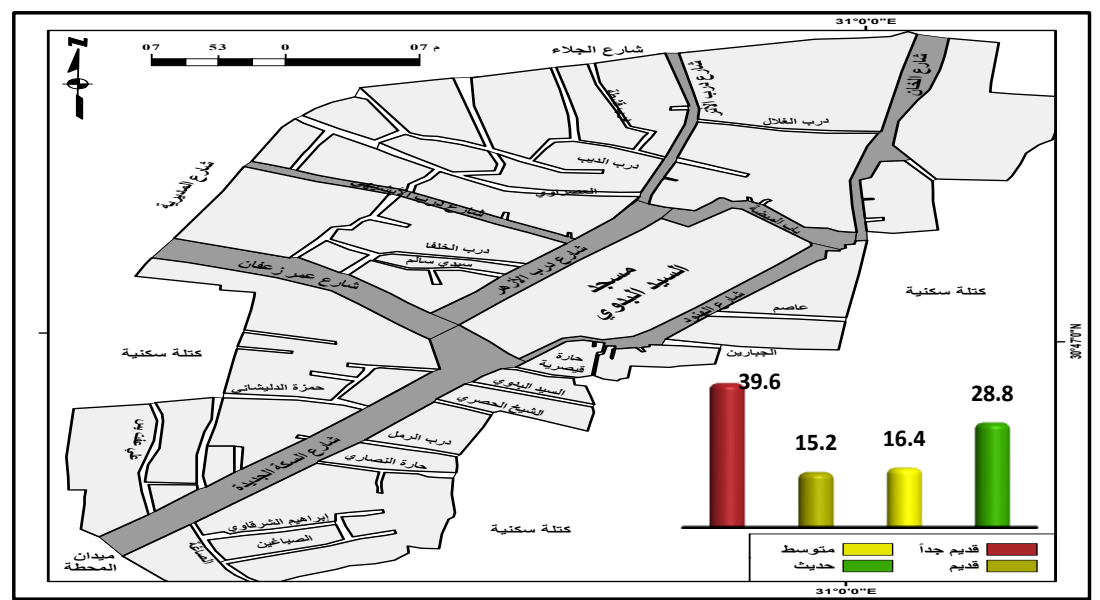

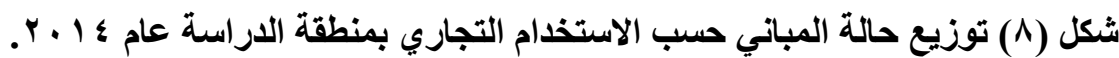
r. أعداد طوابق المحال التجارية: 
تتوقف طبيعة المباني وارتفاعاتها علي عـدة أمور مـ بينها ارتفاع ثمـ الأرض ومـدي

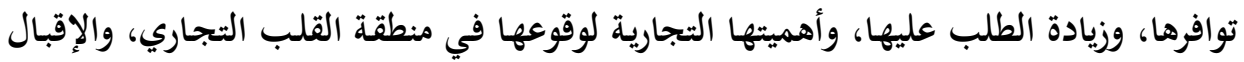

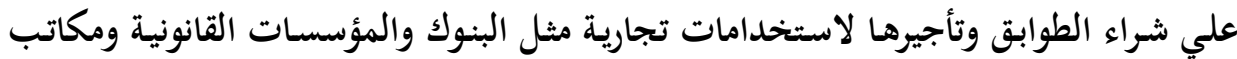

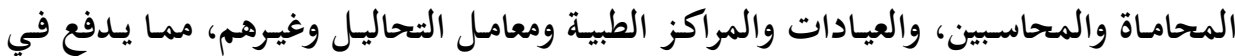

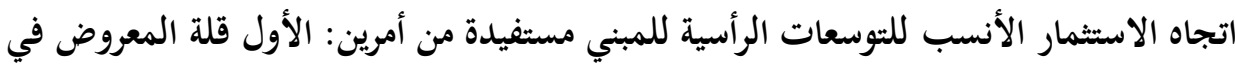

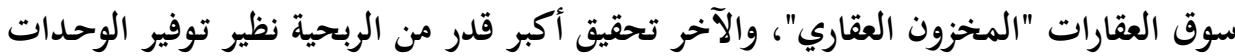
السكنية.

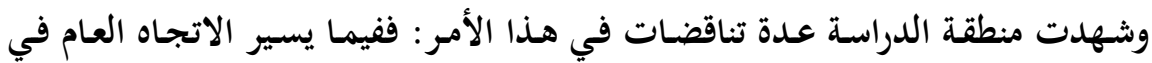

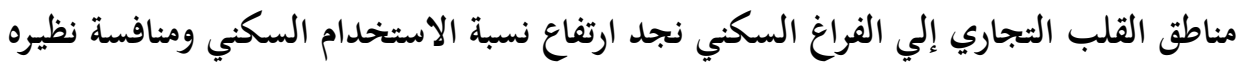

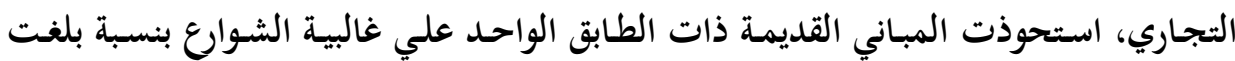

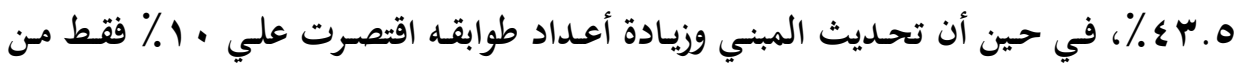

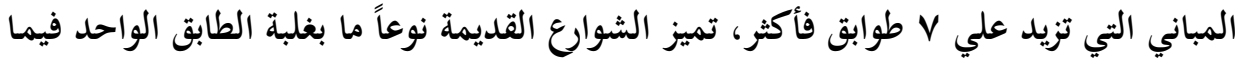

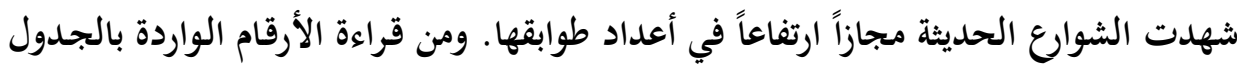

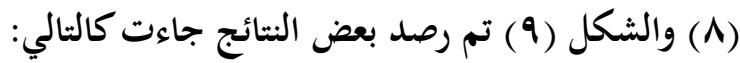

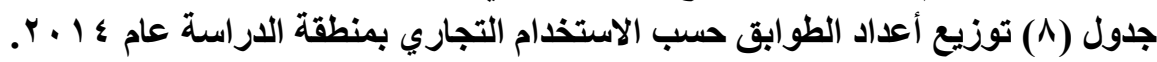

\begin{tabular}{|c|c|c|c|c|c|c|c|c|}
\hline \multicolumn{2}{|c|}{ بأكثر } & \multicolumn{2}{|c|}{$\theta_{-} \varepsilon$} & \multicolumn{2}{|c|}{ r-Y } & \multicolumn{2}{|c|}{ طابق طاب } & \multirow{2}{*}{ الطوابق } \\
\hline$\%$ & العدد & $\%$ & العدد & $\%$ & العدد & $\%$ & العدد & \\
\hline Y.^ & $\bar{r}$ & 10.0 & 11 & $1 \leqslant .1$ & 1. & $7 V .7$ & $\varepsilon \Lambda$ & الخان \\
\hline$r \leqslant . \wedge$ & rq & $1 Y . \Lambda$ & 10 & Y1.द & ro & «1. & $\varepsilon \Lambda$ & السكة الجديدة \\
\hline & & & & r.r & 1 & QV.V & $\varepsilon r$ & الهنود \\
\hline & & 9.1 & r & 14.9 & $r$ & VV.r & IV & باب الميضة البحرى \\
\hline$r 0.7$ & Y & $\leq 9 . \%$ & T & IY.r & 9 & Y.V & r & درب الأبشيهي \\
\hline rv. .9 & ro & YO.A & IV & 14.7 & 9 & TY.V & 10 & درب الأتر \\
\hline TV.T & $\Lambda$ & $r v .9$ & 11 & r.£ & $T$ & rI. & 9 & درب الأزهر \\
\hline & & & & & & $1 \ldots$ & $r r$ & سور المسجد \\
\hline$\leqslant 7 . \wedge$ & YY & $\leqslant \leqslant . V$ & $Y_{1}$ & $\Lambda .0$ & $\varepsilon$ & & & عمر زعفان \\
\hline YY.\& & $11 \mathrm{r}$ & YY.T & 114 & TY. & 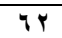 & \&Y. & rIT & جملة \\
\hline
\end{tabular}

المصدر/ الجدول من إعداد الباحث اعتماداً علي الدراسة الميدانية.

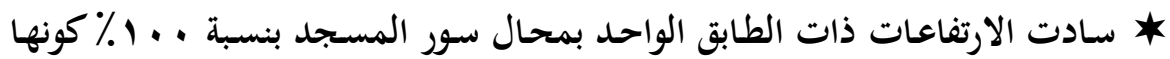

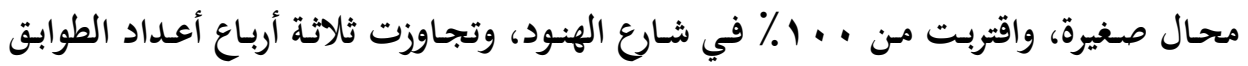

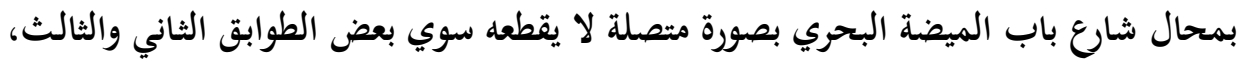

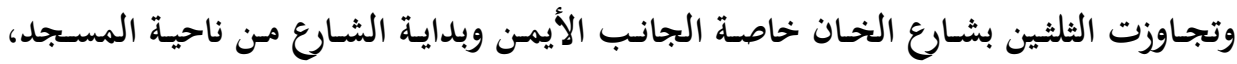

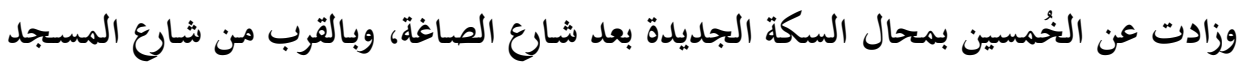


الأحمدي والأكشاك الموجودة بجوار مسجد البهي، وأكثر من الخُمس بمحال درب الأتر واقتربت من الثلث بمحال درب الأزهر.

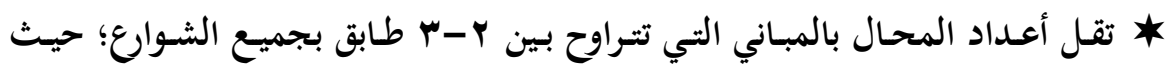

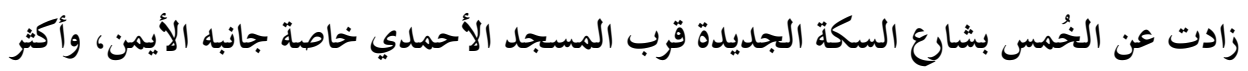

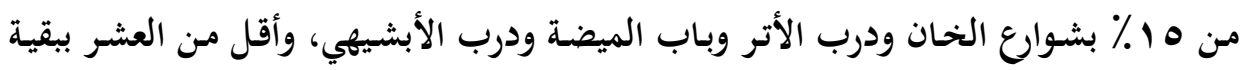

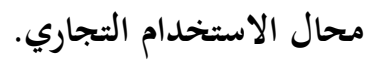

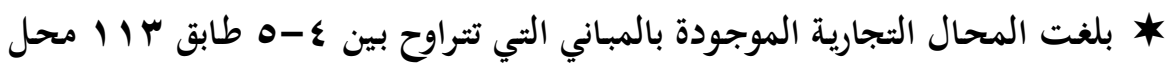

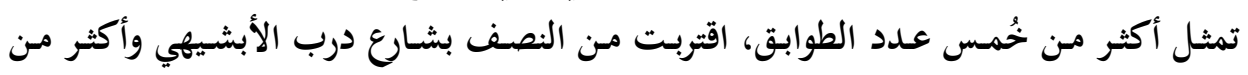

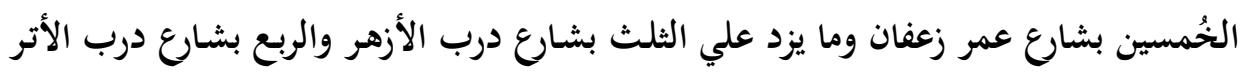

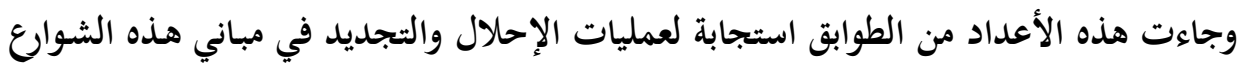

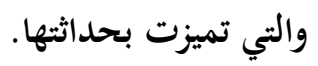

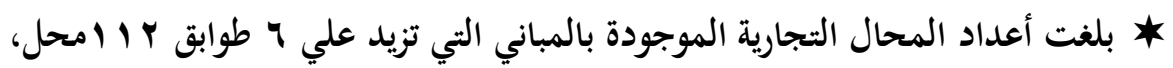

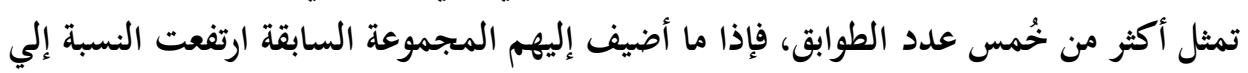

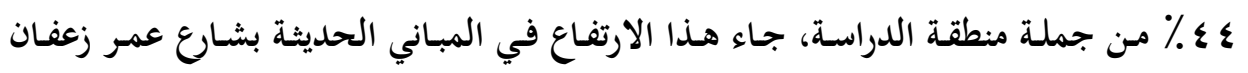

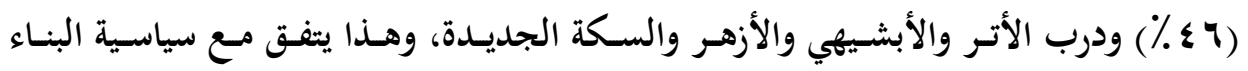

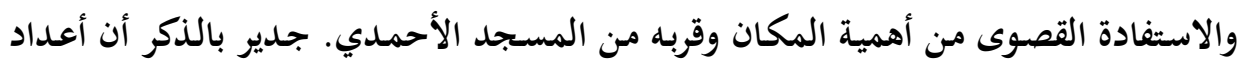

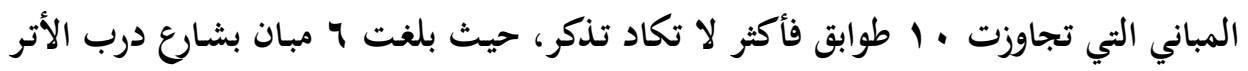

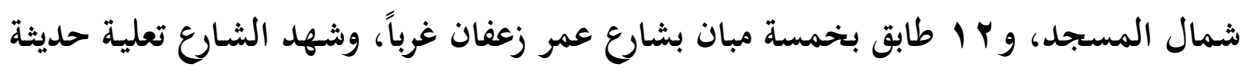

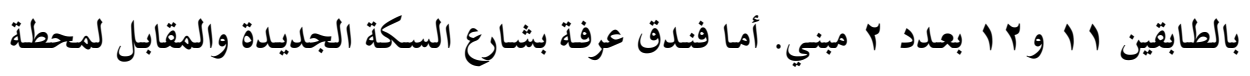

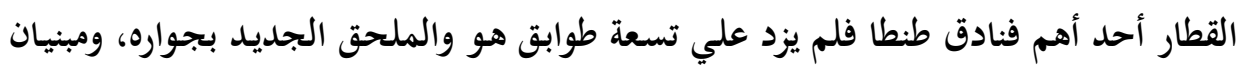
بواجهة معدنية بشارع درب الأتر. 


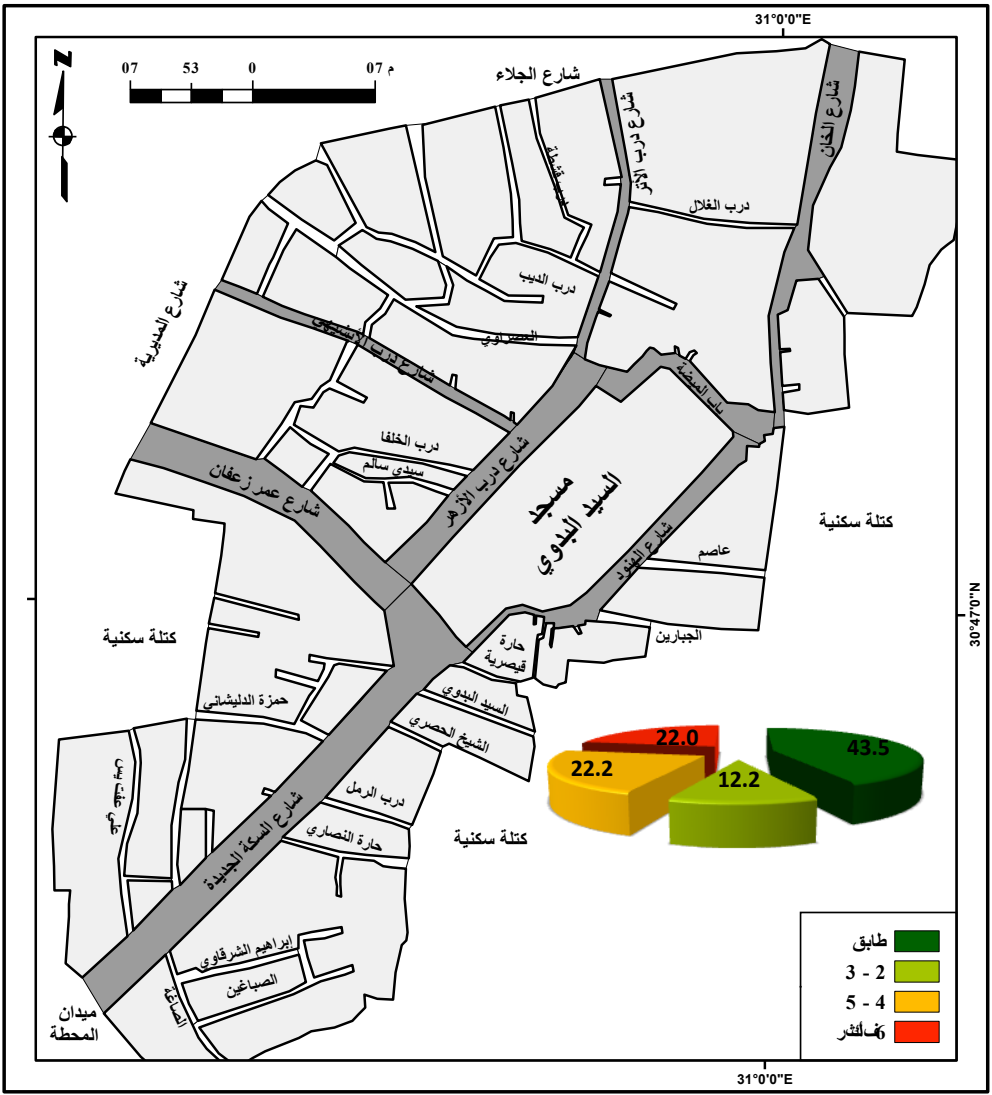

شكل (9) توزيع أعداد الطوابق حسب الاستخدام التجاري بمنطقة الاراسة عام ع ا بـ.

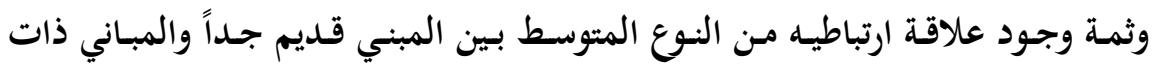

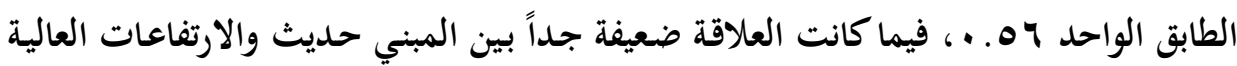

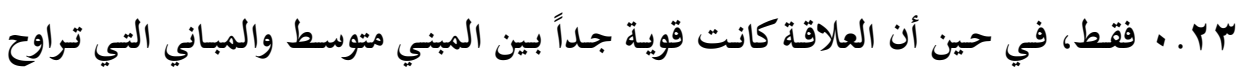

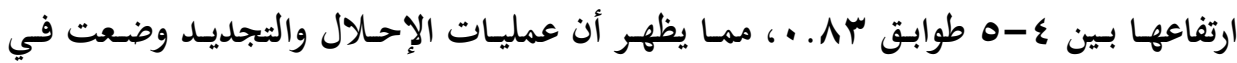

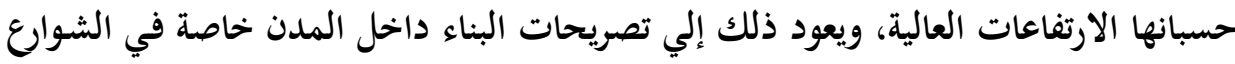
الضيقة، كما في شارعي عمر زعفان والسكة الجديدة. "ا. استخدامات مباني المحال التجارية: لا شك أن تباين العلاقة بين توزيع المباني المنخفضة الارتفاعات وأنواع الاستخدامات

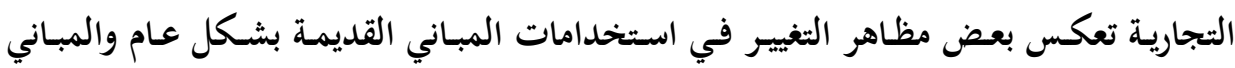

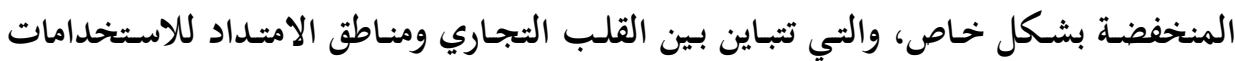


التجارية خارج القلب (Rhind \& Hudson, 1980, p175). ويختلف التنظم المكاني لاستخدامات الأرض من منطقة لأخرى داخل المدينة الواحدة، كما يختلف من من مدينة لأخرى

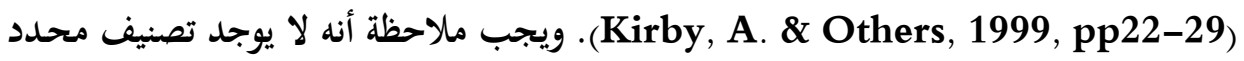

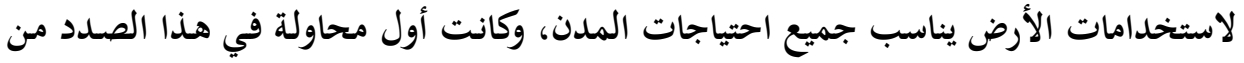

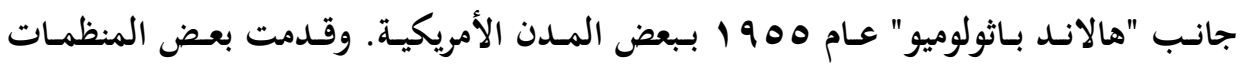

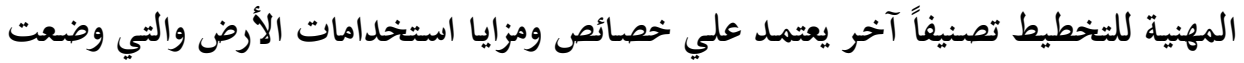
في مجموعتين: خصائص وظيفية، وخصائص أخرى (Norhtam R., 1975, p173). وبشكل عام يمكن تصنيف استخدامات الأرض في المدن إلى ست فئات هي: وضئ أغراض

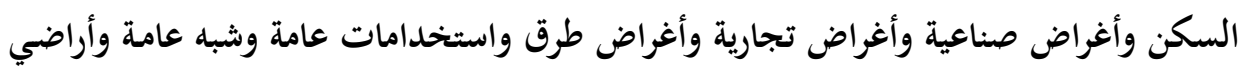

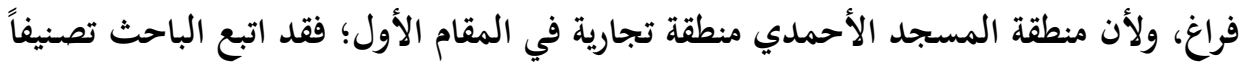

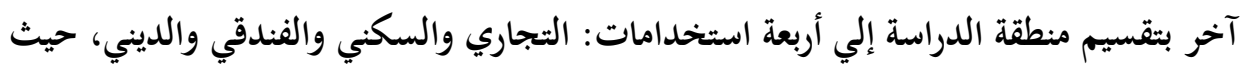

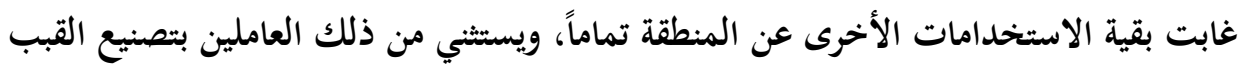

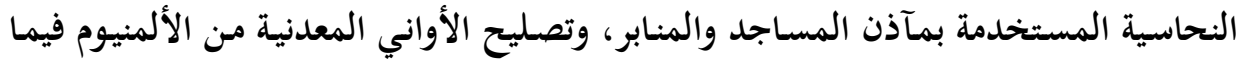
يعرف بحارة النحاسين.

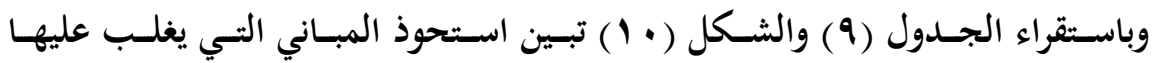

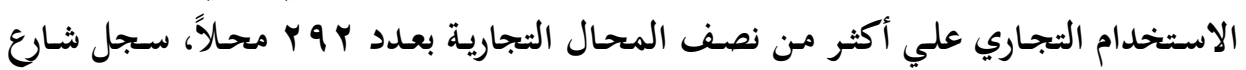

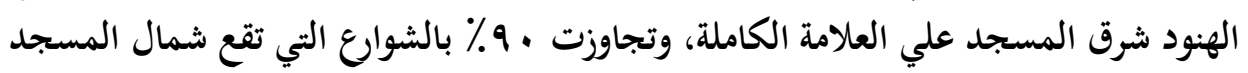

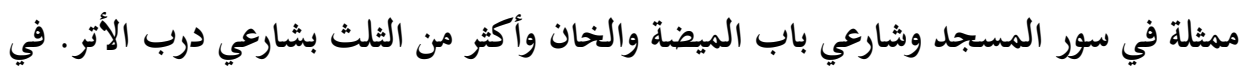

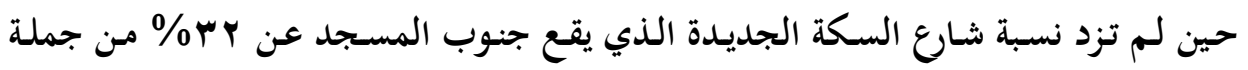

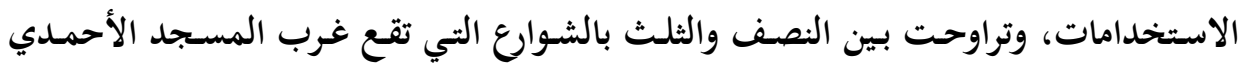
ممثلة في درب الأبشيهي وعمر زعفان ودرب الأزهر.

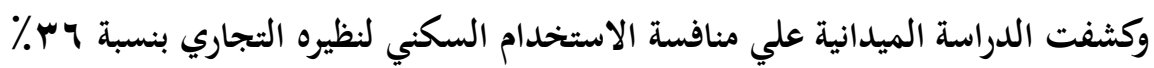

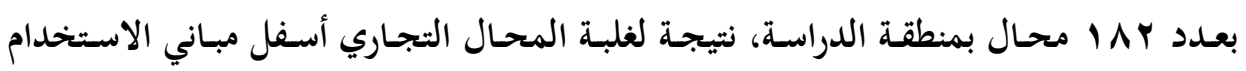

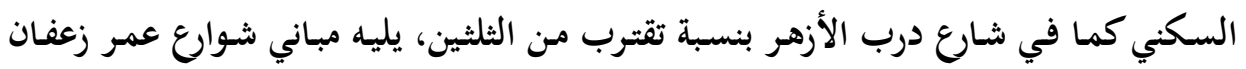

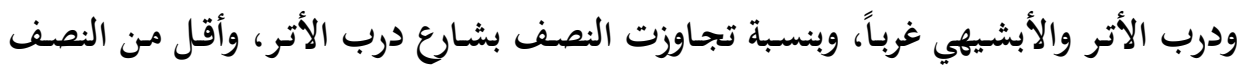
بشارع السكة الجديدة.

جدول (9) توزيع استخدامات المباني حسب الاستخدام التجاري بمنطقة الاراسة ؛ ا ـ ؟. 


\begin{tabular}{|c|c|c|c|c|c|c|c|c|}
\hline \multicolumn{2}{|c|}{ ديني } & \multicolumn{2}{|c|}{ فندق } & \multicolumn{2}{|c|}{ سكني } & \multicolumn{2}{|c|}{ تجاري } & \multirow{2}{*}{ المبني } \\
\hline$\%$ & العدد & $\%$ & العدد & $\%$ & العدد & $\%$ & العدد - ال العد & \\
\hline & & & & $\Lambda .0$ & 7 & 91.0 & 10 & الخان \\
\hline 1.1 & Y & $1 V .7$ & $Y_{1}$ & $\varepsilon \wedge . V$ & $0 \Lambda$ & 41.9 & $r \Lambda$ & السكة الجليدة \\
\hline & & & & & & $1 \ldots$ & $\varepsilon r$ & الهنود \\
\hline$\varepsilon . r$ & 1 & & & & & $90 . V$ & YY & باب الميضة البحري \\
\hline Y.V & $r$ & & & $\varepsilon \wedge . \cdot$ & $r q$ & $\{9 . r$ & $r v$ & درب الأبشيهي \\
\hline r. 9 & $r$ & $V . \varepsilon$ & 0 & or.q & ri & $r q .1$ & ro & درب الأتر \\
\hline & & & & 70.0 & 19 & $r \leqslant .0$ & 1. & درب الأزهر \\
\hline & & & & & & $1 \ldots$ & TY & سور المسجد \\
\hline$r_{.} \cdot$ & 1 & & & $09 . r$ & rV & $\leqslant 1 . V$ & r. & عمر زعفان \\
\hline 1.7 & $\Lambda$ & 0.1 & Yq & $r 0 . \Lambda$ & INY & OV.O & YqY & جملة \\
\hline
\end{tabular}

المصيدر/ الجدول من إعداد الباحث اعتماداً علي الدراسة الميدانية.

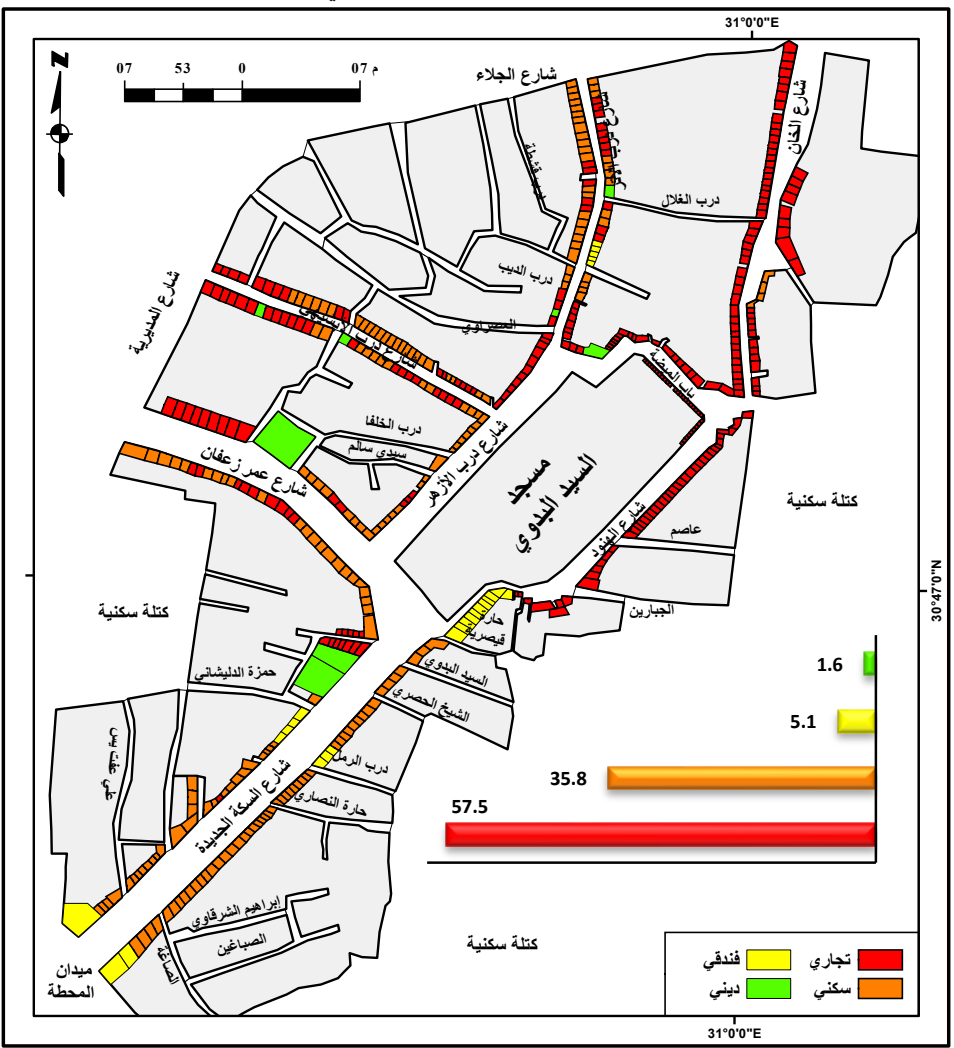

شكل (• 1) توزيع الاستخدام التجاري حسب نوع المباني بمنطقة المسجد الأحمدي ؛ ـ ـ ب.

واقتصر الاستخدام الفندقي علي شارعي السكة الجديدة بعدد إب محل تجاري بنسبة

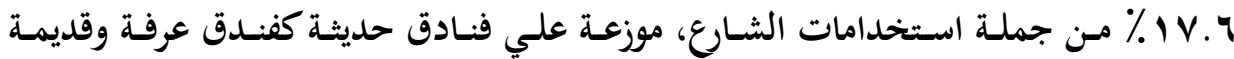

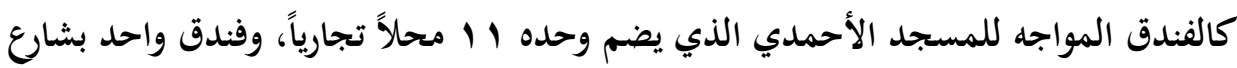

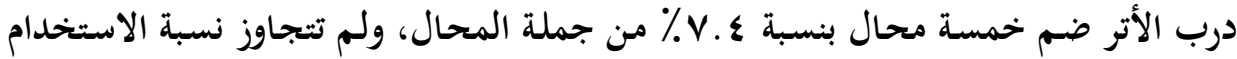


الفندقي بمنطقة الدراسة عن 1.0.

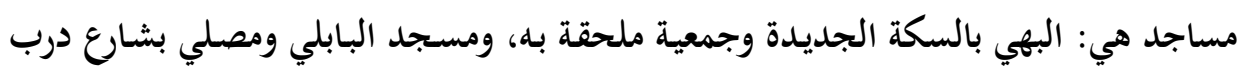

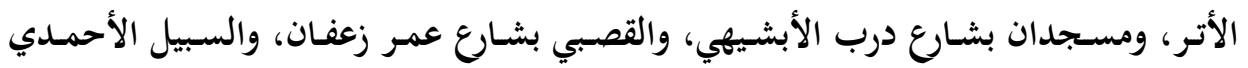

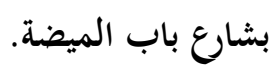

وثمة وجود علاقة ارتباطيه قوية بين المباني القديمة جداً والاستخدام التجاري بلغت AV

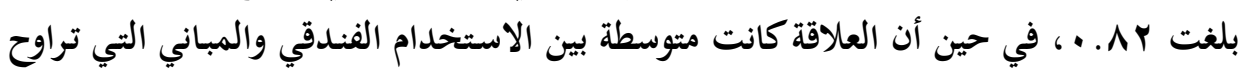

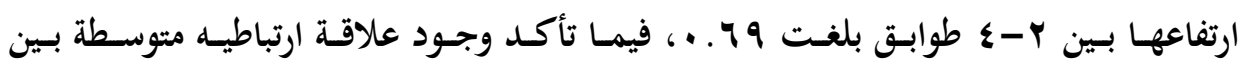
الاستخدام السكني والمبني المتوسط بمنطقة الدراسة. رابعاً: خصائص الاستخدام التجاري بمنطقة الدراسة

يعد تصنيف الاستخدام التجاري وتجميعه في مجموعات أمراً ضرورياً من أجل دراستها،

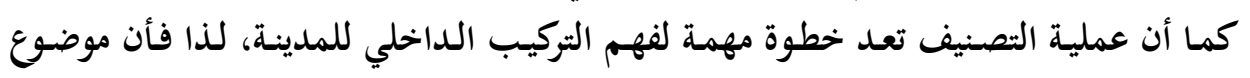
الاستخدام التجاري قد نال حظه من الدراسة من قبل الجغرافيين منذ فترة طويلة، وتبعهم وسار

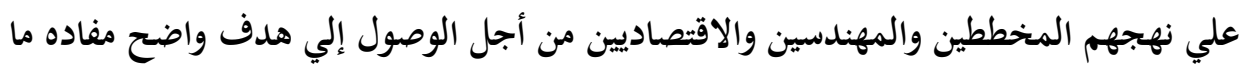

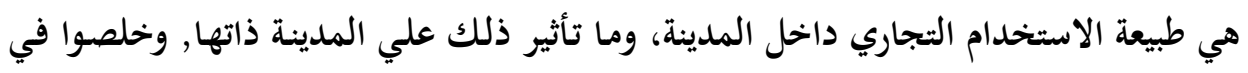

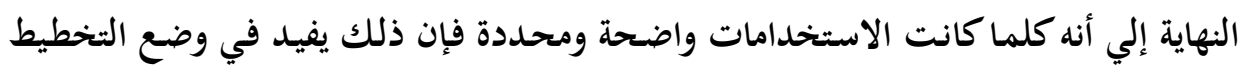

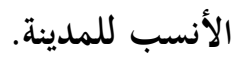

وتخضع استخدامات الأرض في المدينة إلى متغيرات متعددة تؤثر بشكل أو بأخر في

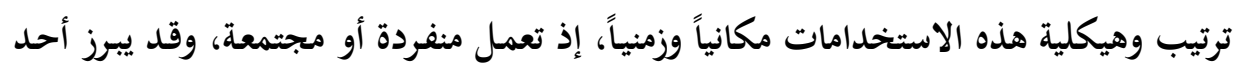

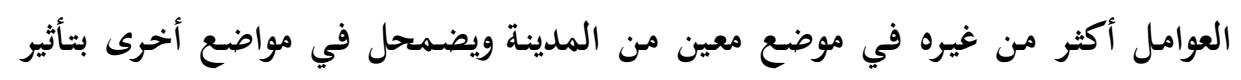

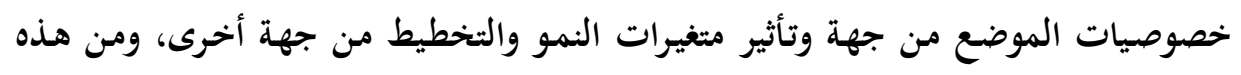

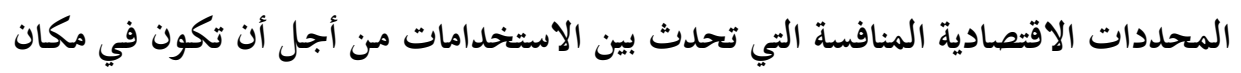

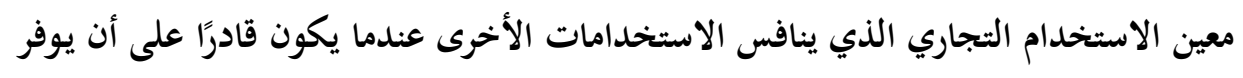

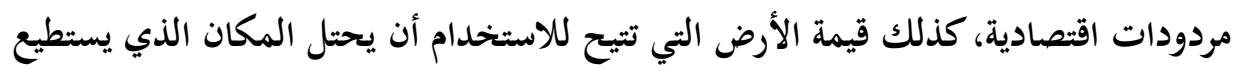

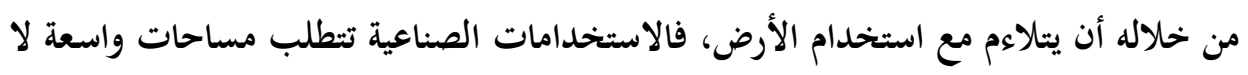

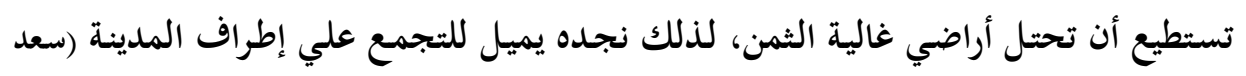

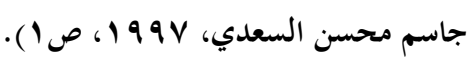


وكان مـن نتيجـة الحصر الميـداني رصـد ـ . .0 محلاً تجارياً بعـد استبعاد ثمانيـة مبـان

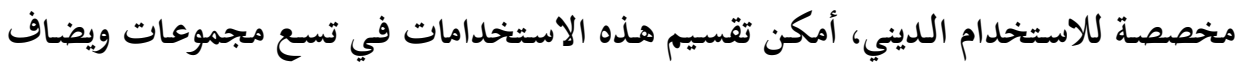

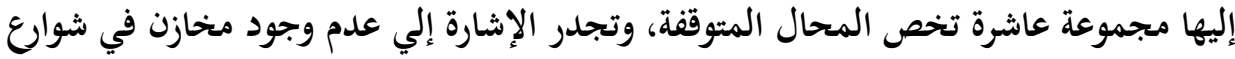

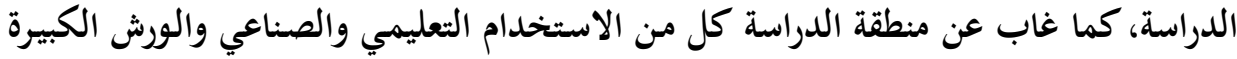

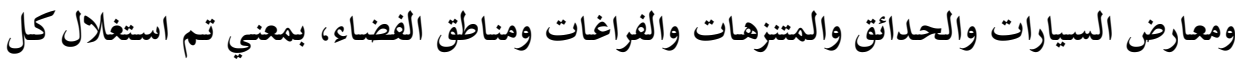
جزء في منطقة النواة أو قلب المدينة التجاري بصورة جيدة إلي حدِ كبيرة.

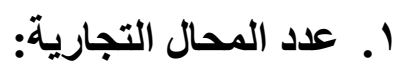

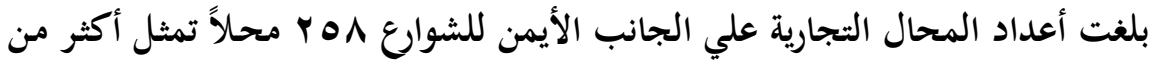

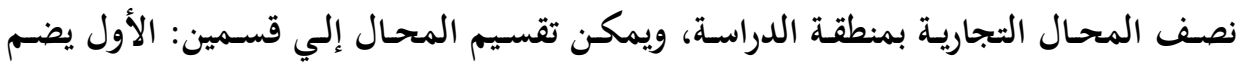

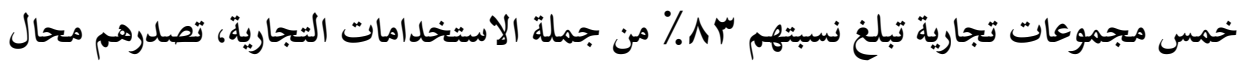

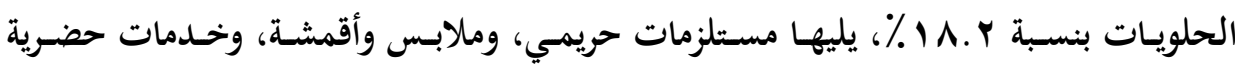

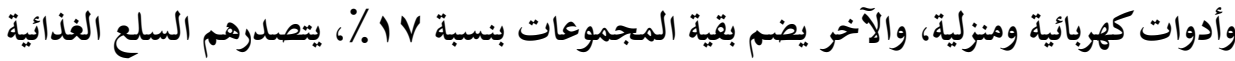

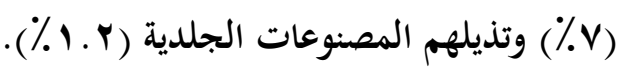

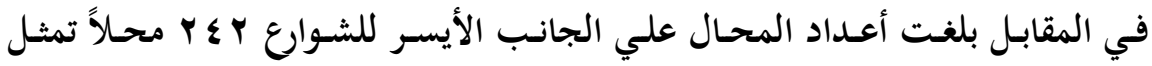

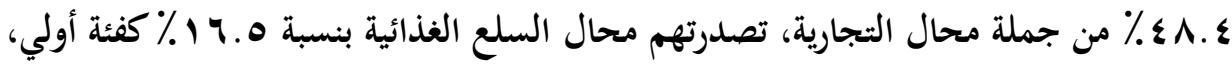

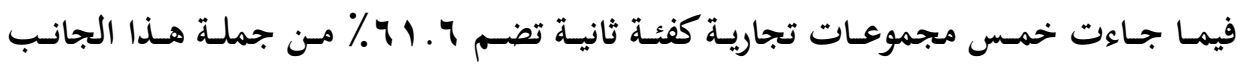

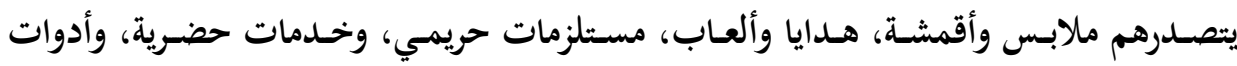

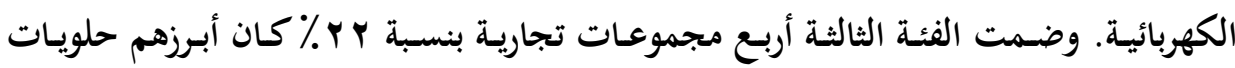

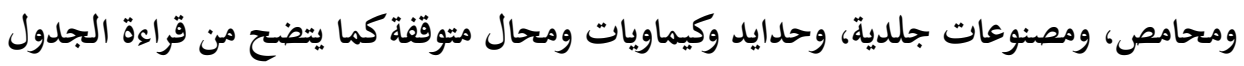

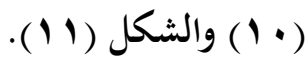

ويمكن تقسيم الاستخدام التجاري إلي ثلاثة فئات: الأولي مجموعات تجارية تزيد علي

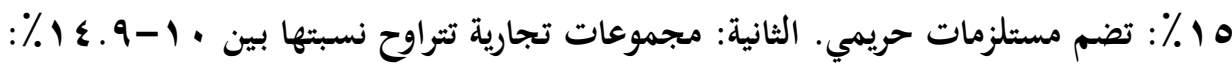

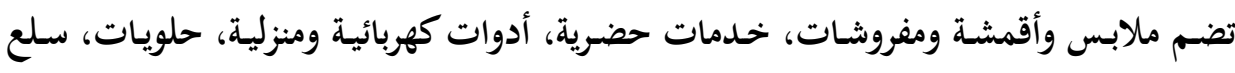

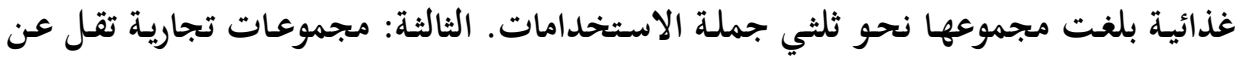

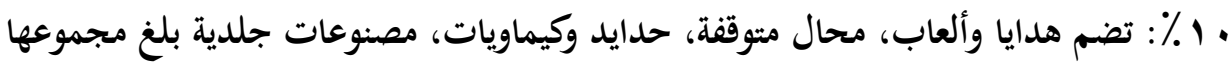
أقل من خُمسي الاستخدامات.

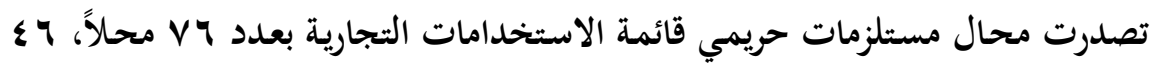

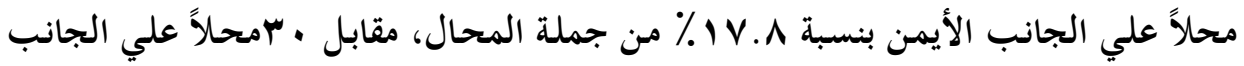




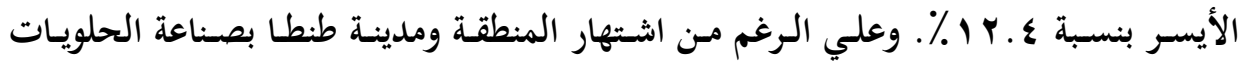

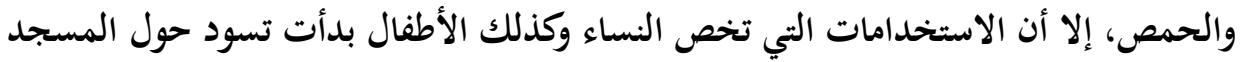

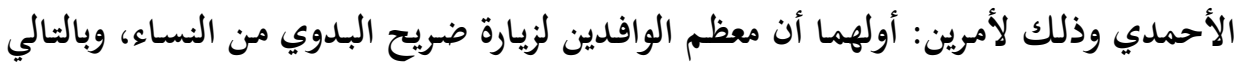

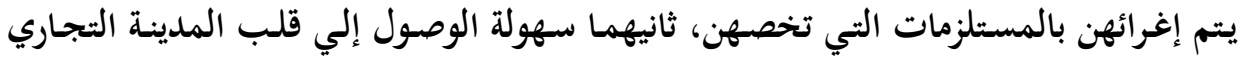

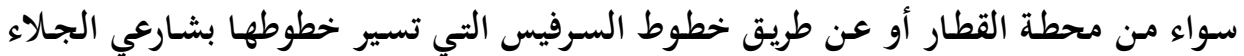

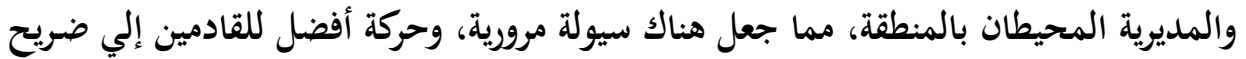

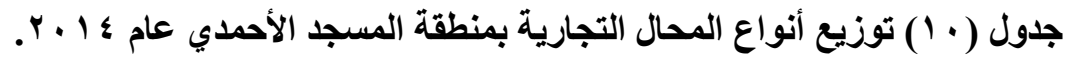

\begin{tabular}{|c|c|c|c|c|c|c|c|}
\hline \multirow{2}{*}{ المجموعة الرئيسية } & \multicolumn{2}{|c|}{ جملة } & \multicolumn{2}{|c|}{ أيسر } & \multicolumn{2}{|c|}{ أيمن } & \multirow{2}{*}{ أنوال } \\
\hline & $\%$ & العدد & $\%$ & العدد & $\%$ & العدد & \\
\hline 71.9 & $9 . \xi$ & $\varepsilon V$ & $\Lambda . r$ & $r$. & $1 \cdot . \varepsilon$ & TV & ملابس و عبايات حريمي \\
\hline $1+.1$ & $Y_{0} \cdot$ & 1. & 1.7 & $\varepsilon$ & T.r & 7 & مستلزمات تجميل \\
\hline$v .9$ & 1.5 & 7 & 1.9 & $r$ & 1.5 & $r$ & طرح حريمي \\
\hline 7.7 & 1.9 & - & & & 1.9 & 0 & مجوهرات \\
\hline 7.7 & $1 . \cdot$ & 0 & $\cdot . \xi$ & 1 & 1.7 & $\varepsilon$ & ملابس داخلية \\
\hline r.9 &. .7 & $r$ & $\cdot . \wedge$ & $r$ &..$\xi$ & $T$ & إكسسوارات \\
\hline $1 \ldots$ & $10 . r$ & V & Ir.s & $r$. & $1 V . \Lambda$ & $\leqslant 7$ & مستلزمات حريمي \\
\hline rr.r & $\varepsilon . \wedge$ & $r \varepsilon$ & T.V & 9 & 0.1 & 10 & ملابس أطفال \\
\hline rT.r & \&.^ & $r \varepsilon$ & 0.9 & Ir & $\varepsilon . V$ & Ir & ملابس رجالي \\
\hline ro. & $r .7$ & 11 & r.V & 9 & r.o & 9 & أقمشة وملابس \\
\hline$\Lambda . r$ & 1.5 & 7 &..$\varepsilon$ & 1 & 1.9 & 0 & مفروشات \\
\hline $1 \ldots$ & $1 \leqslant . \varepsilon$ & VY & $1 Y . \Lambda$ & $r$ & 10.9 & \&1 & ملابس وأقمشة ومفروشات \\
\hline$r \wedge . \varepsilon$ & 0.4 & $r V$ & ๕. & 1. & 7.7 & IV & خردوات \\
\hline$r \cdot . \cdot$ & Y.A & $1 \varepsilon$ & r.o & 7 & r.Y & $\Lambda$ & مكتبة ومطبعة \\
\hline $10 . \mathrm{V}$ & Y.r & 11 & r. & $\bullet$ & r.r & 7 & صيدالية \\
\hline$\varepsilon . r$ &. .7 & $r$ &..$\xi$ & 1 & $\cdot . \wedge$ & r & كاست \\
\hline r.9 &. .4 & $r$ & & & $\cdot . \wedge$ & $r$ & زهور صناعية \\
\hline$r .9$ & $\because \varepsilon$ & $r$ & $\cdot . \wedge$ & $r$ & & & لوازم شبشة \\
\hline$r .9$ & $\cdot . \varepsilon$ & r &..$\varepsilon$ & 1 &.$\varepsilon$ & 1 & فوانيس \\
\hline r.q & $\cdot . \varepsilon$ & $r$ & 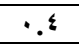 & 1 & $\because \varepsilon$ & 1 & مقهى \\
\hline Y.^ &. .4 & $r$ &..$\wedge$ & 1 &.$\varepsilon$ & 1 & ستوديو وسنترال \\
\hline $1 . \varepsilon$ & $\cdot . r$ & 1 & $\cdot . \varepsilon$ & 1 & & & تأجير سيارات \\
\hline $1 . \varepsilon$ & $\cdot . r$ & $T$ &.$\AA$ & $T$ & & & تكيفات \\
\hline $1 . \varepsilon$ & $\because r$ & 1 &.$\varepsilon$ & 1 & & & كوافير كو \\
\hline $1 . \varepsilon$ &.$r$ & 1 & & &..$\varepsilon$ & 1 & فرن إفرنجي \\
\hline $1 . \varepsilon$ & $\cdot r$ & 1 & & &.$\varepsilon$ & 1 & معمل تحاليل \\
\hline $1 \ldots$ & $1 \leqslant$. & $V$. & IY. & $r$. & 10.0 & $\varepsilon$ & خدمات حضريةة \\
\hline $09 . \mathrm{V}$ & A. & $\varepsilon$ & $0 . \varepsilon$ & 14 & $1 . .0$ & $r V$ & أجهزة وأدوات كهربائية \\
\hline rv.r & 0. & ro & $0 . \varepsilon$ & ir & $\varepsilon . V$ & Ir & أدوات منزلية \\
\hline 1.0 &..$r$ & 1 & & & 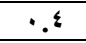 & 1 & بيع ألمونيوم \\
\hline 1.0 & $\cdot . r$ & 1 &.$\varepsilon$ & 1 & & & مطابخ وأساس معدني \\
\hline $1 \ldots$ & $1 \% . \varepsilon$ & $7 V$ & $11 . r$ & $r V$ & 10.0 & $\varepsilon$ & أدوات كهربائية ومنزلية \\
\hline 10.0 & $1 . .7$ & or & ๕.0 & 11 & 17.5 & $\varepsilon r$ & حلو اني \\
\hline
\end{tabular}




\begin{tabular}{|c|c|c|c|c|c|c|c|}
\hline $9 . v$ & $1 . r$ & 7 & $1 . r$ & $r$ & $1 . r$ & $r$ & لوازم أفراح وسبوع \\
\hline$\varepsilon . \Lambda$ &. .7 & $r$ & $\cdot . \xi$ & 1 & $\cdot . \wedge$ & r & محمصة \\
\hline $1 \ldots$ & IY. & Tr & $7 . r$ & 10 & $1 \Lambda . r$ & $\varepsilon V$ & حلويات ومحامص \\
\hline$r 1.0$ & $T .7$ & 11 & $0 . \xi$ & it & 1.9 & 0 & عطارة ولوازم أفراح \\
\hline rV.T & $r . r$ & 17 & ๕.1 & 1. & T.Y & 7 & 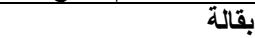 \\
\hline$r \cdot . V$ & Y. \{ & Ir & $r . r$ & $\Lambda$ & 1.7 & $\varepsilon$ & مطعم وحاتي \\
\hline$\Lambda .7$ & 1.9 & 0 & $1 . v$ & $\varepsilon$ & 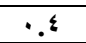 & 1 & عصارة \\
\hline 7.9 & $\cdot . \wedge$ & $\varepsilon$ & $\cdot . \wedge$ & $r$ & $\because \wedge$ & $r$ & جزارة \\
\hline $0 . Y$ &. .7 & $r$ & $1 . r$ & $r$ & & & زيوت وطحينة \\
\hline $1 \ldots$ & 11.7 & $\Delta \wedge$ & 17.0 & $\varepsilon$. & $v_{.} \cdot$ & 11 & سلع غذائية \\
\hline
\end{tabular}

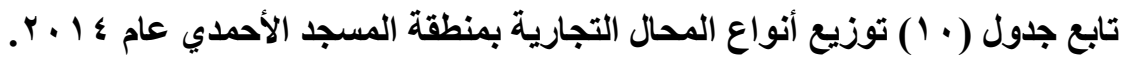

\begin{tabular}{|c|c|c|c|c|c|c|c|}
\hline \multirow{2}{*}{ المجموعة الرئيسية } & \multicolumn{2}{|c|}{ جملة } & \multicolumn{2}{|c|}{ أيسر } & \multicolumn{2}{|c|}{ أيمن } & \multirow{2}{*}{ ألمحال } \\
\hline & $\%$ & العدد & $\%$ & العدد & $\%$ & العدد & \\
\hline 09.0 & $\varepsilon . \xi$ & rY & $V . \varepsilon$ & 11 & 1.7 & $\xi$ & لعب أطفال \\
\hline rq.V & Y.r & 11 & £.1 & $1 \cdot$ & $\cdot . \varepsilon$ & 1 & تجف وتحف وهدايا \\
\hline $0 . \varepsilon$ & $\cdot . \varepsilon$ & $r$ & $\cdot . \wedge$ & $r$ & & & لو ازمم شماسي وعصا \\
\hline $0 . \varepsilon$ &.$\varepsilon$ & r & $\cdot . \xi$ & 1 & $\cdot . \varepsilon$ & 1 & ساعات وبراويز \\
\hline $1 \ldots$ & $V . \varepsilon$ & $r v$ & $1 Y . \wedge$ & $r$ & $r . r$ & 7 & هدايا وألعاب \\
\hline $1 \ldots$ & $\varepsilon . \varepsilon$ & rr & $\varepsilon .1$ & 1. & $\varepsilon . V$ & Ir & محال متوقفة \\
\hline$r \wedge .9$ & $1 . \varepsilon$ & $\mathrm{V}$ & 1.7 & $\varepsilon$ & $1 . r$ & $r$ & تصليح وقطع غيار \\
\hline rT.r & $1 . r$ & 7 & Y. & 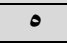 &.$\varepsilon$ & 1 & مبيدات ومنظفات \\
\hline TY.Y & $\cdot \wedge$ & $\varepsilon$ & 1.5 & $r$ & $\cdot . \varepsilon$ & 1 & خراطة وحدايد وموازين \\
\hline 0.7 & $\cdot r$ & 1 &..$\varepsilon$ & 1 & & & أدوات صحية مستعملة \\
\hline $1 \ldots$ & $r .7$ & 11 & 0.5 & ir & 1.9 & 0 & حدايد وكيماويات \\
\hline$r \wedge .9$ & $1 . \varepsilon$ & $\mathrm{v}$ & Y. 1 & 。 & $\cdot . \wedge$ & r & شنط \\
\hline$r \wedge .9$ & 1.2 & $\mathrm{~V}$ & Y.9 & $\mathrm{V}$ & & & أحذية \\
\hline $17 . V$ & $\cdot .9$ & $r$ & $\cdot . \wedge$ & $r$ &.$\varepsilon$ & 1 & أحذية وشنط \\
\hline 0.7 & $\cdot r$ & 1 &.$\varepsilon$ & 1 & & & مستلزمات أحذية \\
\hline $1 \ldots$ & $r .7$ & 11 & $7 . r$ & 10 & $1 . r$ & $r$ & مصنوعات جلدية \\
\hline - & $1 \ldots$ & $0 \ldots$ & $1 \ldots$ & $r \leqslant r$ & $1 \ldots$ & $r \otimes \Lambda$ & جملة \\
\hline
\end{tabular}

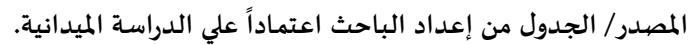

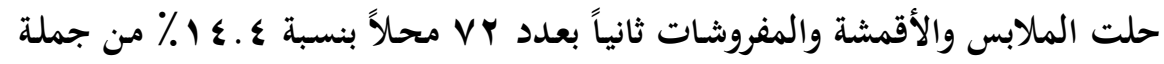

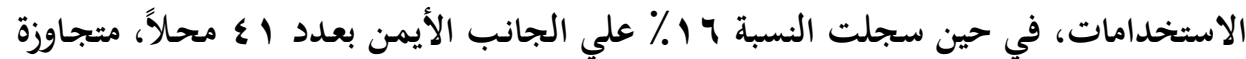

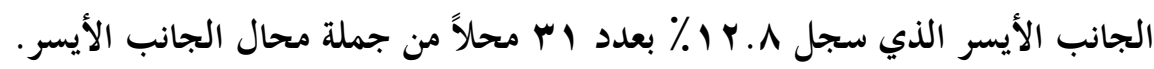

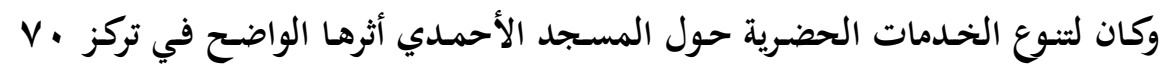

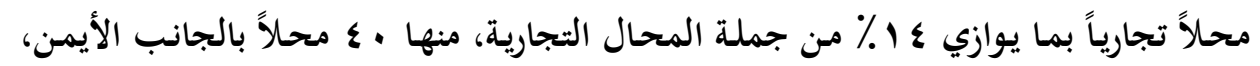

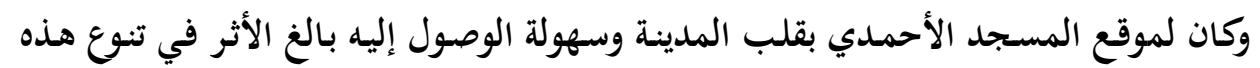

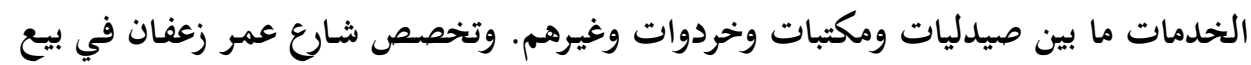

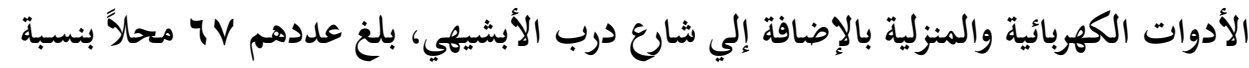
ع.ب ا ٪ من جملة المحال. 
برغم الشهرة الواسعة التي عرفت عن مدينة طنطا في صناعة الحلويات وبيع الحمص

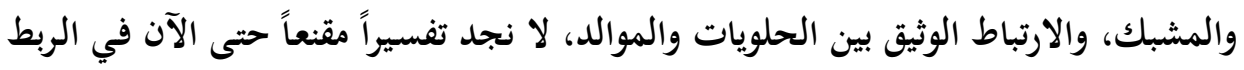

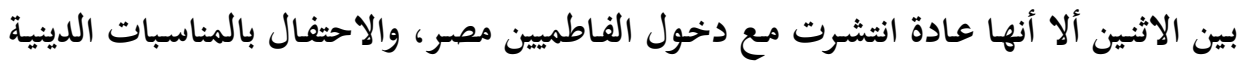

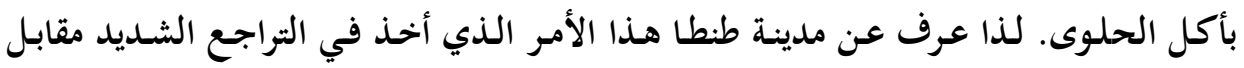

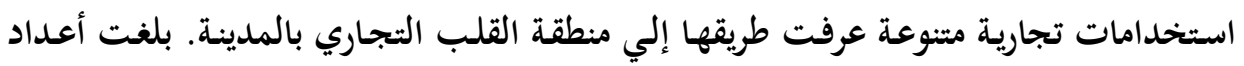

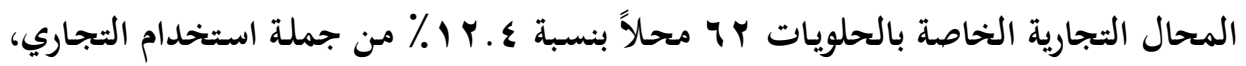

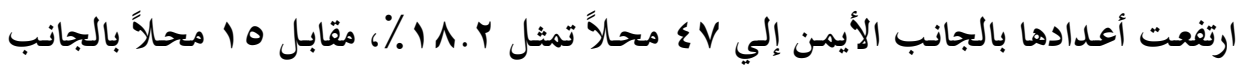

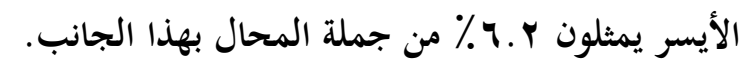

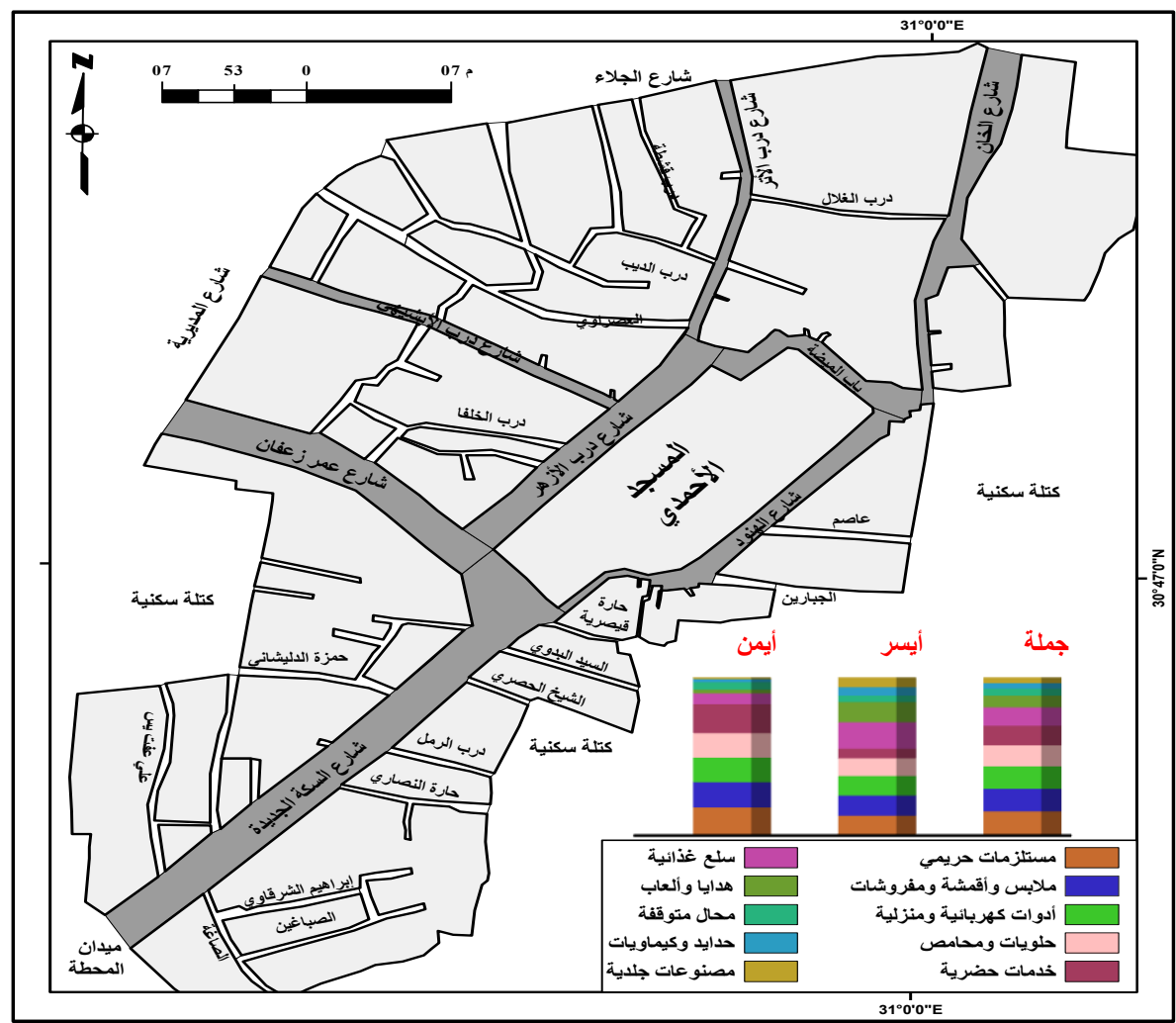

شكل (1 (1) توزيع الاستخدام التجاري بمنطقة المسجد الأحمدي بمدينة طنطا عام ؛ 1 ـ ب.

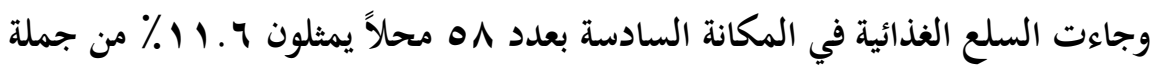

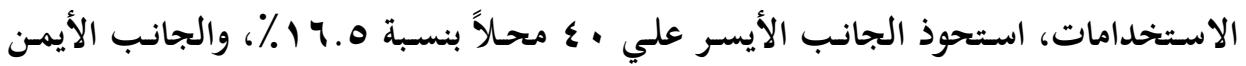

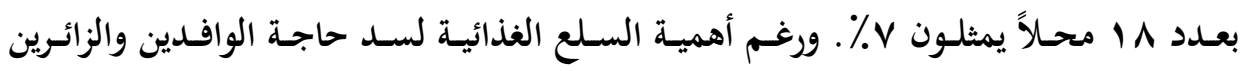
للمسجد الأحمدي والاعتماد الكلي علي المطاعم في فترة انعقاد المولد إلا أن أعداد المحال المدال 


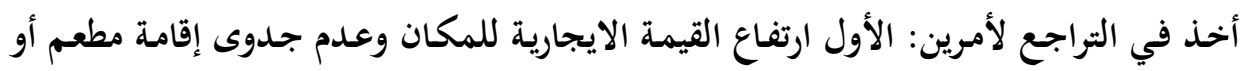

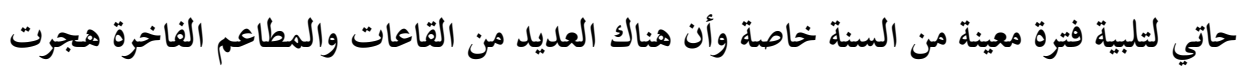

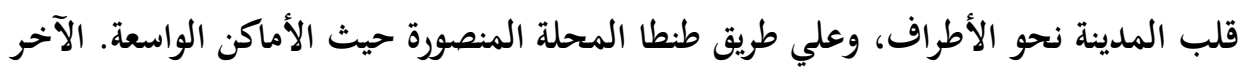

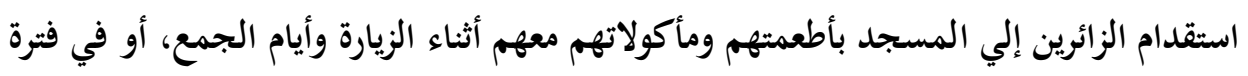

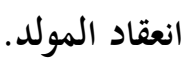

r. توزيع المحال علي مستوي المجموعات:

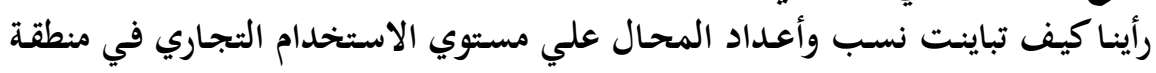

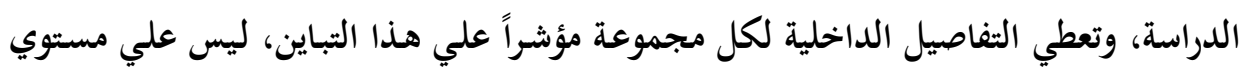

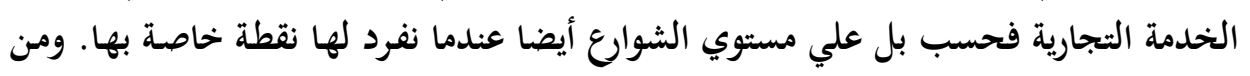

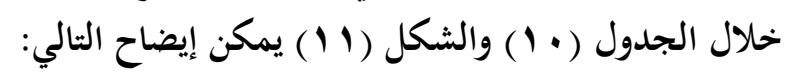

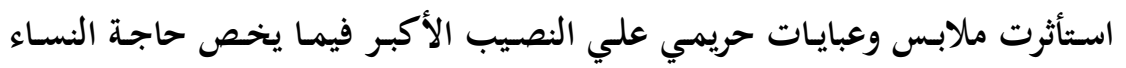

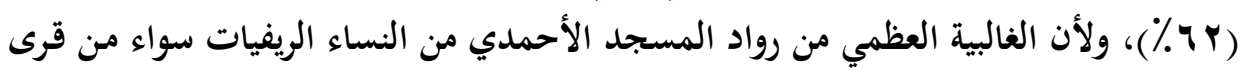

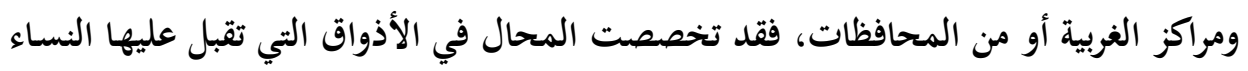

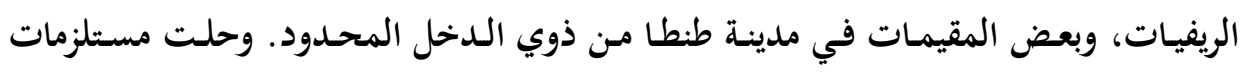

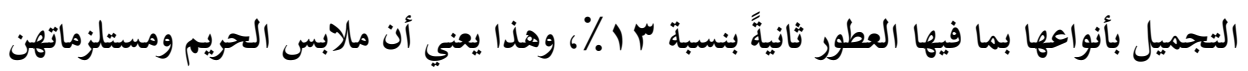

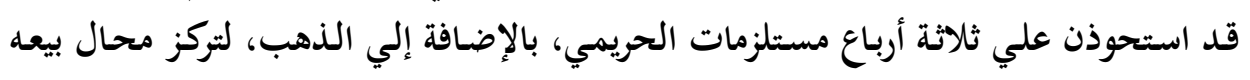
بشارع الصاغة المتفرع من شارع السكة الجديدة. كان لملابس الأطفال نصيب الثلث من جملة الملابس والأقمشة والمفروشات الجديلة المات، يليها

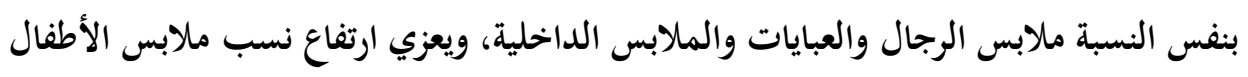

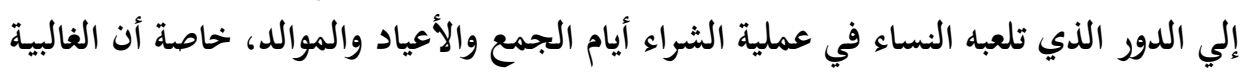

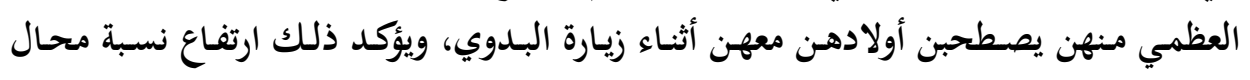

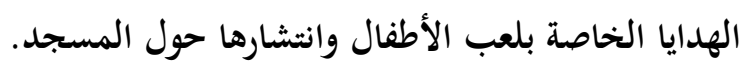

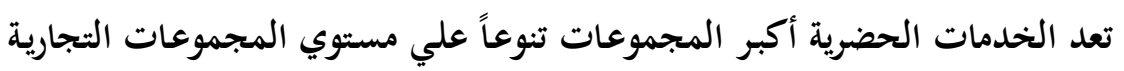

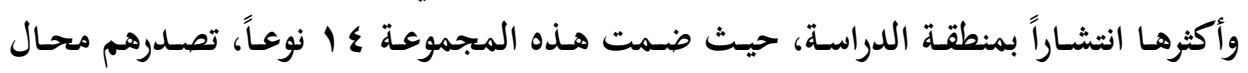

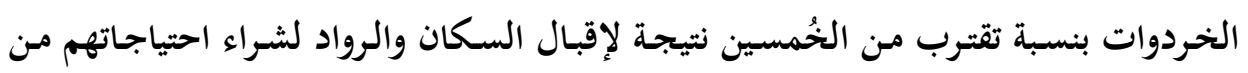

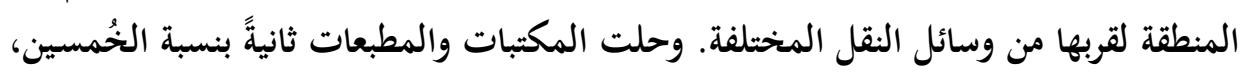

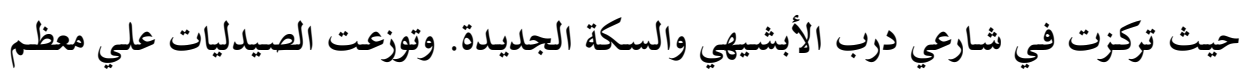

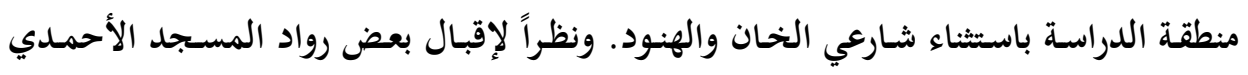


لشراء شرائط التواشيح والقصص والنوادر انتشرت محال بيع الكاست، حيث يوجد مقر شركة

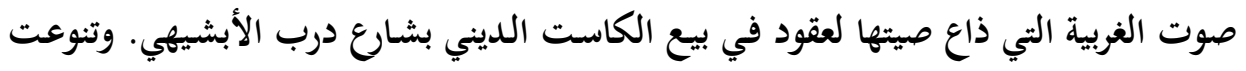

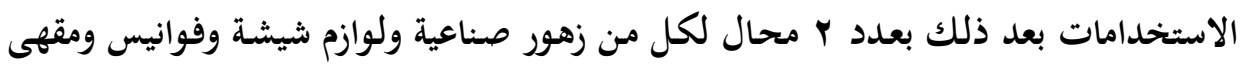

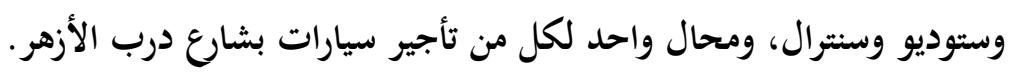

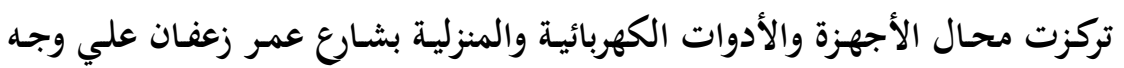

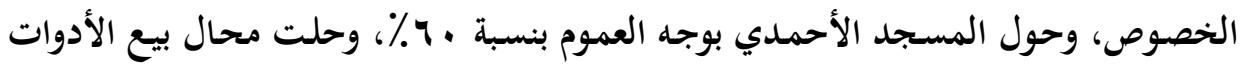

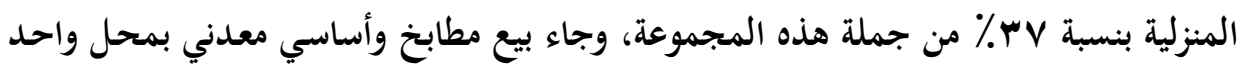

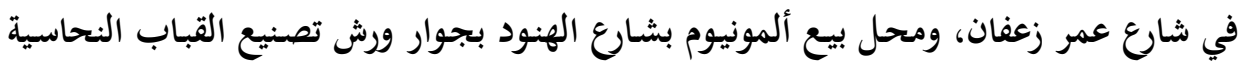
المستخدمة في المآذن بحارة النحاسين.

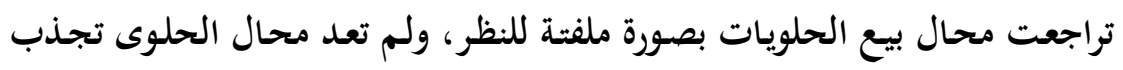

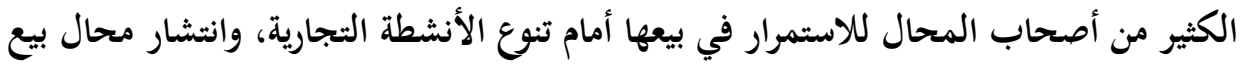

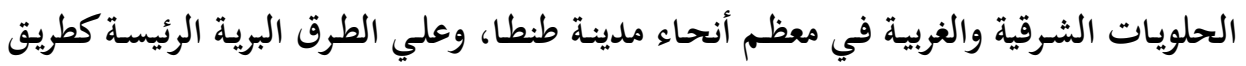

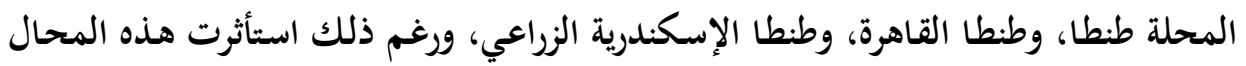

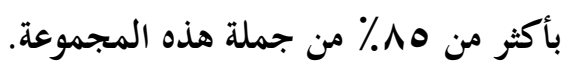
تنوعت مجموعة السلع الغذائي بصورة تشبه الخدمات من هدمات الحضرية وإن اختلفت عنها

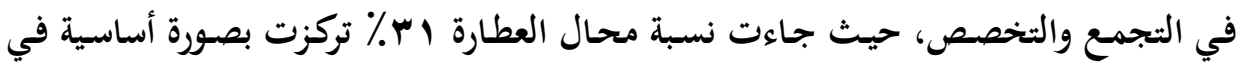

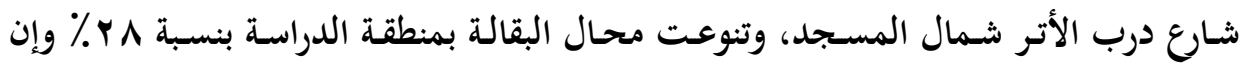

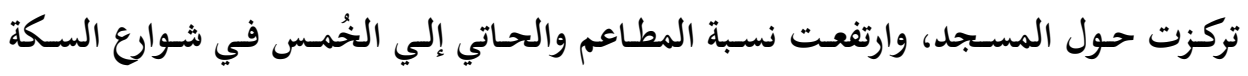
الجديدة وعمر زعفان ودرب الأزهر. كان للعب الأطفال نصيب الأسد في المحال التجارية في منطقة تشتهر بأن معظم

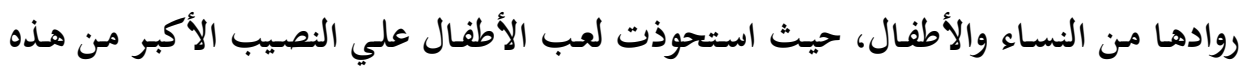

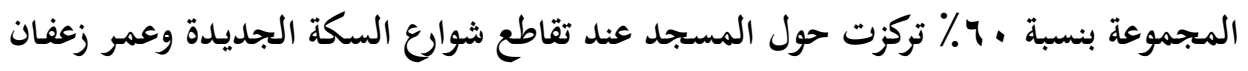

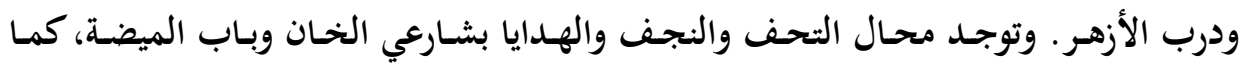

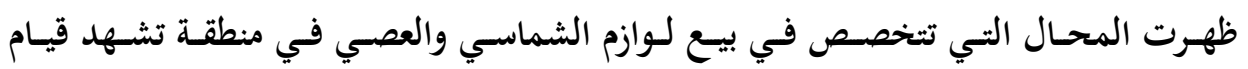

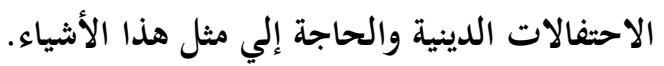

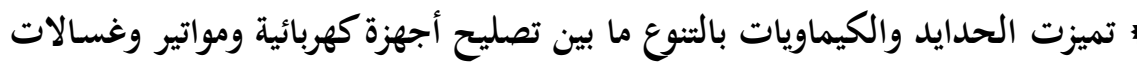

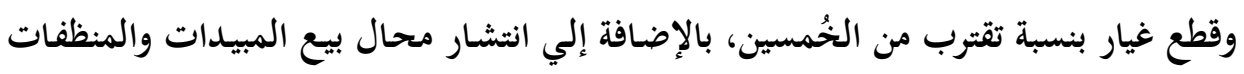

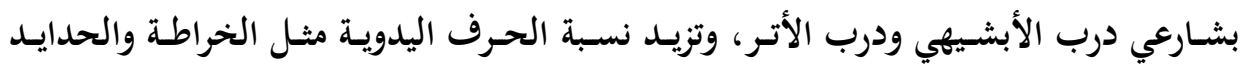


والموازين علي الخُمسين. وتركزت معظم محال بيع الأحذية والشنط بشارع الخان والسكة الجديدة وباب الميضة البحري. r. مساحة المحال التجارية وكثافتها: البحري.

تلقي دراسـة كثافة المحال التجارية الكثير مـ الحقائق الميدانية التي قد تبدو غائبسة

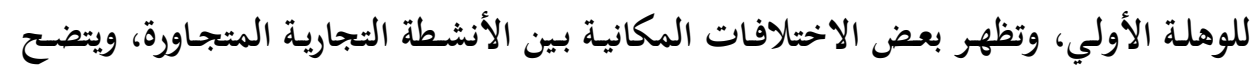

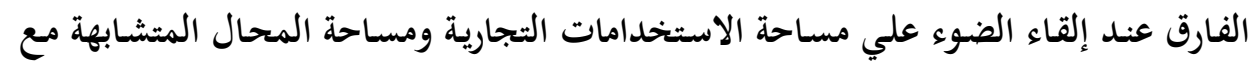
بعضها البعض في سلة واحدة. أ. مساحة المجموعات التجارية وكثافتها:

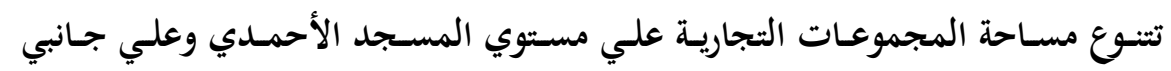

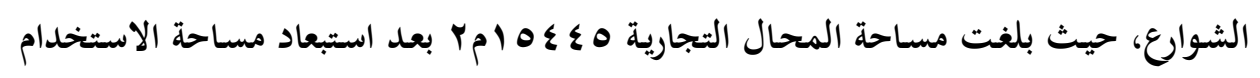

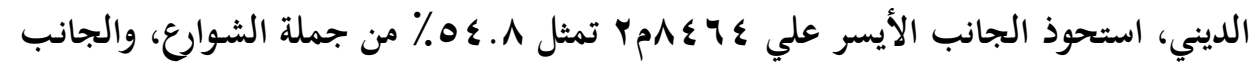

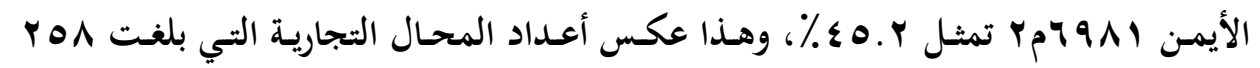

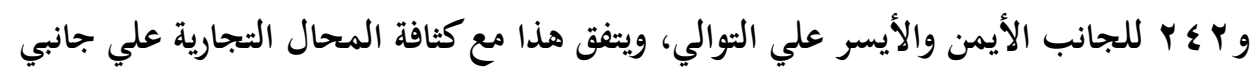

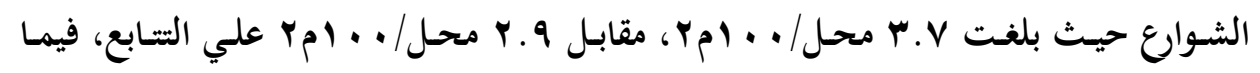

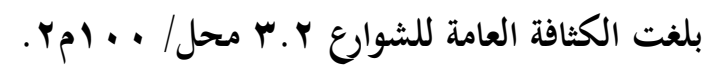

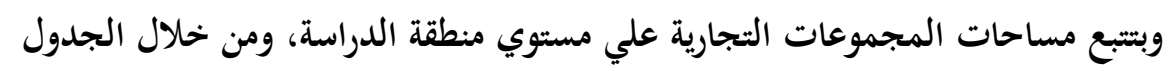

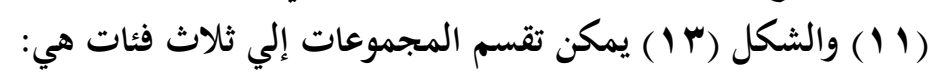

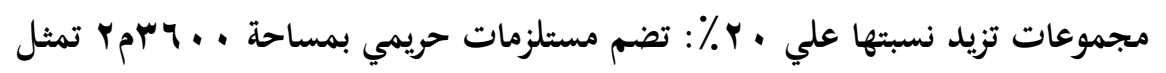

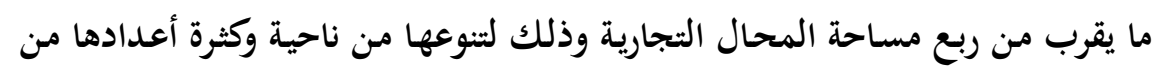
ناحية أخرى.

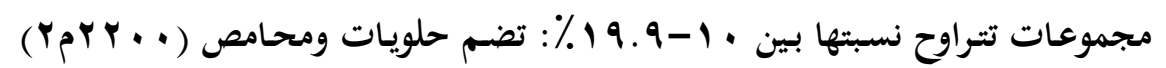

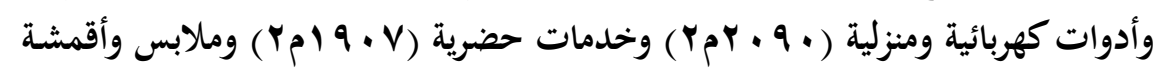

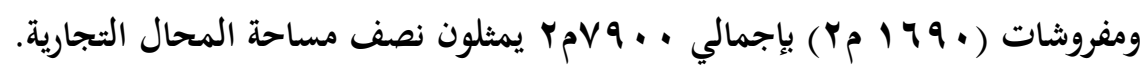

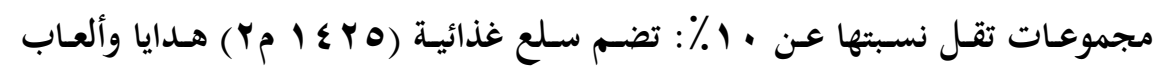

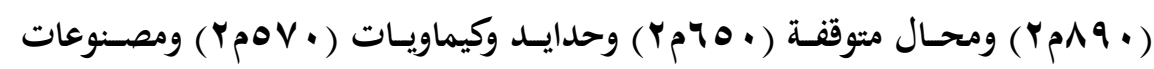

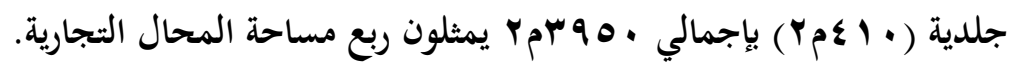

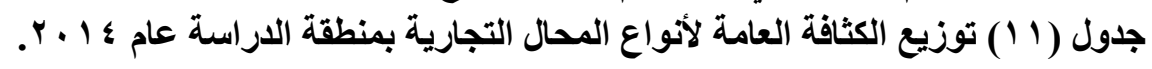

\begin{tabular}{|c|c|c|c|c|c|c|c|c|c|}
\hline المساحة من المجة & الكثافة & $\%$ & $\left(r_{P}\right)$ & أنواع المحال & ا المساحة منة & الكثافة & $\%$ & $\left(Y_{P}\right)$ & النحال \\
\hline
\end{tabular}




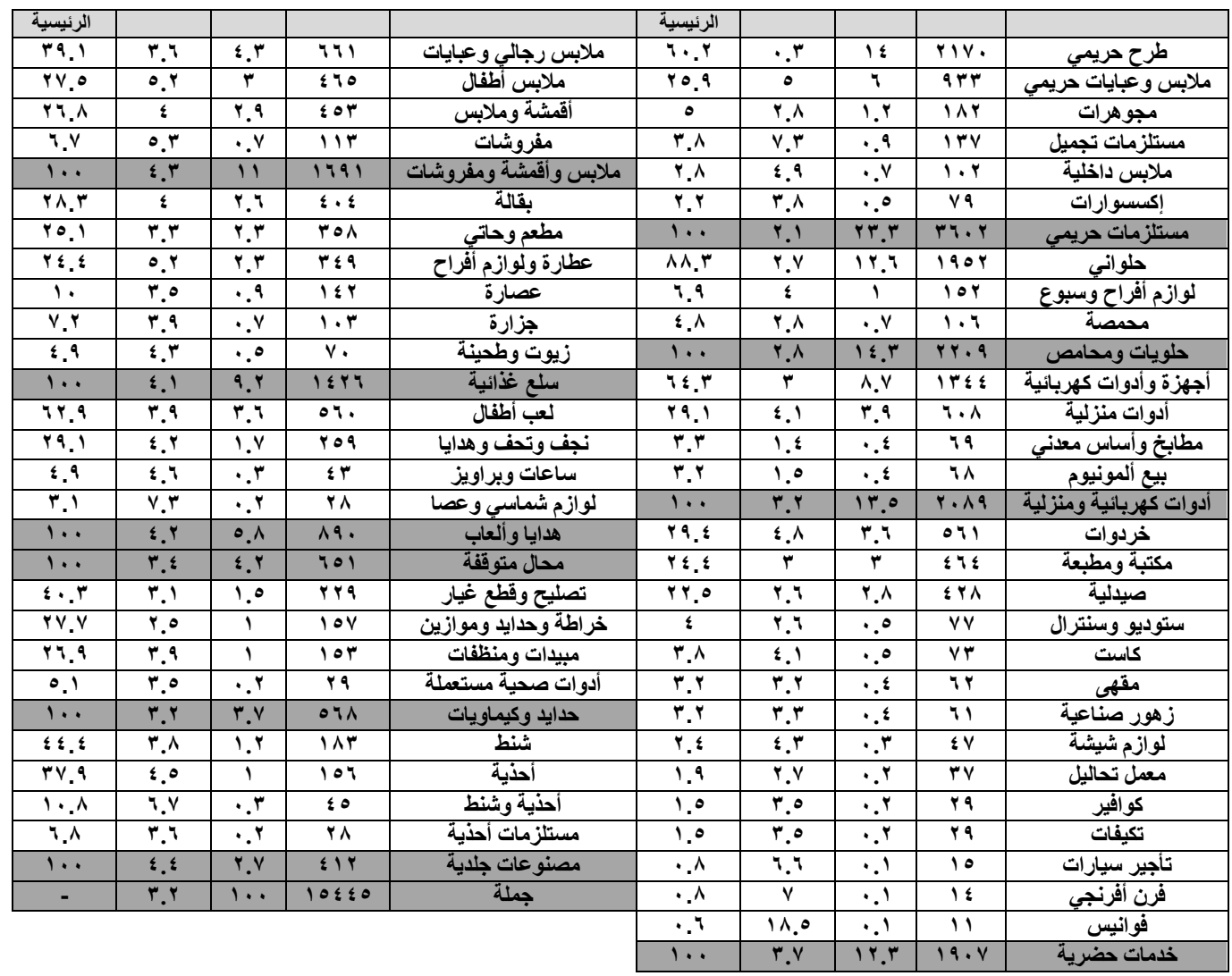

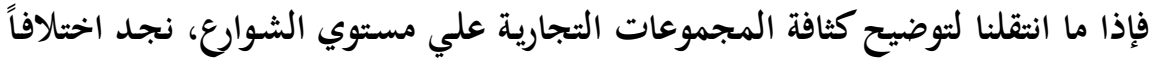

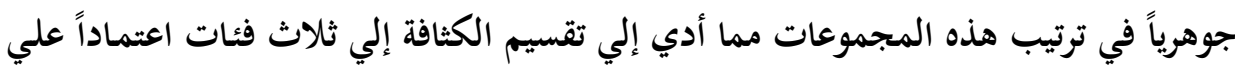

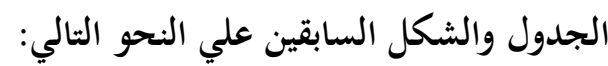

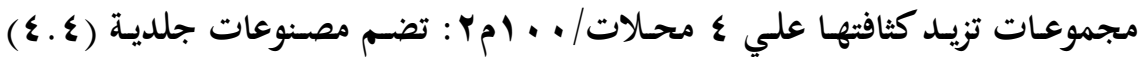

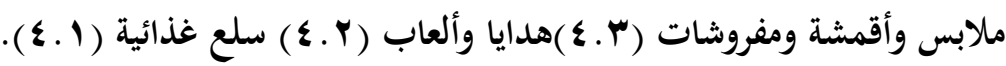

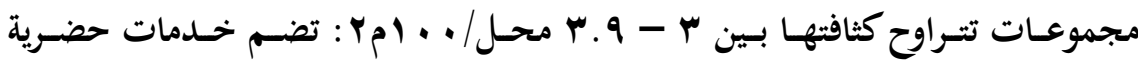

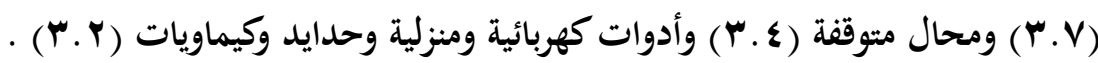

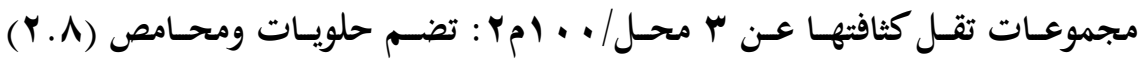

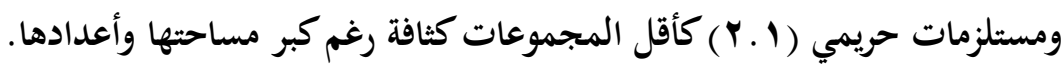




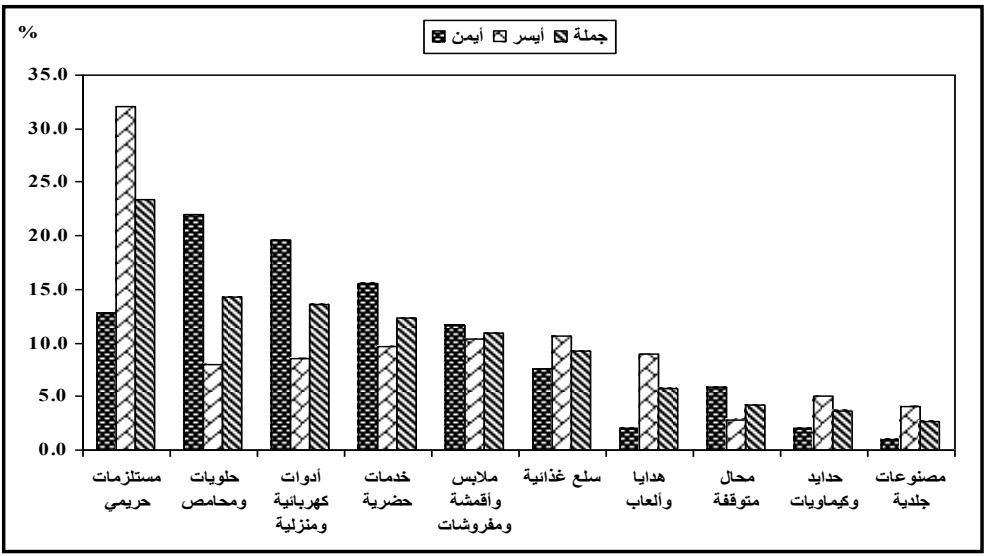

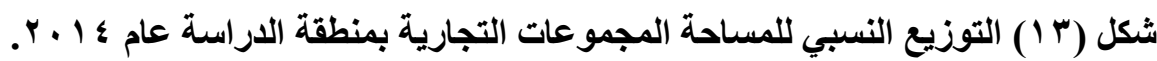
ب. مساحة المحال التجارية وكثافتها: تختلـف مسـاحة وكثافـة المحسال التجاريـة فيمـا بينها اختلافـاً واضـحاً علـي مسـتوي

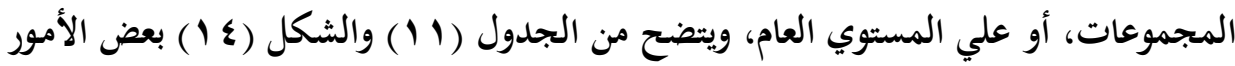

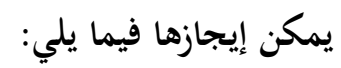

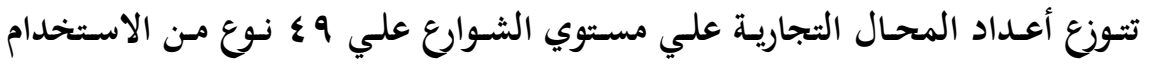

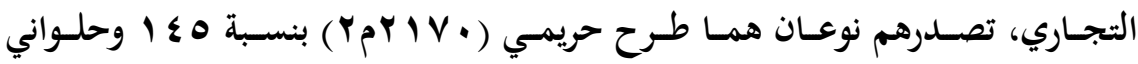

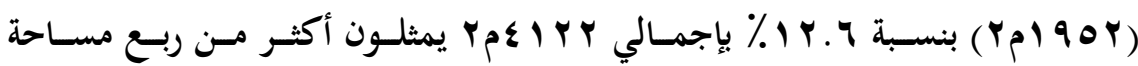
الاستخدام التجاري للمحال.

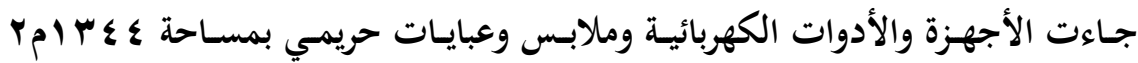

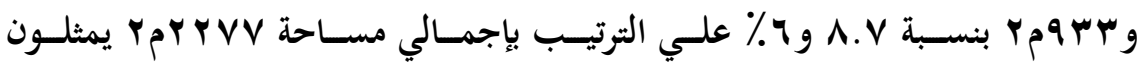

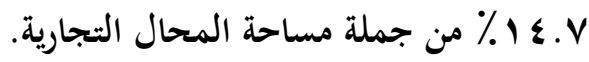

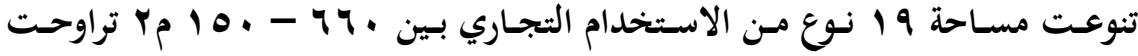

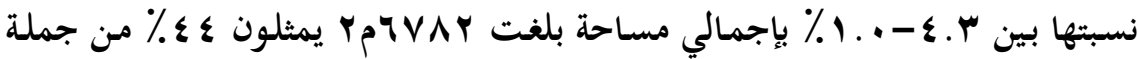

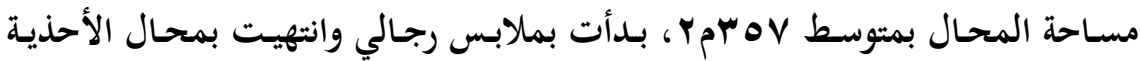

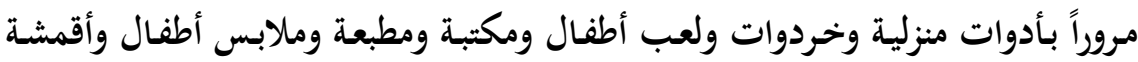

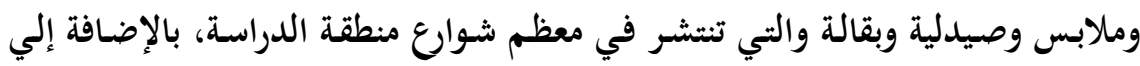

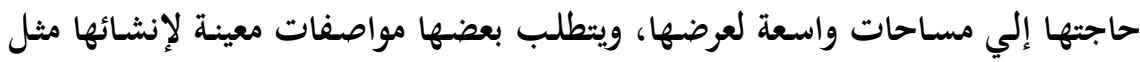
الصيدليات والمكتبات والمطابع. 


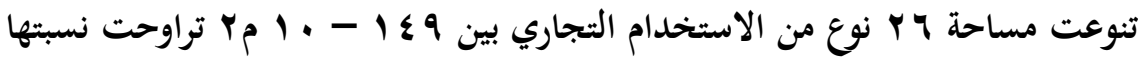

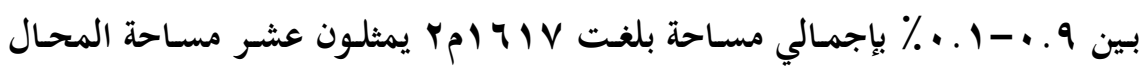

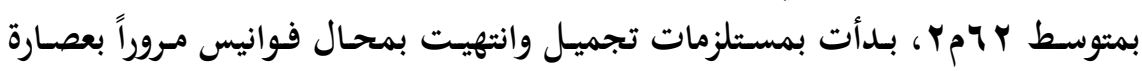

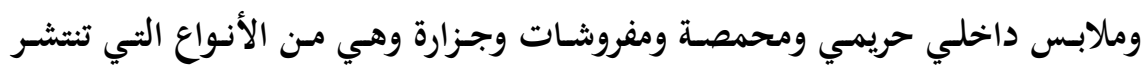

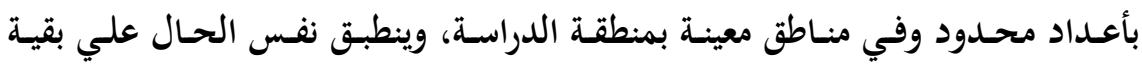

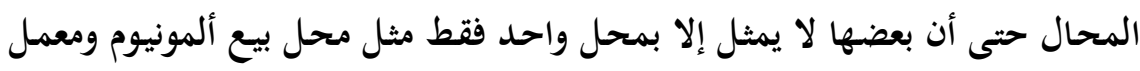

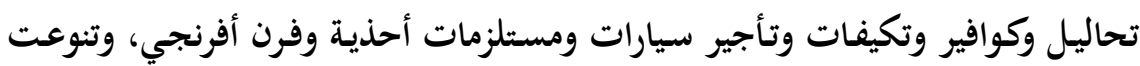

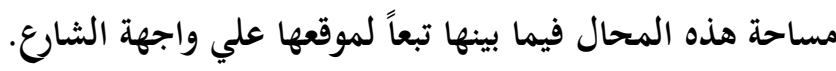

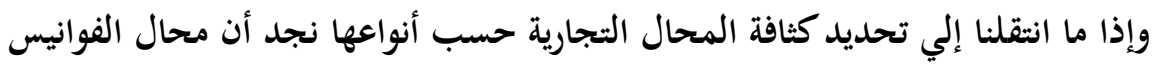

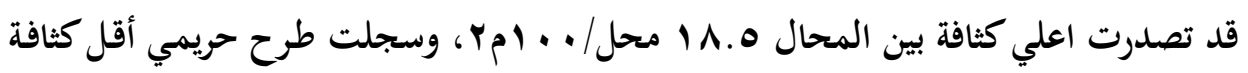

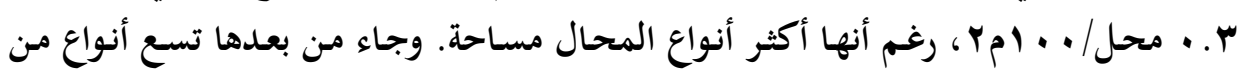

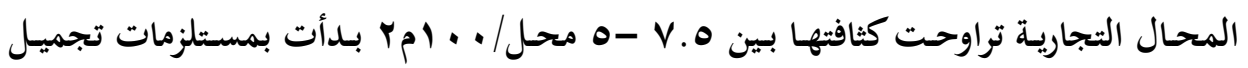

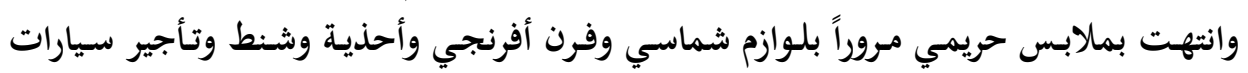
ومفروشات وملابس أطفال وعطارة.

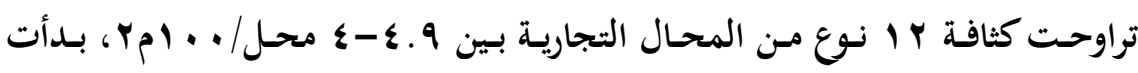

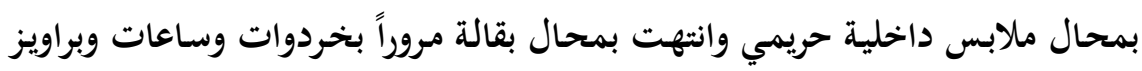

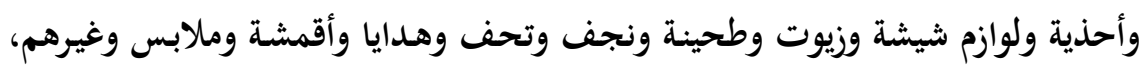

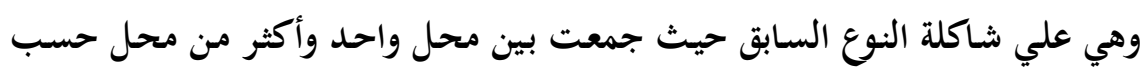
موقعها في شوارع منطقة الدراسة.

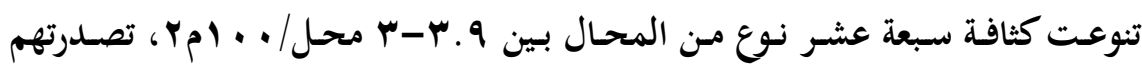

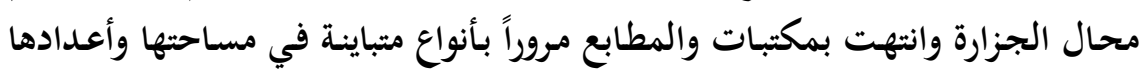

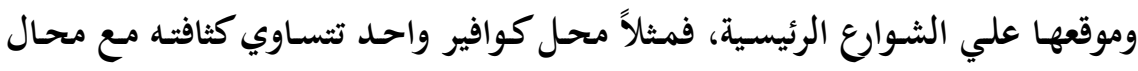

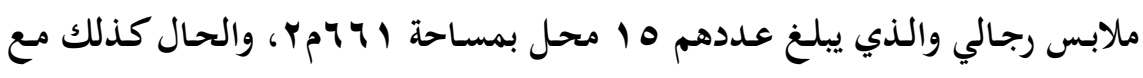

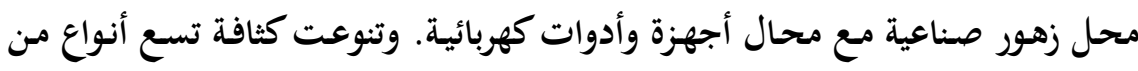

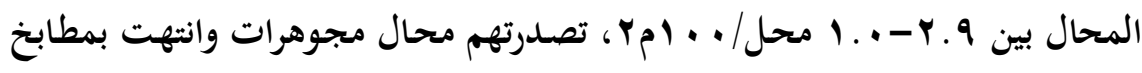

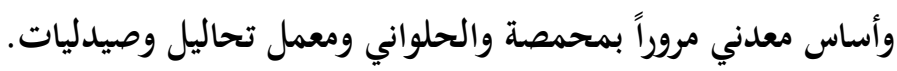




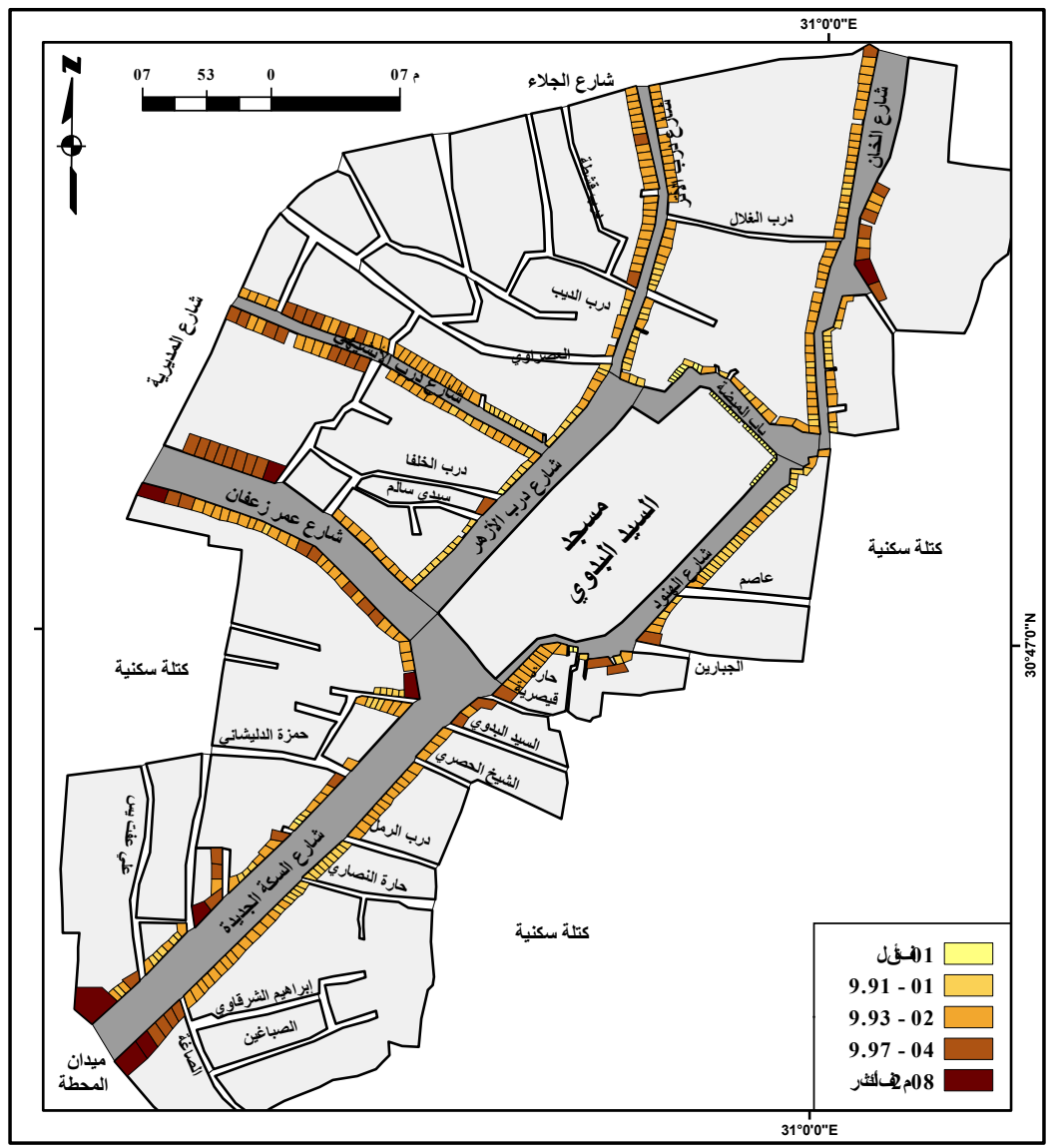

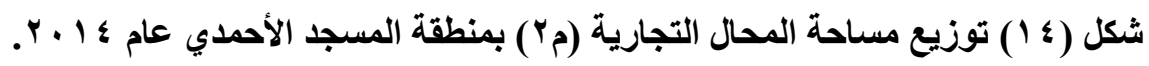
؛. توزيع المحال علي مستوي الشوارع:

لإلقاء الضوء علي الاستخدامات التجارية بنوع من التفصيل فضل الباحث عرض كل

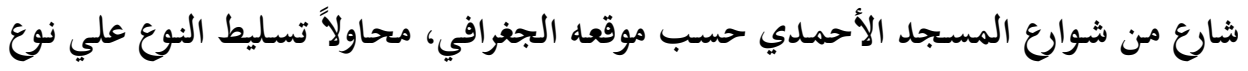

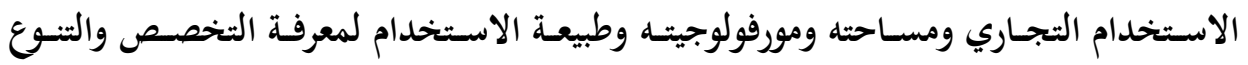
لشوارع الدراسة. 囚 شوارع تقع شمال المسجد: تضم شوارع الخان ودرب الأتر وباب الميضة ومحال سور المسجد.

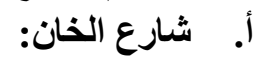

يتميز شارع الخان بقدم مبانيه التي تعود إلي أواخر القرن التاسع عشر، ويغلب عليها

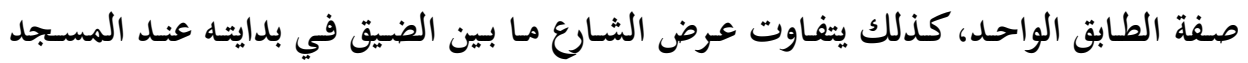


الأحمدي، واتساعه الواضح وازدواجه أمام شركة بيع المصنوعات قبل إزالتها. كما يغلب عليه

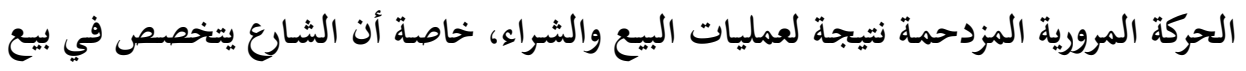

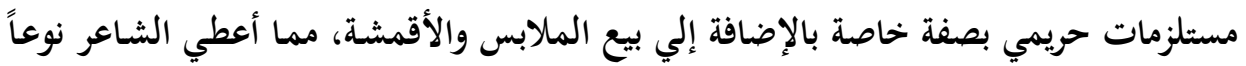

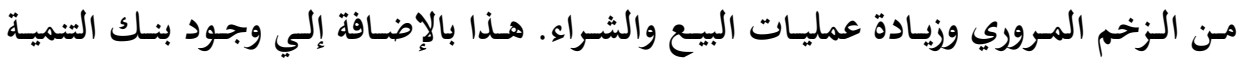

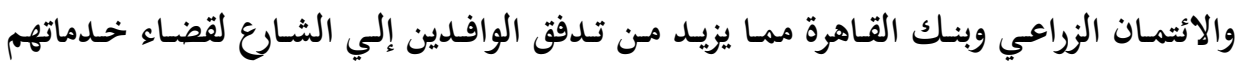
المصرفية.

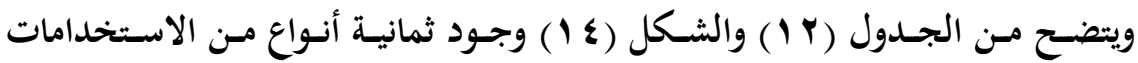

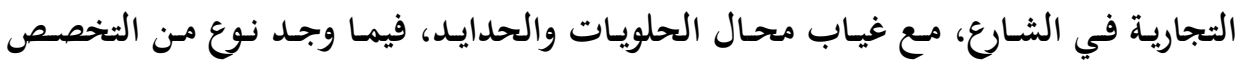

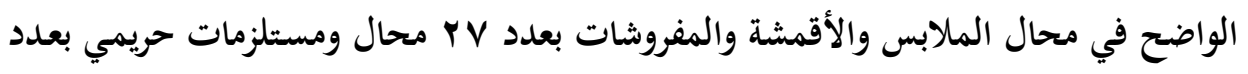

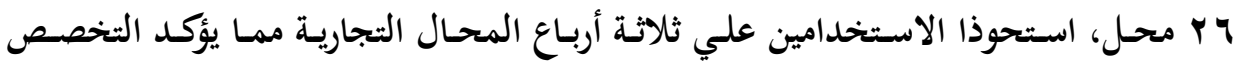

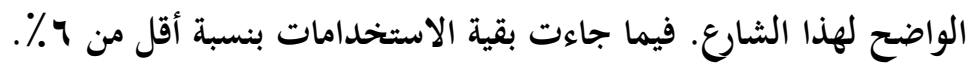

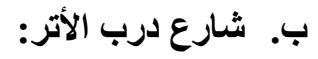

يبدأ شارع درب الأتر من شارع الجـلاء ليلتقي بشارع درب الأزهر وباب الميضـة عند

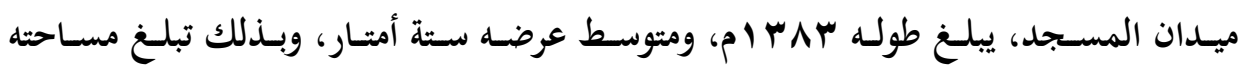

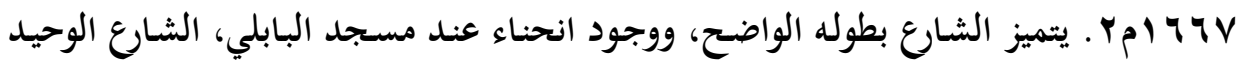

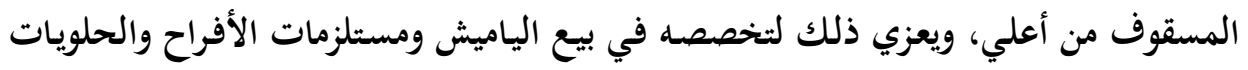

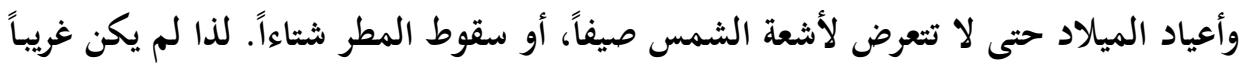

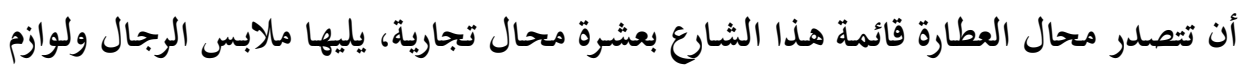

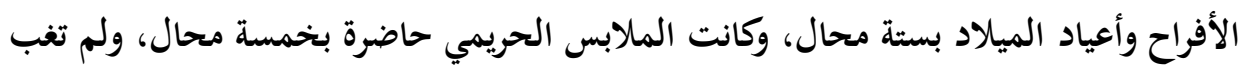

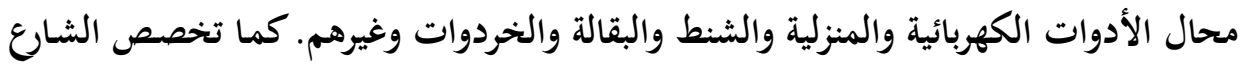
في بيع الزيوت والطحينة التي تدخل مع الكثير من السلع الغذائية.

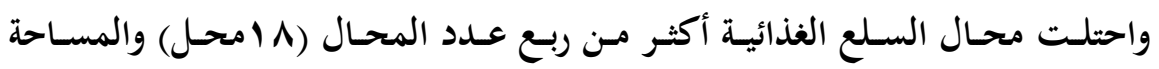

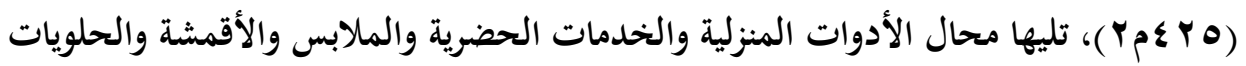

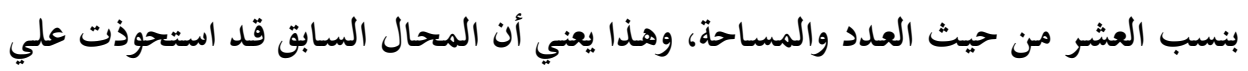

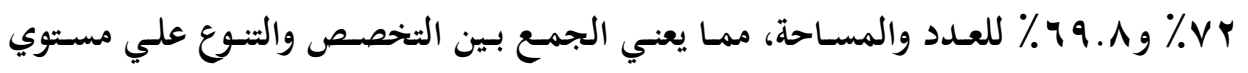

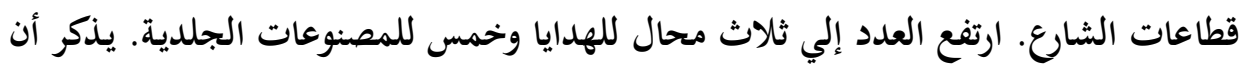

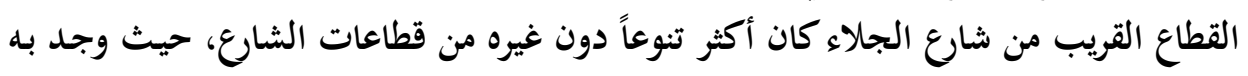

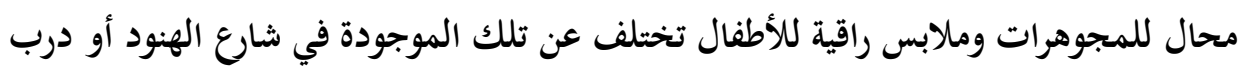


الأزهـر مـثلاً، في حسين شهـد القطاع الأوسط نوعـاً مـ التخصص في محسال بيـع الأدوات

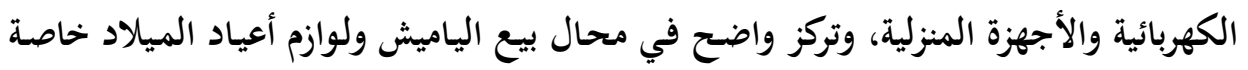

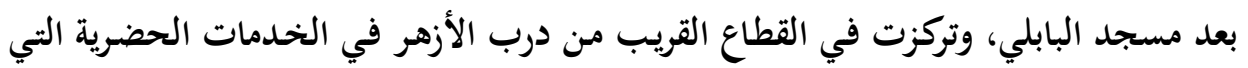

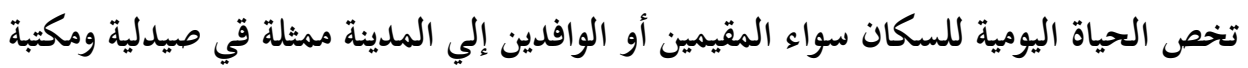
وغيرهم من المحال.

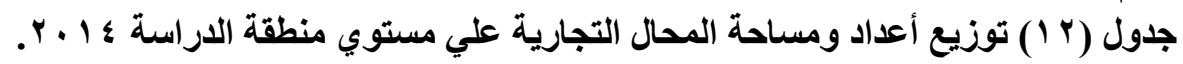

\begin{tabular}{|c|c|c|c|c|c|c|c|c|c|c|c|}
\hline جملة & زعفان & سور & الأزهر & الأتر & الأبثيهي درب & المبضة & الهنود & الجليدة & الخان & \multicolumn{2}{|c|}{ نوع المحال } \\
\hline VY & 1 & iv & & 7 & $r$ & $r$ & 9 & ir & rq & العدد & \multirow{4}{*}{ مريتلزمات } \\
\hline $10 .$. & r. 1 & or.1 & $\because \cdot$ & $\wedge . \wedge$ & Y.V & $\wedge . \vee$ & $r \cdot .9$ & $1 \cdot .9$ & พч. & $\%$ & \\
\hline rq. r & 7. & Vr & & $1 \leq 0$ & VV & iv & YI & พчq & YYOE & المساحة & \\
\hline rr.r & $r .1$ & or.A & $\because \cdot$ & $\wedge . \wedge$ & $r .7$ & $\leq . r$ & rT.r & 9.7 & TV.V & $\%$ & \\
\hline Tr & $\varepsilon$ & & 0 & $v$ & & 1 & 0 & $\leq$ & & العدد & \multirow{4}{*}{ ومحامص حلات } \\
\hline Ir.r & $\Lambda . r$ & $\because \cdot$ & IV.r & $1 \cdot . r$ & $\because \cdot$ & $\varepsilon . r$ & 11.7 & rr. & $\because \cdot$ & $\%$ & \\
\hline rr.q & 1.1 & & vr & 189 & & rY & 71 & IVov & & المساحة & \\
\hline $1 \leq . r$ & 0.7 & $\because \cdot$ & $1 \% . r$ & $1 \cdot .1$ & $\because \cdot$ & 7.7 & $v_{0} .0$ & $\leq 0.9$ & $\because \cdot$ & $\%$ & \\
\hline iv & 17 & 1 & $r$ & $\wedge$ & 19 & 1. & • & 1 & $\varepsilon$ & العدد & \multirow{4}{*}{ كهربائية } \\
\hline Ir.r & rr.r & $r .1$ & $1 \cdot . r$ & 11.1 & ro.r & $\leqslant r .0$ & 11.7 &..$\wedge$ & 0.7 & $\%$ & \\
\hline$r . \wedge q$ & $7 \leq \leqslant$ & $\varepsilon$ & 91 & rrq & $7 \leq 9$ & 114 & IVV & 17 & Irr & المساحة & \\
\hline $1 r .0$ & rr.r & r.V & $11 . r$ & $1 \% . \wedge$ & $r \cdot . \varepsilon$ & $\leq v .9$ & 19.7 & 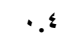 & r. & $\%$ & \\
\hline$\vee \wedge$ & $\wedge$ & r & $r$ & $\wedge$ & rr & $r$ & $v$ & ri & $\varepsilon$ & العدد & \multirow{4}{*}{ خدمات } \\
\hline 10.5 & 17.8 & $7 . r$ & $1 \cdot . r$ & 11.1 & rq.r & $1 T$. & $17 . r$ & 18.7 & 0.7 & $\%$ & \\
\hline 19.8 & Pry & $\wedge$ & or & $10 \leqslant$ & $7 \leq 0$ & rY & $1 \pi$. & $\leqslant V V$ & 91 & المساحة & \\
\hline Ir.r & 17.9 & $0 . V$ & $9 . \wedge$ & $9 . r$ & $r \cdot r$ & 0.7 & $1 \leq . \varepsilon$ & $1 \% .0$ & $r . r$ & $\%$ & \\
\hline Vr & 7 & 7 & & $\wedge$ & r & r & 10 & 7 & $r v$ & العدد & \multirow{4}{*}{ ومفروشت ملابس } \\
\hline $1 \leq . r$ & $1 \% .0$ & $1 \wedge .1$ & $\because \cdot$ & 11.1 & r.V & ^. V & $r \varepsilon .9$ & ๑. & $r \Lambda_{.} \cdot$ & $\%$ & \\
\hline 1791 & rvo & $r V$ & & 179 & $\leqslant 0$ & 74 & r7q & 179 & $7 V \varepsilon$ & المساحة & \\
\hline $11 .$. & $1 \varepsilon . Y$ & 19.1 & $\because$ & $1 \cdot . r$ & r. & $17 . r$ & ২৭.^ & โ. & IV.r & $\%$ & \\
\hline $0 \wedge$ & 0 & 1 & 7 & 11 & 9 & 1 & 1 & $1 \varepsilon$ & $r$ & العدد & \multirow{4}{*}{ غذائية } \\
\hline 11.5 & $1 . .5$ & r. 1 & $r \cdot . V$ & Y..० & Ir.e & $\varepsilon . r$ & Y.r & 11.1 & $\varepsilon . Y$ & $\%$ & \\
\hline $1 \leqslant Y 4$ & 111 & . & $1 \leq r$ & $\leq$ ro & $I V \leq$ & 19 & 17 & ry & 99 & المساحة & \\
\hline $9 . r$ & 9.8 & $r .0$ & rY. & $r O . V$ & $\wedge .1$ & $\varepsilon .9$ & 1.1 & 9.0 & r.o & $\%$ & \\
\hline rv & r & 1 & $\wedge$ & $r$ & r & $r$ & & 10 & $r$ & العدد & \multirow{4}{*}{ هدايا } \\
\hline$v . r$ & $\varepsilon . r$ & r. 1 & YV.T & $\varepsilon . \varepsilon$ & Y.V & $1 \%$. & $\because \cdot$ & $1 Y .7$ & $\varepsilon . Y$ & $\%$ & \\
\hline$\wedge 9$. & ov & $\varepsilon$ & IrY & $V_{7}$ & $\leq V$ & $\leqslant \wedge$ & & $\leq 01$ & Vr & المساحة & \\
\hline 0.1 & $r .$. & $r . r$ & $r \leq . r$ & $\varepsilon .7$ & $r . r$ & $1 Y . \varepsilon$ & $\because$ & 11.1 & 1.9 & $\%$ & \\
\hline rr & & r & 1 & $\varepsilon$ & $\wedge$ & & 1 & $\varepsilon$ & r & العدد & \multirow{4}{*}{ متوقفة } \\
\hline$\varepsilon . r$ & $\because \cdot$ & $7 . r$ & r.s & 0.9 & $1 \cdot . v$ & $\because \cdot$ & $r . r$ & Y.s & Y.^ & $\%$ & \\
\hline 901 & & $\wedge$ & rr & Irr & $r \cdot \varepsilon$ & & rr & qr & 109 & المساحة & \\
\hline \&.Y & $\because \cdot$ & 7.1 & 0.9 & $v . \varepsilon$ & 9.0 & $\because \cdot$ & r. & Y. & $\leq .1$ & $\%$ & \\
\hline 11 & • & r & & 1 & $\wedge$ & & & $r$ & & العدد & حدايد \\
\hline
\end{tabular}




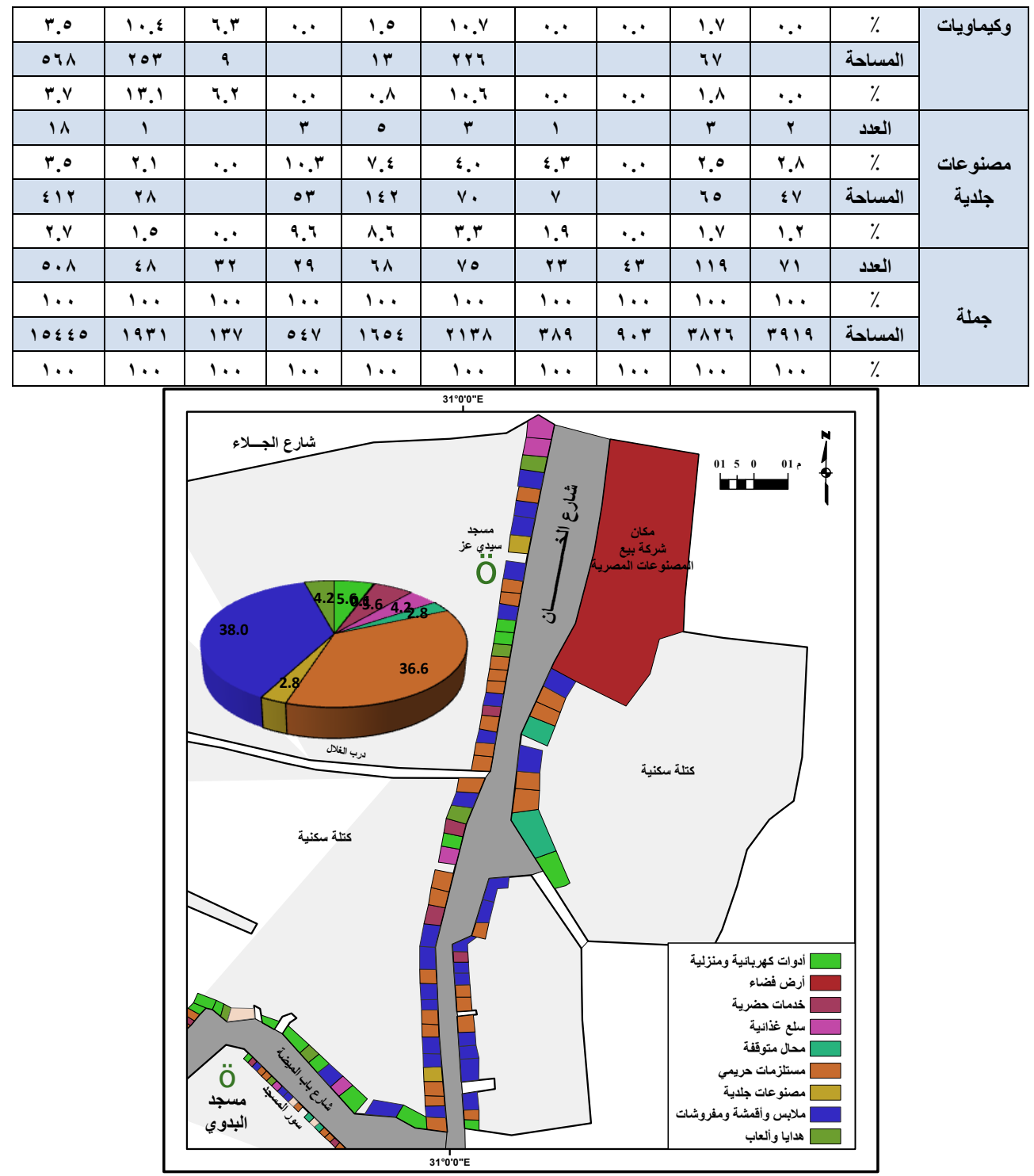

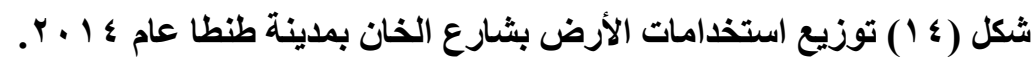

ج. شارع باب الميضة البحري وسور المسجد:

يعـد الشـارع امتـداد لثـارع الهنود في كثير مـن خصائصسه العامـة، ويزيـد عليه اتسـاعه

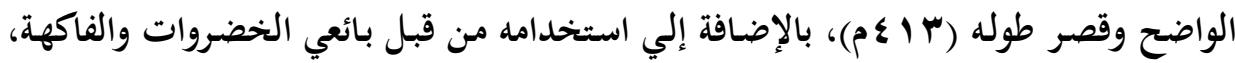

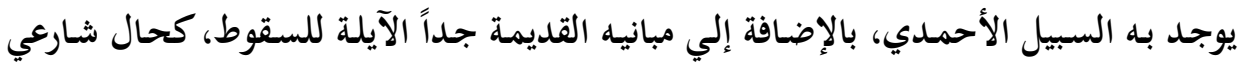

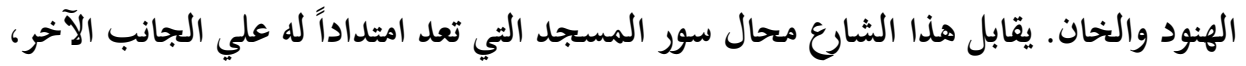


وإن اختلفـت سـماتها عـن جميـع شـوارع المسـجد الأحمـــي مـن حيـث مظهرهـا الخـارجي

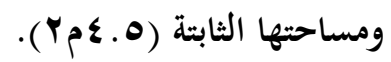

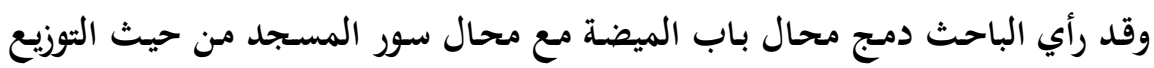

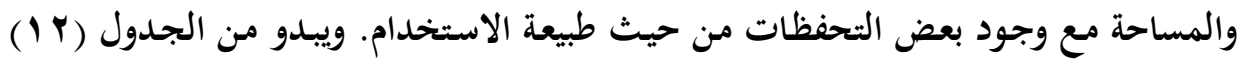

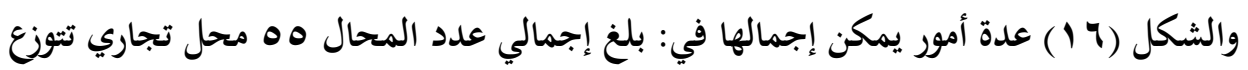

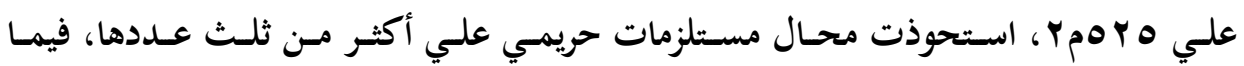

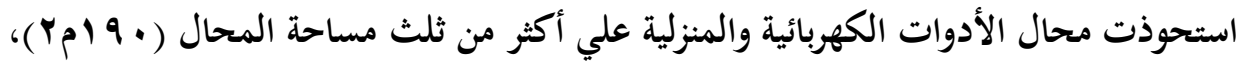

وذلك لأن محال الأدوات الكهربائية والمنزلية تحتاج إلي مساحة واسعة لعرضها وتخزينها.

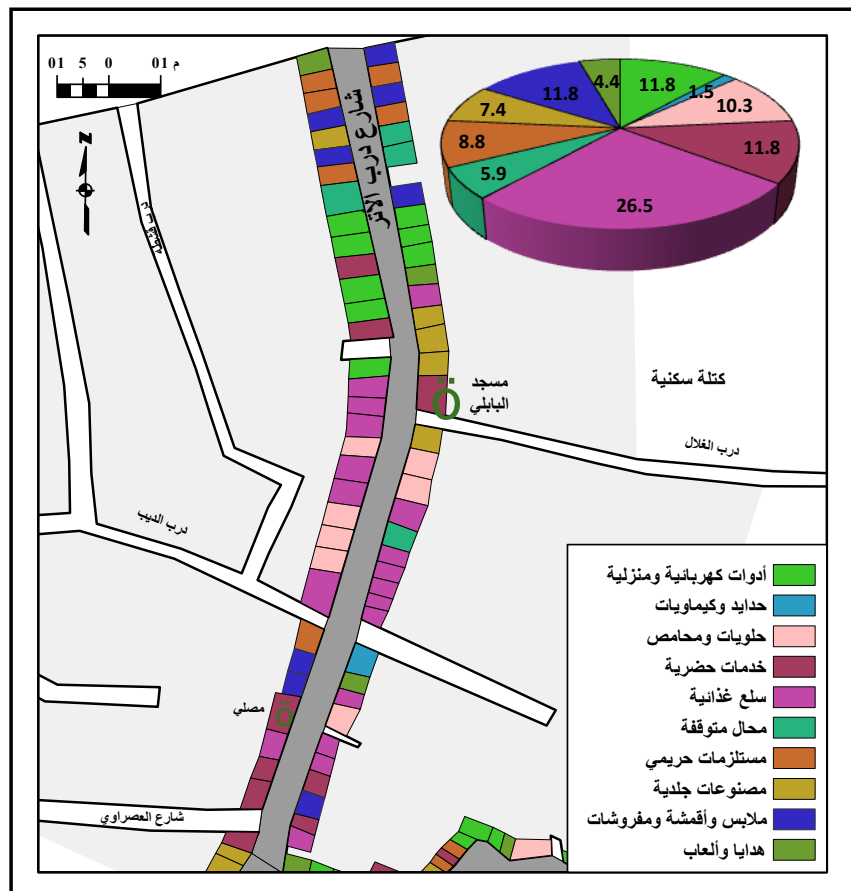

شكل (ه 1) توزيع استخدامات الأرض بثارع درب الأتر بمدينة طنطا عام ؛ ا بـ. 


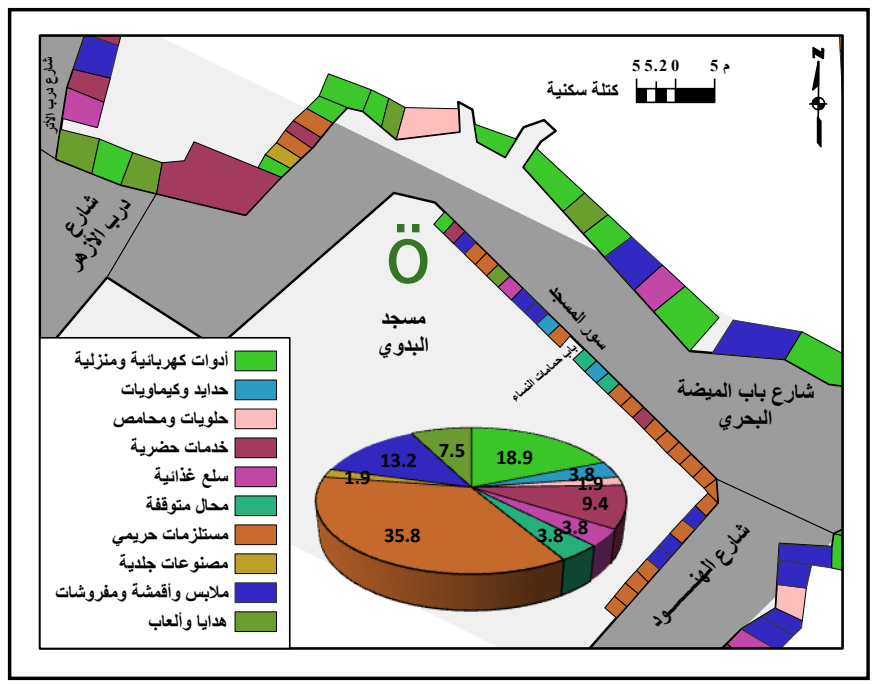

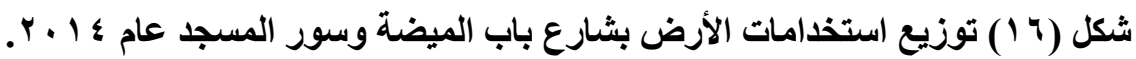

يذكر أن محال الحلويات والمصنوعات الجلدية لم تمثل سوي بمحل واحد فقط بشارع

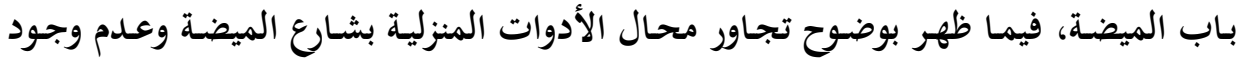

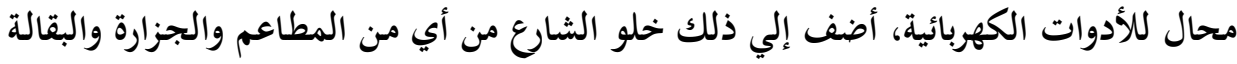

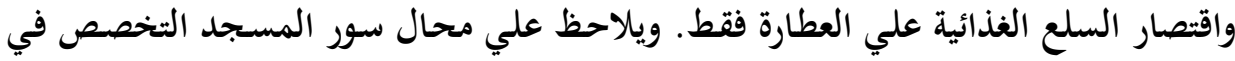

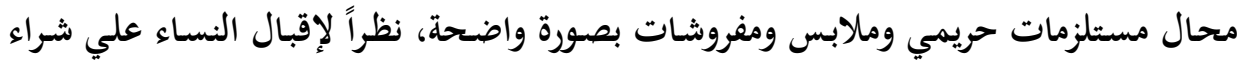

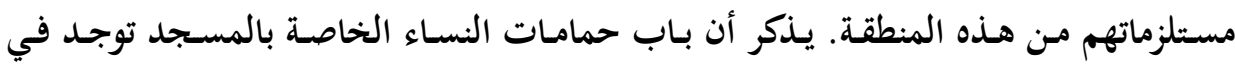

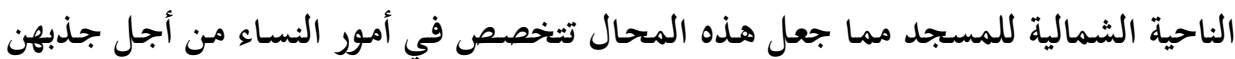
في عمليات البيع والشراء.

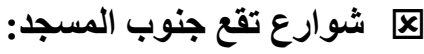

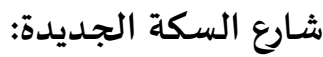
يتفرد هذا الشـارع علي سائر شوارع المسجد الأحمدي من عدة التدة أمور : اتسـاع عرضسه

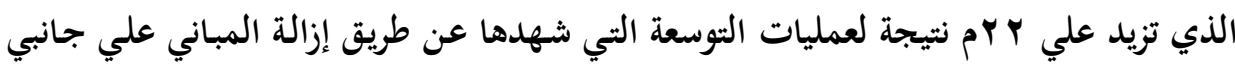

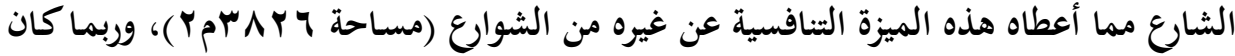

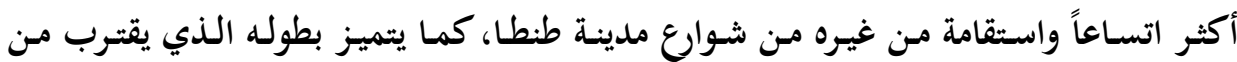
هANV وخروج سيارات الأجرة، ولا يسمح سوي لسيارات الملاكي والتاكسي بالمرور. كما يتميز بتنوع 
مبانيسه، وإن غلـب علي جانبـه الأيمسن المبـاني القديمـة والحديثة، والجانـب الأيسـر المبـاني

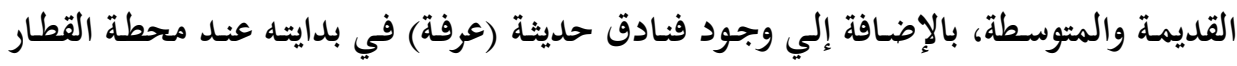
وفنادق قديمة متهالكة بالقرب من المسجد الأحمدي، فيما أذيلت معظم الأدوار العليا للمباني

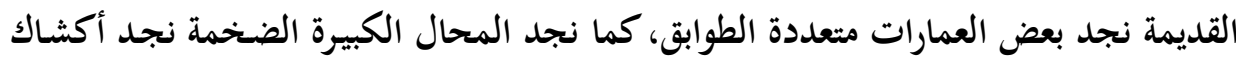

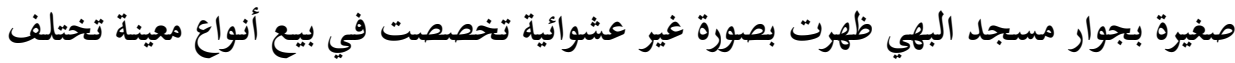

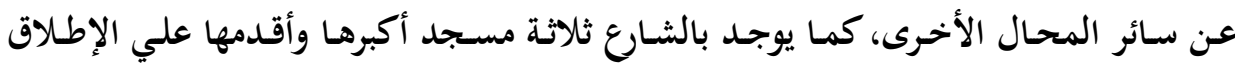

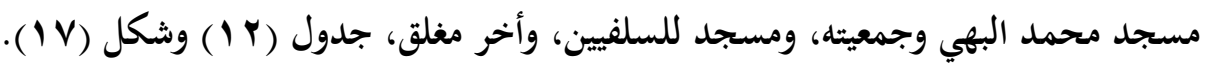

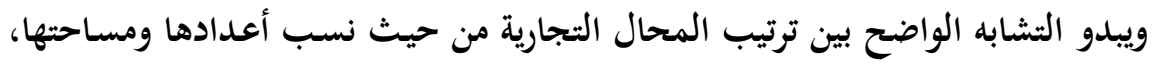

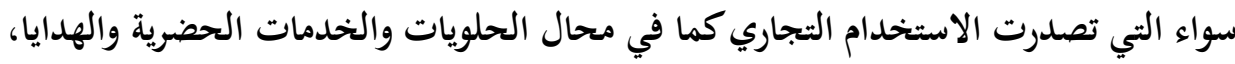

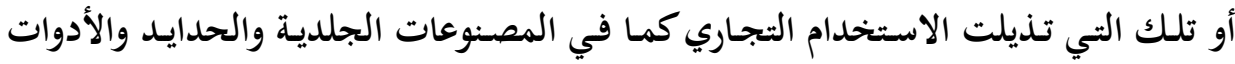

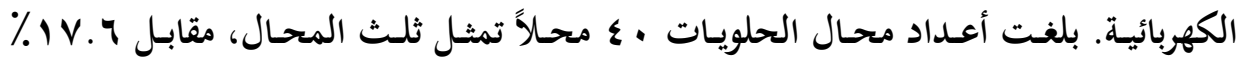

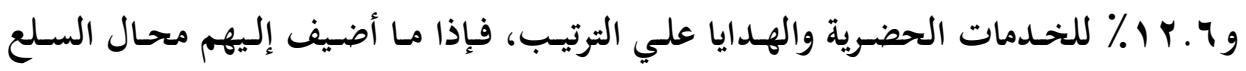

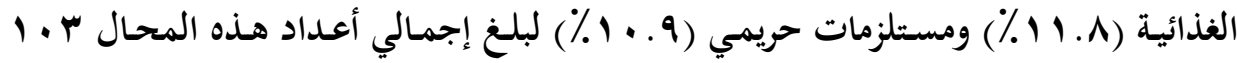

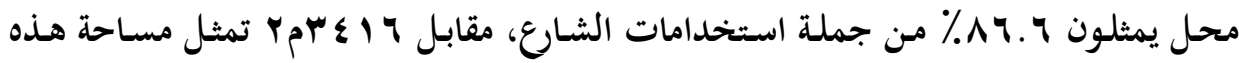

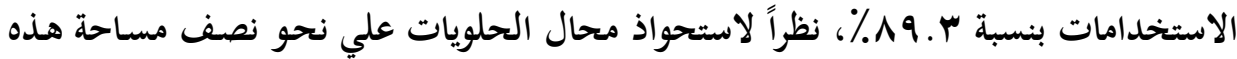

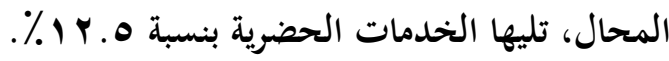

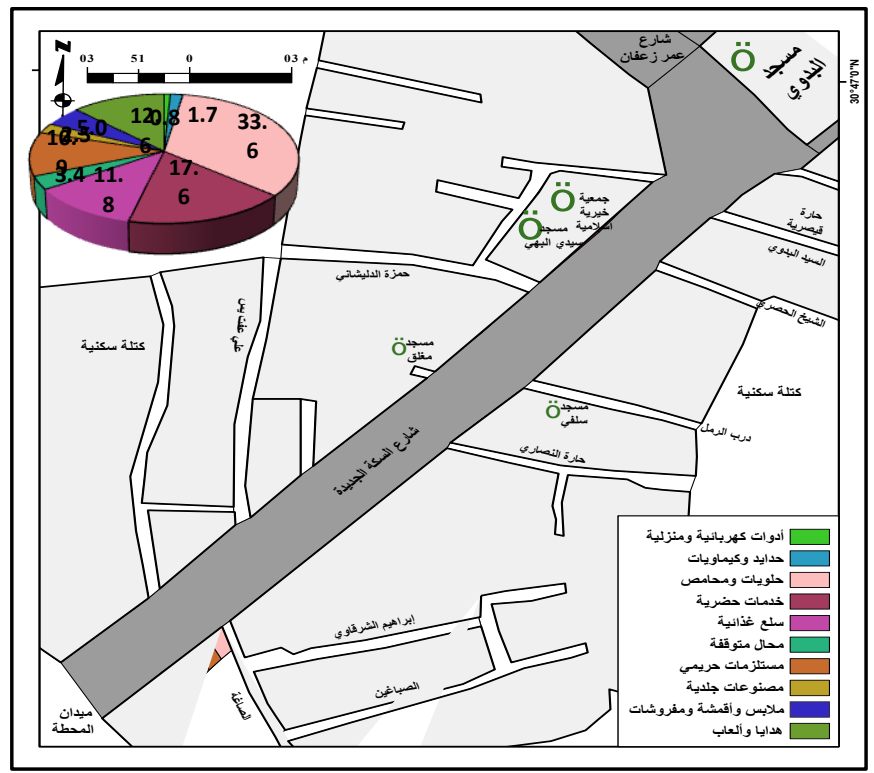

شكل (V ا ) توزيع استخدامات الأرض بشارع السكة الجديدة بمدينة طنطا عام ؛ 1 ـ r. 
ويلاحظ التركز الواضـح لمحـال الحلويـات علـي الجانـب الأيمسن للشـارع فيمـا يشـبه

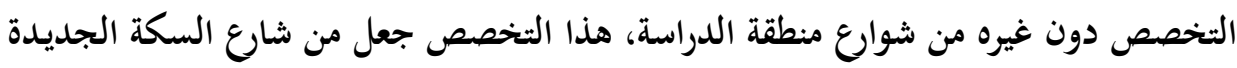

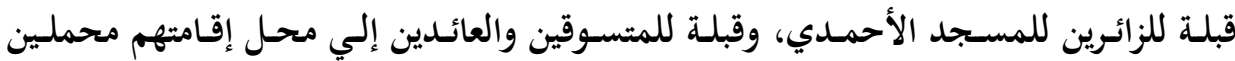

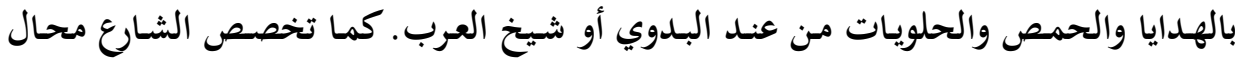

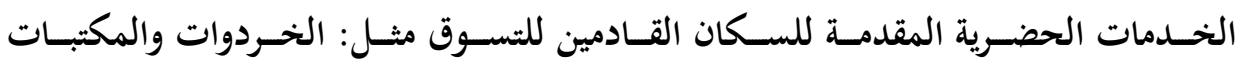

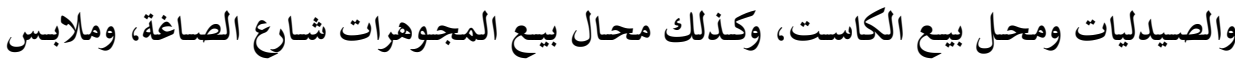

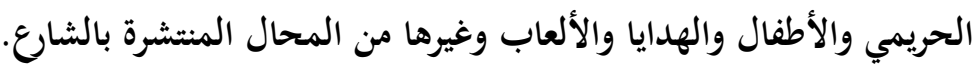
囚 شوارع تقع شرق المسجد (شـارع الهنود):

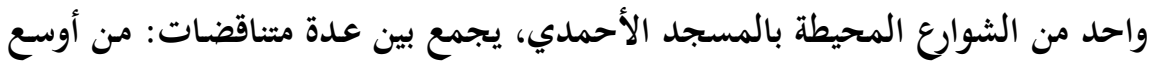

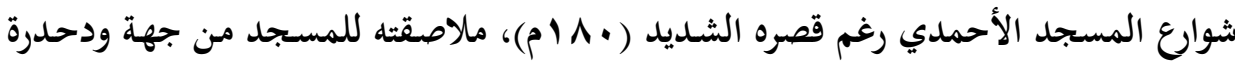

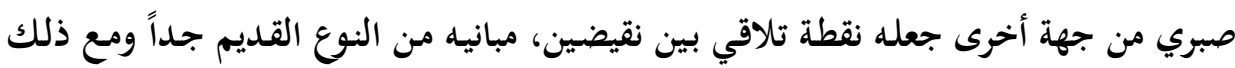

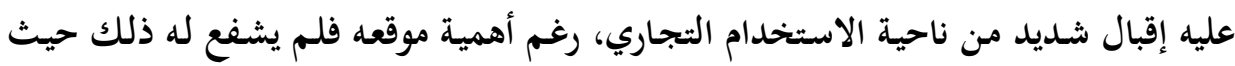

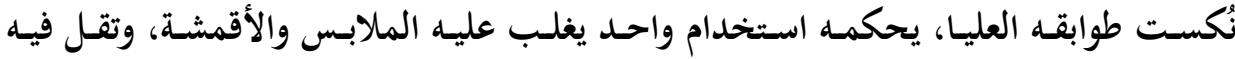
المحال المغلقة والسلع الغذائية.

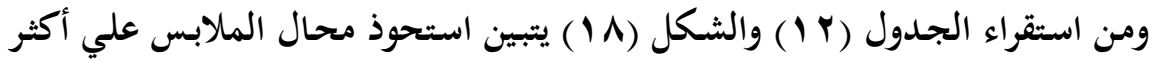

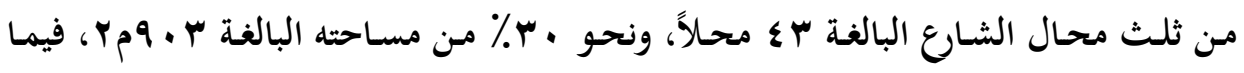

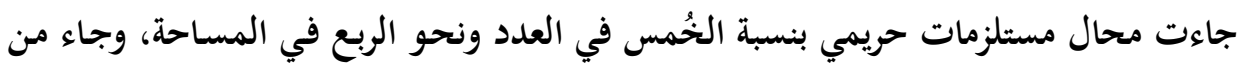

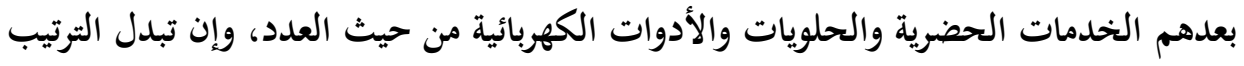
من حيث المساحة.

استحوذت علي هذا الثارع خمسة أنواع من الاستخدام التجاري بالإضـافة إلي محال

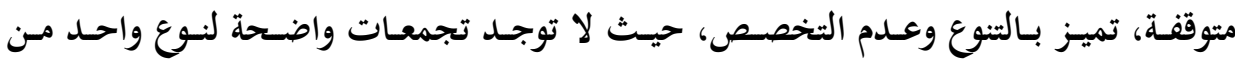

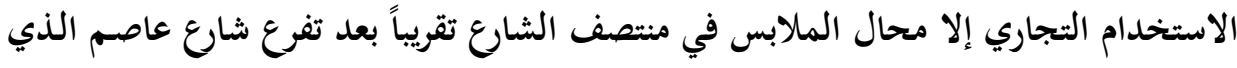
يصب في شارع صبري القريب من المنطقة القديمة في مدينة طنطا. كما بدأ الشارع بمحال الشال

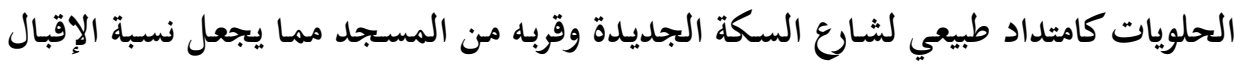

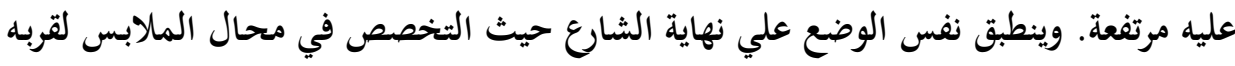

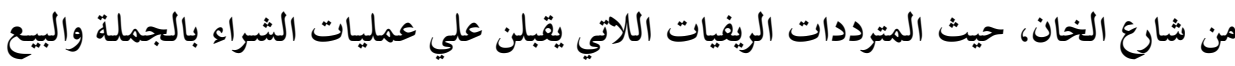

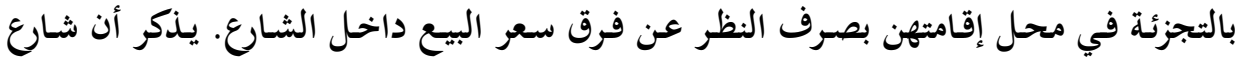

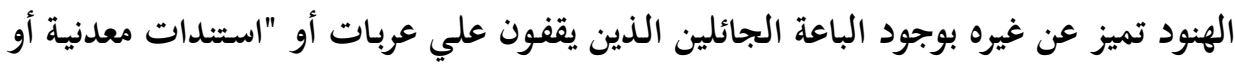


خشبية" يعرضون عليها بضائعهم، مستغلين اتساع الشارع وعدم وجود محلات بجوار المسجد

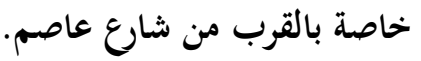

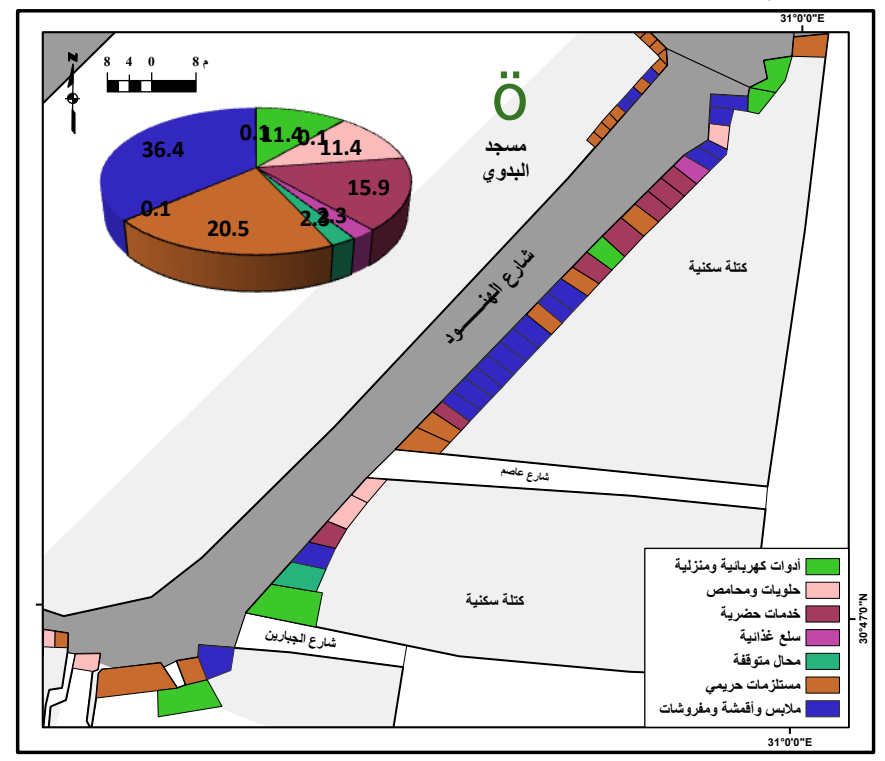

شكل (7 (1) توزيع استخدامات الأرض بشارع الهنود بمدينة طنطا عام ؟ I بـ.

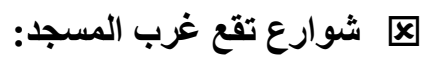

تضم شوارع درب الأبشيهي ودرب الازهر وعمر زعفان:

$$
\text { أ. شارع درب الأبشيهي: }
$$

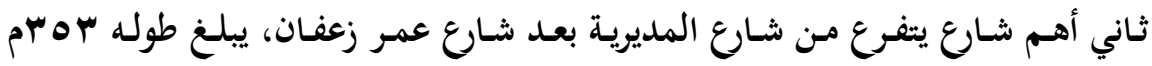

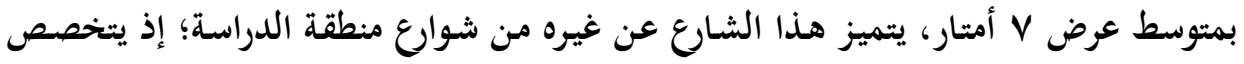

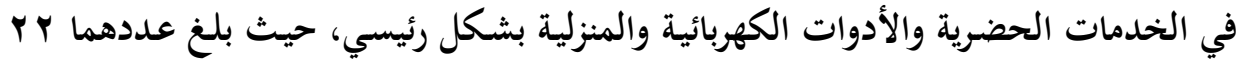

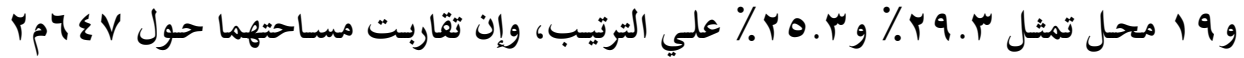

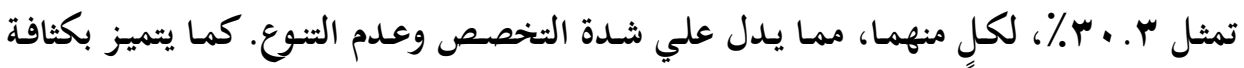

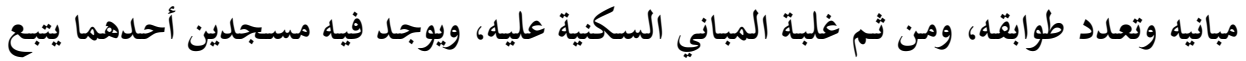
الطرق الصوفية حيث يوجد به ضريح سيدي حمزة.

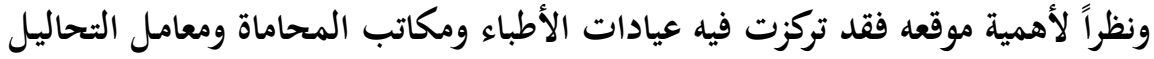

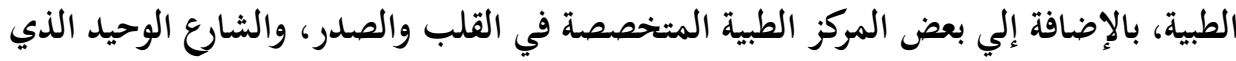

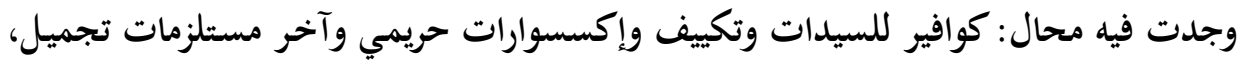

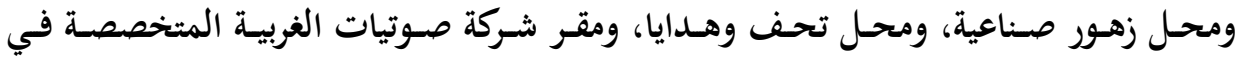


الأناشيد والقصص الدينية، وآخر للموازين وثالث للأدوات الصحية وغيرها من المحال ذات الضرورة اليومية.

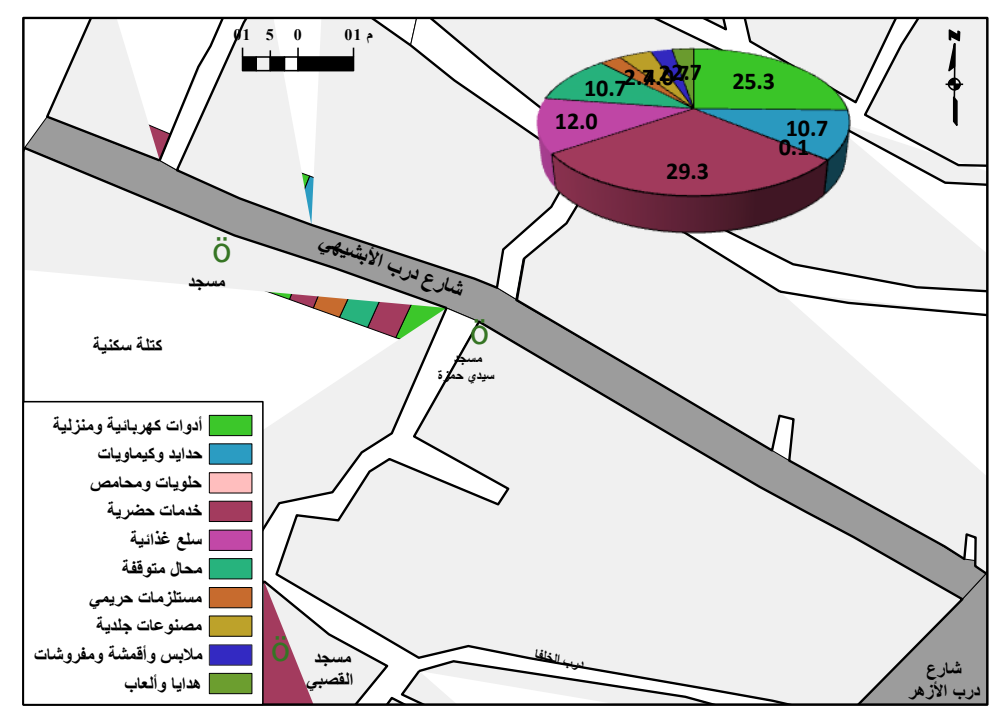

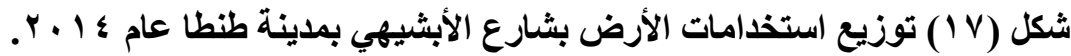

كما يتميز الثـارع بتخصصسه في طباعة الكتب العلمية وتوزيعها من خحلال وجود 17

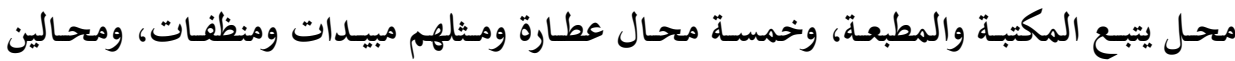

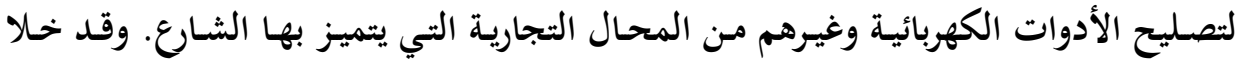

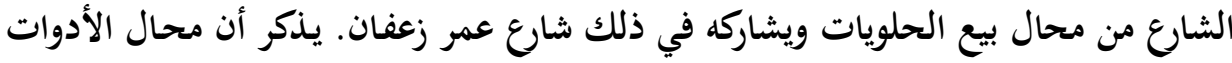

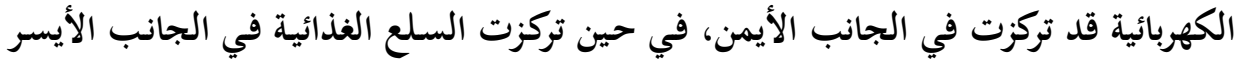

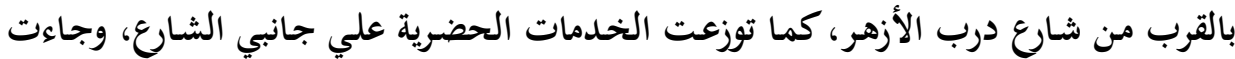
المصنوعات الجلدية في الجانب الأيمن.

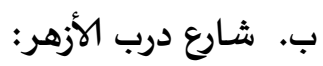

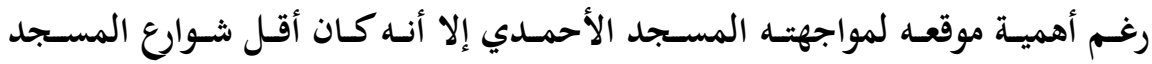

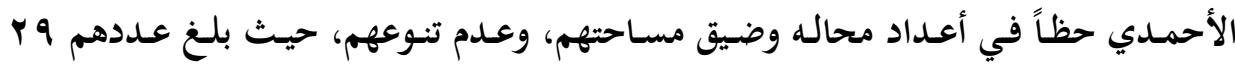

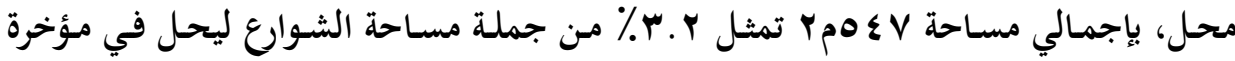

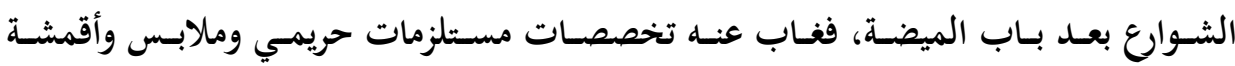
ومفروشات وحدايد وكيماويات. 


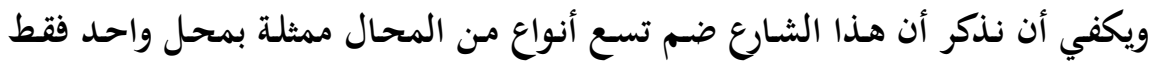

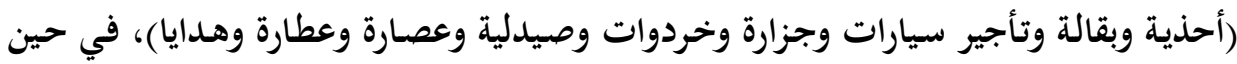

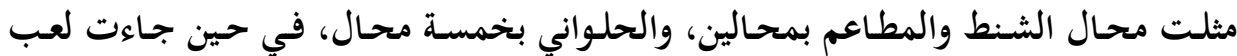

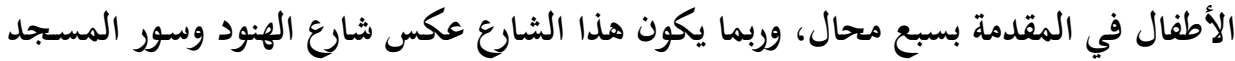
اللذان تخصصا في ملابس حريمي، وتخصصه في لعب الأطفال. ولا يمكن إنكار دور الأطفال

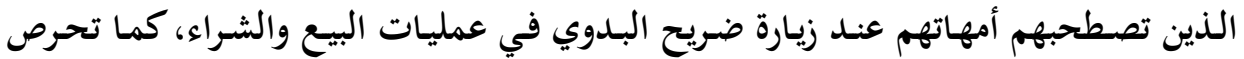

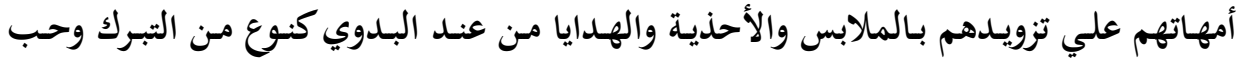
المكان.

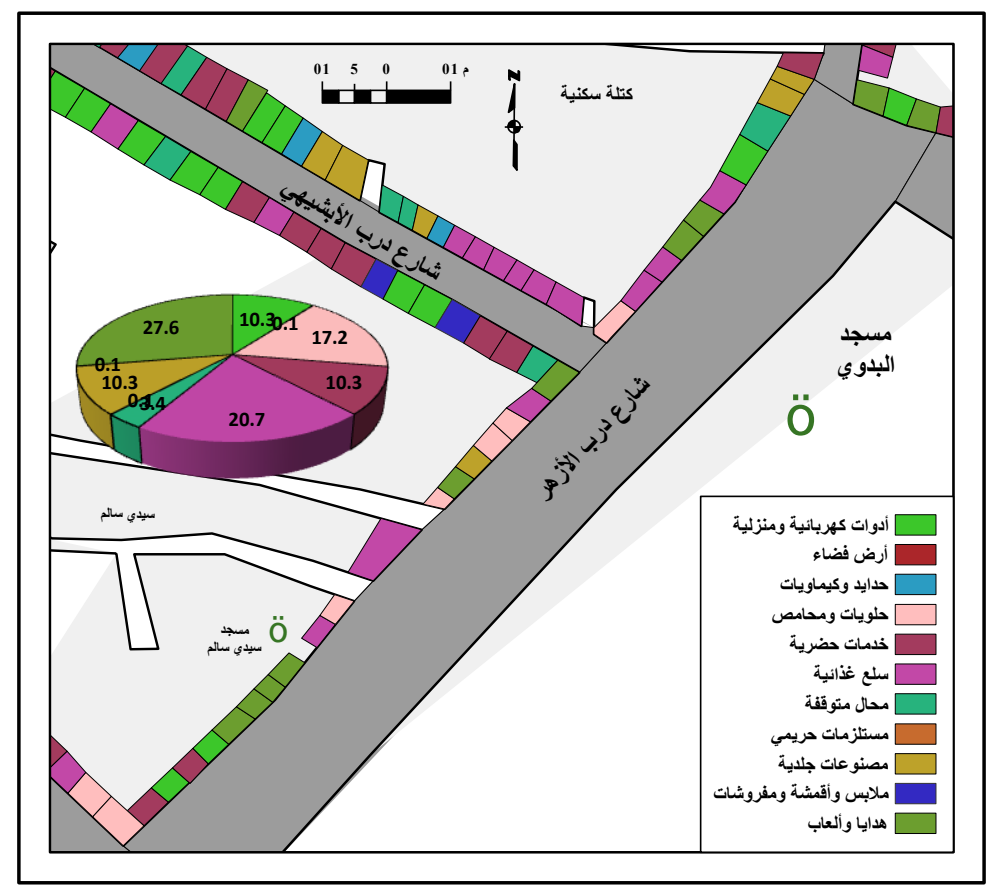

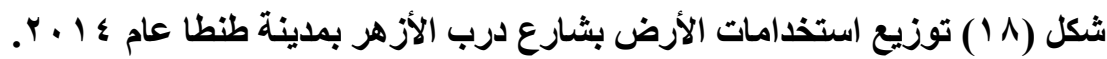

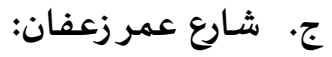

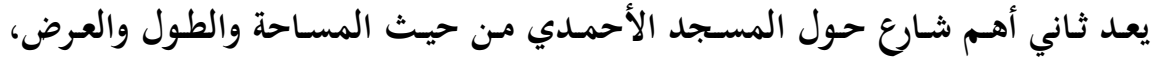

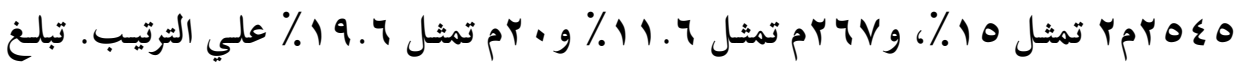

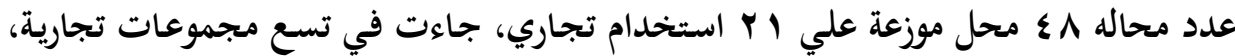
والشارع الوحيد الذي خلي من المحال المتوقفة. تستحوذ نسبة الاستخدام الديني علي حيز الديز

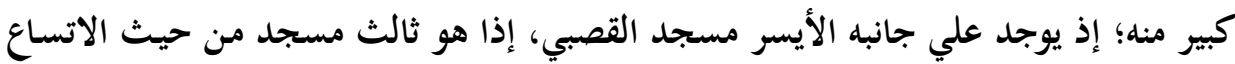




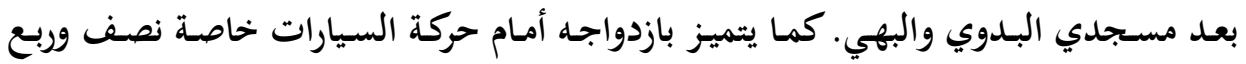

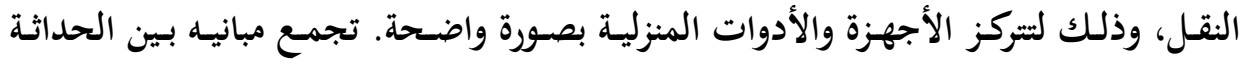

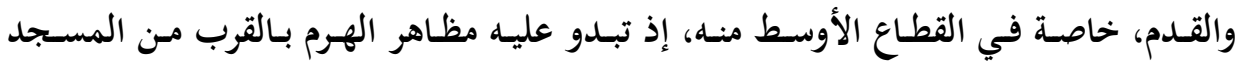

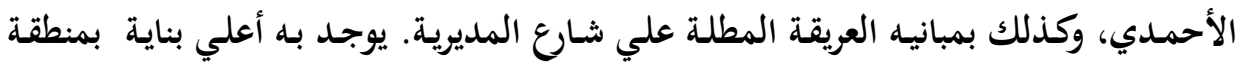

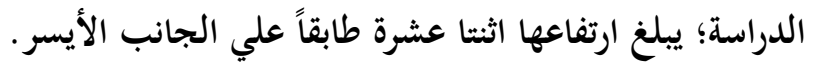

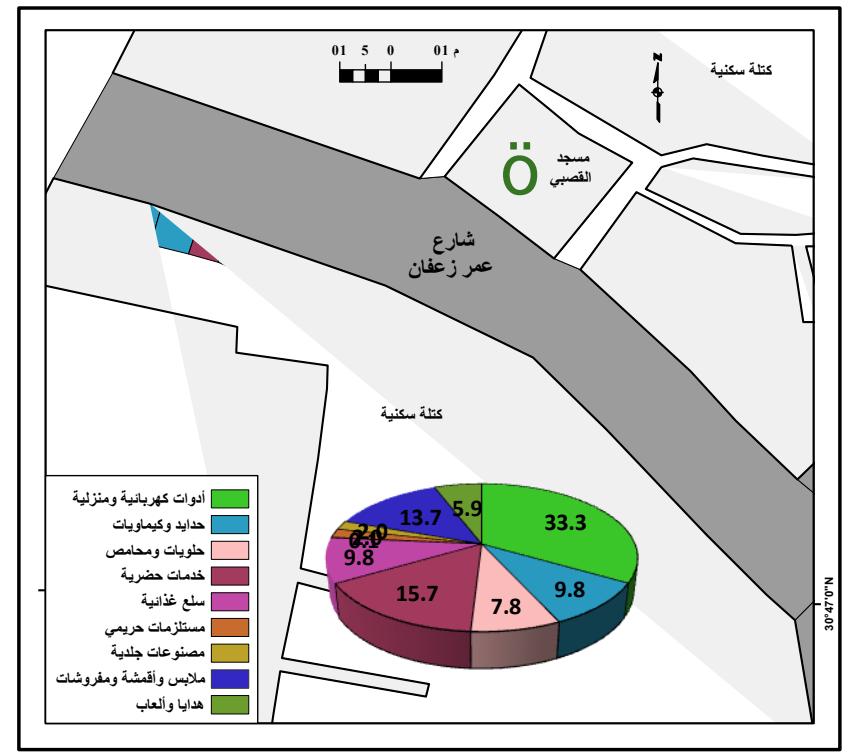

شكل (9 (1) توزيع استخدامات الأرض بثارع عمر زعفان بمدينة طنطا عام ؛ I بـ.

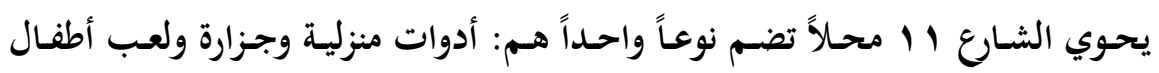

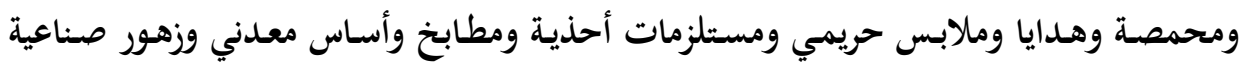

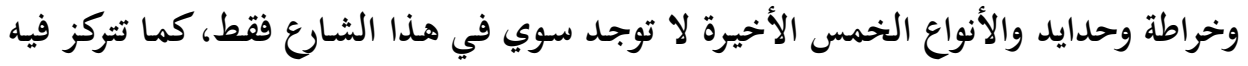

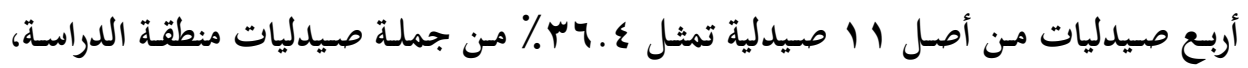

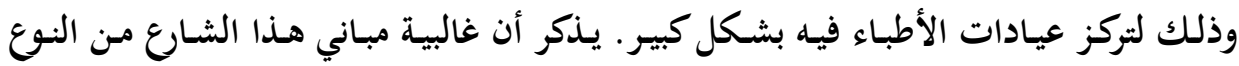

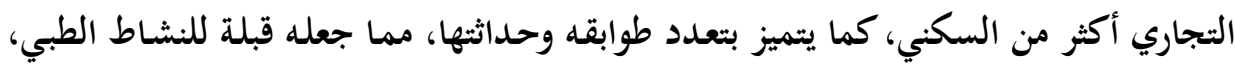

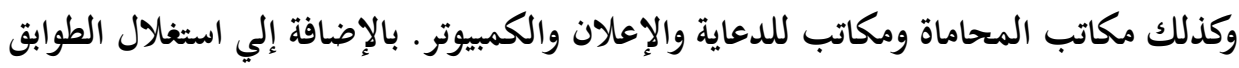

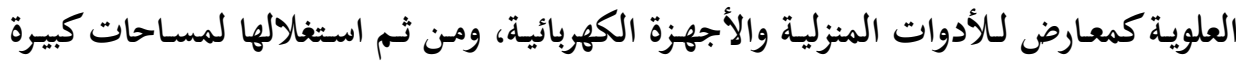

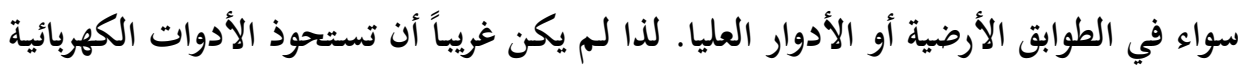

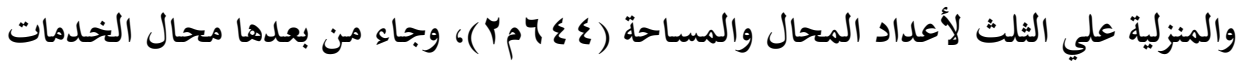
الحضرية والملابس والأقمشة ومستلزمات حريمي. لاعداد المحال والمساحة 


\section{رابعاً: التحليل الكمي المكاني للاستخدام التجاري}

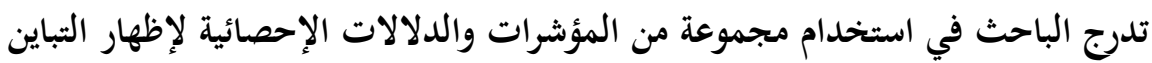

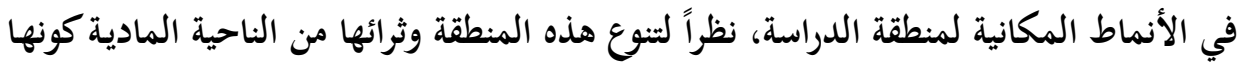

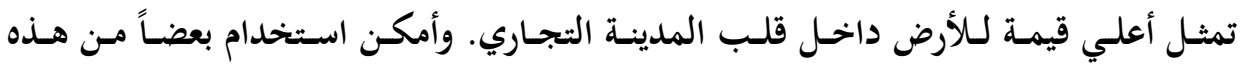

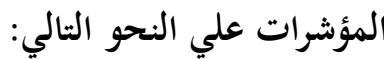

1- استخذام أداة البقع الساخنة (•) Hot Spot Analysis (Getis-Ord Gi* تمكن نظم المعلومات الجغرافية من القيام بعمليات المعالجة والتحليل المكاني للظاهرة

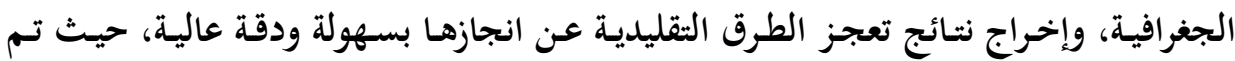

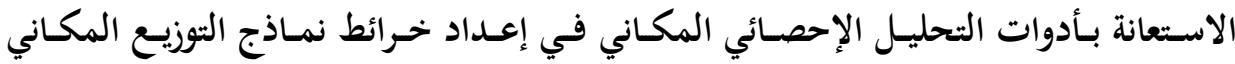

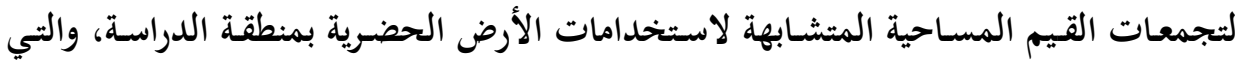

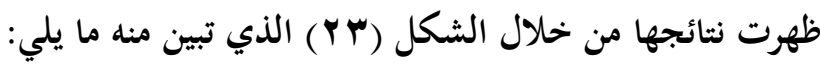

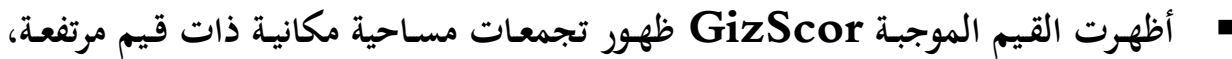

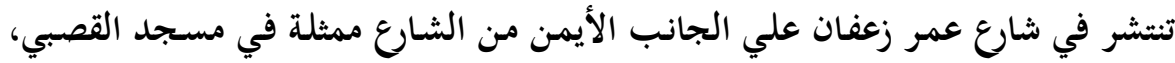

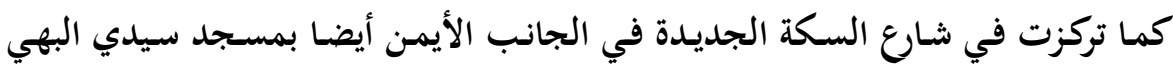

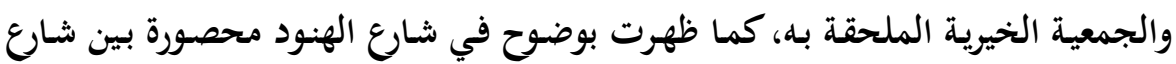
عاصم وشارع الخان، كما ظهرت علي استحياء في شارع الخان.

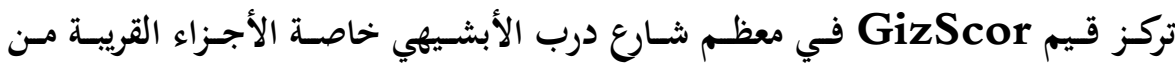

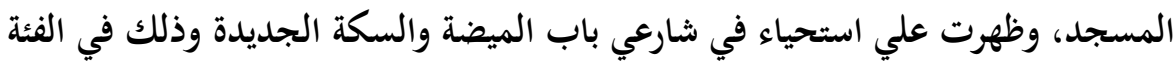

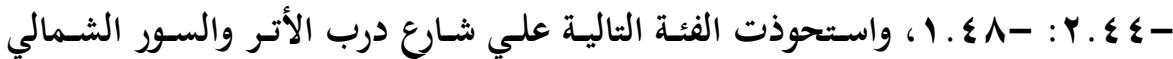

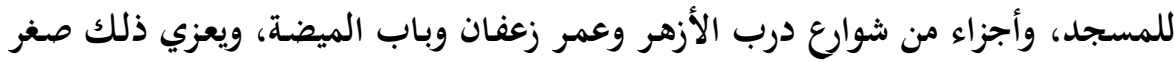

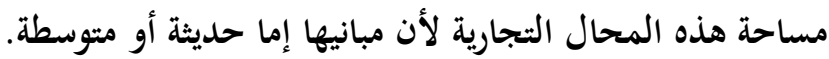

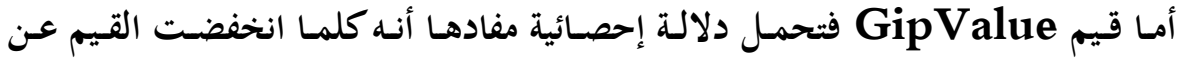

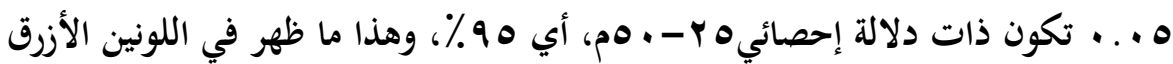

(•) تم استخدام التحليل الإحصائي المكاني Spatial Statistics Tools في برنامج 10.2 ArcMap من

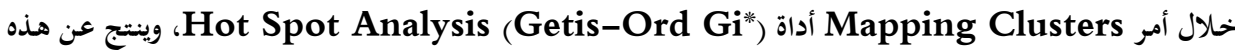

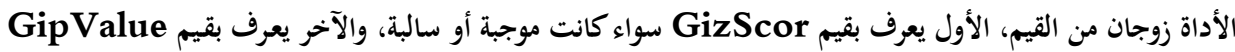

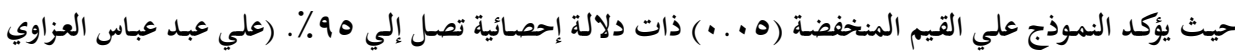

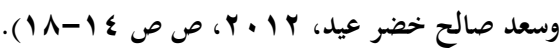


الغامق والفاتح، مما يدل علي تشابه قيم الوحدات المساحية المكانية للمحال التجارية

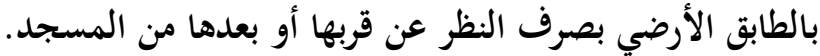

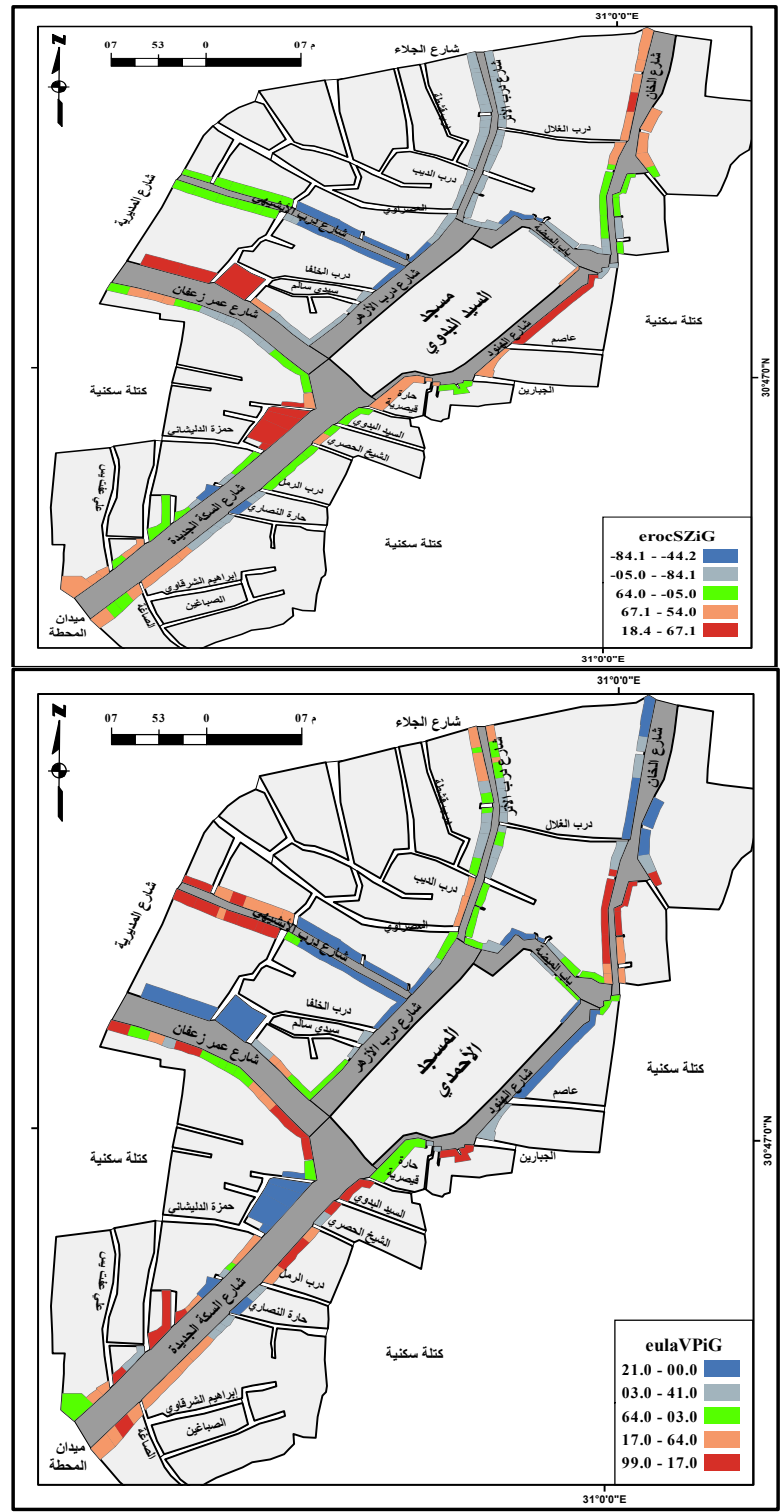

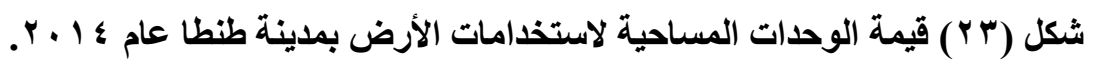




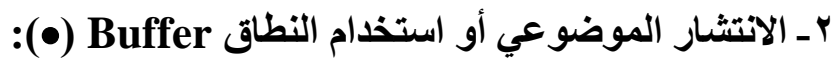

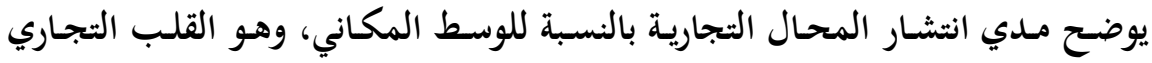

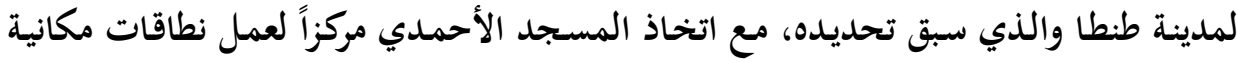

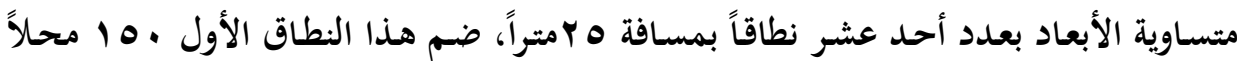

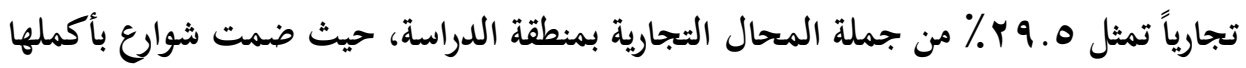

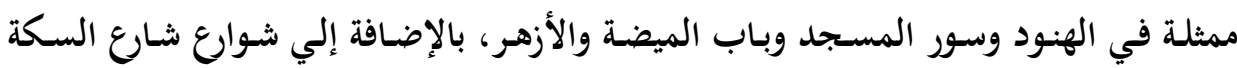
الجديدة وعمر زعفان والأبشيهي والأتر والخان.

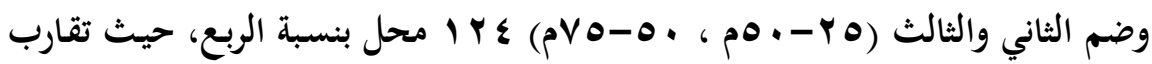

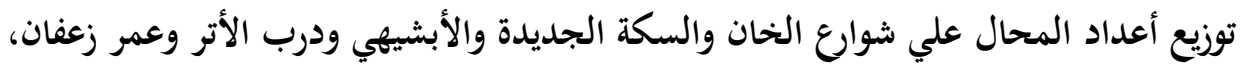

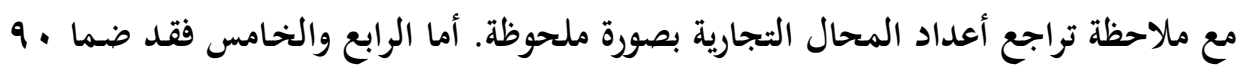

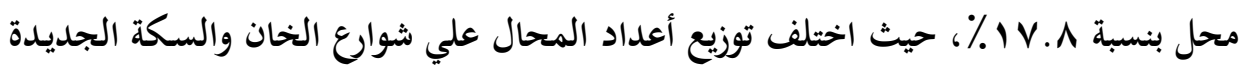

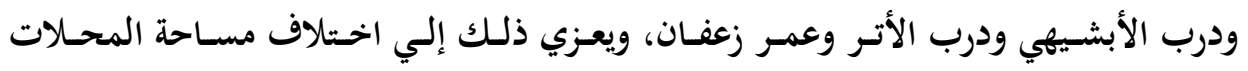

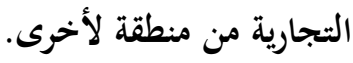

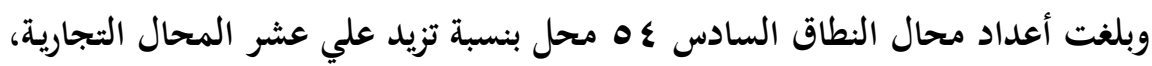

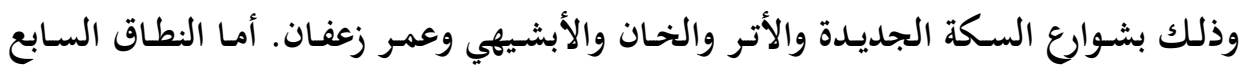

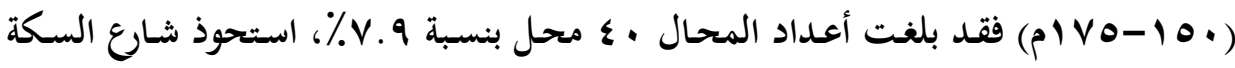

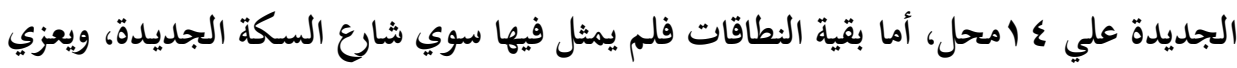

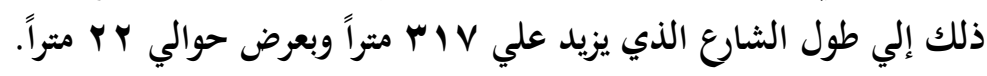

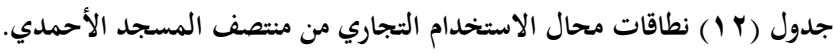

\begin{tabular}{|c|c|c|c|c|c|c|c|c|c|c|c|c|}
\hline$\%$ & المحال & زعفان & سور المسجد & الأزهر & الأتر & الأبشيهي دربي & الميضة & الهنود & الجديدة & الخان & نطاق (م) & r \\
\hline 19.0 & 10. & $r$ & Mr & rq & $r$ & $r$ & $r r$ & $\varepsilon r$ & $1 \leq$ & 1 & صفر _o & 1 \\
\hline IY.Y & $7 r$ & 9 & $\cdot$ & $\cdot$ & $1 \leq$ & IY & . & - & Ir & 10 & $V \theta_{-} 0$. & $r$ \\
\hline$\Lambda . \vee$ & $\varepsilon \varepsilon$ & 0 & - & - & 11 & ir & $\cdot$ & - & $\Lambda$ & $\mathrm{V}$ & $1 \cdots-10$ & $\varepsilon$ \\
\hline$v .9$ & $\varepsilon$ & $\varepsilon$ & - & - & $\Lambda$ & 9 & - & - & $1 \leq$ & 0 & 180.10 & $\mathrm{~V}$ \\
\hline$\varepsilon . r$ & YY & & • & - & & $V$ & • & • & 9 & 7 & $Y \ldots-1 V 0$ & $\Lambda$ \\
\hline 1.7 & $\Lambda$ & & - & - & & & . & - & $\Lambda$ & & YYO_Y.. & 9 \\
\hline Y.* & 1. & & - & - & & & - & - & 1. & & YO.-YYO & 1. \\
\hline
\end{tabular}

المصددر/ الجدول من إعداد الباحث اعتماداً علي الدراسة الميدانية وبرنامج 10.2 GIS.

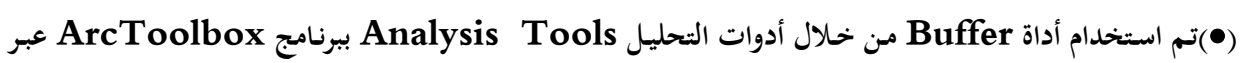
أداة proximity 


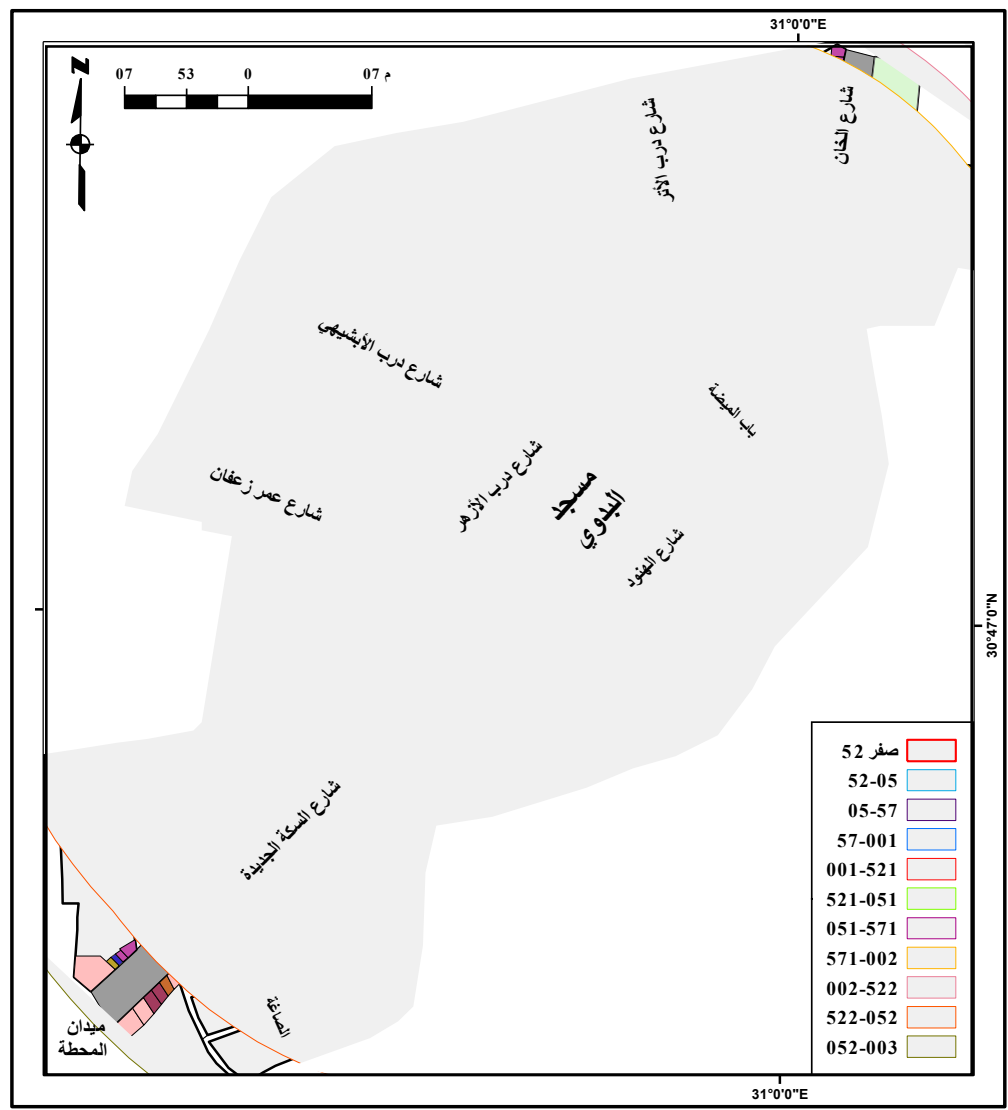

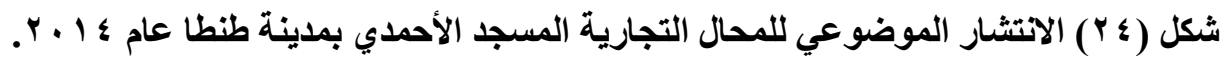

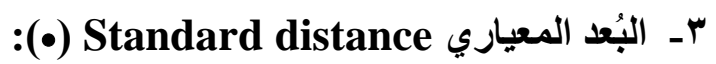

يعد البعد المعياري واحداً من مقاييس التشتت التي تدرس مدي تشتت القيم المدروسة

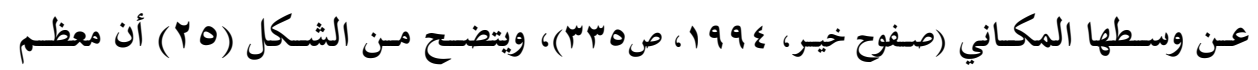

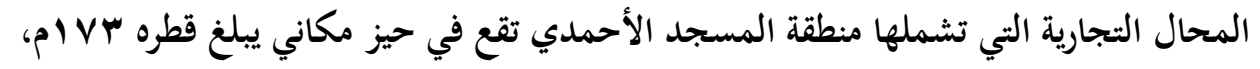

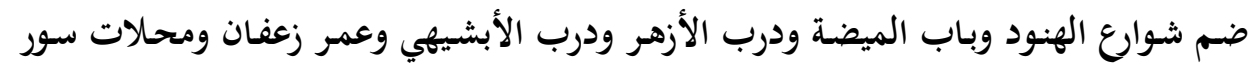

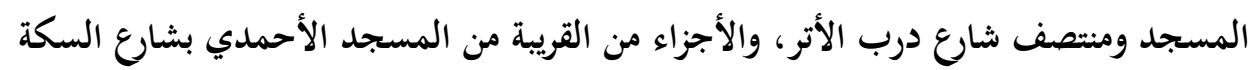

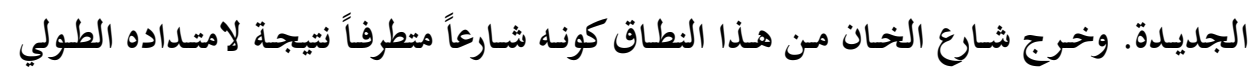
) واتصاله بمنطقة القلب التجاري خاصة شارعي الجلاء والبحر.

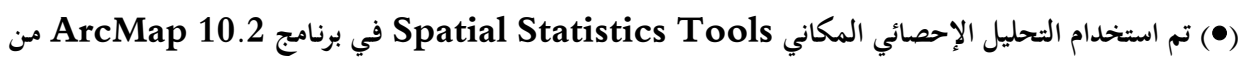

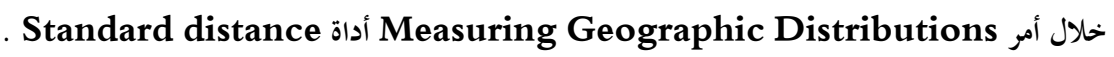




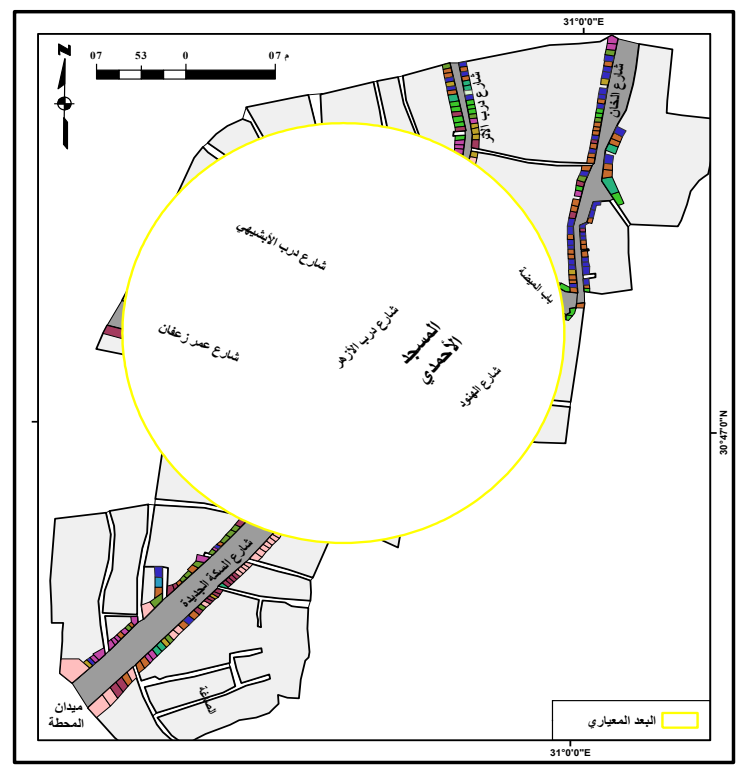

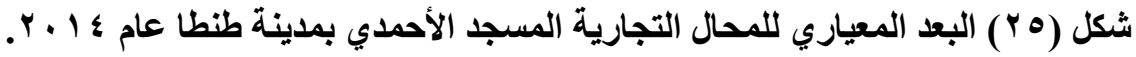
ع - نقطة تقاطع قمم قيم الأراضي:

يشغل القلب التجاري في أي مدينـة مساحة محدودة ، ومع ذلك فأن تركيبه الداخلي يتباين كثيراً، ففي وسطه توجد منطقة النواة حيث تبلغ أسعار الأراضي أقصي ارتفاع في المدينة كلها، وفيها تزداد حركة المشترين والعائد الاقتصادي كبير ) , Toyne \& Newby, 1984, bا 151-p148)، وهو ما يطلق عليه نقطة تقاطع قمم قيم الأراضي، بحيث يحدث اختلاف في طبيعة الاستخدامات التجارية علي أساس المسافة من نقطة تقاطع قمم قيم الأراضي، بحيث

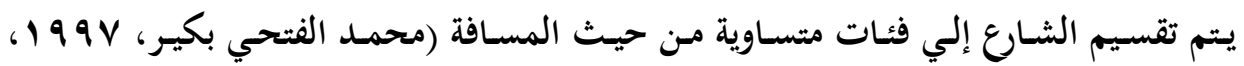

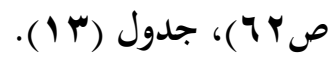

جدول (r ا ) رتب أعداد محال الاستخدام التجاري من نقطة تقاطع قمم قيم الأراضي.

\begin{tabular}{|c|c|c|c|c|c|c|c|c|c|}
\hline جملة & $+1 \vee 0$ & -10 & $-1 Y 0$ & $-1 \ldots$ & $-V_{0}$ & -0 & $-r_{0}$ & ro- & المسافة بالمتر \\
\hline$r \cdot$ & $\varepsilon$ & 1 & 1 & $r$ & $r$ & 1 & $r$ & 0 & خدمات حضرية \\
\hline ro & $r$ & $r$ & $\varepsilon$ & $r$ & 7 & $r$ & $\varepsilon$ & 1 & مستلزمات حريمي \\
\hline$r 4$ & 7 & $r$ & $r$ & 1 & $r$ & $r$ & 0 & $\varepsilon$ & أدوات كهربائية ومنزلية \\
\hline$r V$ & 0 & $r$ & $r$ & 7 & $\varepsilon$ & $r$ & $r$ & $r$ & ملابس وأقششة ومفروشات \\
\hline YV & 1 & . & $\mathrm{V}$ & $\mathrm{V}$ & $r$ & $r$ & 1 & $\mathrm{~V}$ & سلع غذائية \\
\hline M & $r$ & 0 & 7 & $\varepsilon$ & 1 & $\varepsilon$ & 7 & $r$ & حلويات ومحامص \\
\hline$\& 1$ & $\varepsilon$ & $r$ & $\mathrm{~V}$ & 0 & 0 & 7 & 0 & 7 & هدايا وألعاب \\
\hline$\varepsilon \varepsilon$ & $V$ & . & 0 & 7 & 0 & 0 & $\Lambda$ & $\Lambda$ & محال متوقفة \\
\hline or & $V$ & $\varepsilon$ & $\Lambda$ & 7 & 7 & 7 & V & 9 & مصنو عات جلاية \\
\hline $0 \leq$ & $\Lambda$ & 0 & 0 & 9 & 7 & 7 & $\Lambda$ & 1. & حدايل وكيماويات \\
\hline
\end{tabular}

المصددر/ الجدول من إعداد الباحث اعتماداً علي الدراسة الميدانية وبرنامج 10.2 وأو 


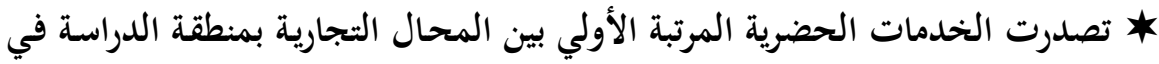

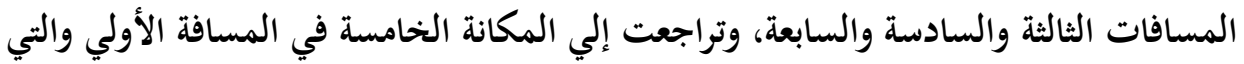

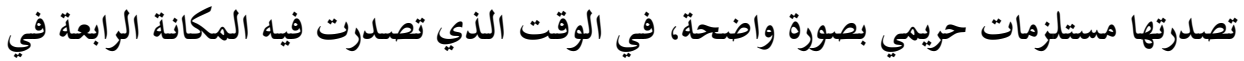

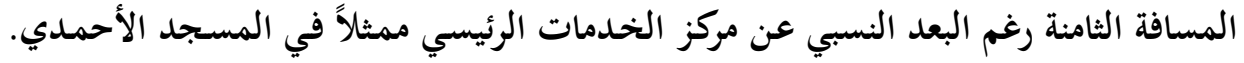

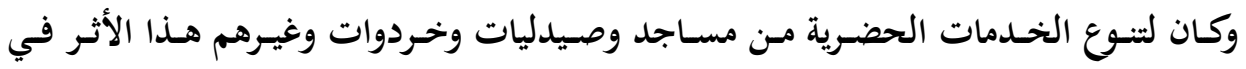

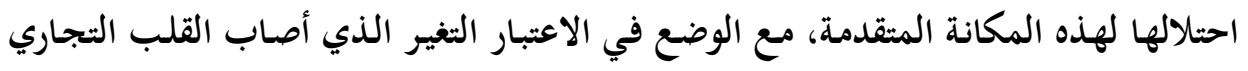
لمدينة طنطا، وتراجع الإقبال من قبل مريدي وأتباع السيد البداعدي البداري.

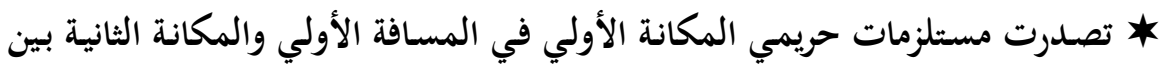

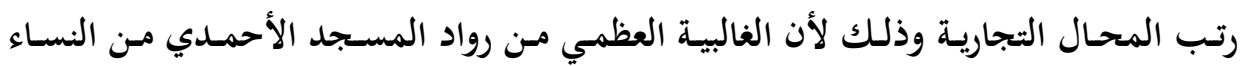

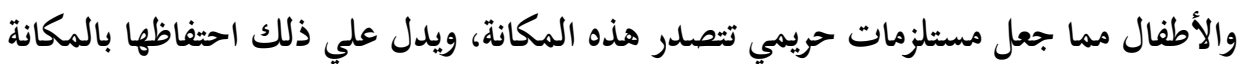

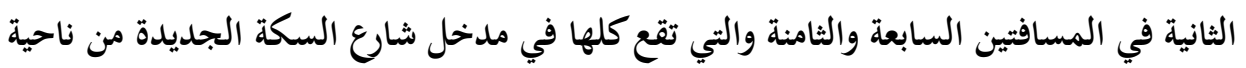

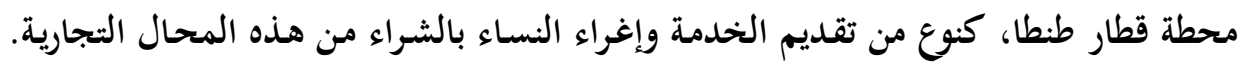

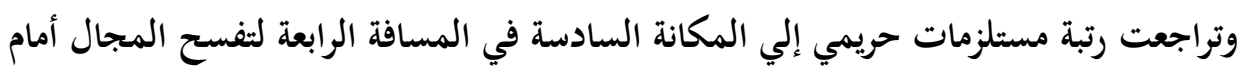

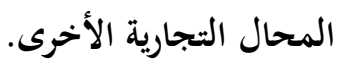

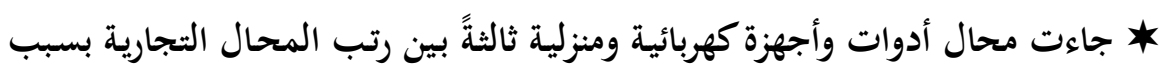

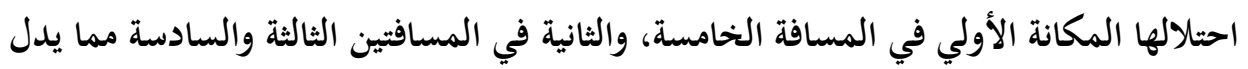

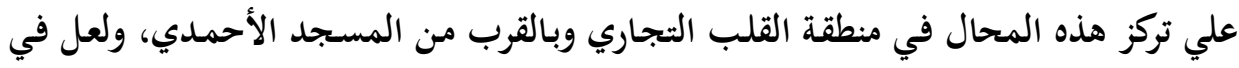

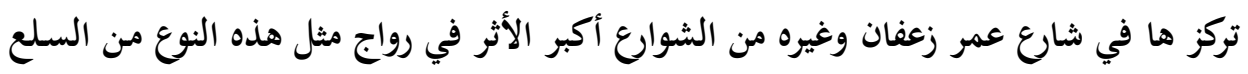

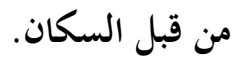
* احتلت محال ملابس وأقمشة ومفروشات وكذلك سلع غذائية المكانة الرابعة بين

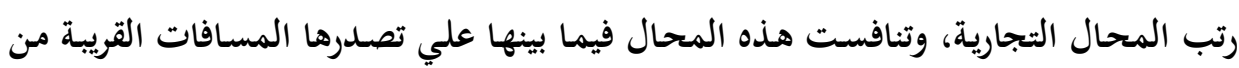

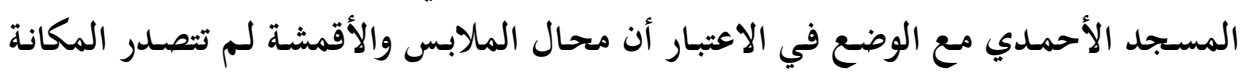

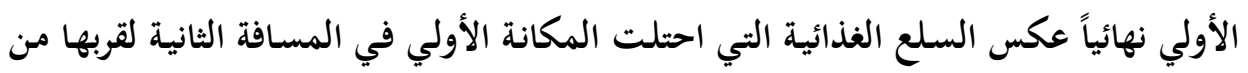

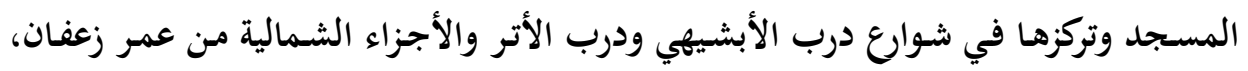

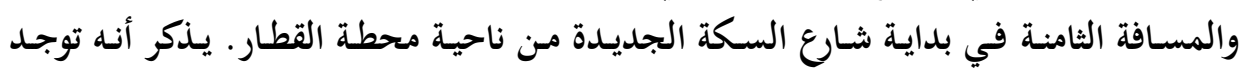

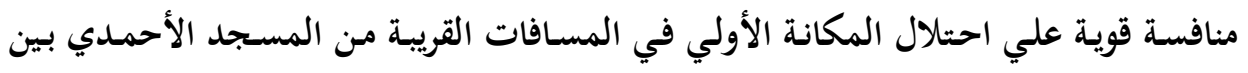

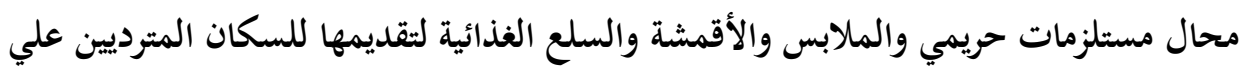


المسـد، أو للسكان المقيمين في هـذه المنطقة والتي ترتفع فيها الكثافة السكانية بصورة واضحة.

* تراجع ترتيب رتب محال الحلويات وبيع الحمص ومستلزمات الأفراح بين المحال

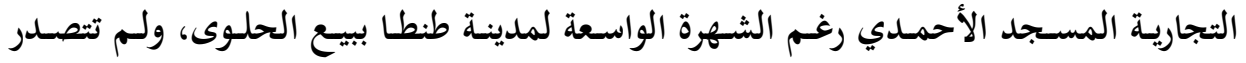

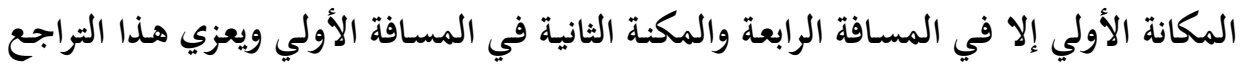

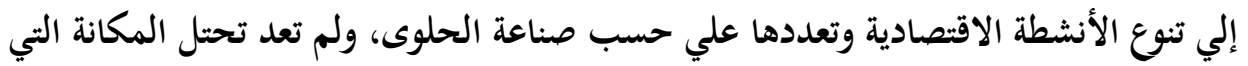
كانت ترتبط بها قديماً خاصة أثناء انعقاد الموالد.

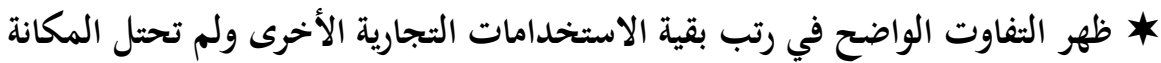

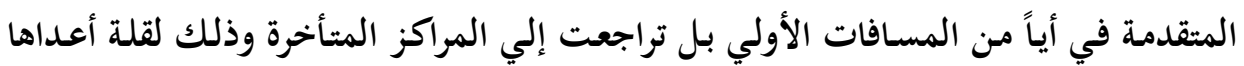

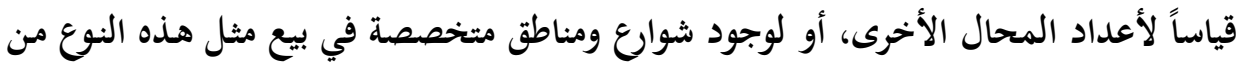

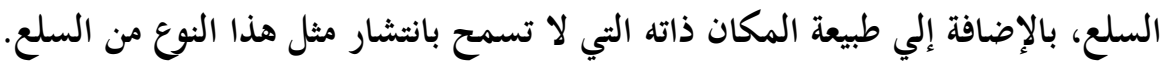
هـ معامل التوطن:

يعد الهدف من تطبيق مؤشر الأهمية النسبية الوقوف علي البعد المكاني في توطن

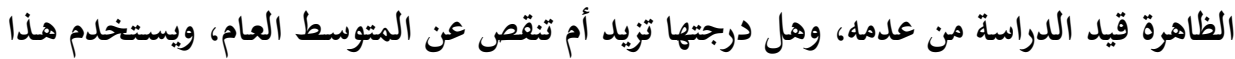

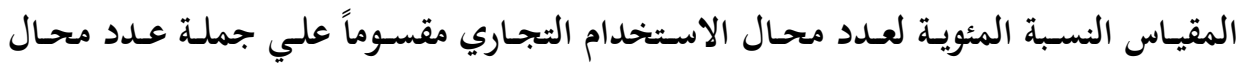

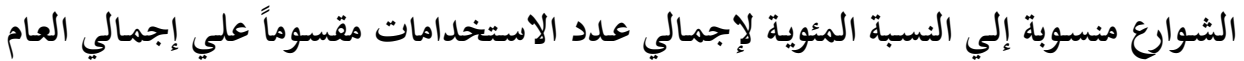

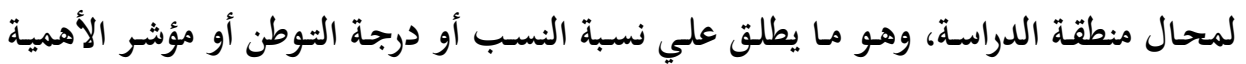

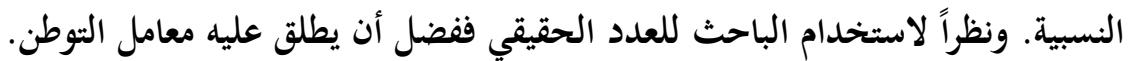

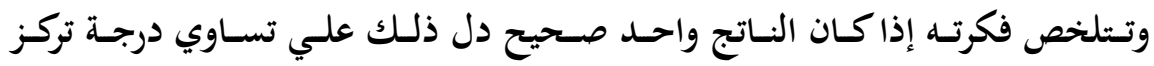

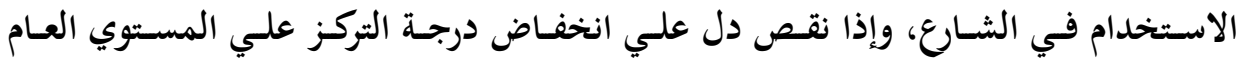

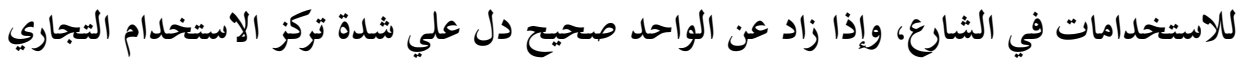

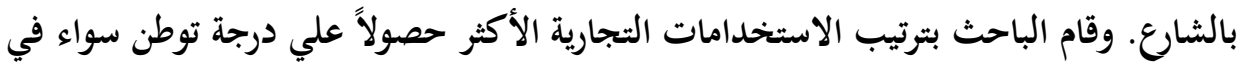

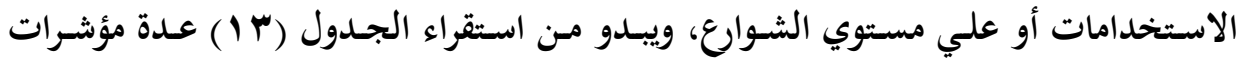

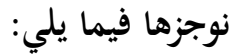

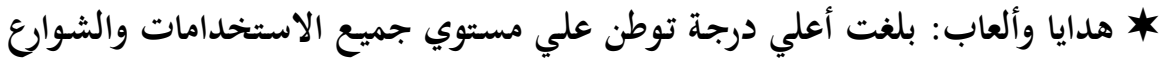

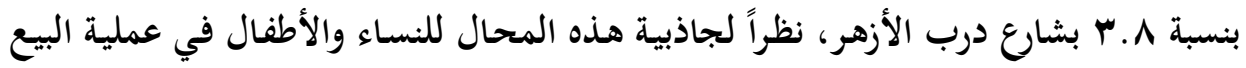

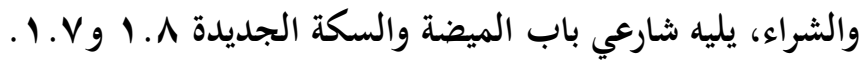




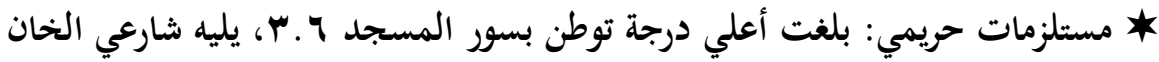

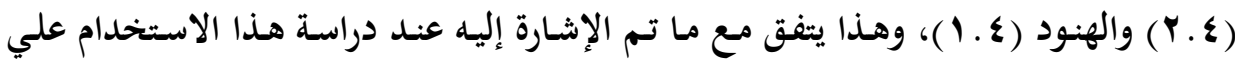

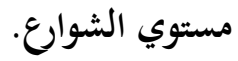
* أدوات كهربائية ومنزلية: حلت ثالثاً بدرجة توطن بلغت أعلاها بشارع بـاب الميضسة

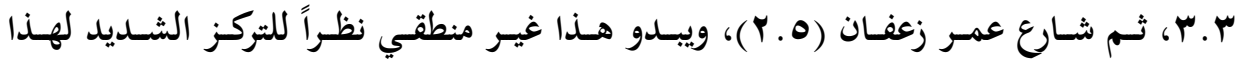

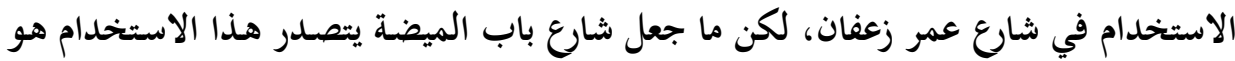

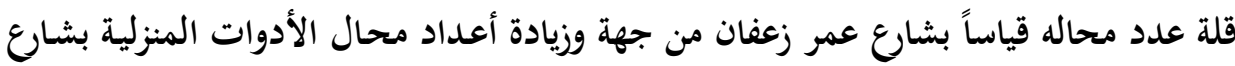

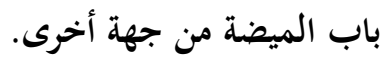

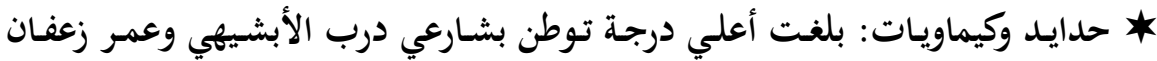

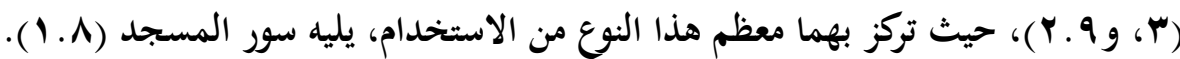

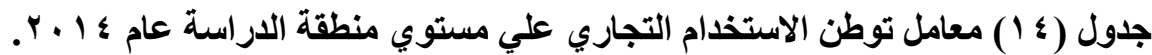

\begin{tabular}{|c|c|c|c|c|c|c|c|c|c|}
\hline زعفان & سلور & الازربر & الأتر & الأبشيهي & الميضة & الهنود & الجديدة & 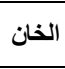 & نوع الاستخدام \\
\hline$\cdot .1$ & $r .7$ & $\because \cdot$ & .7 & $\cdot Y$ & $\cdot .7$ & 1.5 & $\because \mathrm{V}$ & Y.द & مستلزمات حريمي \\
\hline$\because \mathrm{V}$ & $\because \cdot$ & 1.5 &.$\wedge$ & $\because *$ & $\because$. & $1 . *$ & Y.A & $\because \cdot$ & حلويات ومحامص \\
\hline Y.o & $\cdot r$ & $\cdot \wedge$ & $\cdot .9$ & 1.9 & $r . r$ & $\because .9$ & $\because 1$ & $\because \varepsilon$ & أدوات كهربائية ومنزلية \\
\hline 1.1 & $\cdot . \varepsilon$ & $\cdot . \wedge$ & $\cdot . \wedge$ & 1.9 & $\cdot . \wedge$ & 1.1 & 1.1 &. .4 & خدمات حضرية \\
\hline$\because 9$ & $1 . r$ & $\because \cdot$ & $\cdot \wedge$ & $\because Y$ & $\cdot .7$ & Y.0 & $\because \varepsilon$ & Y.V & ملابس وأقمشة ومفروشات \\
\hline$\cdot .9$ & $\cdot r$ & $1 . \wedge$ & r.r & 1.1 & $\cdot$. & $\cdot r$ & 1. &.$\varepsilon$ & سلع غذائية \\
\hline$\because 7$ & $\because \varepsilon$ & $r . \wedge$ & .7 & $\because . \varepsilon$ & 1.1 & $\because \cdot$ & $1 . v$ & $\because .7$ & هدايا وألعاب \\
\hline$\because \cdot$ & 1.2 & $\cdot \wedge$ & $1 . \varepsilon$ & Y.o & $\because \cdot$ & $\because 0$ & $\cdot \wedge$ & $\because V$ & محال متوقفة \\
\hline Y.9 & 1.1 & $\because \cdot$ &. .5 & r.. & $\ddots^{*}$ & $\ddots^{*}$ & $\because 0$ & $\ddots^{\circ}$ & حدايد وكيماويات \\
\hline. .7 & $\because \cdot$ & r.9 & r. & 1.1 & $1 . r$ & $\because \cdot$ & $\because \mathrm{V}$ & $\because \wedge$ & مصنوعات جلدية \\
\hline
\end{tabular}

المصدر/ الجدول من إعداد الباحث اعتماداً علي الدراسة الميدانية.

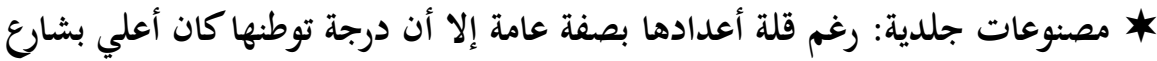

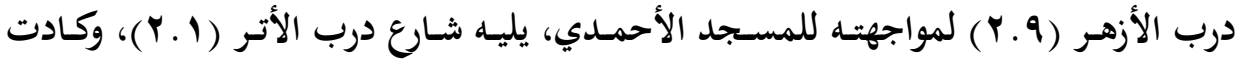

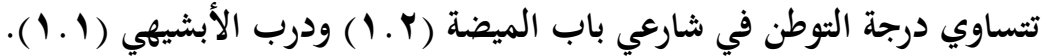

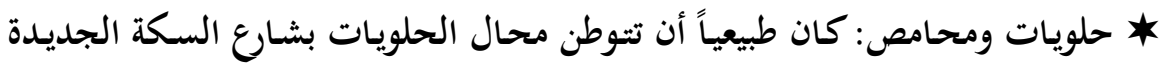

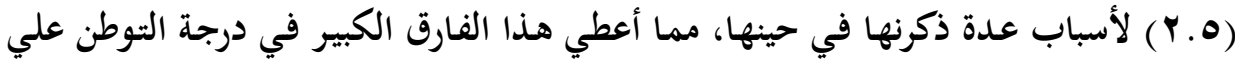

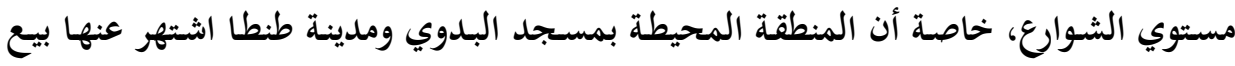

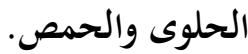

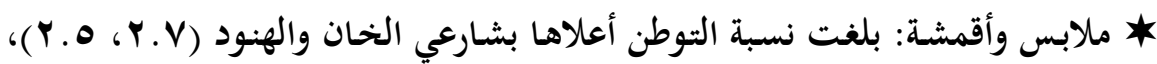

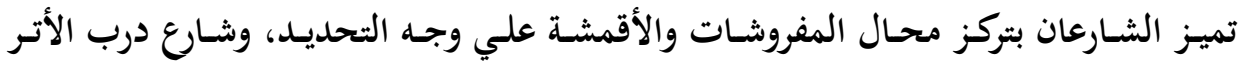
لملابس الرجال. 


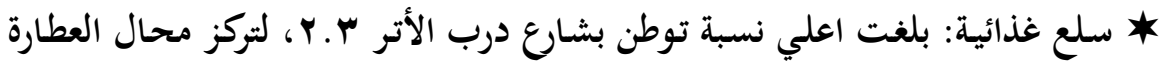

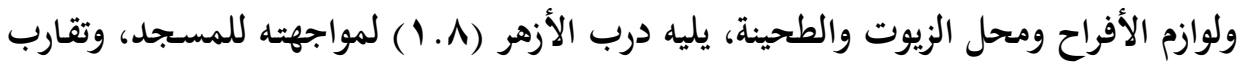

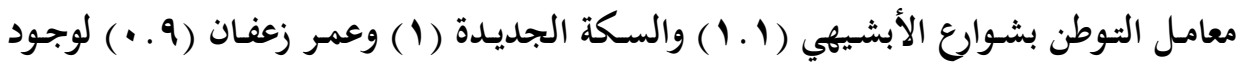
محال البقالة والحاتي. * خدمات حضرية: لا يوجد توطن بالمعني المعرف نظراً لحاجة السكان اليومية إلي هذا

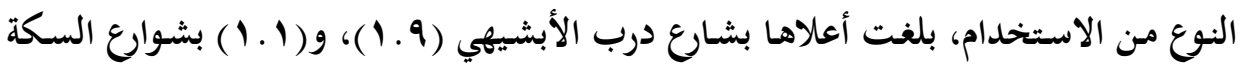

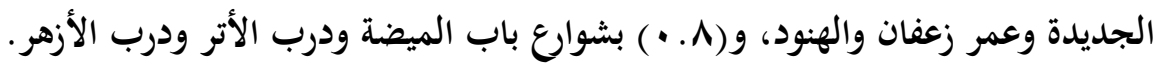

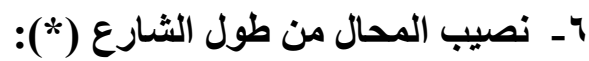
تعطي نسب أطوال واجهات المحال الثجارية من الطول الكلي للشولة الثوارع صورة حقيقية

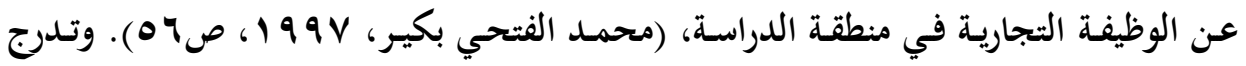

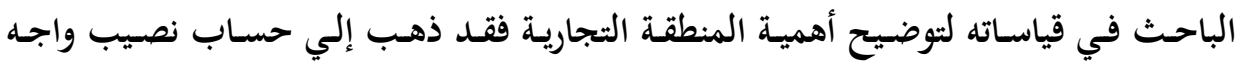

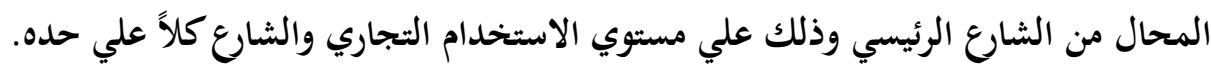
وباستقراء الجدول (0 1 ) تبين عدة حقائق يمكن توضيحيها في النقاط التالية:

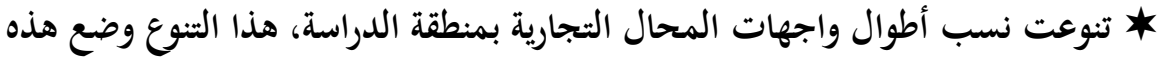

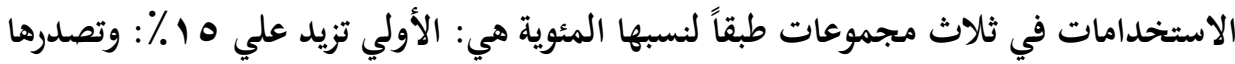

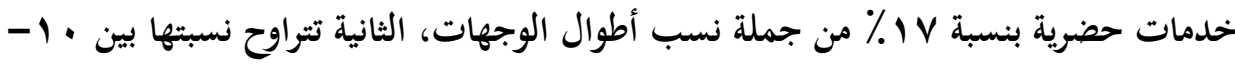

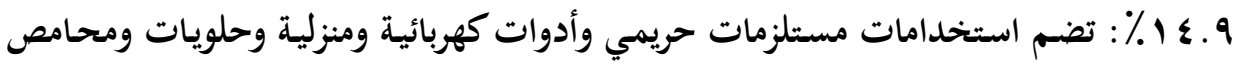

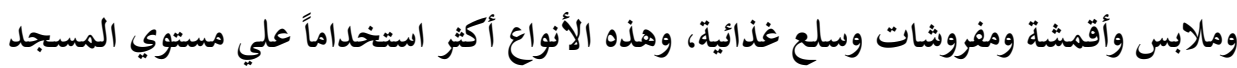

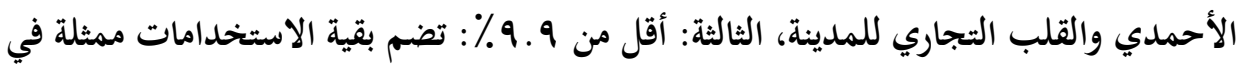

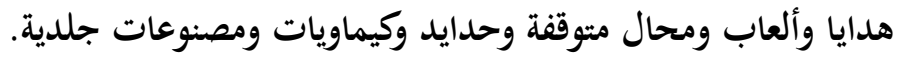

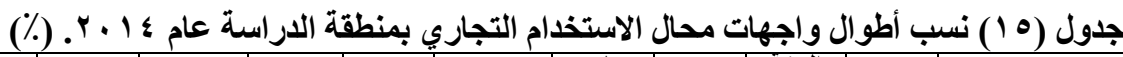

\begin{tabular}{|c|c|c|c|c|c|c|c|c|c|c|}
\hline جملة & زعفان & المسوجد & الأزّر & لالآنّ & الأبشِيهي & المبضضة & الهنود - ل الهن & الجديدة & الخان & أطوال المحال (٪) \\
\hline IV. & YY.Y & 4. & $1 \cdot . r$ & $11 . \mathrm{V}$ & 1.1 & 18.4 & 10.4 & 19.5 & $\varepsilon .7$ & خلمات حضرية \\
\hline 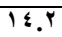 & Y.O & OY.1 & $\because \cdot$ & $\Lambda . \Lambda$ & r. & 0.9 & YY. & 9.9 & $\leqslant \% .0$ & مستلزمات حريمي \\
\hline $1 \% . \Lambda$ & $r \cdot . \Lambda$ & r.9 & $1 \cdot .7$ & $1 Y . \Lambda$ & YV.Y & $\leqslant$ \&.1 & 10.4 & $\cdot .7$ & $0 . \Gamma$ & دوات كهربائية ومنزليّية \\
\hline $1 \% . r$ & 7.9 & $\because$ & 10.4 & $1 . .4$ & $\because$ & 0.4 & 9.4 & $r 4.9$ & ${ }^{\circ}$ & لحلويات ومحامص \\
\hline 14.9 & IY.V & 19.4 & $\because \cdot$ & 1.99 & Y.r & 11.7 & rY.A & $\{.7$ & rr.. & ملابس و أقمشة \\
\hline $1 \cdot . \mathrm{V}$ & 9.1 & $r . r$ & Tr.Y & $r 0.7$ & 9.7 & 乡. & Y. 1 & $1 \cdot . r$ & $\varepsilon_{.} Y$ & سلع غذائية \\
\hline $7 . \mathrm{V}$ & T.T & r.1 & $Y 0.9$ & $\xi . \xi$ & Y.० & $11 . \mathrm{V}$ & $\because \cdot$ & $11 . \mathrm{V}$ & $r .9$ & هدايا وألعاب \\
\hline$\varepsilon . \Gamma$ & $\because \cdot$ & 7.1 & $\varepsilon 0$ & $7 . \varepsilon^{2}(x)$ & 9.9 & $\because \cdot$ & $r . \cdot$ & Y.A & $\xi_{. \top}$ & محال متّوففة \\
\hline r.V & $11 . \cdot$ & 7.4 & $\because \cdot$ & 1.1 & $1 \cdot . \mathrm{V}$ & $\because \cdot$ & $\because \cdot$ & 1.8 & $\because \cdot$ & حدايد وكيماويات \\
\hline T.Y & $1 . \mathrm{V}$ & $\because$ & $1 \cdot . Y$ & V.A & r.0 & Y.A & $\because \cdot$ & T. & T.द & مصنو عات جلدية \\
\hline I.. & $1 \cdots$ & $1 \cdots$ & $1 \ldots$ & $1 \ldots$ & $1 \cdots$ & $1 \ldots$ & $1 \ldots$ & $1 \cdots$ & $1 \ldots$ & الجملة \\
\hline
\end{tabular}

المصدر/ الجدول من إعداد الباحث اعتماداً علي الدراسة الميدانية.

( ) نصيب المحل من طول الشارع= طول الشارع ٪ عدد المحال في الشارع. 
* شارع الخان: استحوذت مستلزمات حريمي علي الشارع بواجهة زادت نسبتها علي

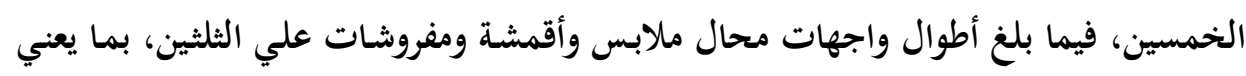

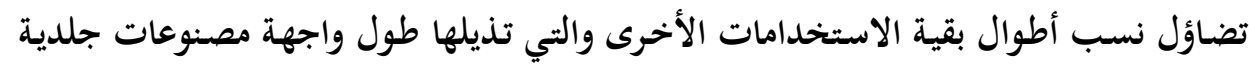

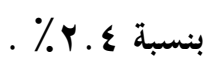

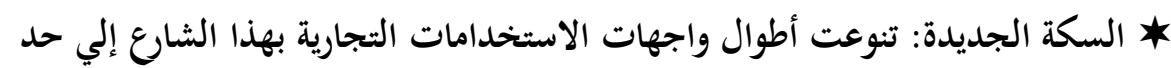

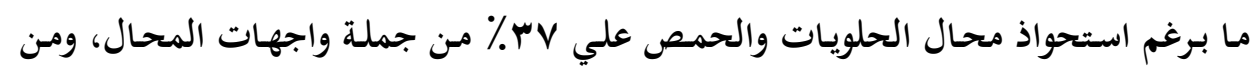

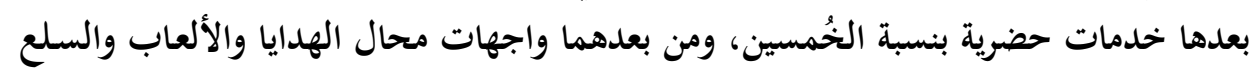

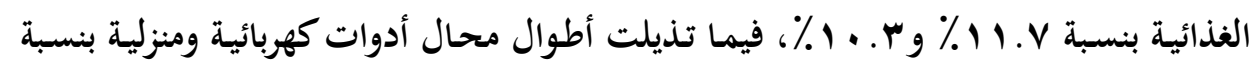

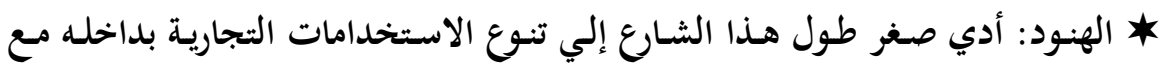

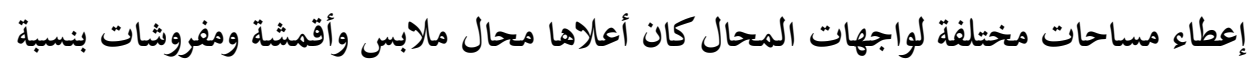

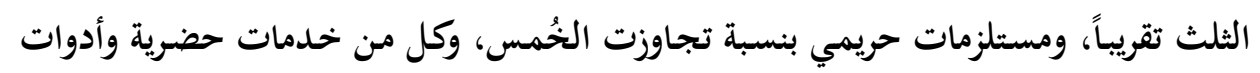

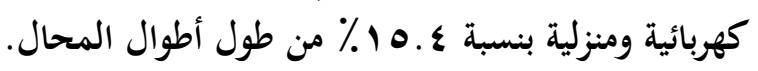

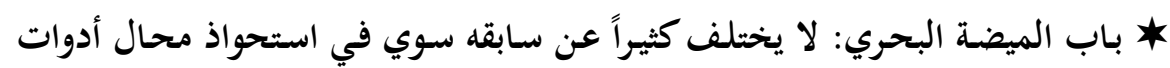

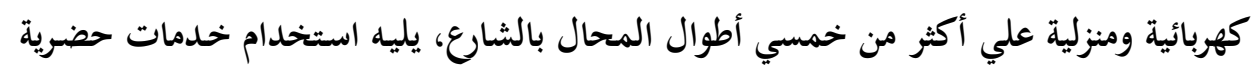

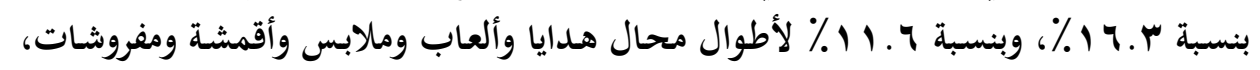

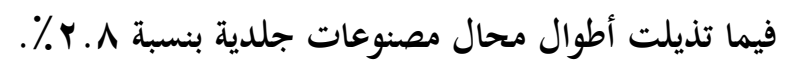

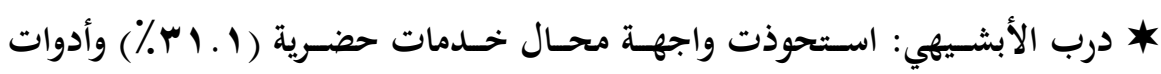

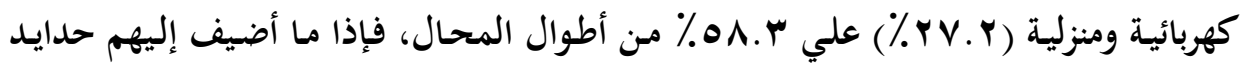

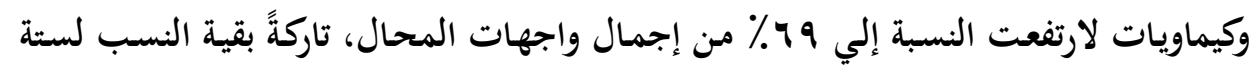

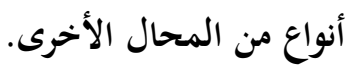
* درب الأتر: يعد هذا الشارع واحد من أفضل واجهات المحال في منطقة الدراسة،

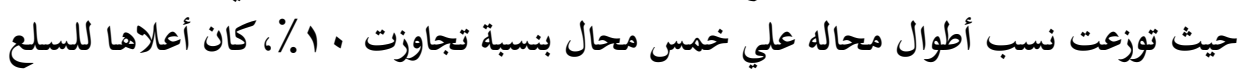

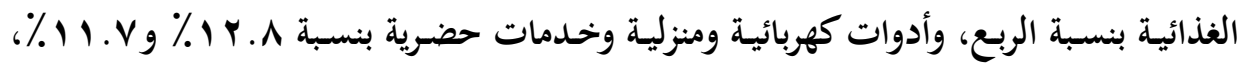

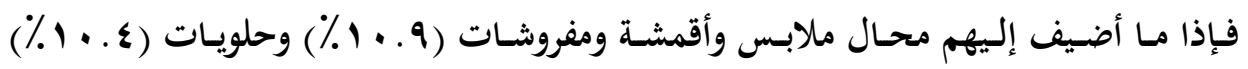

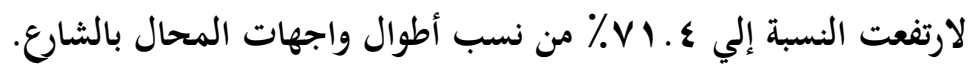

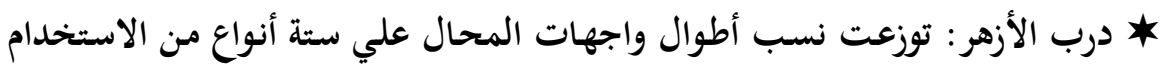

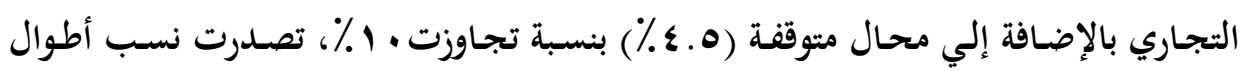




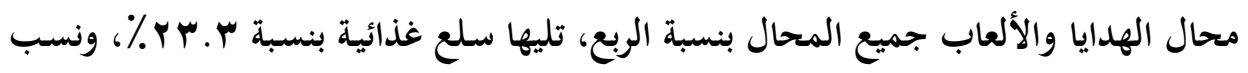

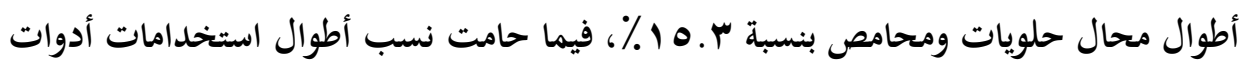

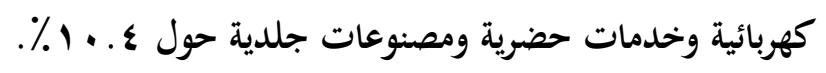

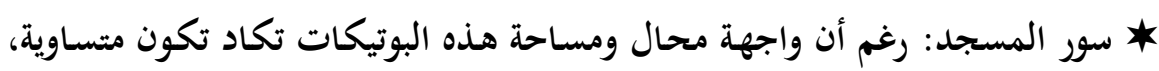

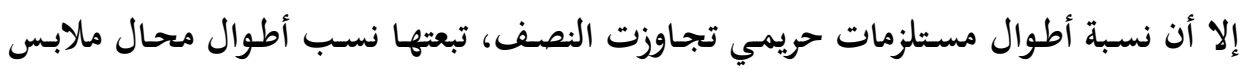

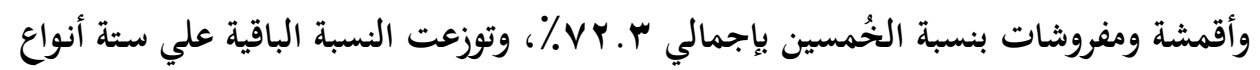
أُخر تذيلهم نسب أطوال محال أدوات كهربائية ومنزلية.

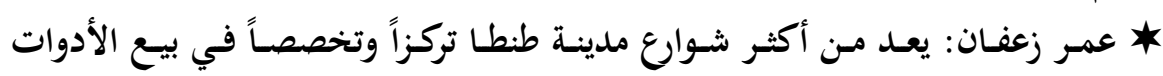

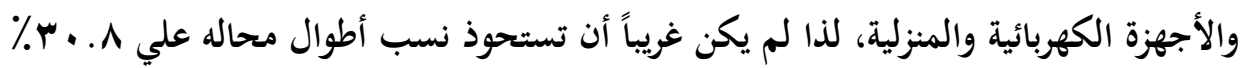

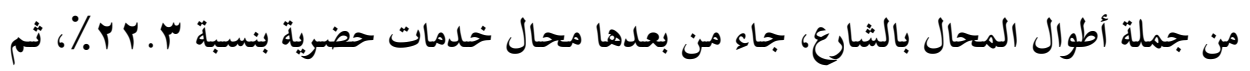

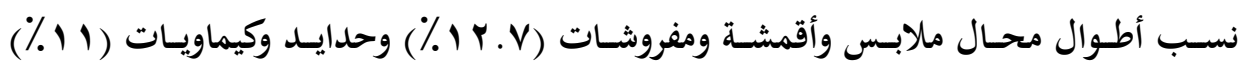

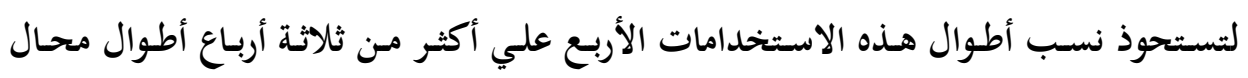

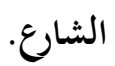

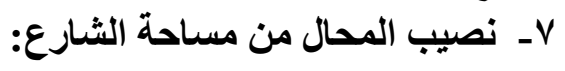

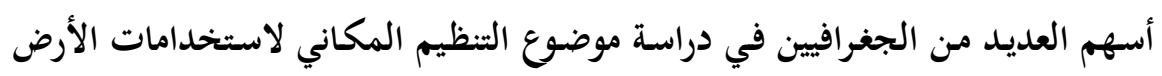

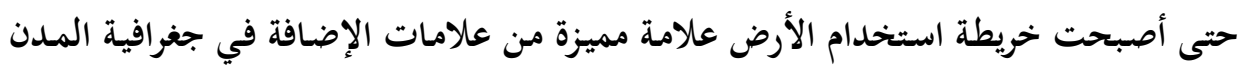

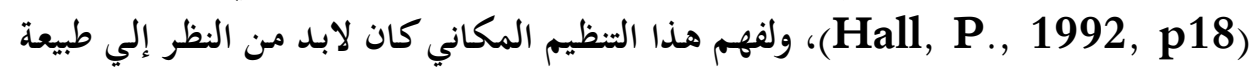

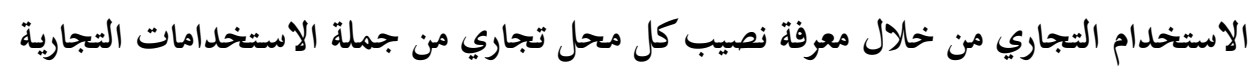

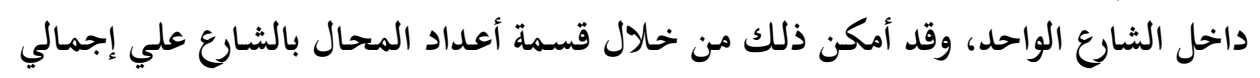

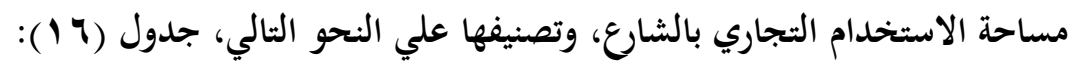

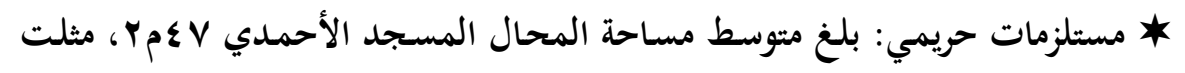

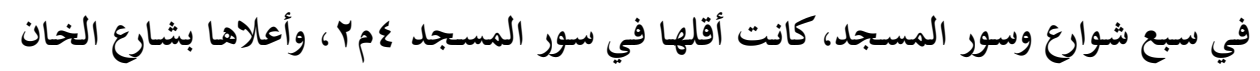

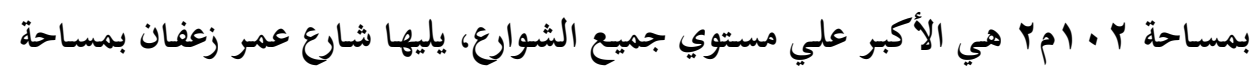

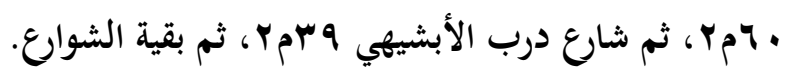

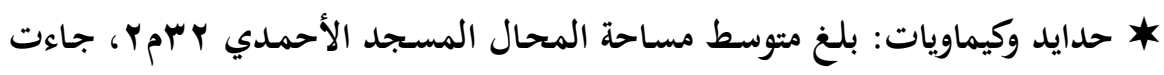

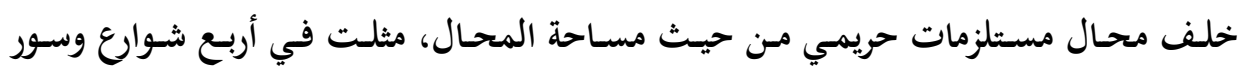

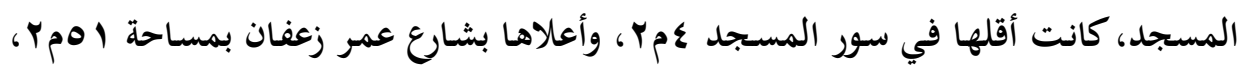




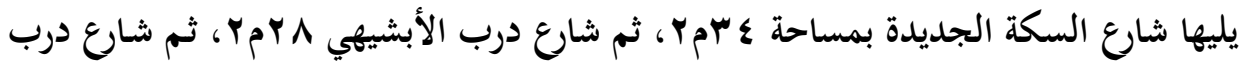

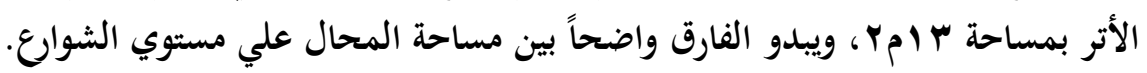

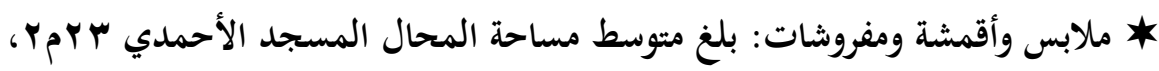

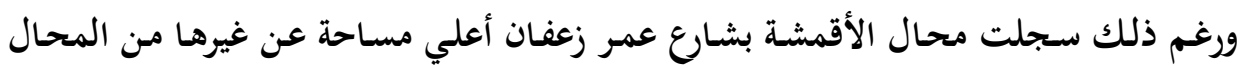

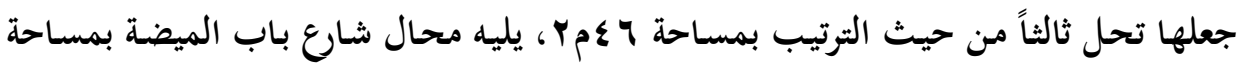

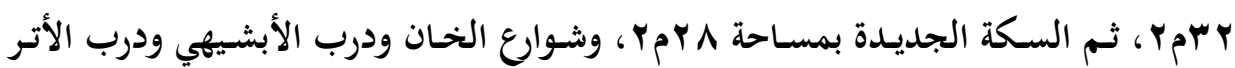

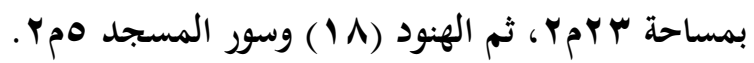

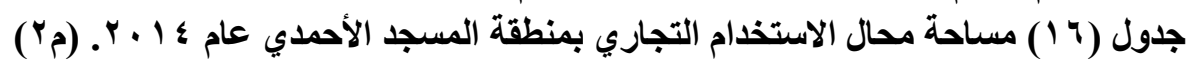

\begin{tabular}{|c|c|c|c|c|c|c|c|c|c|c|}
\hline جملة & زعفان & سورد & الازربر & الأثر & الأبشيهي دربي & الميضة & الهنود & الجديدة & الخان & مساحة المحال (مY) \\
\hline$\varepsilon V$ & 7. & $\varepsilon$ & & $r \leq$ & $r q$ & $\Lambda$ & $r \mu$ & rk & $1 \cdot r$ & مستلزمات حريمي \\
\hline rq & rq & & 10 & rq & & rq & 10 & $\leq \leqslant$ & & حلويات ومحامص \\
\hline rr & 01 & $\varepsilon$ & & ir & rA & & & $r \varepsilon$ & & حدايل وكيماويات \\
\hline$r$ & $\leqslant$ & $\varepsilon$ & $r \cdot$ & $r$. & ro & $r$. & ro & 17 & $r \cdot$ & أدوات كهربائية ومنزلية \\
\hline$r$. & & $\varepsilon$ & rr & $m$ & rq & & rr & rr & V9 & محال متوقفة \\
\hline ro & $r 4$ & 0 & $Y \leq$ & $Y \leq$ & 19 & 19 & 17 & YY & $r r$ & سلع غذائية \\
\hline$r \leq$ & $\leqslant$ & $\varepsilon$ & 19 & 19 & $r$. & $\mathrm{V}$ & 19 & Yr & rr & خدمات حضرية \\
\hline$r \leq$ & $r$. & $\varepsilon$ & 17 & $Y \leq$ & $r \leqslant$ & 17 & & $r$. & $Y \leq$ & هدايا وألعاب \\
\hline$r r$ & $\leq 7$ & 0 & & Yr & YT & rr & 11 & YA & Yr & ملابس و أقمشة ومفروشات \\
\hline rr & $r \wedge$ & & 11 & $r \wedge$ & rT & $\mathrm{V}$ & & YY & $r \mu$ & مصنو عات جلدية \\
\hline$r \cdot$ & $\xi$ & $\varepsilon$ & 19 & $Y \leq$ & rq & IV & Y & rY & 00 & جملة \\
\hline
\end{tabular}

$$
\text { المصدر/ الجدول من إعداد الباحث اعتماداً علي الدراسة الميدانية. }
$$

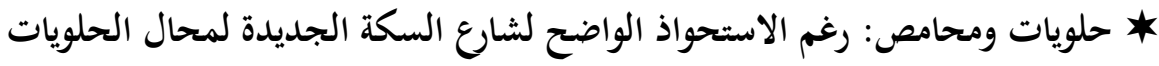

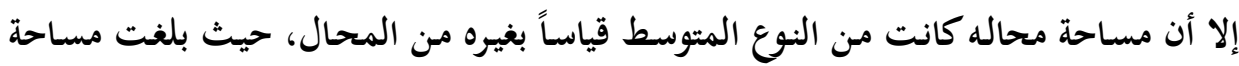

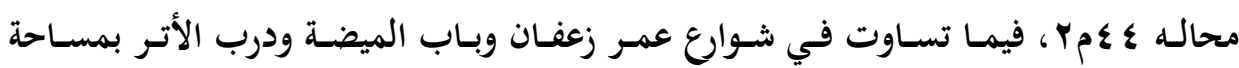

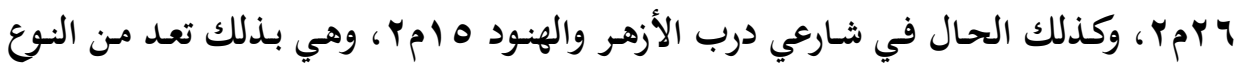
المثالي من حيث المساحة علي مستوي شوارع منطقة الدراسة.

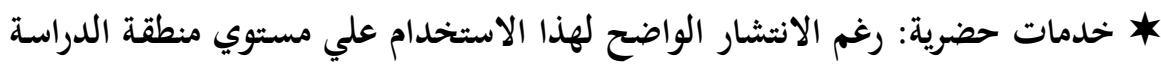

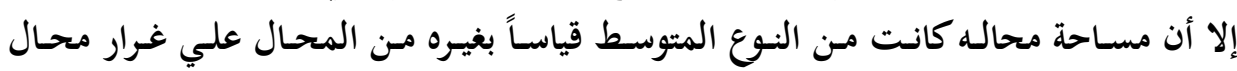

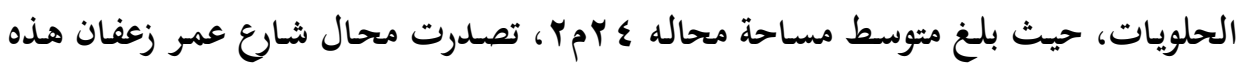

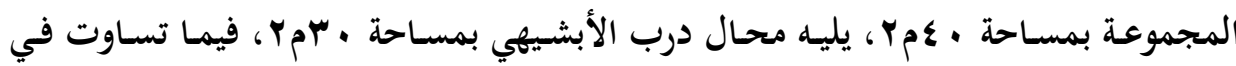

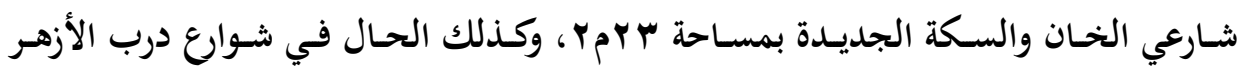

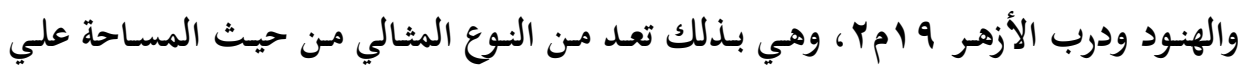

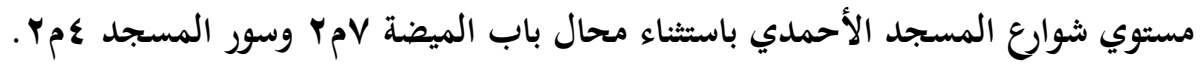


* أدوات كهربائيسة ومنزليـة: رغم انتشارها الواضـح علي مستوي منطقة الدراسة إلا أن

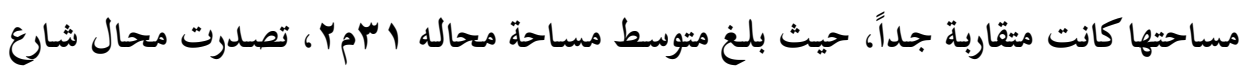

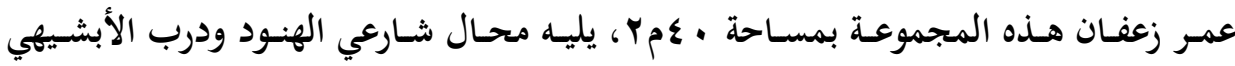

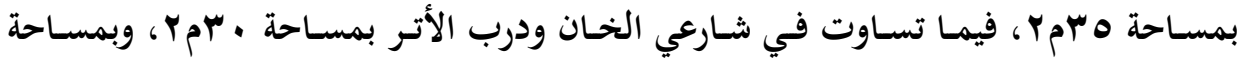

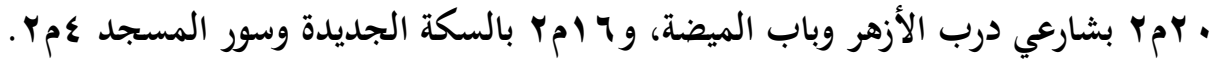

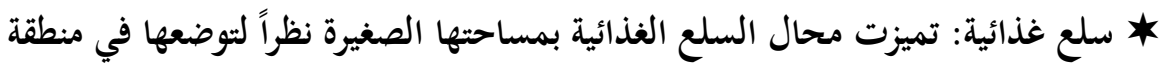

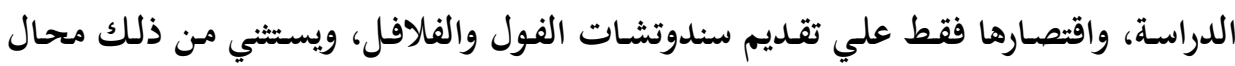

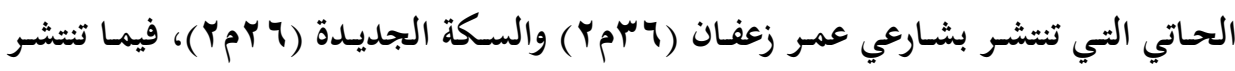

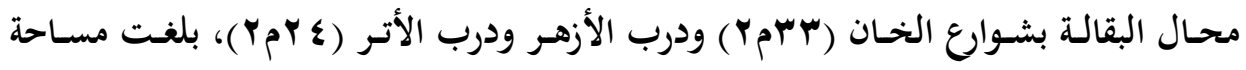

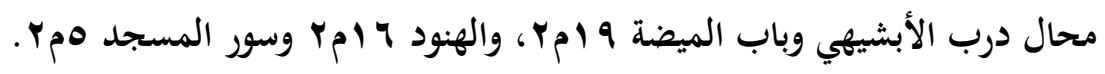

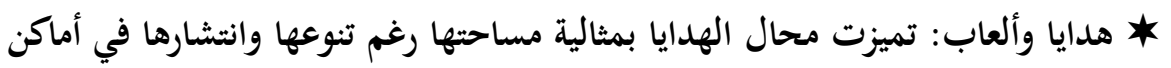

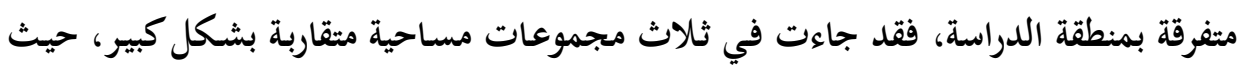

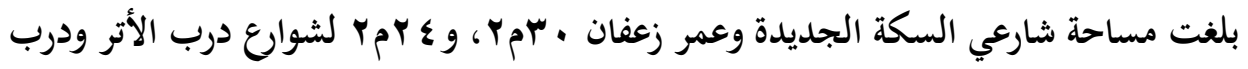

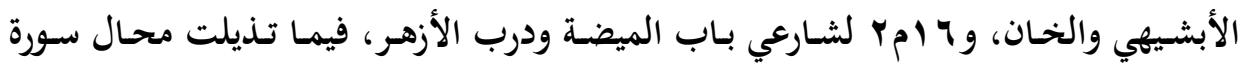

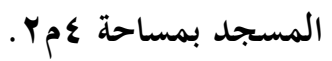

* مصنوعات جلدية: تشترك مع محال الهدايا بمثالية مساحتها رغم قلة أعدادها وصغر

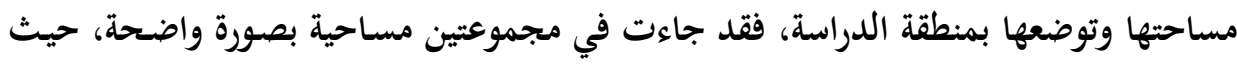

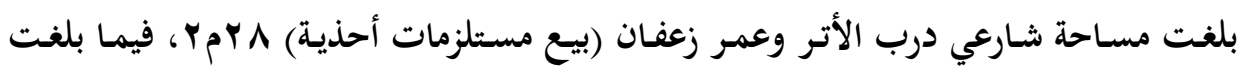

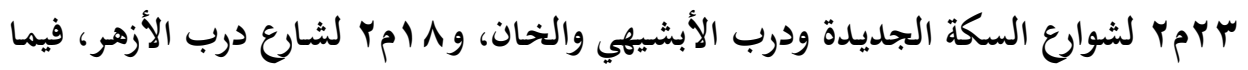

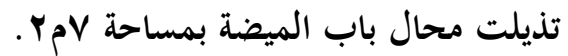




\section{النتائج}

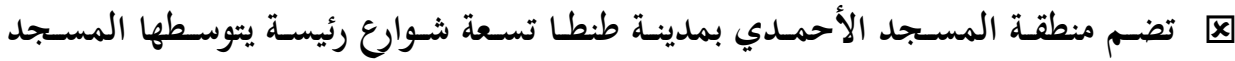

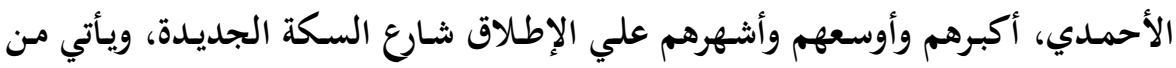

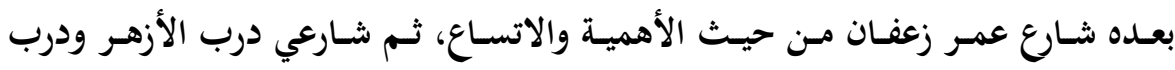

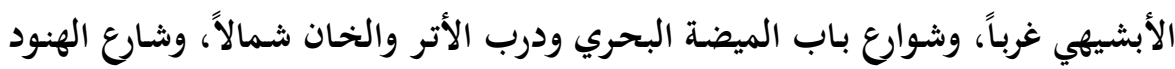

凤 أدي اتساع رقعة المدينة وأنشطتها التجارية إلي ظهور نويات جديدة للقلب التجاري سواء

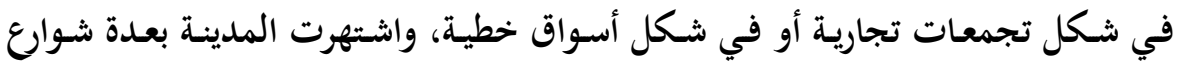

$$
\text { تخصصت في أنواع بعينها من التجارة. }
$$

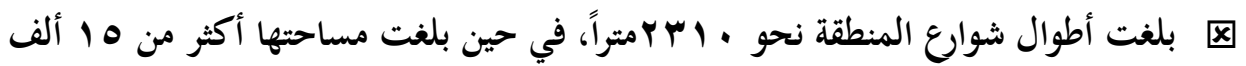

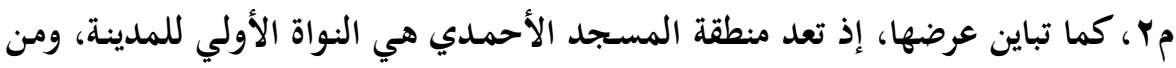

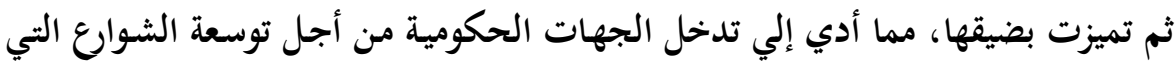

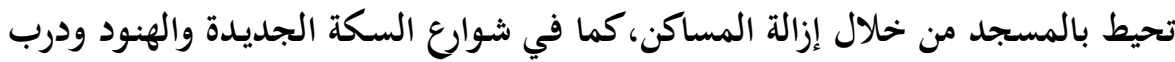

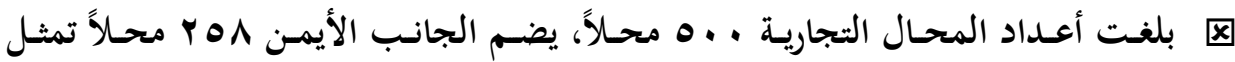

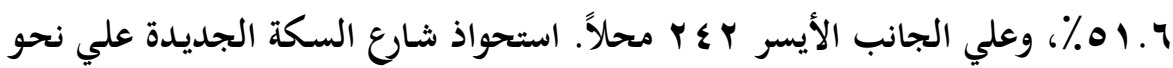

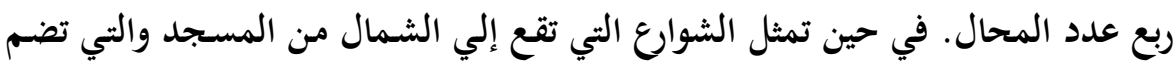

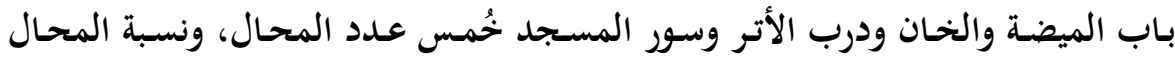

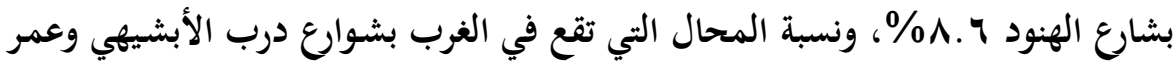

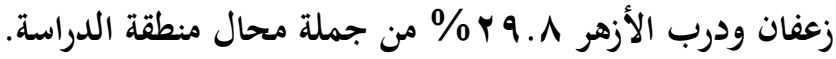

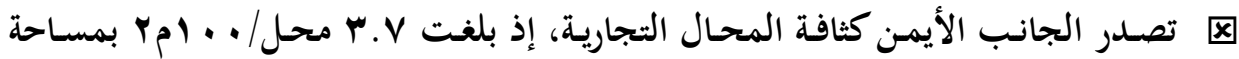

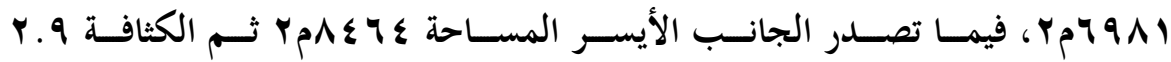

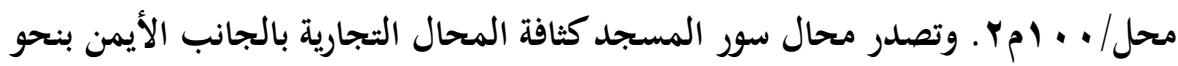

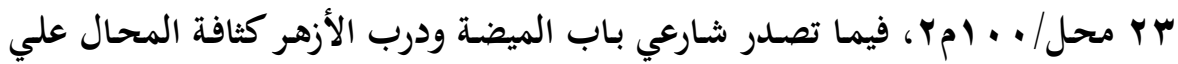

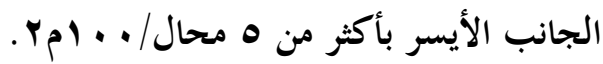

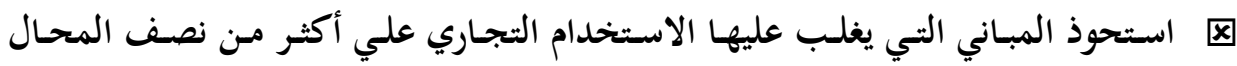

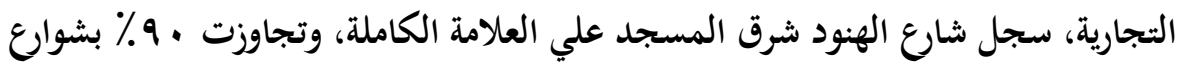

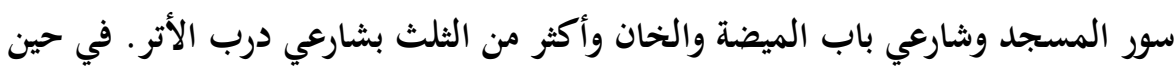


لم تزد نسبة شـارع السكة الجديدة الذي يقع جنوب المسـد عن بr\% مـ جملة الاستخدامات.

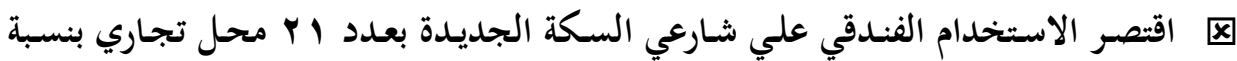

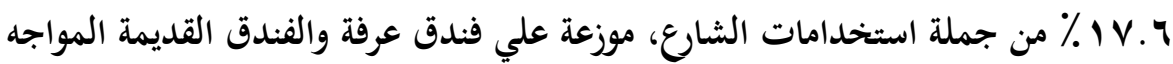

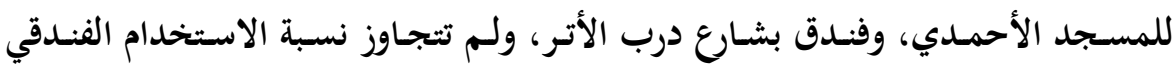

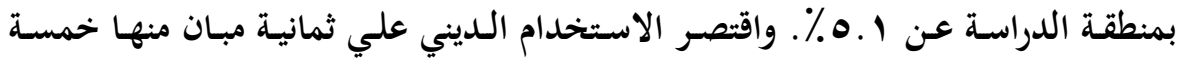

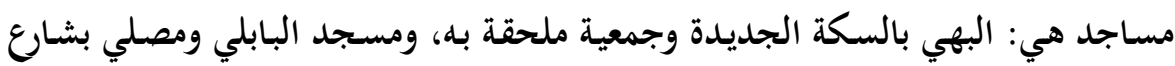

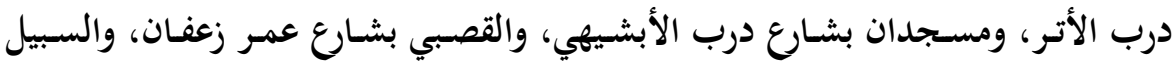
الأحمدي بشارع باب الميضة.

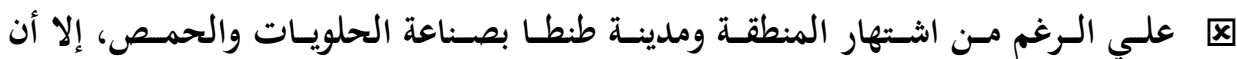

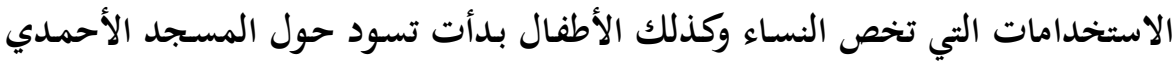

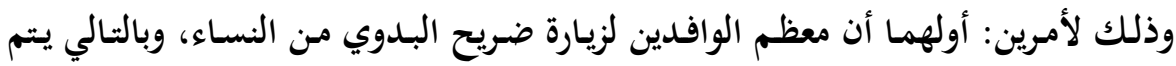

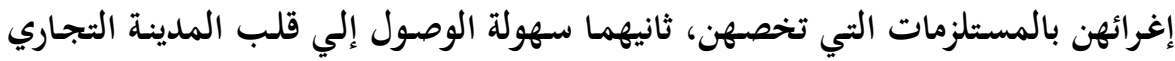

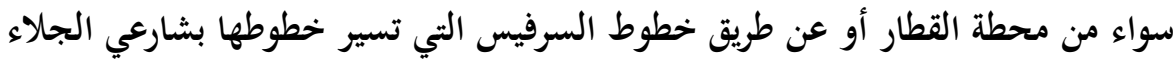
والمديرية المحيطان بالمنطقة.

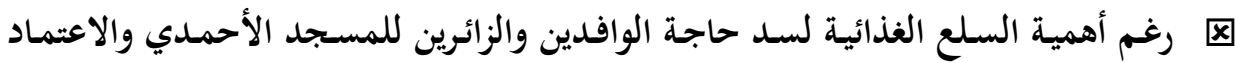

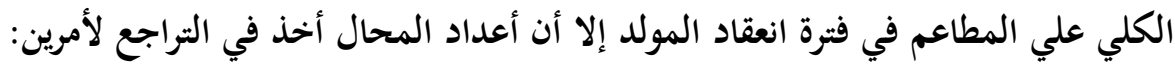

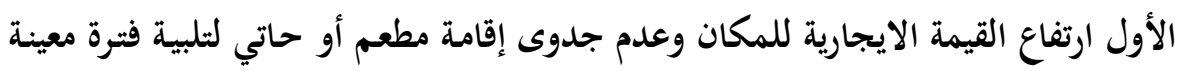

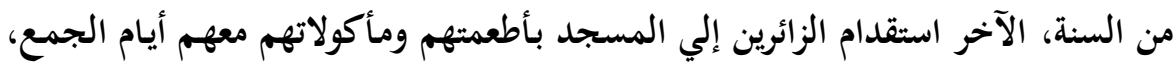
أو في فترة انعقاد المولد.

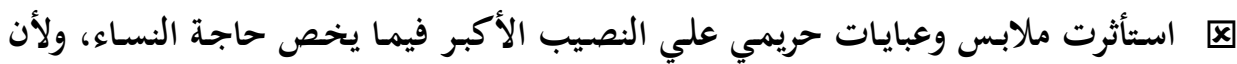

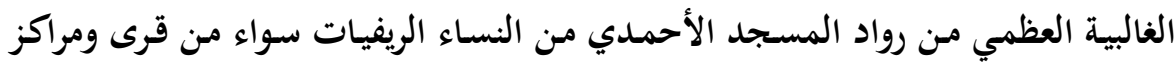
الغربية أو من المحافظات، فقد تخصصت المحال في الأذواق التي تقبل عليها النساء

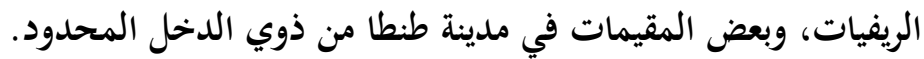

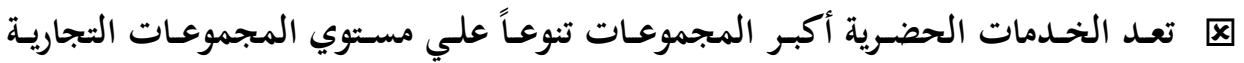

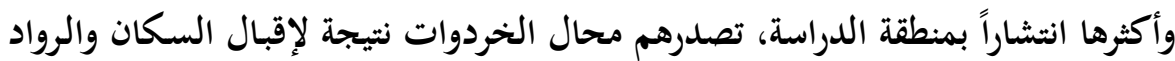

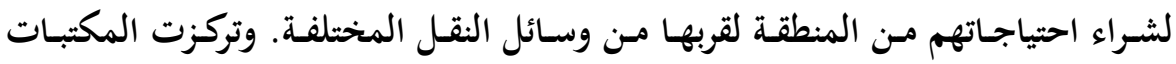


والمطبعات في شارعي درب الأبشيهي والسكة الجديدة، وتوزعت الصيدليات علي معظم

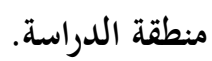

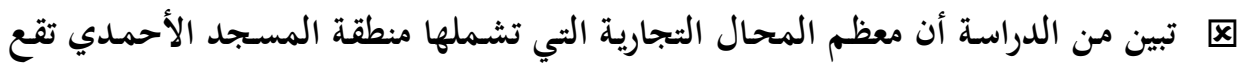

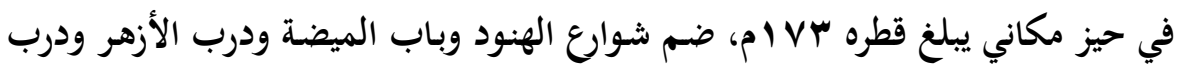

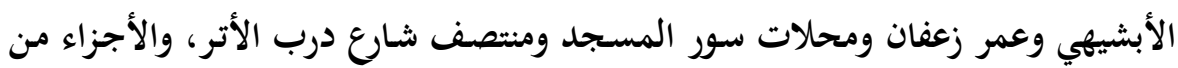

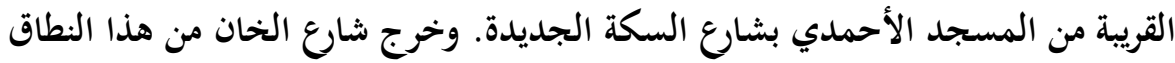
كونه شارعاً متطرفاً.

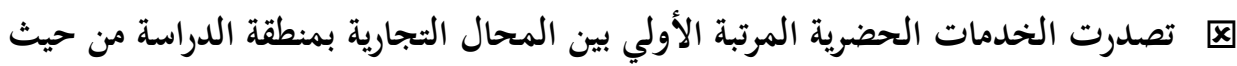

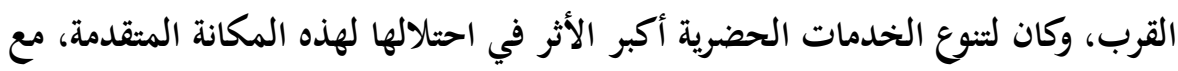

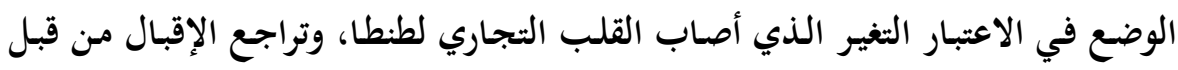

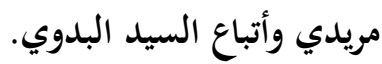

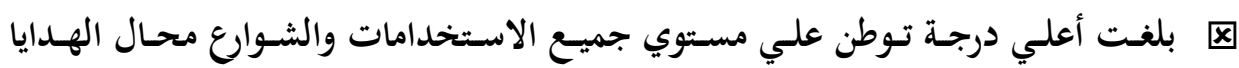

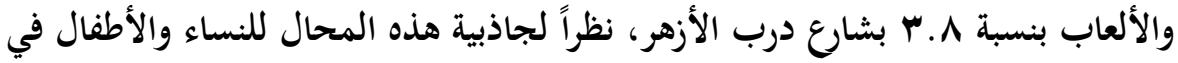

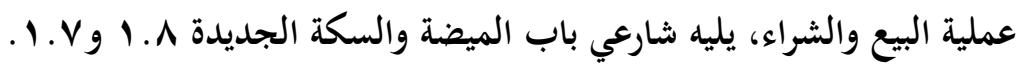




$$
\text { المراجع والمصادر }
$$

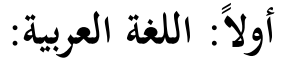

1. إبراهيم علي غانم (19191)، محافظة الغربية دراسة في الجغرافيا الاقتصادية، ماجستير

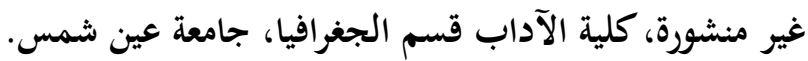

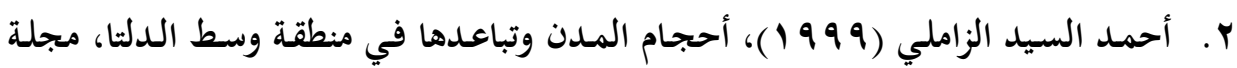

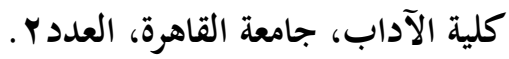

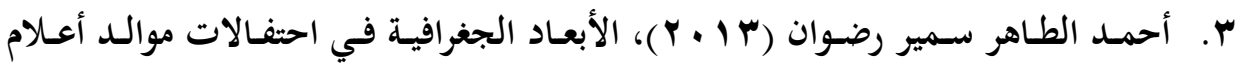

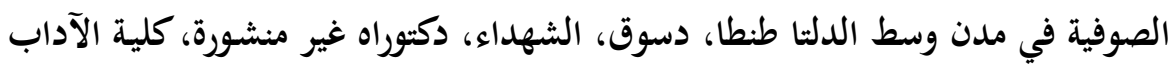

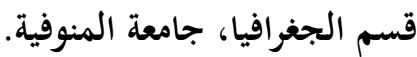

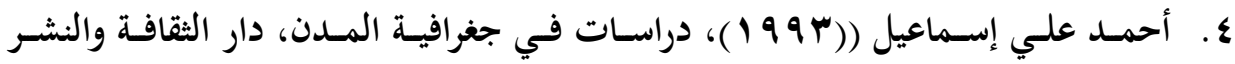
والتوزيع، القاهرة

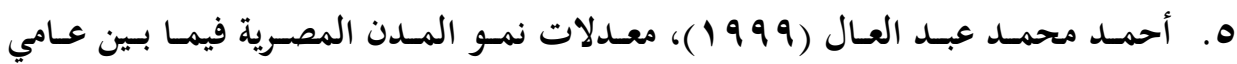

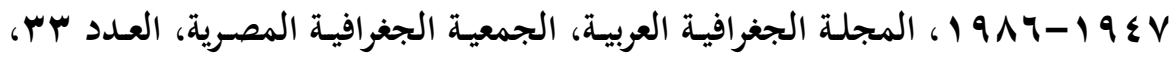

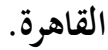

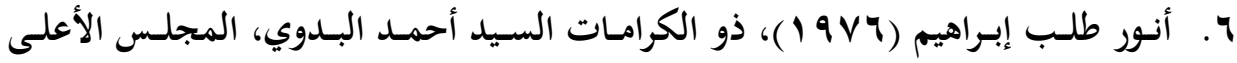
كلشئون الإسلامية، القاهرة.

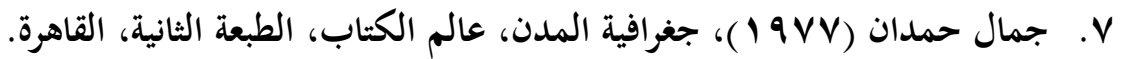

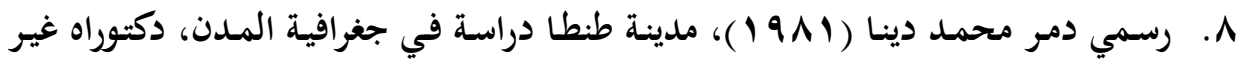
منشورة، كلية البنات قسم الجغرافيا، جامعة عين شمس. 9. سامي إبراهيم عبد الرحمن (ب9 99 (1)، النقل الداخلي لمدينة طنطا ومشكلاته الرئيسية، ماجستير غير منشورة، كلية الآداب قسم الجغرافيا، جامعة طنطا.

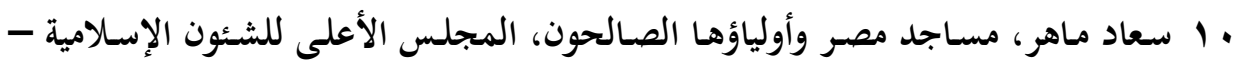

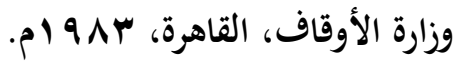
II سعد جاسم محسن السعدي (997 (9 )، وظائف استعمالات الأرض في مراكز المدن، ماجستير غير منشورة، مركز التخطيط الحضري والإقليمي، جامعة بغداد. 


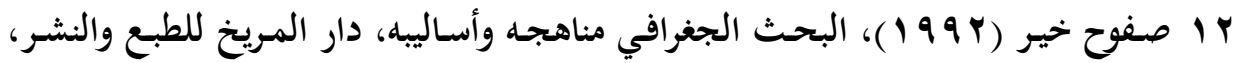
طع، الرياض، السعودية.

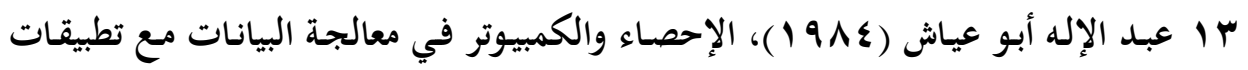
جغرافية، وكالة المطبوعات، الكويت. ع ا عبد الصاحب ناجي رشيد البغدادي (9999 199)، الملائمة المكانية لاستعمالات الأرض

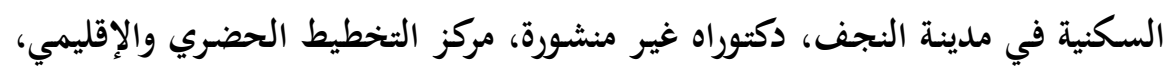
جامعة بغداد.

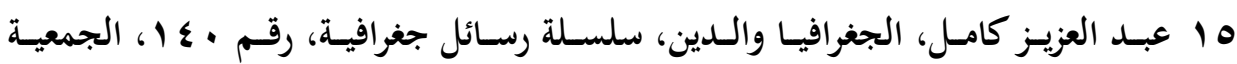

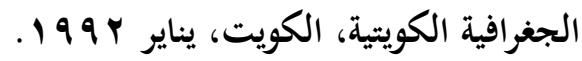
17

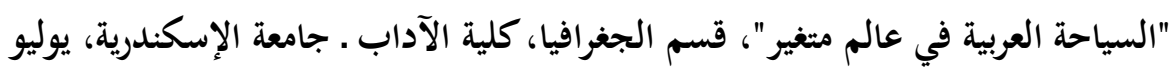
$. r+1$. IV عبـد الفتـاح إمـام حـزين (9199 (1)، استخدامات الأرض بمدينـة أبها بالمملكـة العربيـة

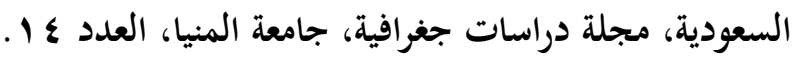

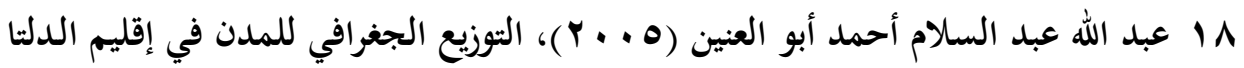

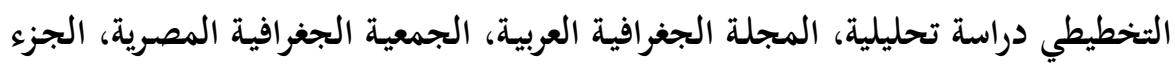
الثاني، العدد צ ع ، القاهرة.

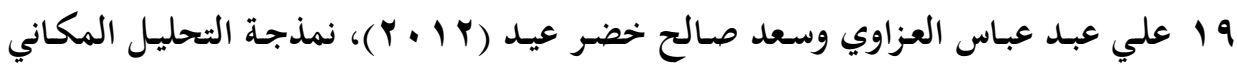

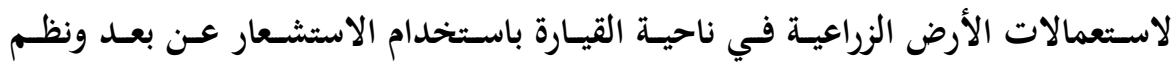

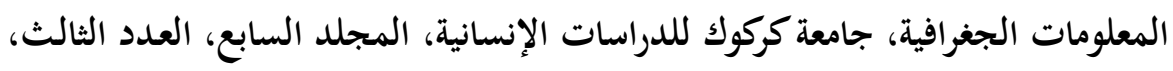
جامعة كركوك.

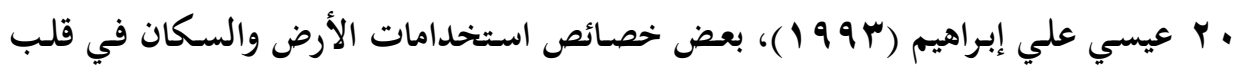

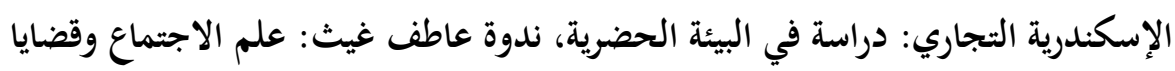

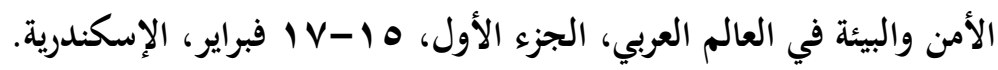

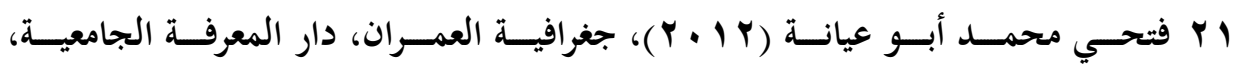
الإسكندرية. 


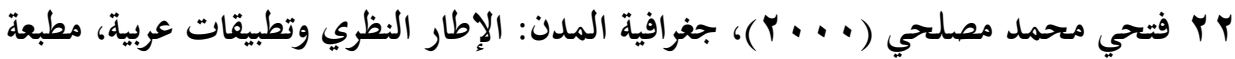
التوحيد، شبين الكوم.

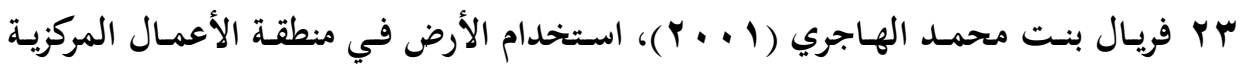

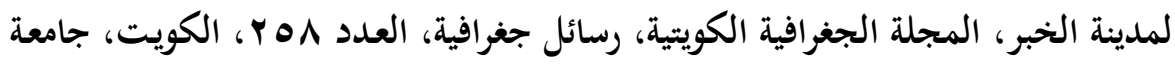
الكويت.

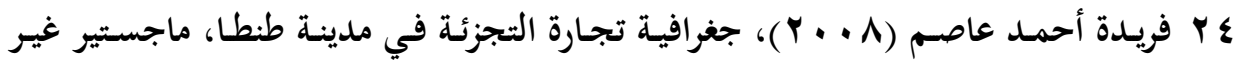
منشورة، كلية الآداب قسم الجغرافيا، جامعة المنوفية.

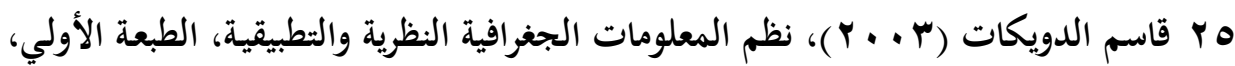
مطبعة دائرة المطبوعات والنشر، عمان الأردن.

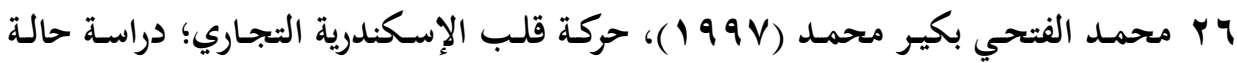
منطقة الإبراهيمية، إصدارات مجلة كلية الآداب، فرع دمنهور جامعة الإسكندرية.

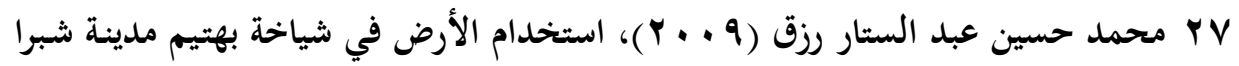

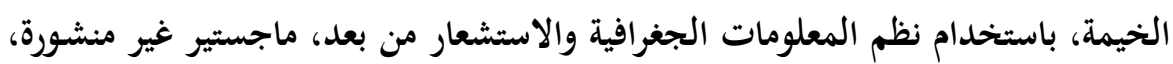

$$
\text { كلية الآداب قسم الجغرافيا، جامعة عين شمس. }
$$

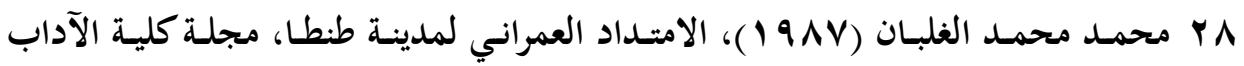
جامعة طنطا، المجلد الرابع.

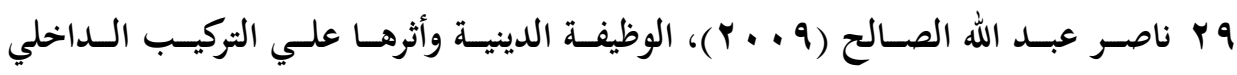

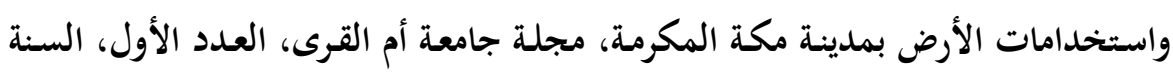

ثانياً: اللغة الانجليزية:

1 Clark, D, (1982), Urban Geography, Croom Helm, London.

2 David J. Maguire. Michael Batty \&Michael F. Godchild (eds), (2005) GIS Spatial analysis and modeling, ESRI Press, Redland, California.

3 Harold M. Mayer, (1959), Reading in urban geography the university of Chicago .

4 Kirby, A. \& Others, (1999), public Provision And Urban Development, Croom Helm, London.

5 Northam, R.M, (1979), Urban Geography, John Wiley, New York. 
6 Rhind, D, \& Hudson, R., (1980), Land Use, New York.

7 Hall, p, (1992), Urban And Regional Planning, Rout ledge, London. 
نموذج حصر استخذام الأرض حول المسجد الأحمدي ومداخله

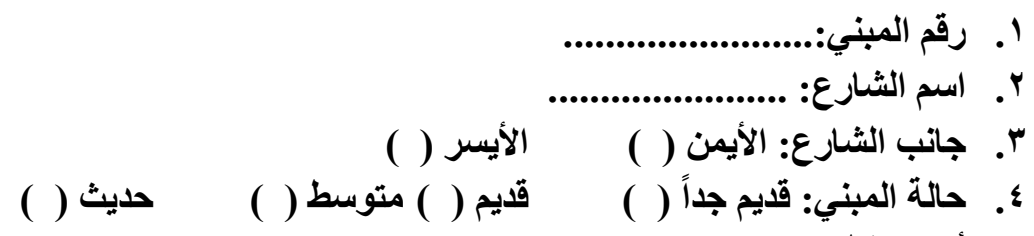

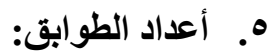

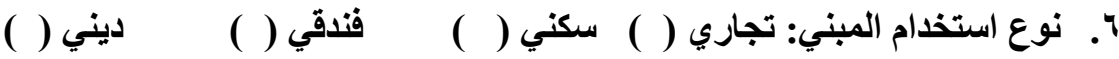

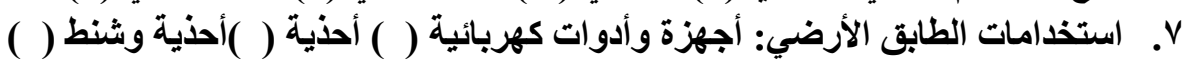

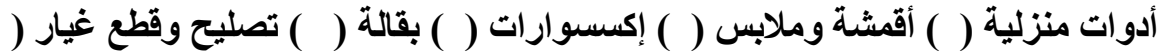

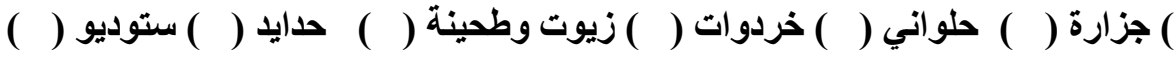

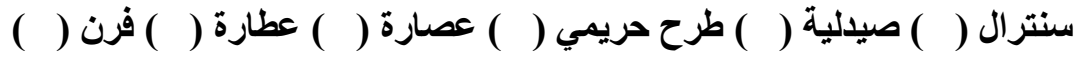

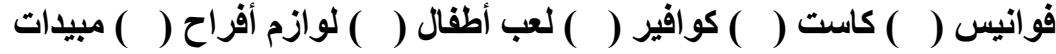

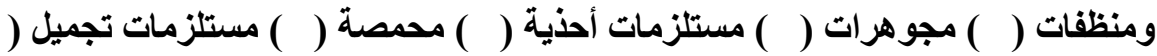

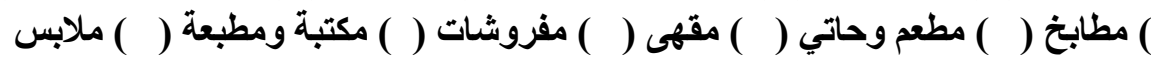

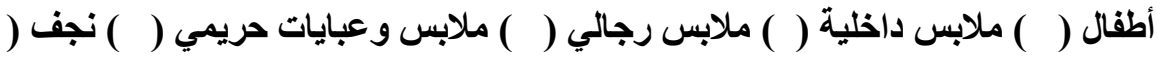

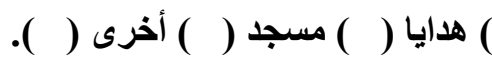

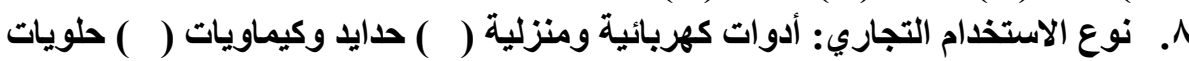

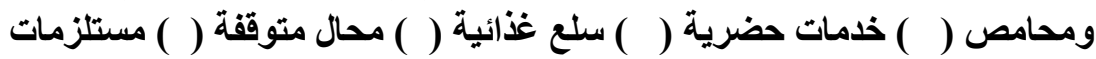

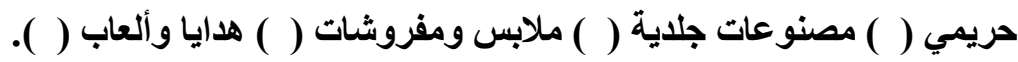

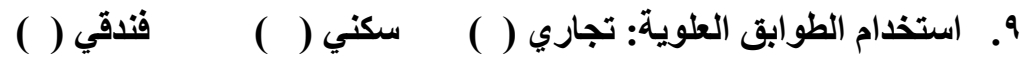

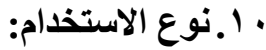
11 أملاحظات عامة: 